Amanda Rehbein

Sistemas convectivos de mesoescala observados na bacia Amazônica durante o projeto GOAmazon

São Paulo

2016 

Amanda Rehbein

\title{
Sistemas convectivos de mesoescala observados na bacia Amazônica durante o projeto GOAmazon
}

\begin{abstract}
Dissertação apresentada ao Departamento de Ciências Atmosféricas do Instituto de Astronomia, Geofísica e Ciências Atmosféricas da Universidade de São Paulo como requisito parcial para a obtenção do título de Mestre em Ciências. Área de concentração: Meteorologia. Versão Corrigida. O original encontra-se disponível na Unidade.
\end{abstract}

\author{
Universidade de São Paulo (USP) \\ Instituto de Astronomia Geofísica e Ciências Atmosféricas (IAG) \\ Departamento de Ciências Atmosféricas
}

Orientador: Tercio Ambrizzi

São Paulo

2016 
Às pessoas que temem tempestades.

Em especial, para minha mãe, Esther. 


\section{Agradecimentos}

Gostaria de agradecer todas as pessoas que apoiaram esta pesquisa e que de alguma forma contribuíram para que sua realização fosse possível. Em especial, gostaria de agradecer:

- Ao professor Tercio Ambrizzi, pela orientação, paciência, confiança e oportunidades;

- À Dra. Meiry Sakamoto e ao meteorologista Leandro Valente pelo treinamento e auxílio com as primeiras rodadas do ForTraCC, realizadas na FUNCEME (Fundação Cearense de Meteorologia e Recursos Hídricos) em Fortaleza, Ceará;

- À CAPES (Coordenação de Aperfeiçoamento de Pessoal de Nível Superior) pela concessão da bolsa de mestrado e apoio financeiro;

- Às professoras membros da banca de Exame de Qualificação, Rita Ynoue e Rosmeri da Rocha, pelas sugestões e críticas construtivas para o desenvolvimento deste trabalho; Além disso, pela prestatividade e atenção ao longo destes dois anos;

- À professora Rosmeri pelo empréstimo da Juquey, onde as rodadas do ForTraCC foram realizas;

- Aos demais professores do IAG-USP, em especial ao Ricardo Hallak e Rachel Albretch, que sempre foram muito prestativos e atenciosos comigo;

- Ao INCLINE e ao IUGG pelo suporte financeiro concedido para minha participação no $26^{\circ}$ IUGG, ocorrido em Praga, República Tcheca;

- Aos funcionários do IAG-USP, em especial à Elisabete, Carol e Lilian que sempre foram muito atenciosos e prestativas comigo, auxiliando em questões além de suas funções no Departamento;

- Ao Jean Peres, que, entre muitas outras, ajudou com a expulsão das formigas que invadiram meu computador;

- Ao Instituto de Controle do Espaço Aéreo de São José dos Campos (ICEA-SJC) pelo fornecimento dos dados de radiossondagem realizados em Manaus e ao Dr. Gilberto Fisch e Dra. Rachel Albretch no auxílio de obtenção destes dados.

Se por um lado o suporte técnico foi muito importante nesta caminhada, por outro, não posso deixar de agradecer à quem prestou suporte emocional. Por isso, agradeço:

- Imensamente à minha mãe, Esther Salvati Rehbein, que além de ser um exemplo de vida, foi a inspiração para eu estudar meteorologia. Obrigada também, mãe, 
por entender os momentos de ausência, longos períodos sem ir para casa e todo o apoio incondicional!

- Ao meu pai, Rogerio Rehbein, e minhas irmãs, Jéssica e Jane, por todo carinho, torcida e apoio incondicionais;

- À acolhida e amizade da tia Maria em São Paulo, que foram fundamentais em minha adaptação;

- À Lívia Dutra por toda a ajuda com dados, códigos, scripts, etc. Mas, principalmente pela amizade, companhia, apoio, torcida e paciência comigo;

- Ao Sergio Ibarra, não só pela ajuda com R, Grass e QGIS... Mas, principalmente pela amizade, dedicação, companhia e paciência;

- Aos colegas de mestrado, em especial ao Flávio D’Oliveira, Rafael Abreu e Ana Sena.

- Ao apoio e amizade incondicionais dos meus ex-colegas e veteranos da UFSM, principalmente à Vanessa Ferreira, Daiane Brondani, Maurício llha e Anderson Bier. Os agradecimentos são extensivos aos demais ex-colegas e veteranos;

- Ao William Bevilaqua, pelo apoio e incentivo desde o tempo da graduação;

- Aos ex-professores Otávio Acevedo e Simone Ferraz, pelas orientações e ajuda de escolha do mestrado e orientador;

- Aos colegas do GrEC, pela convivência e aprendizados. 
"Cada um dá o que tem no coração e cada um recebe com o coração que tem."

(Oscar Wilde) 



\section{Resumo}

REHBEIN, A. Sistemas convectivos de mesoescala observados na bacia Amazônica durante o projeto GOAmazon, 2016. 170 f. Dissertação (Mestrado) - Instituto de Astronomia, Geofísica e Ciências Atmosféricas, Universidade de São Paulo, São Paulo, 2016.

O presente trabalho verifica as principais características dos sistemas convectivos de mesoescala (SCMs), com origem continental e oceânica que, em pelo menos um momento do seu ciclo de vida, tiveram trajetória sobre a bacia Amazônica, durante um ano e meio de realização do projeto Green Ocean Amazon (GOAmazon). A análise incluiu a verificação da distribuição espacial, variabilidade diurna, ciclo de vida, deslocamento e áreas médias nas diferentes fases do ciclo de vida. Foi criada uma climatologia utilizando 14 anos de dados para comparar os resultados obtidos durante o GOAmazon. Para os SCMs que se formaram próximos às estações do GOAmazon foram realizadas análises das condições sinóticas, dinâmicas e termodinâmicas observadas durante a gênese e ao longo do ciclo de vida. Os resultados mostram que o número de ocorrências de SCMs continentais é de 7053 por ano. Em 2014 a ocorrência foi de 56,3\% deste valor e em 2015 foi de $58 \%$ da climatologia para a mesma época do ano. Os SCMs ocorridos durante o GOAmazon também apresentaram menores tempos de vida, deslocamentos médios e velocidades médias. A evolução do ciclo de vida é muito similar para os SCMs de curta e longa duração, com poucas horas de diferença entre a mesma fase. O tempo que os sistemas de curta duração levam em média para alcançar a fase de maturação é de 2 a 3 horas enquanto que os SCMs de longa duração levam 5 a 6 horas. Durante o projeto GOAmazon este tempo foi igual a climatologia para SCMs de curta duração, porém variou entre 3 a 4 horas para SCMs de longa duração. A velocidade média, direção de propagação e deslocamentos médios variam de acordo com a época do ano e ao longo de toda bacia Amazônica. Os deslocamentos médios são maiores durante o inverno. A densidade média mensal de SCMs revela regiões preferenciais de gênese. São elas: 1) corrente abaixo da Cordilheira dos Andes, entre $10^{\circ} \mathrm{S}$ e $20^{\circ} \mathrm{S} / 70^{\circ} \mathrm{W}$ a $75^{\circ} \mathrm{W}$; 2) confluência do rio Tapajós com o rio Amazonas, por volta de $2,5^{\circ} \mathrm{S} / 54^{\circ} \mathrm{W}$; 3) sobre a Serra da Pacaraima, no Planalto das Guianas, em aproximadamente $5^{\circ} \mathrm{N} / 60^{\circ} \mathrm{W}$; 4) Serra do Imeri, no Planalto das Guianas, em $0^{\circ} / 65^{\circ} \mathrm{W}$ e; 5) no norte do Mato Grosso, em torno de $10^{\circ} \mathrm{S} / 55^{\circ} \mathrm{W}$. Durante o projeto GOAmazon as anomalias negativas de densidade de SCMs ocorreram espalhadas ao longo de toda a bacia, com algumas regiões pontuais de maior ocorrência de sistemas. Os SCMs oceânicos ocorrem preferencialmente no período de inverno ao norte da bacia Amazônica. A frequência de ocorrência é baixa (em média 4 sistemas por mês), no 
entanto, eles possuem grandes áreas durante sua fase de maturação, grandes tempos de vida e deslocamentos. Como a maioria apresenta gênese muito próxima a costa, o desenvolvimento destes sistemas ocorre majoritariamente sobre a bacia Amazônica. Durante o projeto GOAmazon sua ocorrência foi muito menor comparado a climatologia e suas características médias diferentes. A análise detalhada para os 21 casos em que os SCMs ocorreram próximos às estações do GOAmazon mostrou que a combinação entre os ventos alísios direcionados para a bacia Amazônica e sistemas frontais que se aproximaram da região Tropical foram fundamentais na manutenção dos SCMs com longo ciclo de vida. Durante a ocorrência de SCMs com grandes áreas, os valores de cisalhamento foram mais altos comparados aos outros casos. Durante a maior parte dos anos 2014 e 2015 ocorreram padrões anômalos na circulação atmosférica, impulsionados por anomalias na temperatura da superfície do mar no oceano Pacífico Equatorial, o que justificaria a menor ocorrência, tempos de vida e deslocamento dos SCMs. De acordo com a literatura revisada, este é o primeiro trabalho que realiza uma análise climatológica anual da ocorrência de SCMs através de dados de alta resolução temporal e espacial com pouquíssimas falhas usando uma delimitação geográfica da bacia Amazônica, isto é, considerando somente os SCMs que em pelo menos um momento do seu ciclo de vida interagiram com a bacia Amazônica.

Palavras-chaves: Sistemas convectivos de mesoescala, bacia Amazônica, GOAmazon, ForTraCC. 


\section{Abstract}

REHBEIN, A. Mesoscale convective systems over the Amazon Basin during the GOAmazon project, 2016. 170 p. Master thesis - Instituto de Astronomia, Geofísica e Ciências Atmosféricas, Universidade de São Paulo, São Paulo, 2016.

In the present study, we analyzed the continental and oceanic mesoscale convective systems (MCSs) that occurred over the Amazon Basin, during one year and six months of Green Ocean Amazon Project (GOAmazon). The analysis included the spatial distribution, diurnal variability, lifecycle, displacement and morphological parameters of the MCSs. A climatology using 14 years data was developed to compare the results obtained during the GOAmazon. A synoptic, thermodynamic and dynamic analysis was made for 21 MCSs that occurred next to the GOAmazon data collection sites. The climatology results show 7053 continental MCSs occurring along the year. In 2014, the occurrence was $56.3 \%$ of that value and during the period analyzed in 2015 it was $58 \%$. The MCSs occurred during the GOAmazon also presented shorter lifecycles, displacements and speeds compared to climatology. The lifetime evolution of short lived and long lived MCSs present few hours of difference between the same phase. The time from genesis to maturation phase of short lived systems is 2 to 3 hours and for those long lived the time is 3 to 4 hours. The mean speed, direction and displacement are greater during the winter. The average density reveal preferential regions of genesis. They are: 1) downstream Andes Mountain, among $10^{\circ} \mathrm{S}$ and $20^{\circ} \mathrm{S} / 70^{\circ} \mathrm{W}$ and $75^{\circ} \mathrm{W}$; 2) confluence of Amazon and Tapajós Rivers, near to $2.5^{\circ} \mathrm{S} / 54^{\circ} \mathrm{W}$; 3 ) Pacaraima Mountains at Guyana Shield, in approximately $5^{\circ} \mathrm{N} / 60^{\circ} \mathrm{W}$; 4) Imeri Mountains at Guyana Shield, in $0 \% 65^{\circ} \mathrm{W}$ and; 5) between north of Mato Grosso state and south of Pará state, around $10^{\circ} \mathrm{S} / 55^{\circ} \mathrm{W}$. During the GOAmazon the negative density anomalies occurred spread along the Amazon Basin, with some points of greater occurrence. The oceanic MCSs occurred preferentially in the winter season in the northeast of Amazon Basin. Their frequency of occurrence is fewer than continental, in average four MCSs per month. Nevertheless, they have large areas during their maturation phase, longer lifecycles and displacements. Most of them have genesis next to the land and their development is over the Amazon Basin. During GOAmazon their occurrence was fewer than the climatology and the features were different. The analysis for the 21 cases in which MCSs occurred next to GOAmazon stations showed that a combination of trade winds driven to Amazon Basin and frontal systems close to Tropical region were important for keeping the long lived MCSs. During occurrence of large area systems, the wind shear was greater than during other events. In most of 2014 and 2015, anomalous patterns in the atmospheric circulation, triggered by anomalous sea surface temperature 
in the Equatorial Pacific Ocean, occurred and this may justify the fewer occurrence of MCSs, lifecycle and displacement in that period. From our knowledge of the literature, this is the first work that makes an annual climatological analysis of MCSs occurrence through high temporal and spatial data and very few missing data using a geographical delimitation of Amazon basin. That is, considering only the MCSs that in one moment of their lifecycle, at least, interact with the Amazon Basin.

Key-words: Mesoscale convective systems, Amazon Basin, GOAmazon, ForTraCC. 


\section{Lista de ilustrações}

Figura 1 - Delimitação espacial e topografia $(m)$ da bacia Amazônica. Em destaque a localização das estações de coleta de dados do projeto GOAmazon. . . . . . . . . . . . . . . . . . . . . . . . .

Figura 2 - Climatologia da frequência relativa (\%) de ocorrência de SCMs continentais de acordo com o ciclo de vida (horas). Período utilizado: 2000 a 2013. No total, 98743 SCMs foram considerados. . . . . . . . . .

Figura 3 - Ocorrência média mensal de SCMs sobre a bacia Amazônica de acordo com o tempo de vida. Em (a) SCMs com curta duração, (b) SCMs com longa duração e (c) todos SCMs. Os números em cima das barras representam a frequência relativa (\%). Período utilizado: 2000 a 2013. No total, 98743 SCMs foram considerados.

Figura 4 - Climatologia do horário de gênese de (a) SCMs com curto tempo de vida, (b) SCMs com longo ciclo de vida e (c) todos SCMs. Período utilizado: 2000 a 2013. No total, 98743 SCMs foram considerados. .

Figura 5 - Climatologia do horário de maturação de (a) SCMs com curto tempo de vida, (b) SCMs com longo ciclo de vida e (c) todos SCMs. Período utilizado: 2000 a 2013. No total, 98743 SCMs foram considerados. .

Figura 6 - Climatologia do horário de dissipação de (a) SCMs com curto tempo de vida, (b) SCMs com longo ciclo de vida e (c) todos SCMs. Período utilizado: 2000 a 2013. No total, 98743 SCMs foram considerados. .

Figura 7 - Climatologia da densidade de gênese, maturação e dissipação, respectivamente, dos SCMs com curto ciclo de vida em (a.i), (a.ii) e (a.iii) janeiro; (b.i), (b.ii), (b.iii) fevereiro; (c.i), (c.ii),(c.iii) março; (d.i), (d.ii), (d.iii) abril; (e.i), (e.ii), (e.iii) maio; (f.i), (f.ii), (f.iii) junho; (g.i), (g.ii), (g.iii) julho; (h.i), (h.ii), (h.iii) agosto; (i.i), (i.ii), (i.iii) setembro; (j.i), (j.ii), (j.iii) outubro; (k.i), (k.ii), (k.iii) novembro e (l.i), (l.ii), (l.iii) dezembro. O contorno em preto indica os limites da bacia Amazônica. Período utilizado: 2000 a 2013. . . . . . . . . . . . . . . . . . . . . . .

Figura 8 - Climatologia da densidade de gênese, maturação e dissipação, respectivamente, dos SCMs com longo ciclo de vida em (a.i), (a.ii) e (a.iii) janeiro; (b.i), (b.ii), (b.iii) fevereiro; (c.i), (c.ii),(c.iii) março; (d.i), (d.ii), (d.iii) abril; (e.i), (e.ii), (e.iii) maio; (f.i), (f.ii), (f.iii) junho; (g.i), (g.ii), (g.iii) julho; (h.i), (h.ii), (h.iii) agosto; (i.i), (i.ii), (i.iii) setembro; (j.i), (j.ii), (j.iii) outubro; (k.i), (k.ii), (k.iii) novembro e (I.i), (l.ii), (I.iii) dezembro. O contorno em preto indica os limites da bacia Amazônica. Período utilizado: 2000 a $2013 . \ldots$. . . . . . . . . . . . . . . . . . . . . 
Figura 9 - Climatologia da densidade com relação à gênese, maturação e dissipação, respectivamente, de todos os SCMs em (a.i), (a.ii) e (a.iii) janeiro; (b.i), (b.ii), (b.iii) fevereiro; (c.i), (c.ii),(c.iii) março; (d.i), (d.ii), (d.iii) abril; (e.i), (e.ii), (e.iii) maio; (f.i), (f.ii), (f.iii) junho; (g.i), (g.ii), (g.iii) julho; (h.i), (h.ii), (h.iii) agosto; (i.i), (i.ii), (i.iii) setembro; (j.i), (j.ii), (j.iii) outubro; (k.i), (k.ii), (k.iii) novembro e (l.i), (l.ii), (l.iii) dezembro. O contorno em preto indica os limites da bacia Amazônica. Período utilizado: 2000 a 2013. . . . . . . . . . . . . . . . . . . . .

Figura 10 - Deslocamentos médios mensais dos (a) SCMs com curto tempo de vida, (b) SCMs com longo ciclo de vida e (c) todos SCMs. Período utilizado: 2000 a 2013. No total, 98743 SCMs foram considerados. .

Figura 11 - Climatologia da direção de propagação, deslocamentos médios e velocidade média dos SCMs com curto ciclo de vida ocorridos na bacia Amazônica. O comprimento do vetor indica o deslocamento médio e a largura indica a velocidade. Período utilizado: 2000 a 2013. 63

Figura 12 - Climatologia da direção de propagação, deslocamentos médios e velocidade média dos SCMs com longo ciclo de vida ocorridos na bacia Amazônica. O comprimento do vetor indica o deslocamento médio e a largura indica a velocidade. Período utilizado: 2000 a 2013. 65

Figura 13 - Climatologia da direção de propagação, deslocamentos médios e velocidade média de todos SCMs ocorridos na bacia Amazônica. O comprimento do vetor indica o deslocamento médio e a largura indica a velocidade. Período utilizado: 2000 a 2013. . . . . . . . . . . . .

Figura 14 - Climatologia da frequência relativa (\%) dos SCMs oceânicos de acordo com seu ciclo de vida (horas). Período utilizado: 2000 a 2013. No total 682 SCMs foram considerados. . . . . . . . . . . . 70

Figura 15 - Ocorrência média mensal dos SCMs oceânicos de acordo com tempo de duração. Em (a) SCMs com curto tempo de vida, (b) SCMs com longo ciclo de vida e (c) todos SCMs. Os números em cima das barras representam a frequência relativa (\%). Período utilizado: 2000 a 2013. No total 682 SCMs foram considerados. . . . . . . . . . 71

Figura 16 - Climatologia do horário de gênese dos SCMs oceânicos (a) com curto tempo de vida, (b) com longo ciclo de vida e (c) todos SCMs. Período utilizado: 2000 a 2013. No total 682 SCMs foram considerados. 73

Figura 17 - Climatologia do horário de maturação dos SCMs oceânicos (a) com curto tempo de vida, (b) com longo ciclo de vida e (c) todos SCMs. Período utilizado: 2000 a 2013. No total 682 SCMs foram considerados. 74 
Figura 18 - Climatologia do horário de dissipação dos SCMs oceânicos (a) com curto tempo de vida, (b) com longo ciclo de vida e (c) todos SCMs. Período utilizado: 2000 a 2013. No total 682 SCMs foram considerados. 75

Figura 19 - Deslocamentos mensais dos SCMs oceânicos (a) com curto tempo de vida, (b) com longo ciclo de vida e (c) todos SCMs. Período utilizado: 2000 a 2013. No total 682 SCMs foram considerados. . . . 76

Figura 20 - Frequência relativa (\%) de SCMs continentais de acordo com o ciclo de vida $(\mathrm{h})$ ocorridos durante o projeto GOAmazon. . . . . . . . . .

Figura 21 - Ocorrência mensal dos SCMs continentais ocorridos na bacia Amazônica em 2014 e primeiro semestre de 2015 de acordo com o tempo de vida. Em (a) SCMs de curta duração (b) SCMs de longa duração e (c) todos SCMs. Os valores sobre as barras são as frequências relativas (\%) calculadas com base em 3974 SCMs que ocorreram durante 2014 e 2163 SCMs ocorridos entre 01/01 - 30/06/2015. . .

Figura 22 - Horário de gênese (UTC) dos SCMs com duração (a) SCMs com curto tempo de vida, (b) SCMs com longo ciclo de vida e (c) todos SCMs. Cada horário representa o intervalo da hora cheia mais meia hora. A frequência relativa (\%) foi calculada com base em 3974 SCMs que ocorreram durante 2014 e 2163 SCMs ocorridos entre 01/01 30/06/2015. . . . . . . . . . . . . . . . . . . .

Figura 23 - Horário de maturação (UTC) dos SCMs com ciclo de vida (a) SCMs com curto tempo de vida, (b) SCMs com longo ciclo de vida e (c) todos SCMs. Cada horário representa o intervalo da hora cheia mais meia hora. A frequência relativa (\%) foi calculada com base em 3974 SCMs que ocorreram durante 2014 e 2163 SCMs ocorridos entre 01/01-30/06/2015. . . . . . . . . . . . . . . . . . . .

Figura 24 - Horário de dissipação (UTC) dos SCMs com ciclo de vida (a) SCMs com curto tempo de vida, (b) SCMs com longo ciclo de vida e (c) todos SCMs. Cada horário representa o intervalo da hora cheia mais meia hora. A frequência relativa (\%) foi calculada com base em 3974 SCMs que ocorreram durante 2014 e 2163 SCMs ocorridos entre 01/01 - 30/06/2015.

Figura 25 - Anomalias da densidade de gênese, maturação e dissipação dos SCMs com curto ciclo de vida ocorridos em 2014 sobre a bacia Amazônica. Em (a.i), (a.ii) e (a.iii) janeiro; (b.i), (b.ii), (b.iii) fevereiro; (c.i), (c.ii), (c.iii) março; (d.i), (d.ii), (d.iii) abril; (e.i), (e.ii), (e.iii) maio; (f.i), (f.ii), (f.iii) junho; (g.i), (g.ii), (g.iii) julho; (h.i), (h.ii), (h.iii) agosto; (i.i), (i.ii), (i.iii) setembro; (j.i), (j.ii), (j.iii) outubro; (k.i), (k.ii), (k.iii) novembro e (l.i), (l.ii), (l.iii) dezembro. . . . . . . . . . . . . . . . . . 
Figura 26 - Anomalias da densidade de gênese, maturação e dissipação dos SCMs com longo ciclo de vida ocorridos em 2014 sobre a bacia Amazônica. Em (a.i), (a.ii) e (a.iii) janeiro; (b.i), (b.ii), (b.iii) fevereiro; (c.i), (c.ii),(c.iii) março; (d.i), (d.ii), (d.iii) abril; (e.i), (e.ii), (e.iii) maio; (f.i), (f.ii), (f.iii) junho; (g.i), (g.ii), (g.iii) julho; (h.i), (h.ii), (h.iii) agosto; (i.i), (i.ii), (i.iii) setembro; (j.i), (j.ii), (j.iii) outubro; (k.i), (k.ii), (k.iii) novembro e (l.i), (l.ii), (l.iii) dezembro.

Figura 27 - Anomalias da densidade de gênese, maturação e dissipação de todos os SCMs ocorridos em 2014 sobre a bacia Amazônica. Em (a.i), (a.ii) e (a.iii) janeiro; (b.i), (b.ii), (b.iii) fevereiro; (c.i), (c.ii),(c.iii) março; (d.i), (d.ii), (d.iii) abril; (e.i), (e.ii), (e.iii) maio; (f.i), (f.ii), (f.iii) junho; (g.i), (g.ii), (g.iii) julho; (h.i), (h.ii), (h.iii) agosto; (i.i), (i.ii), (i.iii) setembro; (j.i), (j.ii), (j.iii) outubro; (k.i), (k.ii), (k.iii) novembro e (l.i), (I.ii), (I.iii) dezembro.

Figura 28 - Anomalias da densidade de gênese, maturação e dissipação dos SCMs com curto ciclo de vida ocorridos em 2015 sobre a bacia Amazônica. Em (a.i), (a.ii) e (a.iii) janeiro; (b.i), (b.ii), (b.iii) fevereiro; (c.i), (c.ii),(c.iii) março; (d.i), (d.ii), (d.iii) abril; (e.i), (e.ii), (e.iii) maio; (f.i), (f.ii), (f.iii) junho; (g.i), (g.ii), (g.iii) julho; (h.i), (h.ii), (h.iii) agosto; (i.i), (i.ii), (i.iii) setembro; (j.i), (j.ii), (j.iii) outubro; (k.i), (k.ii), (k.iii) novembro e (I.i), (I.ii), (l.iii) dezembro.

Figura 29 - Anomalias da densidade de gênese, maturação e dissipação dos SCMs com longo ciclo de vida ocorridos em 2015 sobre a bacia Amazônica. Em (a.i), (a.ii) e (a.iii) janeiro; (b.i), (b.ii), (b.iii) fevereiro; (c.i), (c.ii),(c.iii) março; (d.i), (d.ii), (d.iii) abril; (e.i), (e.ii), (e.iii) maio; (f.i), (f.ii), (f.iii) junho; (g.i), (g.ii), (g.iii) julho; (h.i), (h.ii), (h.iii) agosto; (i.i), (i.ii), (i.iii) setembro; (j.i), (j.ii), (j.iii) outubro; (k.i), (k.ii), (k.iii) novembro e (l.i), (l.ii), (l.iii) dezembro.

Figura 30 - Anomalias da densidade de gênese, maturação e dissipação de todos os SCMs ocorridos entre 01/01 a 30/06/2015 sobre a bacia Amazônica. Em (a.i), (a.ii) e (a.iii) janeiro; (b.i), (b.ii), (b.iii) fevereiro; (c.i), (c.ii),(c.iii) março; (d.i), (d.ii), (d.iii) abril; (e.i), (e.ii), (e.iii) maio; (f.i), (f.ii), (f.iii) junho; (g.i), (g.ii), (g.iii) julho; (h.i), (h.ii), (h.iii) agosto; (i.i), (i.ii), (i.iii) setembro; (j.i), (j.ii), (j.iii) outubro; (k.i), (k.ii), (k.iii) novembro e (I.i), (l.ii), (l.iii) dezembro.

Figura 31 - Direção de propagação, deslocamentos médios e velocidade média dos SCMs com curto ciclo de vida ocorridos na bacia Amazônica em 2014. O comprimento do vetor indica o deslocamento médio e a largura indica a velocidade. 
Figura 32 - Direção de propagação, deslocamentos médios e velocidade média dos SCMs com longo ciclo de vida ocorridos na bacia Amazônica em 2014. O comprimento do vetor indica o deslocamento médio e a largura indica a velocidade.

Figura 33 - Direção de propagação, deslocamentos médios e velocidade média de todos SCMs ocorridos na bacia Amazônica em 2014. O comprimento do vetor indica o deslocamento médio e a largura indica a velocidade.

Figura 34 - Direção de propagação, deslocamentos médios e velocidade média dos SCMs com curto ciclo de vida ocorridos na bacia Amazônica em 2015. O comprimento do vetor indica o deslocamento médio e a largura indica a velocidade.

Figura 35 - Direção de propagação, deslocamentos médios e velocidade média dos SCMs com longo ciclo de vida ocorridos na bacia Amazônica em 2015. O comprimento do vetor indica o deslocamento médio e a largura indica a velocidade.

Figura 36 - Direção de propagação, deslocamentos médios e velocidade média de todos SCMs ocorridos na bacia Amazônica em 2015. O comprimento do vetor indica o deslocamento médio e a largura indica a velocidade.

Figura 37 - Frequência relativa (\%) de SCMs oceânicos de acordo com o ciclo de vida (h) ocorridos durante o projeto GOAmazon.

Figura 38 - Horário de (a) gênese, (b) maturação e (c) dissipação dos SCMs oceânicos ocorridos em 2014 de acordo com o tempo de vida. Cada horário representa o intervalo da hora cheia mais meia hora. . . . .

Figura 39 - Localização e deslocamentos dos SCMs ocorridos próximo às estações do GOAmazon de acordo com o tempo de vida. Os SCMs são identificados através do número no início de cada seta (Tabela 4). 0 início da seta indica a posição inicial do SCM, a ponta da seta indica a posição final e sua inclinação indica a direção de deslocamento. As estações de coleta de dados do GOAmazon estão indicadas por círculos brancos fechados.

Figura 40 - Média mensal e horária dos índices de instabilidade calculados usando dados de radiossondagens lançadas em Manaus - SBMN (2014) e Manacapuru - T3 (2014 e 01/01-30/02/2015) . . . . . . . . . 115

Figura 41 - Índices de instabilidade de acordo com o horário e estação de lançamento da radiossonda. . . . . . . . . . . . . . . . . . . . . 117

Figura 42 - Cartas sinóticas do dia 10/01/2014 - 06 UTC em (a) 250 hPa, (b) 700 hPa e (c) superfície. Fonte: CPTEC/INPE. . . . . . . . . . . . . . . . 119 
Figura 43 - Imagens de satélite do canal infravermelho em 10/01/2014. Fase de (a) gênese - 0730 UTC, (b) maturação - 0900 UTC e (c) dissipação 1030 UTC. . . . . . . . . . . . . . . . . . . . . 120

Figura 44 - Condições de tempo na estação de coleta de dados meteorológicos T3, localizada em Manacapuru, Amazonas em 10/01/2014. Em (a) precipitação $(\mathrm{mm}),\left(\right.$ b) direção do vento $\left(^{\circ}\right)$, (c) velocidade do vento $(\mathrm{m} / \mathrm{s}),(\mathrm{d})$ pressão atmosférica $(\mathrm{kPa}),(\mathrm{e})$ temperatura do $\operatorname{ar}\left({ }^{\circ} \mathrm{C}\right),(\mathrm{f})$ umidade relativa $(\%) \ldots \ldots \ldots \ldots \ldots \ldots$. . . . . . . . 120

Figura 45 - Cartas sinóticas do dia 09/02/2014 - 12 UTC em (a) 250 hPa, (b) 700 hPa e (c) superfície. Fonte: CPTEC/INPE. . . . . . . . . . . . . . . 121

Figura 46 - Imagens de satélite do canal infravermelho em 09/02/2014 na fase de (a) gênese - 1330 UTC, (b) maturação - 1630 UTC e (c) dissipação 1730 UTC.

Figura 47 - Condições de tempo na estação de coleta de dados meteorológicos T3, localizada em Manacapuru, Amazonas em 09/02/2014. Em (a) precipitação $(\mathrm{mm}),(\mathrm{b})$ direção do vento $\left(^{\circ}\right)$, (c) velocidade do vento $(\mathrm{m} / \mathrm{s}),(\mathrm{d})$ pressão atmosférica $(\mathrm{kPa}),(\mathrm{e})$ temperatura do $\operatorname{ar}\left({ }^{\circ} \mathrm{C}\right),(\mathrm{f})$ umidade relativa $(\%) \ldots \ldots \ldots \ldots \ldots \ldots$

Figura 48 - Cartas sinóticas do dia 13/02/2014 - 12 UTC (a) 250 hPa, (b) 700 hPa e (c) superfície. Fonte: CPTEC/INPE.

Figura 49 - Imagens de satélite do canal infravermelho em 13/02/2014 na fase de (a) gênese - 1030 UTC, (b) maturação - 1530 UTC e (c) dissipação 1730 UTC. . . . . . . . . . . . . . . . . . . . . . 123

Figura 50 - Condições de tempo na estação de coleta de dados meteorológicos T3, localizada em Manacapuru, Amazonas no dia 13/02/2014. Em (a) precipitação $(\mathrm{mm})$, (b) direção do vento $\left(^{\circ}\right)$, (c) velocidade do vento $(\mathrm{m} / \mathrm{s}),(\mathrm{d})$ pressão atmosférica $(\mathrm{kPa}),(\mathrm{e})$ temperatura do $\operatorname{ar}\left({ }^{\circ} \mathrm{C}\right),(\mathrm{f})$ umidade relativa $(\%) . \ldots \ldots$. . . . . . . . . . . . . . . 123

Figura 51 - Cartas sinóticas do dia 19/04/2014 - 00 UTC (a) $250 \mathrm{hPa}$, (b) 700 hPa e (c) superfície. Fonte: CPTEC/INPE. . . . . . . . . . . . . . 124

Figura 52 - Imagens de satélite do canal infravermelho em 19/04/2014 na fase de (a) gênese - 0200 UTC, (b) maturação - 0400 UTC e (c) dissipação 0600 UTC. . . . . . . . . . . . . . . . . . . . . .

Figura 53 - Condições de tempo na estação de coleta de dados meteorológicos T3, localizada em Manacapuru, Amazonas no dia 19/04/2014. Em (a) precipitação $(\mathrm{mm})$, (b) direção do vento $\left(^{\circ}\right)$, (c) velocidade do vento $(\mathrm{m} / \mathrm{s}),(\mathrm{d})$ pressão atmosférica $(\mathrm{kPa}),(\mathrm{e})$ temperatura do $\operatorname{ar}\left({ }^{\circ} \mathrm{C}\right),(\mathrm{f})$ umidade relativa $(\%) \ldots \ldots \ldots \ldots \ldots \ldots$. . . . . . . . . 
Figura 54 - Cartas sinóticas do dia 02/06/2014 - 06 UTC (a) 250 hPa, (b) 700 hPa e (c) superfície. Fonte: CPTEC/INPE. . . . . . . . . . . . . . . 126

Figura 55 - Imagens de satélite do canal infravermelho em 02/06/2014 na fase de (a) gênese - 0730 UTC, (b) maturação - 1100 UTC e (c) dissipação 1300 UTC.

Figura 56 - Condições de tempo na estação de coleta de dados meteorológicos T3, localizada em Manacapuru, Amazonas no dia 02/06/2014. Em (a) precipitação $(\mathrm{mm})$, (b) direção do vento $\left(^{\circ}\right)$, (c) velocidade do vento $(\mathrm{m} / \mathrm{s}),(\mathrm{d})$ pressão atmosférica $(\mathrm{kPa}),(\mathrm{e})$ temperatura do $\operatorname{ar}\left({ }^{\circ} \mathrm{C}\right),(\mathrm{f})$

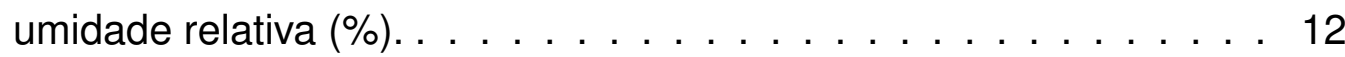

Figura 57 - Cartas sinóticas do dia 29/06/2014 - 18 UTC (a) $250 \mathrm{hPa}$, (b) 700 hPa e (c) superfície. Fonte: CPTEC/INPE.

Figura 58 - Imagens de satélite do canal infravermelho em 29 e 30/06/2014 na fase de (a) gênese - 1800 UTC, (b) maturação - 0130 UTC e (c) dissipação - 0830 UTC.

Figura 59 - Condições de tempo na estação de coleta de dados meteorológicos T3, localizada em Manacapuru, Amazonas nos dias 29 e 30/06/2014. Em (a) precipitação $(\mathrm{mm}),(\mathrm{b})$ direção do vento $\left({ }^{\circ}\right)$, (c) velocidade do vento $(\mathrm{m} / \mathrm{s}),(\mathrm{d})$ pressão atmosférica $(\mathrm{kPa}),(\mathrm{e})$ temperatura do ar $\left({ }^{\circ} \mathrm{C}\right)$, (f) umidade relativa $(\%)$

Figura 60 - Cartas sinóticas do dia 12/07/2014 - 18 UTC (a) 250 hPa, (b) 700 hPa e (c) superfície. Fonte: CPTEC/INPE.

Figura 61 - Condições de tempo na estação de coleta de dados meteorológicos T3, localizada em Manacapuru, Amazonas no dia 12/07/2014. Em (a) precipitação $(\mathrm{mm})$, (b) direção do vento $\left(^{\circ}\right)$, (c) velocidade do vento $(\mathrm{m} / \mathrm{s}),(\mathrm{d})$ pressão atmosférica $(\mathrm{kPa}),(\mathrm{e})$ temperatura do $\operatorname{ar}\left({ }^{\circ} \mathrm{C}\right),(\mathrm{f})$ umidade relativa $(\%) . \ldots \ldots \ldots \ldots \ldots$

Figura 62 - Imagens de satélite do canal infravermelho em 12/07/2014 na fase de (a) gênese - 1700 UTC, (b) maturação - 2100 UTC e (c) dissipação 2330 UTC.

Figura 63 - Cartas sinóticas do dia 19/07/2014 - 00 UTC (a) 250 hPa, (b) 700 hPa e (c) superfície. Fonte: CPTEC/INPE.

Figura 64 - Imagens de satélite do canal infravermelho em 19/07/2014 na fase de (a) gênese - 0300 UTC, (b) maturação - 0630 UTC e (c) dissipação 0730 UTC. 
Figura 65 - Condições de tempo na estação de coleta de dados meteorológicos T3, localizada em Manacapuru, Amazonas no dia 19/07/2014. Em (a) precipitação $(\mathrm{mm})$, (b) direção do vento $\left(^{\circ}\right)$, (c) velocidade do vento $(\mathrm{m} / \mathrm{s}),(\mathrm{d})$ pressão atmosférica $(\mathrm{kPa}),(\mathrm{e})$ temperatura do $\operatorname{ar}\left({ }^{\circ} \mathrm{C}\right),(\mathrm{f})$ umidade relativa $(\%) \ldots \ldots \ldots \ldots \ldots \ldots$

Figura 66 - Cartas sinóticas do dia 29/07/2014 - 00 UTC (a) 250 hPa, (b) 700 hPa e (c) superfície. Fonte: CPTEC/INPE.

Figura 67 - Imagens de satélite do canal infravermelho em 29/07/2014 na fase de (a) gênese - 1930 UTC, (b) maturação - 2200 UTC e (c) dissipação 2230 UTC.

Figura 68 - Condições de tempo na estação de coleta de dados meteorológicos T3, localizada em Manacapuru, Amazonas no dia 29/07/2014. Em (a) precipitação $(\mathrm{mm}),\left(\right.$ b) direção do vento $\left(^{\circ}\right)$, (c) velocidade do vento $(\mathrm{m} / \mathrm{s}),(\mathrm{d})$ pressão atmosférica $(\mathrm{kPa}),(\mathrm{e})$ temperatura do $\operatorname{ar}\left({ }^{\circ} \mathrm{C}\right),(\mathrm{f})$ umidade relativa $(\%) \ldots \ldots \ldots \ldots \ldots \ldots$. . . . . . . . . .

Figura 69 - Cartas sinóticas do dia 03/08/2014 - 06 UTC (a) $250 \mathrm{hPa}$, (b) 700 hPa e (c) superfície. Fonte: CPTEC/INPE. . . . . . . . . . . . . . . 133

Figura 70 - Imagens de satélite do canal infravermelho em 03/08/2014 na fase de (a) gênese - 0430 UTC, (b) maturação - 0700 UTC e (c) dissipação 0830 UTC. . . . . . . . . . . . . . . . . . . . . .

Figura 71 - Condições de tempo na estação de coleta de dados meteorológicos T3, localizada em Manacapuru, Amazonas no dia 03/08/2014. Em (a) precipitação $(\mathrm{mm})$, (b) direção do vento $\left(^{\circ}\right)$, (c) velocidade do vento $(\mathrm{m} / \mathrm{s}),(\mathrm{d})$ pressão atmosférica $(\mathrm{kPa}),(\mathrm{e})$ temperatura do $\operatorname{ar}\left({ }^{\circ} \mathrm{C}\right),(\mathrm{f})$

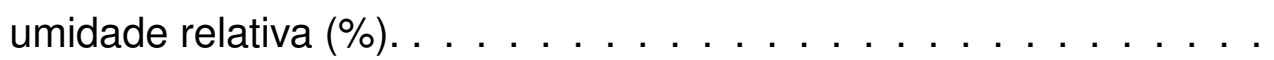
134

Figura 72 - Cartas sinóticas do dia 04/08/2014 - 18 UTC (a) 250 hPa, (b) 700 hPa e (c) superfície. Fonte: CPTEC/INPE.

Figura 73 - Imagens de satélite do canal infravermelho em 04 e 05/08/2014 na fase de (a) gênese - 1630 UTC, (b) desenvolvimento - 2130 UTC e (c) maturação - 2330 UTC.

Figura 74 - Condições de tempo na estação de coleta de dados meteorológicos T3, localizada em Manacapuru, Amazonas nos dias 04 e 05/08/2014. Em (a) precipitação $(\mathrm{mm}),(\mathrm{b})$ direção do vento $\left(^{\circ}\right)$, (c) velocidade do vento $(\mathrm{m} / \mathrm{s})$, (d) pressão atmosférica $(\mathrm{kPa}),(\mathrm{e})$ temperatura do ar $\left({ }^{\circ} \mathrm{C}\right)$, (f) umidade relativa $(\%) \ldots \ldots \ldots \ldots$

Figura 75 - Cartas sinóticas do dia 09/08/2014 - 00 UTC (a) 250 hPa, (b) 700 hPa e (c) superfície. Fonte: CPTEC/INPE. . . . . . . . . . . . . 136 
Figura 76 - Imagens de satélite do canal infravermelho em 08 e 09/08/2014 na fase de (a) gênese - 2230 UTC, (b) maturação - 0230 UTC e (c) dissipação - 0430 UTC. . . . . . . . . . . . . . . . . . . . . . . . .

Figura 77 - Condições de tempo na estação de coleta de dados meteorológicos T3, localizada em Manacapuru, Amazonas no dia 08 e 09/08/2014. Em (a) precipitação $(\mathrm{mm})$, (b) direção do vento $\left({ }^{\circ}\right)$, (c) velocidade do vento $(\mathrm{m} / \mathrm{s})$, (d) pressão atmosférica $(\mathrm{kPa}),(\mathrm{e})$ temperatura do ar

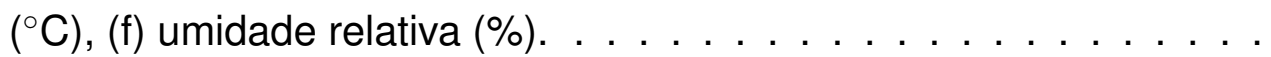

Figura 78 - Cartas sinóticas do dia 15/08/2014 - 18 UTC (a) 250 hPa, (b) 700 hPa e (c) superfície. Fonte: CPTEC/INPE. . . . . . . . . . . . . . . .

Figura 79 - Imagens de satélite do canal infravermelho em 15 e 16/08/2014 na fase de (a) gênese - 1800 UTC, (b) maturação - 2030 UTC e (c) dissipação - 0100 UTC.

Figura 80 - Condições de tempo na estação de coleta de dados meteorológicos T3, localizada em Manacapuru, Amazonas no dia 15 e 16/08/2014. Em (a) precipitação $(\mathrm{mm})$, (b) direção do vento $\left({ }^{\circ}\right)$, (c) velocidade do vento $(\mathrm{m} / \mathrm{s}),(\mathrm{d})$ pressão atmosférica $(\mathrm{kPa}),(\mathrm{e})$ temperatura do ar $\left({ }^{\circ} \mathrm{C}\right),(\mathrm{f})$ umidade relativa $(\%)$.

Figura 81 - Cartas sinóticas do dia 12/09/2014 - 12 UTC (a) 250 hPa, (b) 700 hPa e (c) superfície. Fonte: CPTEC/INPE. 139

Figura 82 - Imagens de satélite do canal infravermelho em 12/09/2014 na fase de (a) gênese - 1500 UTC, (b) maturação - 2030 UTC e (c) dissipação 2330 UTC.

Figura 83 - Condições de tempo na estação de coleta de dados meteorológicos T3, localizada em Manacapuru, Amazonas no dia 12/09/2014. Em (a) precipitação $(\mathrm{mm}),(\mathrm{b})$ direção do vento $\left({ }^{\circ}\right)$, (c) velocidade do vento $(\mathrm{m} / \mathrm{s}),(\mathrm{d})$ pressão atmosférica $(\mathrm{kPa}),(\mathrm{e})$ temperatura do $\operatorname{ar}\left({ }^{\circ} \mathrm{C}\right),(\mathrm{f})$ umidade relativa $(\%) \ldots \ldots \ldots \ldots . \ldots \ldots$

Figura 84 - Cartas sinóticas do dia 24/09/2014 - 12 UTC (a) 250 hPa, (b) 700 hPa e (c) superfície. Fonte: CPTEC/INPE. . . . . . . . . . . . . . . . 140

Figura 85 - Imagens de satélite do canal infravermelho em 24/09/2014 na fase de (a) gênese - 1130 UTC, (b) maturação - 1230 UTC e (c) dissipação 1430 UTC.

Figura 86 - Condições de tempo na estação de coleta de dados meteorológicos T3, localizada em Manacapuru, Amazonas no dia 24/09/2014. Em (a) precipitação $(\mathrm{mm}),(\mathrm{b})$ direção do vento $\left(^{\circ}\right),(\mathrm{c})$ velocidade do vento $(\mathrm{m} / \mathrm{s}),(\mathrm{d})$ pressão atmosférica $(\mathrm{kPa}),(\mathrm{e})$ temperatura do $\operatorname{ar}\left({ }^{\circ} \mathrm{C}\right),(\mathrm{f})$ umidade relativa $(\%) \ldots \ldots \ldots \ldots . \ldots . \ldots$ 
Figura 87 - Cartas sinóticas do dia 16/11/2014 - 12 UTC (a) 250 hPa, (b) 700 hPa e (c) superfície. Fonte: CPTEC/INPE. . . . . . . . . . . . . . 141

Figura 88 - Imagens de satélite do canal infravermelho em 16 e 17/11/2014 na fase de (a) gênese - 1900 UTC, (b) maturação - 2130 UTC e (c) dissipação - 0100 UTC. . . . . . . . . . . . . . . . . . . . . . 142

Figura 89 - Condições de tempo na estação de coleta de dados meteorológicos T3, localizada em Manacapuru, Amazonas no dia 16/11/2014. Em (a) precipitação $(\mathrm{mm})$, (b) direção do vento $\left(^{\circ}\right)$, (c) velocidade do vento $(\mathrm{m} / \mathrm{s}),(\mathrm{d})$ pressão atmosférica $(\mathrm{kPa}),(\mathrm{e})$ temperatura do $\operatorname{ar}\left({ }^{\circ} \mathrm{C}\right),(\mathrm{f})$ umidade relativa $(\%) \ldots \ldots \ldots$. . . . . . . . . . . . . 142

Figura 90 - Cartas sinóticas do dia 13/12/2014 - 00 UTC (a) 250 hPa, (b) 700 hPa e (c) superfície. Fonte: CPTEC/INPE. . . . . . . . . . . . . . 143

Figura 91 - Imagens de satélite do canal infravermelho em 13/12/2014 na fase de (a) gênese - 0500 UTC, (b) maturação - 0830 UTC e (c) dissipação 1130 UTC.

Figura 92 - Condições de tempo na estação de coleta de dados meteorológicos T3, localizada em Manacapuru, Amazonas no dia 13/12/2014. Em (a) precipitação $(\mathrm{mm})$, (b) direção do vento $\left(^{\circ}\right)$, (c) velocidade do vento $(\mathrm{m} / \mathrm{s}),(\mathrm{d})$ pressão atmosférica $(\mathrm{kPa}),(\mathrm{e})$ temperatura do $\operatorname{ar}\left({ }^{\circ} \mathrm{C}\right),(\mathrm{f})$ umidade relativa $(\%) \ldots \ldots \ldots \ldots \ldots$. . . . . . . . .

Figura 93 - Cartas sinóticas do dia 09/01/2015 - 12 UTC (a) 250 hPa, (b) 700 hPa e (c) superfície. Fonte: CPTEC/INPE. . . . . . . . . . . . . . 144

Figura 94 - Imagens de satélite do canal infravermelho em 09/01/2015 na fase de (a) gênese - 1300 UTC, (b) maturação - 1330 UTC e (c) dissipação 1630 UTC.

Figura 95 - Condições de tempo na estação de coleta de dados meteorológicos T3, localizada em Manacapuru, Amazonas no dia 09/01/2015. Em (a) precipitação $(\mathrm{mm})$, (b) direção do vento $\left(^{\circ}\right)$, (c) velocidade do vento $(\mathrm{m} / \mathrm{s}),(\mathrm{d})$ pressão atmosférica $(\mathrm{kPa}),(\mathrm{e})$ temperatura do $\operatorname{ar}\left({ }^{\circ} \mathrm{C}\right),(\mathrm{f})$ umidade relativa $(\%) \ldots \ldots \ldots \ldots \ldots \ldots$

Figura 96 - Cartas sinóticas dos dias 12 e 13/01/2015 - 00 UTC (a) $250 \mathrm{hPa}$, (b) $700 \mathrm{hPa}$ e (c) superfície. Fonte: CPTEC/INPE.

Figura 97 - Imagens de satélite do canal infravermelho em 12 e 13/01/2015 na fase de (a) gênese - 2130 UTC, (b) maturação - 0100 UTC e (c) dissipação - 0500 UTC. 
Figura 98 - Condições de tempo na estação de coleta de dados meteorológicos T3, localizada em Manacapuru, Amazonas no dia 12 e 13/01/2015. Em (a) precipitação $(\mathrm{mm})$, (b) direção do vento $\left(^{\circ}\right)$, (c) velocidade do vento $(\mathrm{m} / \mathrm{s})$, (d) pressão atmosférica $(\mathrm{kPa}),(\mathrm{e})$ temperatura do ar $\left({ }^{\circ} \mathrm{C}\right)$, (f) umidade relativa $(\%)$. . . . . . . . . . . . . . . . . . 146

Figura 99 - Cartas sinóticas do dia 28/03/2014 - 06 UTC (a) 250 hPa, (b) 700 hPa e (c) superfície. Fonte: CPTEC/INPE. . . . . . . . . . . . . .

Figura 100-Imagens de satélite do canal infravermelho em 28/03/2015 na fase de (a) gênese - 0700 UTC, (b) maturação - 0930 UTC e (c) dissipação 1030 UTC. . . . . . . . . . . . . . . . . . . . 147

Figura 101-Condições de tempo na estação de coleta de dados meteorológicos T3, localizada em Manacapuru, Amazonas no dia 28/03/2015. Em (a) precipitação $(\mathrm{mm})$, (b) direção do vento $\left(^{\circ}\right)$, (c) velocidade do vento $(\mathrm{m} / \mathrm{s}),(\mathrm{d})$ pressão atmosférica $(\mathrm{kPa}),(\mathrm{e})$ temperatura do $\operatorname{ar}\left({ }^{\circ} \mathrm{C}\right),(\mathrm{f})$ umidade relativa $(\%) \ldots \ldots \ldots \ldots$. . . . . . . . . . . 147

Figura 102-Cartas sinóticas do dia 23/04/2015 - 12 UTC (a) $250 \mathrm{hPa}$, (b) 700 hPa e (c) superfície. Fonte: CPTEC/INPE. . . . . . . . . . . . . . 148

Figura 103-Imagens de satélite do canal infravermelho em 23/04/2015 na fase de (a) gênese - 1000 UTC, (b) maturação - 1200 UTC e (c) dissipação 1300 UTC. . . . . . . . . . . . . . . . . . .

Figura 104-Condições de tempo na estação de coleta de dados meteorológicos T3, localizada em Manacapuru, Amazonas no dia 23/04/2015. Em (a) precipitação $(\mathrm{mm})$, (b) direção do vento $\left(^{\circ}\right)$, (c) velocidade do vento $(\mathrm{m} / \mathrm{s}),(\mathrm{d})$ pressão atmosférica $(\mathrm{kPa}),(\mathrm{e})$ temperatura do $\operatorname{ar}\left({ }^{\circ} \mathrm{C}\right),(\mathrm{f})$ umidade relativa $(\%) . \ldots \ldots \ldots$. . . . . . . . . . . 149

Figura 105-Distribuição anual dos SCMs na bacia Amazônica. . . . . . . . . . . 169

Figura 106-Deslocamentos médios anuais dos SCMs ocorridos na bacia Amazônica de acordo com o tempo de duração. Em (a) SCMs com curta duração; (b) SCMs com longa duração e; (c) Todos os SCMs. . . . . 170 



\section{Lista de tabelas}

Tabela 1 - Características em comum dos SCMs estudos no presente trabalho. 39

Tabela 2 - Climatologia das áreas médias nas diferentes fases do ciclo de vida dos SCMs continentais e oceânicos de acordo com o tempo de duração. . . . . . . . . . . . . . . . . . . . . . . 69

Tabela 3 - Áreas médias nas diferentes fases do ciclo de vida de acordo com o tempo de duração dos SCMs continentais e oceânicos ocorridos durante o projeto GOAmazon. . . . . . . . . . . . . . . . . . . . . 109

Tabela 4 - SCMs ocorridos próximos às estações do GOAmazon e suas características no período de 02/01/2014 a 30/06/2015. Os SCMs estão ordenados conforme a data de ocorrência. ID é um identificador usado para distinguir os SCMs na Figura $39 . \ldots . \ldots . . . .113$

Tabela 5 - Datas e horários com falhas nas imagens. . . . . . . . . . . . . 165

Tabela 6 - SCMs filtrados segundo o tempo de vida (F1), trajetória sobre a bacia Amazônica (F2), curva de crescimento (F3) e deslocamento (F4). . 167 



\title{
Lista de abreviaturas e siglas
}

\author{
ASAS Alta Subtropical do Atlântico Sul \\ CAPE Convective Available Potencial Energy \\ $\mathrm{Cb} \quad$ Cumulonimbus \\ CCM Complexo Convectivo de Mesoescala \\ CCMs Complexos Convectivos de Mesoescala \\ CINE Convective Inhibition Energy \\ CPTEC Centro de Previsão de Tempo e Estudos Climáticos \\ ENOS El Niño-Oscilação Sul \\ ForTraCC Forecasting and Tracking the evolution of Cloud Clusters \\ GOAmazon Green Ocean Amazon \\ ILEV Índice de LEVantamento \\ INPE Instituto Nacional de Pesquisas Espaciais \\ JST Jato Subtropical \\ K I Índice K \\ LI Linha de Instabilidade \\ LIs Linhas de Instabilidade \\ SCM Sistema Convectivo de Mesoescala \\ SCMs Sistemas Convectivos de Mesoescala \\ TSM Temperatura na Superfície do Mar \\ TT Índice Total Totals \\ UTC Coordinated Universal Time \\ VCAN Vórtice Ciclônico de Altos Níveis \\ ZCAS Zona de Convergência do Atlântico Sul \\ ZCIT Zona de Convergência Intertropical
}





\section{Sumário}

INTRODUÇÃo $\ldots \ldots \ldots \ldots \ldots \ldots \ldots \ldots$

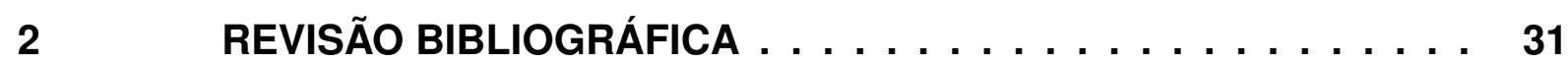

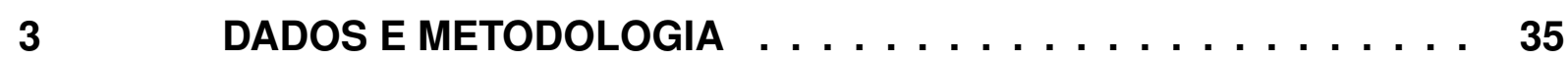

$3.1 \quad$ Período e região de estudo $\ldots \ldots \ldots \ldots \ldots \ldots \ldots$

$3.2 \quad$ Dados . . . . . . . . . . . . . . . . . . 36

$3.3 \quad$ Identificação e rastreamento dos SCMs . . . . . . . . . 37

$3.4 \quad$ Classificação dos SCMs . . . . . . . . . . . . 39

3.5 Cálculos dos índices de instabilidade termodinâmica e cisalhamento do vento . . . . . . . . . . . . . . . . . . 40

4 RESULTADOS E dISCUSSÕES $\ldots \ldots \ldots \ldots \ldots \ldots$

$4.1 \quad$ Climatologia dos SCMs na bacia Amazônica . . . . . . . . 43

$4.1 .1 \quad$ SCMs continentais $\ldots \ldots \ldots \ldots \ldots \ldots \ldots$

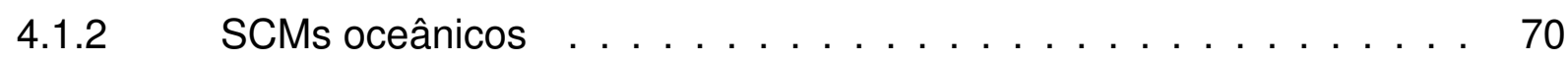

$4.2 \quad$ SCMs ocorridos durante o projeto GOAmazon . . . . . . . . 77

4.2.1 SCMs continentais e suas características . . . . . . . . . . . 77

4.2.2 SCMs oceânicos e suas características . . . . . . . . . . . . . . 109

$4.3 \quad$ SCMs ocorridos próximos às estações do GOAmazon . . . . . . 112

4.3.1 Análise sinótica e das condições dinâmicas e termodinâmicas observadas . . . . . . . . . . . . . . . . . . . . . . . 114

$5 \quad$ CONCLUSÕES $\ldots \ldots \ldots \ldots \ldots \ldots \ldots \ldots \ldots \ldots \ldots \ldots \ldots$

6 SUGESTÕES PARA TRABALHOS FUtUROS $\ldots \ldots \ldots$

REFERÊNCIAS . . . . . . . . . . . . . . . . 159

APÊNDICES 163

APÊNDICE A - DADOS FALTANTES . . . . . . . . . 165

APÊNDICE B - SISTEMAS FILTRADOS . . . . . . . . . . 167

APÊNDICE C - DISTRIBUIÇÃO E DESLOCAMENTO MÉDIOS ANU-

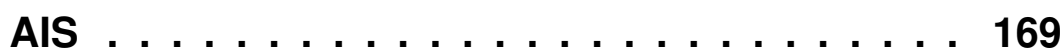





\section{Introdução}

A bacia Amazônica é formada por um conjunto de rios, córregos e mananciais que convergem para o rio Amazonas. Juntos, eles ocupam uma de aproximadamente 6 milhões de $\mathrm{km}^{2}$ e compõem a maior rede hidrográfica do mundo. $\mathrm{O}$ clima desta região é resultado de um complexo sistema de interações de fenômenos meteorológicos, onde a precipitação e a nebulosidade desempenham uma importante função (FISCH; MARENGO; NOBRE, 1998). Entre os principais mecanismos geradores de precipitação sobre a bacia Amazônica estão os sistemas convectivos de mesoescala (SCMs).

Os SCMs são sistemas meteorológicos compostos por aglomerados de nuvens Cumulonimbus (Cbs) organizadas na escala meteorológica de tempo e espaço chamada de mesoescala. Estes sistemas de nuvens possuem extensões entre $20 \mathrm{a}$ 200 km, mas podem alcançar dimensões de 200 a 2000 km (MACHADO; ROSSOW, 1993). Eles são responsáveis por produzirem grandes quantidades de precipitação nos trópicos e em médias latitudes sobre os continentes, além de representarem as maiores tempestades convectivas existentes (HOUZE, 2004). Além disso, são os principais responsáveis pelas transferencias verticais de energia na troposfera tropical (LAURENT et al., 2000).

Dada a importância do conhecimento sobre a precipitação e convecção tropical, vários estudos e experimentos têm sido desenvolvidos nestas regiões ao redor do globo. O mais recente esforço neste sentido é do projeto Green Ocean Amazon (GOAmazon), o qual ocorreu nas áreas adjacentes à Manaus, na região central da bacia Amazônica, durante dois anos, entre 01/01/2014 e 31/12/2015. O projeto é uma colaboração entre instituições brasileiras de ensino e pesquisa, dentre elas a Universidade de São Paulo (USP), o Departamento Americano de Energia (United State Department of Energy DOE) e o Instituto Max Planck da Alemanha'1.

Dentro do contexto do GOAmazon em tentar entender a convecção na Amazônia, o objetivo deste estudo é investigar as características dos SCMs ocorridos na bacia Amazônica e, particularmente, sobre a área experimental do projeto GOAmazon durante sua ocorrência. Baseado em Sakamoto (2009), serão avaliados: a distribuição espacial, variabilidade diurna, ciclo de vida, deslocamento e parâmetros morfológicos dos SCMs continentais e oceânicos ocorridos em toda a bacia Amazônica, condições sinóticas com atenção à identificação dos fatores pré-condicionantes e mecanismos de gatilho à convecção e as condições dinâmicas e termodinâmicas observadas durante a gênese do sistema convectivo e sua evolução ao longo do ciclo de vida daqueles sistemas que ocorrerem próximos às estações do projeto GOAmazon.

\footnotetext{
Mais informações em: http://campaign.arm.gov/goamazon2014/
} 
Até o presente momento não há um estudo que verifique a ocorrência e características médias dos SCMs sobre toda a bacia Amazônica, isto é, utilizando a delimitação geográfica da bacia Amazônica, considerando todos os tipos de SCMs ocorridos ao longo de todo o ano, com longo período de dados de alta resolução espacial e temporal e com poucas falhas. 


\section{Revisão bibliográfica}

A bacia Amazônica é maior rede hidrográfica do mundo, ocupando de aproximadamente 6 de milhões $\mathrm{km}^{2}$ e contribuindo com $18 \%$ do total das descargas fluviais nos oceanos. O clima desta região é resultado de um complexo sistema de interações de fenômenos meteorológicos, onde a precipitação e a nebulosidade desempenham importante função (FISCH; MARENGO; NOBRE, 1998). Contudo, a precipitação sobre a bacia Amazônica não é uniforme, nem no tempo, nem no espaço (MOLION, 1987; HOREL; HAHMANN; GEISLER, 1989; MARENGO; NOBRE, 2009). Isto ocorre devido ao estabelecimento das monções sobre a América do Sul durante o verão austral $\mathrm{e}$ deslocamento da mesma para a América Central durante o inverno (NOBRE et al., 2009).

Entre os principais mecanismos geradores de precipitação sobre a bacia Amazônica estão os sistemas convectivos de mesoescala (SCMs). Estes sistemas são formados principalmente por nuvens Cumulonimbus (Cbs) que se aglomeram e organizam na escala meteorológica de tempo e espaço definida por Orlanski (1975) como mesoescala. Os SCMs frequentemente possuem extensões entre 20 a $200 \mathrm{~km}$, mas podem alcançar dimensões de 200 a 2000 km (MACHADO; ROSSOW, 1993). Além das grandes quantidades de precipitação que estes sistemas causam, nos trópicos e em médias latitudes, eles representam as maiores tempestades convectivas existentes (HOUZE, 2004), são responsáveis pelas transferências verticais de energia na troposfera tropical (LAURENT et al., 2000) e de gases, como por exemplo, o ozônio (BETTS et al., 2002; SILVA DIAS et al., 2002).

Embora, possuam características gerais semelhantes, os SCMs são classificados de acordo com sua forma (lineares ou circulares), tamanho, tempo de vida e temperatura do topo das nuvens. Linhas de Instabilidade (LIs), derechos, bow echos, complexos convectivos de mesoescala (CCMs), aglomerados convectivos tropicais são algumas destas classificações. No presente trabalho não serão feitas distinções entre os diferentes tipos de SCMs e, por isso, os diferentes tipos de SCMs não serão detalhados aqui.

Maddox (1980) e Maddox (1983) verificaram que a organização em mesoescala das Cbs ocorre quando a convecção está embebida em regiões com suprimento de ar quente e úmido. No caso da bacia amazônica, o suprimento de ar úmido advém principalmente do oceano Atlântico Tropical trasportado pelos ventos alísios (SATYAMURTY; COSTA; MANZI, 2012; DRUMOND et al., 2014). A maior entrada de umidade para a bacia Amazônica combinada com o aquecimento da superfície e parcelas de ar adjacente compõem um cenário apetitoso para a convecção. Quando o aporte de 
umidade para a região é sustentado por mais tempo, a convecção evolui e se organiza, sendo mais duradoura e ocupando maiores áreas.

Sobre a região Amazônica vários estudos foram conduzidos na tentativa de identificar e melhor caracterizar a ocorrência dos SCMs naquela região. Alguns exploraram os SCMs separadamente em suas classes. É o exemplo de Velasco e Fritsch (1987), os quais verificaram hábitos e características dos CCMs ocorridos sobre as Américas. O trabalho de Velasco e Fritsch também se limitou ao tempo, utilizando dois períodos quentes (novembro a abril) no início dos anos 80. Sobre a bacia Amazônica eles verificaram que há pouca ocorrência de CCMs e que existe muita convecção, porém com área muito pequena. O estudo de Velasco e Fritsch incluiu um episódio de El Niño (1982/1983), que sobre a região Amazônica causa diminuição da convecção e precipitação. Cohen, Dias e Nobre (1989), Garstang et al. (1994) e Cohen, Dias e Nobre (1995) focaram suas investigações nas Lls, que se originam na costa nordeste da região Amazônica. Dentre as descobertas os autores verificaram que o período de maior ocorrência é entre abril e agosto. Algumas destas LIs podem percorrer longas distâncias continente adentro.

Os trabalhos citados anteriormente exploram tipos particulares de SCMs que ocorrem na Amazônia. Machado e Rossow (1993), contudo, foram mais abrangentes: eles estudaram a evolução de sistemas convectivos sobre a região tropical ao redor do globo, incluindo desde as mais pequenas convecções individuais profundas até SCMs maiores. Os autores verificaram que além das variações de forma e tamanho, a composição das nuvens também se modifica ao longo do seu ciclo de vida, desde a fase inicial composta quase exclusivamente de $\mathrm{Cbs}$, até a fase madura onde uma parte considerável do SCM apresenta nuvens estratiformes, Cbs em dissipação e nuvens do tipo Cirrus.

Machado et al. (1998) estudaram o ciclo de vida dos SCMs sobre as Américas usando uma ano de imagens de satélite com baixa resolução espacial e temporal. A baixa resolução das imagens disponível os fez utilizar um critério de tamanho, onde os sistemas precisariam ter $100 \mathrm{~km}$ no mínimo para seres considerados. Este critério possivelmente eliminou muitos estágios iniciais do desenvolvimento dos SCMs estudados por eles. Apesar disso, este foi um dos primeiros e mais completos trabalhos sobre SCMs que envolveu a região Amazônica.

Alguns anos mais tarde, Laurent et al. (2002) exploraram as características de SCMs ocorridos durante o experimento Wet Season Atmospheric Mesoscale Campaign/Large-Scale Biosphere-Atmosphere (WETAM/LBA) que ocorreu em dois meses do verão (janeiro e fevereiro) sobre o estado de Rondônia, no sul da região Amazônica. Durante este período ocorreram dois regimes de ventos: um de leste e outro de oeste. Os autores descobriram que durante os regimes de vento de leste a propagação dos sistemas é bem definida e segue o fluxo de médios níveis. Por outro lado, 
durante a ocorrência de ventos de oeste há uma tendência dos sistemas se deslocarem para leste, no entanto, esta propagação é bastate desorganizada. Machado e Laurent (2004) utilizaram o mesmo período e a mesma área de estudo de Laurent et al. para relacionar taxa de expansão da área dos SCMs, o tempo de duração e a divergência do vento em altos níveis. Machado e Laurent (2004) relacionaram a duração dos SCMs ocorridos na região Amazônica, em particular sobre a região sudoeste da Amazônia, e a divergência dos ventos em altos níveis. Eles verificaram que pode-se relacionar muito bem a área de expansão e a fase de vida do sistema convectivo e esta relação pode ser usada para prever o ciclo de vida dos sistemas.

Com a melhor resolução das imagens de satélite, resultado de avanços tecnológicos e científicos, e o desenvolvimento algoritmo automático de rastreamento de aglomerados de nuvens (MACEDO; VILA; MACHADO, 2004; VILA et al., 2008), estudos sobre a ocorrência de SCMs puderam detectar sistemas convectivos desde sua fase inicial, onde a área é pequena, até a fase de dissipação, além de permitir análises sobre períodos maiores de tempo. Desta forma, (SALIO; NICOLINI; ZIPSER, 2007) estudaram os sistemas tropicais, ocorridos ao sul de $10^{\circ} \mathrm{S}$, e subtropicais, ocorridos ao sul de $23^{\circ}$ S, sobre a América do Sul durante 2 anos e 3 meses. Neste estudo, Salio et al., excluíram os meses de inverno, uma vez que os critérios que eles haviam adotado detectaram um número bem menor de sistemas comparado às outras épocas do ano. Eles verificaram que os SCMs tropicais têm seu maior desenvolvimento durante o dia e a máxima ocorrência é durante o período de verão. No entanto, quando há atuação de um jato de baixos níveis observa-se a menor ocorrência de SCMs na região tropical.

Mais recentemente, Adams et al. (2013) iniciou a verificação da evolução temporal da convecção profunda sobre a Amazônia Central usando dados de estação meteorológica equipada com o Sistema de Navegação Global por Satélite (do inglês, Global Navigational Satellite System; GNSS) instalada em Manaus.

Atualmente o estudo mais completo que se tem sobre sistemas convectivos na região Amazônica é o trabalho de Pereira Filho et al. (2015). Eles estudaram a precipitação convectiva baseada em dados de satélite integrado ao redor da América do Sul com resolução espacial de $8 \mathrm{~km}$ e temporal de uma hora. O período utilizado compreende 6,5 anos e abrange a região equatorial, entre $0^{\circ}$ a $15^{\circ} \mathrm{S}$, o que inclui boa parte da Amazônia, nordeste do Brasil e oceano Atlântico adjacente. Como o estudo abrangeu uma área não homogênea (amazônia, nordeste brasileiro e oceano) as características dos sistemas encontrados não poderiam ser tomadas como características puras dos SCMs amazônicos. Ademais, sistemas amazônicos com durações acima de 10 horas não são tão comuns (VELASCO; FRITSCH, 1987; SALIO; NICOLINI; ZIPSER, 2007). Apesar disso, este trabalho traz várias características sobre os sistemas convectivos que serão usadas em comparação às encontradas no presente trabalho e, portanto, não caberia repetí-las aqui. 
O que esta breve revisão literária mostra é que entre os estudos realizados até o presente momento não há algum que tenha usado dados de alta resolução espacial e temporal, abrangendo todas as estações do ano e delimitado geograficamente a bacia Amazônica, isto é, tenha considerado somente SCMs que tiveram trajetória sobre a bacia Amazônica em pelo menos um momento do seu ciclo de vida. Os avanços na ciência e tecnologia tornaram a obtenção de imagens de satélite com alta resolução espacial e temporal possíveis. Este tipo de imagem é indispensável em estudos como este. Além disso, o projeto GOAmazon é uma oportunidade ímpar para obtenção de dados que podem auxiliar o entendimento acerca destes sistemas. 


\section{Dados e metodologia}

\subsection{Período e região de estudo}

Os SCMs estudados no presente trabalho ocorreram entre 02 de janeiro de 2014 e 30 de junho de 2015, contemplando a maior parte da ocorrência do projeto GOAmazon.

Foram considerados os SCMs continentais (detectados inicialmente sobre o continente) e oceânicos (detectados inicialmente sobre o oceano) que, em pelo menos um momento de seu ciclo de vida, tiveram trajetória sobre a bacia Amazônica, representada na Figura 1. Os limites espaciais da bacia Amazônica foram obtidos em Observatoire de Recherche en Environnement (ORE HYBAM) e estão disponíveis em <http://www.orehybam.org/index.php/por/Dados/Cartografia/Bacia-amazonica-hidrografia>. A trajetória representa o caminho realizado pelo centro de massa geométrico (daqui para frente será chamado somente de centro de massa) do SCM a cada passo de tempo durante seu ciclo de vida da mesma forma que em Sakamoto (2009). Por outro lado, o deslocamento foi definido pela linha reta que conecta as posições geográficas iniciais e finais do centro de massa do SCM.

Os sistemas que ocorreram próximos às estações de coleta de dados do GOAmazon foram analisados com atenção especial. Nesta oportunidade foram verificadas as condições sinóticas, dinâmicas e termodinâmicas atuantes pouco antes da formação dos sistemas, durante a ocorrência dos mesmos e ligeiramente após sua dissipação, buscando identificar quais mecanismos ajudaram no disparo convectivo e manutenção dos sistemas.

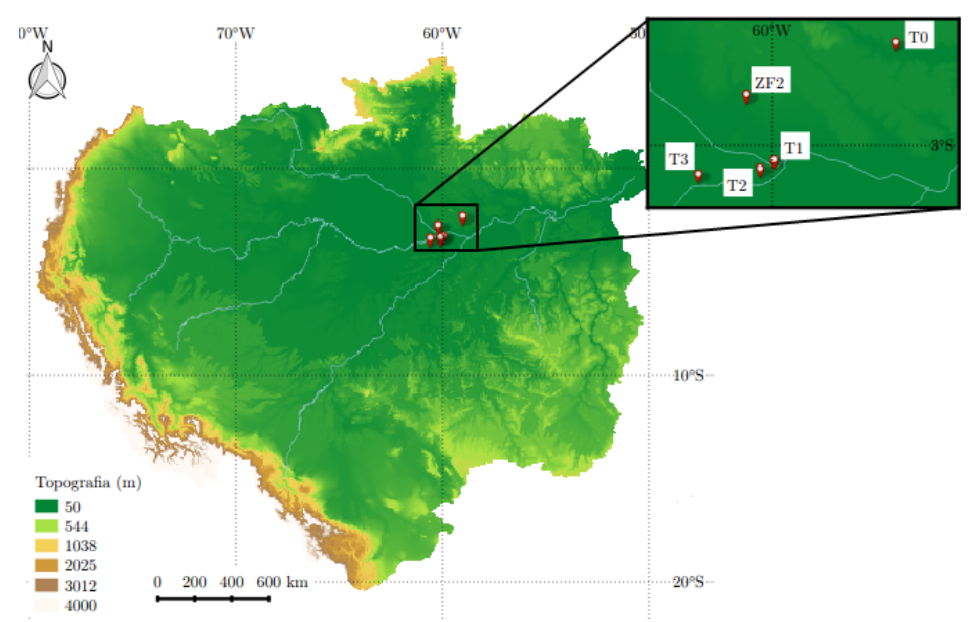

Figura 1 - Delimitação espacial e topografia (m) da bacia Amazônica. Em destaque a localização das estações de coleta de dados do projeto GOAmazon. 
Para fins de comparação entre os resultados obtidos, uma climatologia dos SCMs ocorridos sobre a bacia Amazônica foi criada, utilizando o período entre janeiro de 2000 e dezembro de 2013 e a mesma metodologia adotada na identificação e rastreamento dos SCMs ocorridos durante o GOAmazon.

\subsection{Dados}

A metodologia utilizada é similar a de Sakamoto (2009), que estudou os SCMs atuantes na região Subtropical da América do Sul durante o projeto South American Low Level Jet Experiment (SALLJEX) que foi conduzido no verão de 2002/2003.

Para detecção, rastreamento e obtençao de parâmetros dos SCMs foram utilizadas imagens de satélites geostacionários na banda do infravermelho (aproximadamente $10,8 \mu \mathrm{m})$. Estas imagens foram obtidas e descritas por Janowiak, Joyce e Yarosh (2001), que realizaram uma composição de imagens dos satélites americanos Geostationary Operational Environmental Satellite 8 e 10 (GOES-8 e GOES-10), satélites europeus Meteorological Satellite 5 e 7 (Meteosat-5 e Meteosat-7) e o satélite japonês Geostationary Meteorological Satellite 5 (GMS-5). Estas imagens estão disponíveis em Climate Prediction Center/National Centers for Environmental Prediction/National Weather Service (CPC/NCEP/NWS) no site <ftp://ftp.cpc.ncep.noaa.gov/precip/global_full_res_IR/>. Elas possuem cobertura global, resolução temporal de 30 minutos e espacial de $4 \mathrm{~km}$. Assim como em Sakamoto (2009), elas foram recortadas para a região da América do Sul abrangendo as latitudes de $10^{\circ} \mathrm{N}$ a $45^{\circ} \mathrm{S}$ e longitudes de $85^{\circ} \mathrm{W}$ a $30^{\circ} \mathrm{W}$.

Durante o período do projeto GOAmazon não houve falha nos dados das imagens de satélite, exceto para o dia 01/01/2014. No banco de dados das imagens faltantes ou com muitas falhas e que não puderam ser processadas ao longo do período de 2000 a 2015 incluíram-se algumas que estão descritas na Tabela 5, no Apêndice A.

Para analisar as condições sinóticas, dinâmicas e termodinâmicas que atuaram durante a ocorrência dos SCMs próximos às estações do GOAmazon foram utilizados dados meteorológicos e de radiossondagem da estação localizada no sítio T3, localizado em Manacapuru (Figura 1). Estes dados foram disponibilizados pelo Atmospheric Radiation Measurement (ARM) Climate Research Facility. Os horários das radiossondagens disponíveis utilizados são 00, 06, 12 e 18 UTC e do Aeroporto de Ponta Pelada em Manaus (SBMN) fornecidos pelo Instituto de Controle do Espaço Aéreo de São José dos Campos (ICEA-SJC) e obtidos nos horários das 00 e 12 UTC. A verificação das condições sinóticas em superfície, baixos, médios e altos níveis foram feitas através de cartas sinóticas do Centro de Pesquisas de Tempo e Clima (CPTEC) do Instituto Nacional de Pesquisas Espaciais (INPE). 


\subsection{Identificação e rastreamento dos SCMs}

O esquema de rastreamento de clusters ou aglomerados de nuvens Forecasting and Tracking the evolution of Cloud Clusters (ForTraCC) foi utilizado para detectar, rastrear e obter parâmetros morfológicos e radiativos dos SCMs. O ForTraCC identifica sistemas convectivos através de imagens de satélites geostacionários no canal do infravermelho $(10,8 \mu \mathrm{m})$ (VILA et al., 2008) e parte do pressuposto que baixas temperaturas de brilho representam nuvens associadas à convecção profunda (LAURENT et al., 2000).

O ForTraCC foi desenvolvido em linguagem Fortran e opera em ambiente Linux (MACEDO; VILA; MACHADO, 2004). Ele permite rastrear propriedades radiativas e morfológicas de SCMs, além de prever a evolução destas propriedades no tempo (VILA et al., 2008). As principais etapas de processamento deste algoritmo são: 1) detecção de aglomerados de nuvem baseada em limiares de tamanho e temperatura; 2) cálculos estatísticos para identificar parâmetros morfológicos e radiativos de cada SCM; 3) rastreamento dos SCMs baseado na sobreposição de imagens sucessivas e; 4) previsão da evolução dos SCMs baseado nos passos de tempo anteriores (VILA et al., 2008). No presente trabalho foram utilizadas as três primeiras etapas elencadas acima.

O rastreamento das nuvens convectivas está baseado no método de sobreposição de área (VILA et al., 2008). Vila et al. (2008) explicam que esta técnica considera a existência de pixels comuns em imagens de satélite consecutivas para rastrear um sistema. A mínima área de sobreposição utilizada no presente trabalho é de $25 \%$, o mesmo limiar adotado por Vila et al. (2008) e Sakamoto (2009). Através deste valor e da excentricidade de 0,5 (média do parâmetro), Vila et al. (2008) determinaram a área mínima necessária para representar um SCM, sendo ela 150 pixels, ou seja, $2400 \mathrm{~km}^{2}$.

O método de acompanhamento de sistemas convectivos necessita de imagens em alta resolução temporal e espacial e com poucas falhas (MACEDO; VILA; MACHADO, 2004). Desta forma, quando há falha em linhas, uma linha mais próxima é copiada no lugar das falhas, preenchendo a imagem; se o tempo entre as imagens for superior a um delta a imagem do tempo anterior é considerada e; o mesmo ocorre se houver 7 linhas consecutivas com falha ou 10\% da imagem (MACEDO; VILA; MACHADO, 2004). No presente trabalho, este processo é limitado em 6 imagens virtuais. Caso ultrapasse esta quantidade o processo recomeça com uma nova série de dados. A Tabela 5 mostra os dias em que não houve processamento devido à falhas.

Carvalho e Jones (2001), Laurent et al. (2002) e Machado e Laurent (2004) sugeriram que para a detecção de nuvens associadas à convecção o limiar de temperatura de $235 \mathrm{~K}$ é aceitável para diferentes regiões da América do Sul. Vila et al. (2008) validaram o ForTraCC usando este limiar. Outros limiares foram testados em diferentes 
regiões do mundo, dentre eles destacam-se os $245 \mathrm{~K}$ utilizados para detectar SCMs sobre as Américas (MACHADO et al., 1998), $241 \mathrm{~K}$ utilizados por Maddox (1980) para detectar CCMs ocorridos nos EUA, enquanto que Velasco e Fritsch (1987) usaram um valor menor para estudar os CCMs ocorridos na América do Sul (231 ou $233 \mathrm{~K}$ ). Vila et al. (2008) baseados nos trabalhos de Mapes e Houze (1992) e Machado, Duvel e Desbois (1993) discutem que abaixo de $245 \mathrm{~K}$ em uma faixa de temperatura de brilho entre $10 \mathrm{~K} \mathrm{e} 20 \mathrm{~K}$ os mesmos sistemas são encontrados, pois ocorre uma dependência aproximadamente linear entre tamanho de nuvem e um limiar de temperatura dado nestas condições. No presente trabalho, o limiar de $235 \mathrm{~K}$ foi adotado para identificar os SCM e de $221 \mathrm{~K}$ para garantir áreas de convecção ativa, da mesma forma que Maddox (1980), Velasco e Fritsch (1987) e Sakamoto (2009). Este último limiar deve ocorrer em pelo menos um momento do ciclo de vida do sistema.

O momento em que um sistema convectivo obedecer os critérios de tamanho (150 pixels) e de temperatura de brilho $(235 \mathrm{~K})$ necessários para ser rastreado é chamado de fase inicial ou de gênese (VILA et al., 2008; SAKAMOTO, 2009). A fase madura representa o momento em que o sistema atinge sua máxima extensão horizontal e a fase final ou de dissipação é definida como o momento em que o sistema perde suas características de tamanho mínimo e não atende mais ao limiar de temperatura (SAKAMOTO, 2009).

Para garantir que os sistemas tivessem um único início e fim foram estudados somente sistemas com geração espontânea (MACHADO; LAURENT, 2004; SAKAMOTO, 2009), ou seja, aqueles que não resultaram da junção de um ou mais sistemas menores ou da divisão de sistemas maiores (SAKAMOTO, 2009).

A posição geográfica do centro de massa foi tomado como referência para verificar a localização dos SCMs. Ele é definido pela média das latitudes e longitudes de todos os pixels pertencentes ao sistema (MACHADO et al., 1998). A velocidade calculada pelo ForTraCC considera a distância percorrida entre um passo de tempo e outro, dividido pelo tempo entre as imagens. No caso do presente trabalho o tempo é 30 minutos. No caso de junções ou separações, a velocidade calculada não é real e sim baseada na média da velocidade dos sistemas próximos ao sistema em questão (MACEDO; VILA; MACHADO, 2004). Neste caso, considera-se a velocidade média dos SCMs dentro de um raio de $2^{\circ}$. Outros exemplos de parâmetros calculados pelo ForTraCC e apresentados mais detalhadamente por Machado et al. são: tamanho do sistema convectivo em número de pixels, raio efetivo do sistema convectivo, ou seja, raio de um círculo, cuja área seja igual a área do sistema convectivo, fração convectiva e número de células convectivas, tamanho das cinco maiores células convectivas encontradas no sistema convectivo, eixo de inércia, inclinação, excentricidade, temperatura média, temperatura mínima, temperatura média das cinco maiores células convectivas, coordenadas do centro geométrico (ou centro de massa), coordenadas do 
centro geométrico das cinco maiores células convectivas, data e hora (UTC).

A Tabela 6, no Apêndice B, mostra a quantidade de sistemas que foram rastreados pelo ForTraCC levando em conta somente os limiares de temperatura e tamanho apresentados anteriormente e quantos SCMs sobraram a cada filtragem realizada. Foram usados 4 filtros para a obtenção dos sistemas aqui estudados. Eles filtraram sistemas que apresentaram ciclo de vida inferior a 3 horas, sistemas cujas trajetórias não estiveram em pelo menos um momento de seu ciclo de vida sobre a bacia Amazônica, sistemas com curvas de crescimento (área $\times$ tempo) que não obedeceram padrão de crescimento, máxima expansão da área, seguida de decaimento e por último, sistemas cujos deslocamentos entre um passo de tempo e outro foram maiores que $300 \mathrm{~km}$. Este último filtro foi necessário, pois alguns sistemas sem qualquer relação uns com os outros foram rastreados pelo ForTraCC e identificados como um mesmo sistema.

Desta forma, os SCMs estudados no presente trabalho apresentam as características encontradas na Tabela 1.

Tabela 1 - Características em comum dos SCMs estudos no presente trabalho.

\begin{tabular}{ll}
\hline & Característica Física \\
\hline Tamanho & $\geq 150$ pixels $\left(2400 \mathrm{~km}^{2}\right)$ durante todo o ciclo de vida \\
Temperatura de brilho & $\leq 235 \mathrm{~K}$ durante todo o ciclo de vida e \\
& $\leq 221 \mathrm{~K}$ em pelo menos um momento do ciclo de vida \\
Gênese & $\begin{array}{l}\text { Espontânea } \\
\text { Ciclo de vida }\end{array}$ \\
Trajetória & $\begin{array}{l}\text { Pelo men ou igual a } 3 \text { horas } \\
\text { trajetória esteve sobre a bacia Amazônica }\end{array}$ \\
Curva de crescimento & $\begin{array}{l}\text { Crescimento até a máxima expansão, seguida de } \\
\text { (área } \times \text { tempo })\end{array}$ \\
\hline
\end{tabular}

\subsection{Classificação dos SCMs}

Os SCMs foram classificados e analisados separadamente de acordo com o local de origem. Deste modo, sistemas cujas fases iniciais ocorreram sobre o continente foram denominados sistemas continentais e aqueles cujas fases iniciais ocorreram sobre o oceano foram chamados de sistemas oceânicos.

Após serem classificados como continentais ou oceânicos, os SCMs foram agrupados de acordo com a duração do ciclo de vida. O ciclo de vida de um SCM inicia no momento em que ele é detectado e termina em sua fase de dissipação. Desta forma, a quantidade total de horas usadas para completar seu ciclo de vida é denominada duração ou tempo de vida. Estudos anteriores, como Velasco e Fritsch (1987) e Machado et al. (1998), verificaram que, em geral, sistemas convectivos da região Amazônica possuem menores durações que sistemas de médias latitudes (cerca de 1 a 3 horas). A pesquisa de Sakamoto (2009), cuja metodologia é muito similar 
ao presente trabalho, indicando que seu interesse era estudar sistemas duração mais longa, abordou somente SCMs subtropicais com tempo mínimo de duração acima de 6 horas. Os tempos de vida médios dos SCMs continentais e oceânicos estudados por Sakamoto foi de 12,3 horas e 12,1 horas, respectivamente. No presente estudo, optou-se por estudar os SCMs com durações maiores ou iguais a 3 horas. Porém, como mencionado anteriormente, eles foram agrupados de acordo com suas durações. Portanto, SCMs com curta duração ou curto ciclo de vida apresentam durações entre 3 horas e 5 horas e 30 minutos e SCMs com longa duração ou longo ciclo de vida apresentam duração superior ou igual a 6 horas.

As análises realizadas levam em conta as classificações realizadas acima e, portanto, os SCMs podem ser continentais com curta ou longa duração ou oceânicos com curta ou longa duração. A referência "Todos SCMs" indica que os SCMs não foram classificados de acordo com o tempo de duração. As figuras que representam "Todos SCMs" geralmente será a (c); ela pode ser interpretada como uma representação de todos os SCMs ocorridos na bacia Amazônica, sem fazer distinção entre os tempos de duração.

Não foram feitas distinções entre os diferentes tipos de SCM (CCMs, LIs, Bow Echo, vórtice convectivo de mesoescala, etc).

\subsection{Cálculos dos índices de instabilidade termodinâmica e cisalhamento do vento}

As condições dinâmicas e termodinâmicas associadas à formação, manutenção, decaimento da área e dissipação dos SCMs ocorridos próximo às estações de coleta de dados do GOAmazon foram verificadas através do cisalhamento vertical do vento, cartas sinóticas e índices de instabilidade termodinâmica.

Os índices de instabilidade termodinâmica são baseados em perfis verticais de temperatura, umidade e vento (SILVA DIAS, 2000). Esses índices ou parâmetros convectivos são tipicamente calculados a partir de perfis atmosféricos termodinâmicos e cinemáticos que podem advir de sondagens de ar superior (NASCIMENTO, 2005).

Com a disponibilidade de dados de radiossondagens realizadas em Manaus e Manacapuru, foram calculados os valores da energia potencial convectiva disponível (Convective Available Potencial Energy; CAPE), energia de inibição convectiva (Convective INhibiton Energy; CINE), índice K, índice Total Totals (TT) e índice de Levantamento (ILEV). Para isso foi utilizado o script plotskewt.gs elaborado por Robert Hart e disponível em <http://moe.met.fsu.edu/ rhart/software/skew.html>. 
A CAPE pode ser definida como (HOUZE, 1993):

$$
\mathrm{CAPE}=\mathrm{g} \int_{\mathrm{NCE}}^{\mathrm{NEL}} \frac{\theta_{\mathrm{v}}(\mathrm{z})-\theta_{\mathrm{v}}^{\prime}(\mathrm{z})}{\theta_{\mathrm{v}}^{\prime}(\mathrm{z})} \mathrm{dz}
$$

Onde NCE é o nível de convecção espontânea e NEL é o nível de equilíbrio ou nível de perda de empuxo para uma determinada parcela de ar ascendente. $\theta_{v}$ é a temperatura potencial virtual desta parcela de ar e $\theta_{v}^{\prime}$ é a temperatura potencial virtual do ambiente. A CAPE é medida em J.kg-1.

E a CINE (J.kg-1) é definida como:

$$
\mathrm{CINE}=-\mathrm{g} \int_{\text {SUP }}^{\mathrm{NCE}} \frac{\theta_{\mathrm{v}}(\mathrm{z})-\theta_{\mathrm{v}}^{\prime}(\mathrm{z})}{\theta_{\mathrm{v}}^{\prime}(\mathrm{z})} \mathrm{dz}
$$

Onde SUP é o nível da superfície. Quanto maior a CINE, mais difícil é a iniciação convectiva para uma parcela de superfície, uma vez que mais intensa deverá ser a forçante para o levantamento desta parcela até atingir seu NCE (NASCIMENTO, 2005), ou seja, ela é um obstáculo à convecção por haver falta de flutuação próximo à superfície (SILVA DIAS, 2000).

$\mathrm{O}$ índice $\mathrm{K}$ considera a taxa de resfriamento com a altura em médios níveis, a umidade em 850 hPa e o nível seco da atmosfera em 700 hPa. Valores de K acima de $30^{\circ} \mathrm{C}$ são considerados altos (HENRY, 1987). O K pode ser definido como (GEORGE, 1960):

$$
\mathrm{K}=\mathrm{T}_{850}-\mathrm{T}_{500}+\mathrm{T}_{\mathrm{d}_{850}}-\operatorname{Dep}_{700}
$$

Onde $\mathrm{T}$ é a temperatura, $\mathrm{T}_{\mathrm{d}}$ é a temperatura do ponto de orvalho e $\mathrm{Dep}_{700} \mathrm{a}$ depressão do bulbo úmido do meio ambiente. Todas as medidas estão em ${ }^{\circ} \mathrm{C}$ e os índices sub-escritos designam o nível a qual os valores são calculados.

O índice Total Totals foi introduzido por Miller (1972) e é calculado como:

$$
\mathrm{TT}=\mathrm{T}_{850}+\mathrm{T}_{\mathrm{d}_{850}}-2 \times \mathrm{T}_{500}
$$

As variáveis são as mesmas que na equação 3.3. TT maior ou igual a $40^{\circ} \mathrm{C}$ indica condições favoráveis para tempestadas e maiores que $50^{\circ} \mathrm{C}$ indicam tempo severo.

O índice de Levantamento é definido como em Galway (1956):

$$
\mathrm{ILEV}=\mathrm{T}_{500}-\mathrm{T}_{\mathrm{p}_{500}}
$$

Onde $\mathrm{T}_{500}$ é a temperatura do ambiente em $500 \mathrm{hPa}$ e $\mathrm{T}_{\mathrm{p}_{500}}$ é a temperatura da parcela em $500 \mathrm{hPa}$, ambas em ${ }^{\circ} \mathrm{C}$. Valores negaticos de ILEV indicam condições 
instáveis, devido a parcela de ar ascendente ser mais flutuante em médios níveis. Abaixo de $-5^{\circ} \mathrm{C}$ o ambiente é muito instável e abaixo de $-10^{\circ} \mathrm{C}$ extremamente instável.

$O$ cisalhamento vertical $\left(\mathrm{s}^{-1}\right)$ pode influenciar fortemente no desenvolvimento da convecção que se desenvolverá como células de curta duração, multicelular ou supercélulas (WEISMAN; KLEMP, 1984). Assim como em Sakamoto (2009) o cisalhamento vertical foi calculado na camada entre $1000 \mathrm{hPa}$ e $500 \mathrm{hPa}$, conforme a metodologia descrita por Fogaccia (2001).

$$
\begin{gathered}
\mathrm{C}=\frac{\mathrm{V}_{\mathrm{m}}}{\mathrm{h}} \\
\mathrm{V}_{\mathrm{m}}=\sqrt{\left(\mathrm{u}_{\mathrm{m}}^{2}+\mathrm{v}_{\mathrm{m}}^{2}\right)}
\end{gathered}
$$

Onde h é a altura em metros em $500 \mathrm{hPa}$ (em média $5800 \mathrm{~m}$ ) e Eq. 3.7 é o vento médio horizontal na camada da baixa troposfera (entre $1000 \mathrm{hPa}$ e $500 \mathrm{hPa}$ ); $\mathrm{u}_{\mathrm{m}}$ e $\mathrm{v}_{\mathrm{m}}$ :

$$
\begin{array}{cl}
\mathrm{u}_{\mathrm{m}}=\frac{\left(\mathrm{u}_{1}+\mathrm{u}_{2}+\mathrm{u}_{3}\right)}{3} ; & \mathrm{v}_{\mathrm{m}}=\frac{\left(\mathrm{v}_{1}+\mathrm{v}_{2}+\mathrm{v}_{3}\right)}{3} \\
\mathrm{u}_{1}=\mathrm{u}_{850}-\mathrm{u}_{1000} ; & \mathrm{v}_{1}=\mathrm{v}_{850}-\mathrm{v}_{1000} \\
\mathrm{u}_{2}=\mathrm{u}_{700}-\mathrm{u}_{850} ; & \mathrm{v}_{2}=\mathrm{v}_{700}-\mathrm{v}_{850} \\
\mathrm{u}_{3}=\mathrm{u}_{500}-\mathrm{u}_{700} ; & \mathrm{v}_{3}=\mathrm{v}_{500}-\mathrm{v}_{700}
\end{array}
$$




\section{Resultados e discussões}

\subsection{Climatologia dos SCMs na bacia Amazônica}

\subsubsection{SCMs continentais}

A climatologia realizada no presente trabalho mostra que a média anual de ocorrências de SCMs sobre a bacia Amazônica é 7053 SCMs. A distribuição anual destes sistemas encontra-se na Tabela 6 e Figura 105 dos Apêndices B e C, respectivamente. SCMs com curta duração correspondem a 64\% (4522 SCMs) da ocorrência média anual e os $36 \%$ restantes (2531 SCMs) representam os SCMs com longos ciclos de vida (Figura 2). SCMs com durações acima de 24 horas representam apenas 0,7\% da frequência relativa total. O tempo de vida médio encontrado foi de 6 horas, sendo que o sistema com maior duração possuia 52 horas (não representado na Figura). Salio, Nicolini e Zipser (2007) encontraram durações entre 6 a 9 horas para os SCMs tropicais.

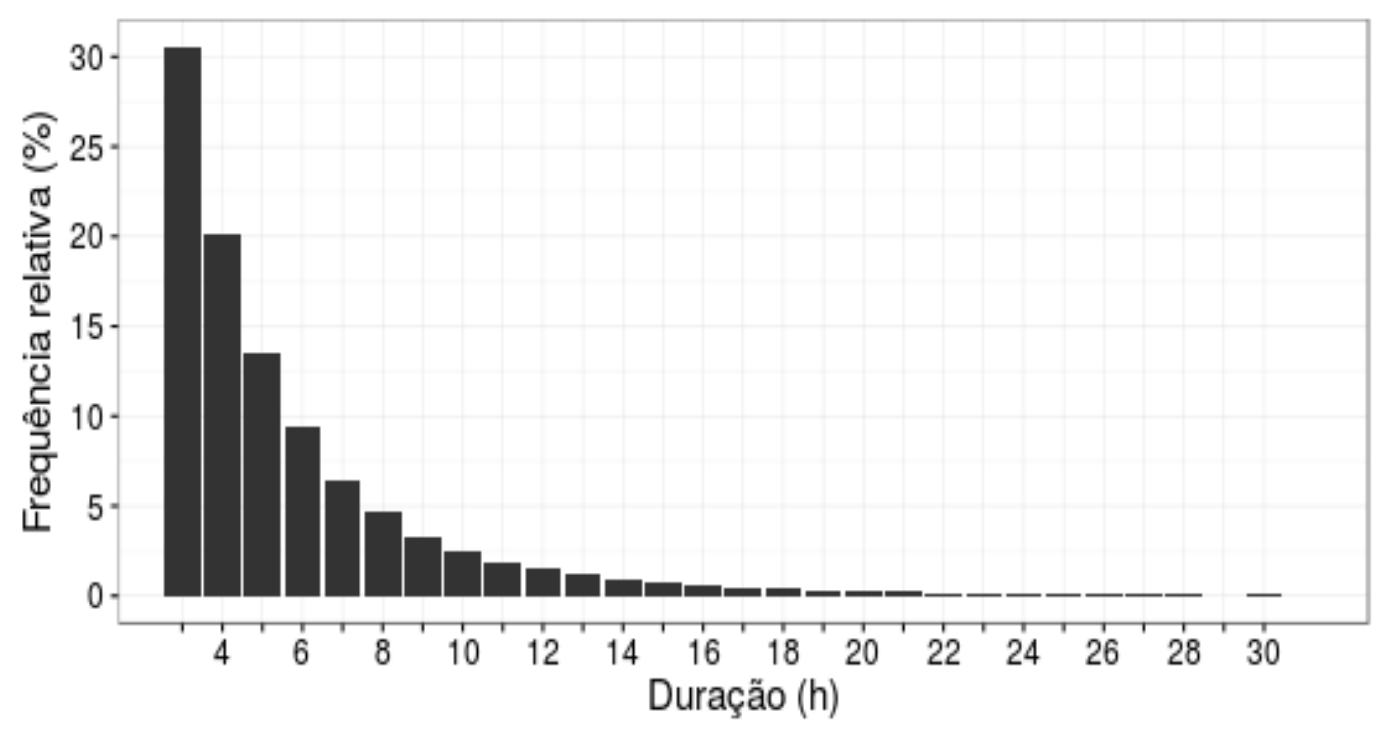

Figura 2 - Climatologia da frequência relativa (\%) de ocorrência de SCMs continentais de acordo com o ciclo de vida (horas). Período utilizado: 2000 a 2013. No total, 98743 SCMs foram considerados.

A distribuição mensal dos SCMs (Figura 3) evidencia a maior ocorrência de sistemas durante os meses mais quentes do ano e destaca a estação de outono (março, abril e maio) com maior ocorrência, seguida pelo verão (dezembro, janeiro e fevereiro). Segundo Pereira Filho et al. (2015) a convecção na Amazônia tende ser mais organizada entre março e junho. A maior frequência e organização de SCMs durante o outono pode estar relacionada ao posicionamento da Zona de Convergência Intertropical (ZCIT), que durante fevereiro e março atinge sua posição mais ao sul 
(HASTENRATH; LAMB, 1977 apud UVO et al., 1998). Nesta época, a parte central da Amazônia, em torno de $5^{\circ} \mathrm{S}$, possui um dos núcleos de precipitação abundantes mencionados por Marengo e Nobre (2009). Além disso, durante o inverno austral a convecção encontra-se deslocada para noroeste da região Amazônica, sobre a América Central e oceano Pacífico adjacente (HOREL; HAHMANN; GEISLER, 1989) juntamente com ela a maioria dos sistemas convectivos ocorrem ao norte do equador nesta época (MACHADO; ROSSOW, 1993). Horel, Hahmann e Geisler (1989) mostraram que a maior atividade convectiva retorna à região Amazônica em novembro, permanecendo até março.

As Figuras 4, 5 e 6 mostram que os SCMs possuem períodos preferenciais de ocorrência para as diferentes fases do seu ciclo de vida, com pequenas variações de acordo com a duração. As Figuras estão em intervalos de uma hora, desta forma, o horário das 00 UTC, por exemplo, corresponte às 00 e 0030 UTC, e assim por diante. A fase inicial dos SCMs com curta duração tem mínima frequência relativa de ocorrência entre 12 e 14 UTC e possuem maior frequência de ocorrência entre as 17 e 20 UTC (Figura $4(\mathrm{a})$ ). Após este período, a frequência de gênese diminui até 00 UTC e à 01 UTC apresenta um pico isolado de maior gênese e volta a diminuir. Entre 06 e 07 UTC a frequência de gênese apresenta um terceiro período preferencial de ocorrência, mas logo em seguida diminui gradativamente até atingir o período de menor gênese.

Os SCMs com longa duração apresentam fase inicial com padrão similar aos de curta duração, porém o período preferencial com maior frequência de gênese ocorre uma hora mais cedo (entre 16 e 19 UTC; Figura 4 (b)). Após este período, a gênese diminui e por volta das 00 UTC novamente aumenta e à 01 UTC sofre um pico de maior ocorrências, da mesma forma que os SCMs de curta duração. Até as 07 UTC a gênese se mantém aproximadamente constante e em seguida reduz até os horários de menor frequência (11 a 13 UTC). Salio, Nicolini e Zipser (2007) e Pereira Filho et al. (2015) encontraram padrões muito similares aos apresentados no presente trabalho, inclusive o terceiro pico de gênese observado. Em geral, os padrões de comportamento de gênese apresentados pelos SCMs, tanto aqueles de curta duração, quanto os de longa duração, estão relacionados ao ciclo diurno do aquecimento radiativo já discutidos na literatura (VELASCO; FRITSCH, 1987; MACHADO et al., 1998; SALIO; NICOLINI; ZIPSER, 2007). Porém, sistemas transientes, tais como frentes frias, frontogênese e ondas desencadeadas pela topografia podem alterar o ciclo diurno da convecção (Pereira Filho et al., 2015).

O horário de maturação preferencial dos SCMs com curta duração ocorre em média entre 2 a 3 horas após a fase inicial do sistema (Figura 5 (a)). A fase de dissipação para os mesmos sistemas tem máxima frequência de ocorrência em $21 \mathrm{e}$ 00 UTC, de acordo com a Figura 6 (a). Desta forma, há uma defasagem de 2 horas entre o início do período de máxima atividade de cada fase do ciclo de vida dos SCMs 

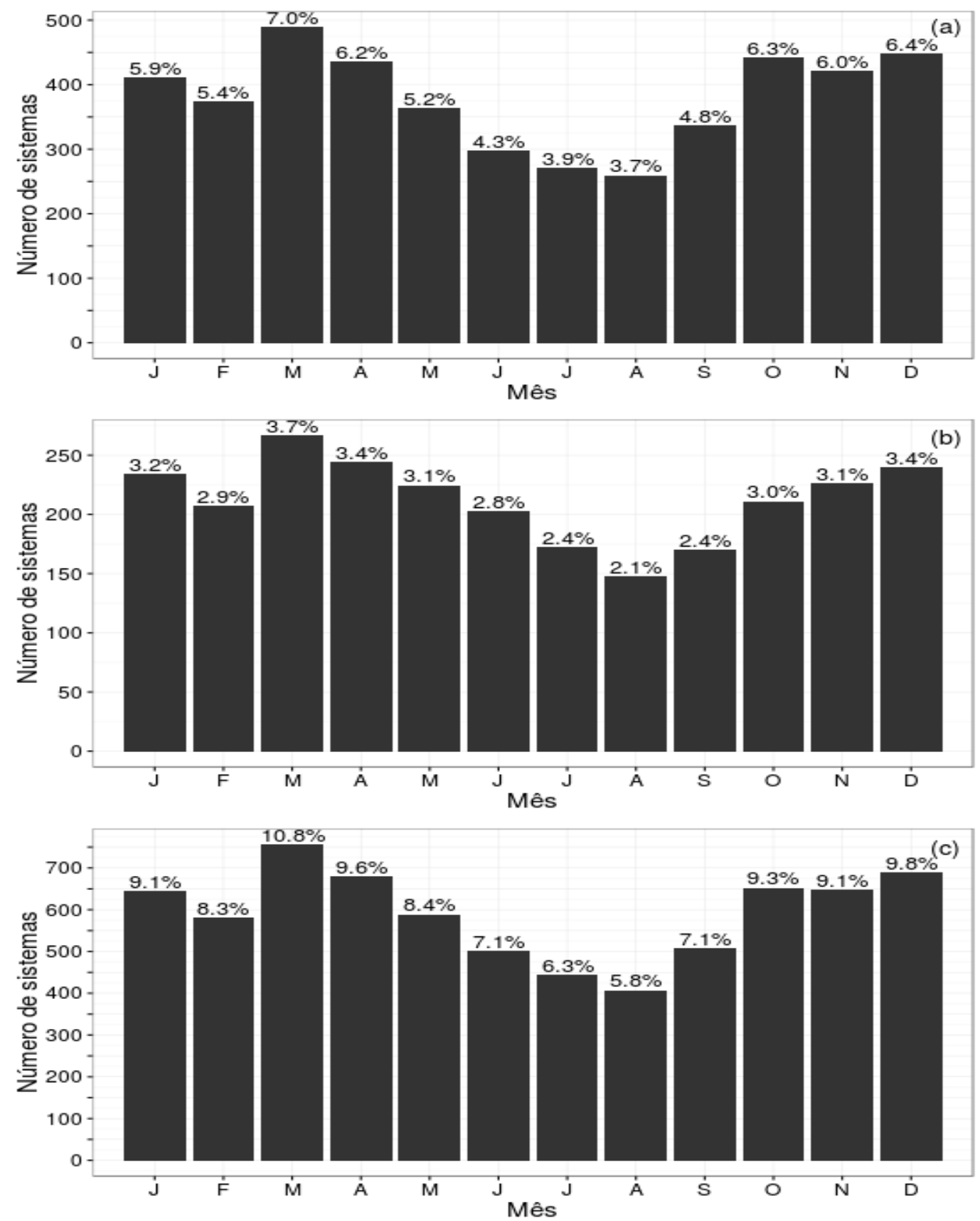

Figura 3 - Ocorrência média mensal de SCMs sobre a bacia Amazônica de acordo com o tempo de vida. Em (a) SCMs com curta duração, (b) SCMs com longa duração e (c) todos SCMs. Os números em cima das barras representam a frequência relativa (\%). Período utilizado: 2000 a 2013. No total, 98743 SCMs foram considerados.

de curta duração.

SCMs com longo ciclo de vida apresentam maior frequência de maturação entre 4 e 6 horas após sua fase inicial. A fase de maturação fica concentrada, portanto, no período das 20 e 22 UTC. Entre as 06 e 11 UTC ocorre um pico secundário de maturação dos SCMs com longa duração o qual corresponde, provavelmente, à gênese ocorrida entre as 01 e 06 UTC. Este pico secundário não acontece pronunciado com os SCMs de curta duração. 

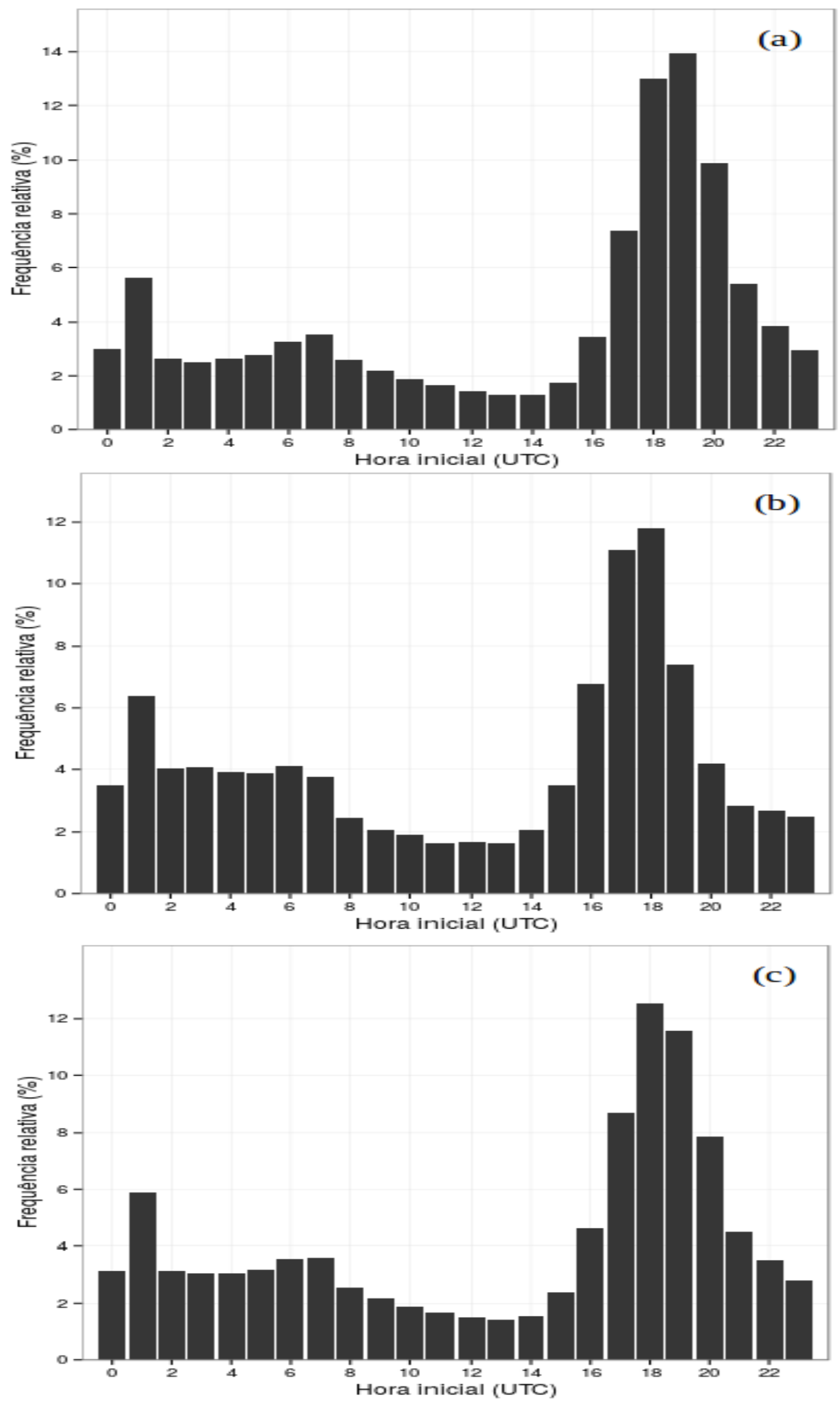

Figura 4 - Climatologia do horário de gênese de (a) SCMs com curto tempo de vida, (b) SCMs com longo ciclo de vida e (c) todos SCMs. Período utilizado: 2000 a 2013. No total, 98743 SCMs foram considerados. 

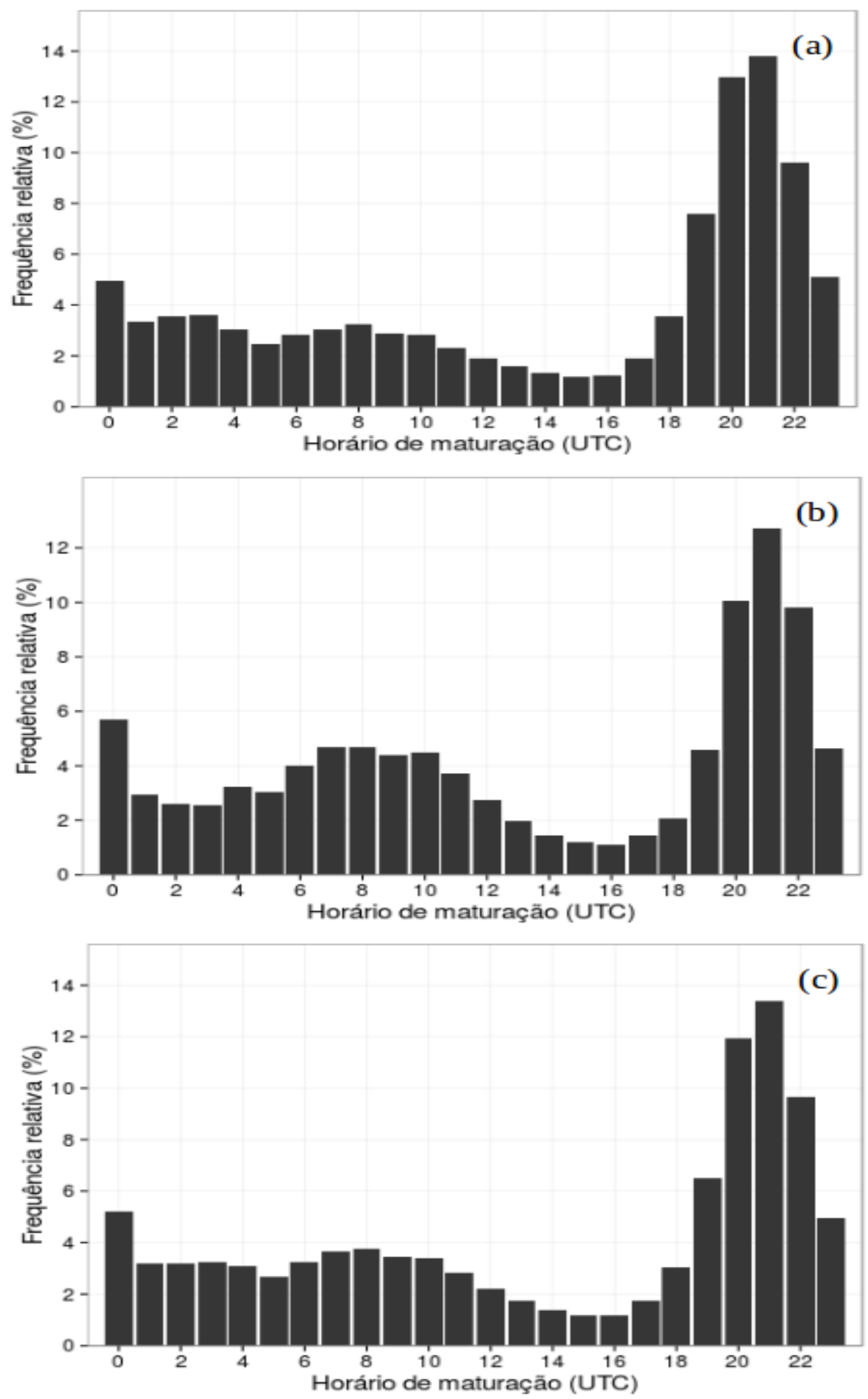

Figura 5 - Climatologia do horário de maturação de (a) SCMs com curto tempo de vida, (b) SCMs com longo ciclo de vida e (c) todos SCMs. Período utilizado: 2000 a 2013. No total, 98743 SCMs foram considerados. 

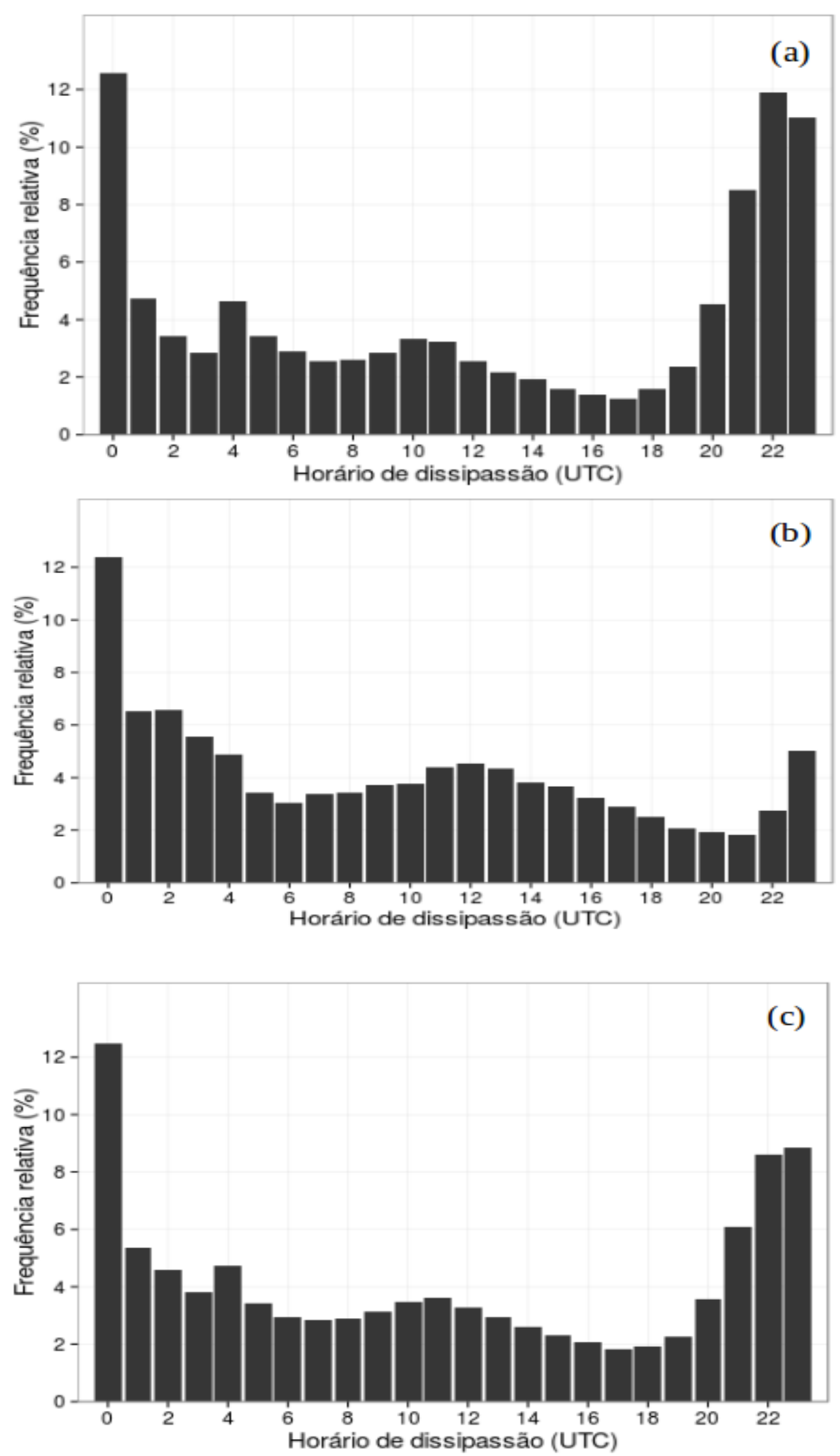

Figura 6 - Climatologia do horário de dissipação de (a) SCMs com curto tempo de vida, (b) SCMs com longo ciclo de vida e (c) todos SCMs. Período utilizado: 2000 a 2013. No total, 98743 SCMs foram considerados. 
As densidades de gênese, maturação e dissipação de acordo com o tempo de vida dos SCMs encontram-se nas Figuras 7, 8 e 9. Os SCMs apresentam grande variabilidade espacial similar ao ciclo anual da convecção, onde durante o verão a gênese dos SCMs ocorre espalhada sobre todo o território amazônico e durante o inverno ela se desloca para o nordeste. Regiões com maior densidade de ocorrência de gênese destacam-se frente à outras e serão chamadas de regiões preferenciais de gênese. Algumas dessas regiões ocorrem tanto nas figuras de densidade de SCMs com curta duração, quanto naqueles de longa duração.

Entre janeiro e abril os SCMs com curta duração ocorrem espalhados em toda a bacia Amazônica, com algumas regiões preferenciais de gênese (Figura 7). Em abril a gênese diminui no sul da bacia Amazônica ao sul de $15^{\circ} \mathrm{S}$. Em junho, julho e agosto pouca atividade de gênese é observada a partir da região central da Amazônia até o sul e toda faixa oeste da bacia Amazônica. Em setembro a gênese volta ocorrer no sul da bacia Amazônica, porém com baixa densidade. Em outubro, novembro e dezembro a densidade de SCMs aumenta e se espalha em toda a bacia. As regiões preferenciais de gênese dos SCMs de curta duração por frequência mensal de ocorrência são: 1) na confluência do rio Tapajós com o rio Amazonas, em aproximadamente $2,5^{\circ} \mathrm{S} / 54^{\circ} \mathrm{W}$, ocorrendo entre janeiro e outubro; 2) na Serra do Imeri, no Planalto das Guianas, em aproximadamente $0^{\circ} / 65^{\circ} \mathrm{W}$, entre setembro e junho; 3 ) próximo aos Andes em $10^{\circ} \mathrm{S} / 75^{\circ} \mathrm{W}$, entre a primavera e o outono; 4) entre o norte de Mato Grosso e sul do Pará, em torno de $10^{\circ} \mathrm{S} / 55^{\circ} \mathrm{W}$, em outubro, janeiro, março, abril e maio; 5) nos Andes, em $14^{\circ} \mathrm{S} / 71^{\circ}$, nos meses mais quentes do ano; 6) na Serra da Pacaraíma, no Planalto das Guianas, em $5^{\circ} \mathrm{N} / 60^{\circ} \mathrm{W}$, em novembro, dezembro, fevereiro e março; 7) na foz do rio Amazonas em agosto e setembro e; 8) no norte da Cordilheira dos Andes, em $0^{\circ} / 75^{\circ} \mathrm{W}$, em novembro e dezembro. Em julho os SCMs ficam localizados no norte da bacia e não apresentam regiões preferenciais de ocorrência.

A gênese dos SCMs de longo ciclo de vida mostra que estes acontecem muito mais concentrados que espalhados sobre a bacia Amazônica, mesmo durante o verão e outono (Figura 8). Assim como os SCMs de curta duração, os SCMs com longo tempo de vida seguem o ciclo anual da convecção na Amazônia, com diminuição da ocorrência na metade sul da bacia Amazônica durante o inverno e regiões preferenciais de gênese ao longo da região. As regiões preferenciais, por frequência de ocorrência mensal, são: 1) Serra da Pacaraíma, no Planalto das Guianas, em $5^{\circ} \mathrm{N} / 60^{\circ} \mathrm{W}$, nos meses de outono, inverno e início de verão; 2) Serra do Imeri, no Planalto das Guianas, em aproximadamente $0^{\circ} / 65^{\circ} \mathrm{W}$, ocorrendo preferencialmente nos meses de inverno; 3) confluência do rio Tapajós com o rio Amazonas, em aproximadamente $2,5^{\circ} \mathrm{S} / 54^{\circ} \mathrm{W}$, meses de primavera e outono; 4) próximo à Cordilheira dos Andes em $10^{\circ} / 75^{\circ}$, entre novembro a fevereiro; 5) próximo à Cordilheira dos Andes, em $14^{\circ} \mathrm{S} / 75^{\circ} \mathrm{W}$, nos meses mais quentes; 6) à Cordilheira dos Andes, em $16^{\circ} \mathrm{S} / 65^{\circ} \mathrm{W}$, nos meses mais quentes; 
7) na foz do rio Amazonas e ; 8) entre o norte de Mato Grosso e sul do Pará, em torno de $10^{\circ} \mathrm{S} / 55^{\circ} \mathrm{W}$, em março e outubro. A Figura 9 pode ser interpretada como a representação da climatologia da densidade de gênese, maturação e dissipação de todos os SCMs que interagem com a bacia Amazônica ao longo do ano, pois ela reúne os comportamentos médios dos SCMs de curta e longa duração.

As regiões preferenciais de gênese que apresentam um pico de maior densidade são dissolvidas ao longo do ciclo de vida do SCM. Apesar disso, as figuras de densidade de maturação e dissipação (Figuras 7 e 8 e 9) mostram poucas diferenças entre as regiões de formação dos SCMs, o que já era previsto na literatura. Sakamoto (2009) verificou que, em geral, as áreas preferenciais em que os SCMs subtropicais atingem a fase madura não diferem muito das áreas onde foram gerados, pois esses sistemas tendem se deslocar para regiões com suprimento de calor e umidade. Apesar disso, as figuras de densidade de maturação dos SCMs com longo ciclo de vida são mais homogêneas, que as de gênese e dissipação e isso pode ser um indicativo de que os SCMs de longa duração geralmente avançam para as mesmas regiões que os levam à dissipação, pois esta ocorre mais concentrada que durante a fase de maturação. Outra hipótese, e talvez mais provável, é de que durante a fase de maturação as áreas dos SCMs de longa duração é muito maior que durante a inicial e a final (Tabela 2), de forma que os centros de massa possam ocorrer mais espalhados ao longo da bacia Amazônica e a densidade de maturação parecer mais homogênea. 

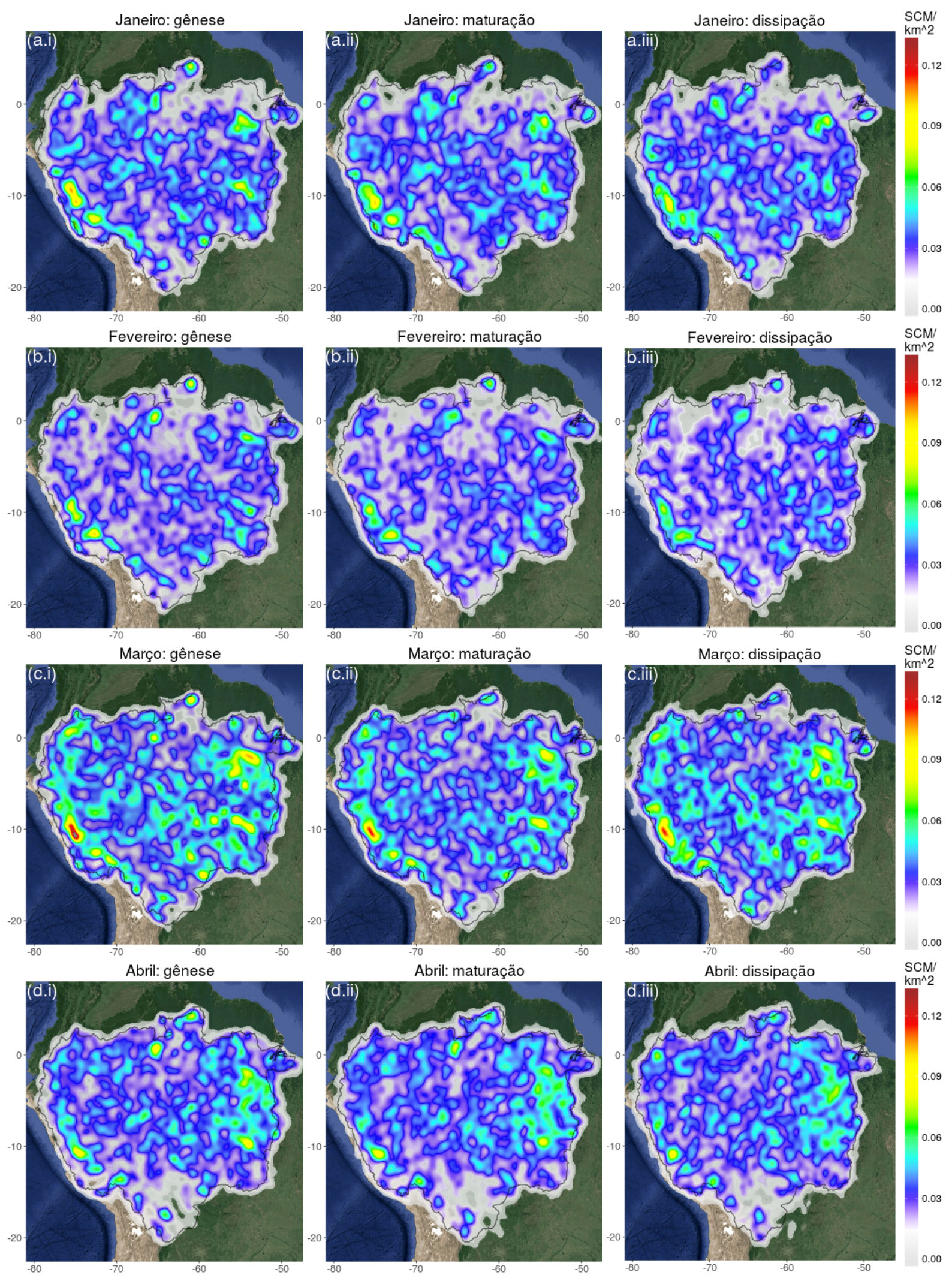

Figura 7 - Climatologia da densidade de gênese, maturação e dissipação, respectivamente, dos SCMs com curto ciclo de vida em (a.i), (a.ii) e (a.iii) janeiro; (b.i), (b.ii), (b.iii) fevereiro; (c.i), (c.ii),(c.iii) março; (d.i), (d.ii), (d.iii) abril; (e.i), (e.ii), (e.iii) maio; (f.i), (f.ii), (f.iii) junho; (g.i), (g.ii), (g.iii) julho; (h.i), (h.ii), (h.iii) agosto; (i.i), (i.ii), (i.iii) setembro; (j.i), (j.ii), (j.iii) outubro; (k.i), (k.ii), (k.iii) novembro e (l.i), (l.iii), (l.iii) dezembro. 0 contorno em preto indica os limites da bacia Amazônica. Período utilizado: 2000 a 2013. 

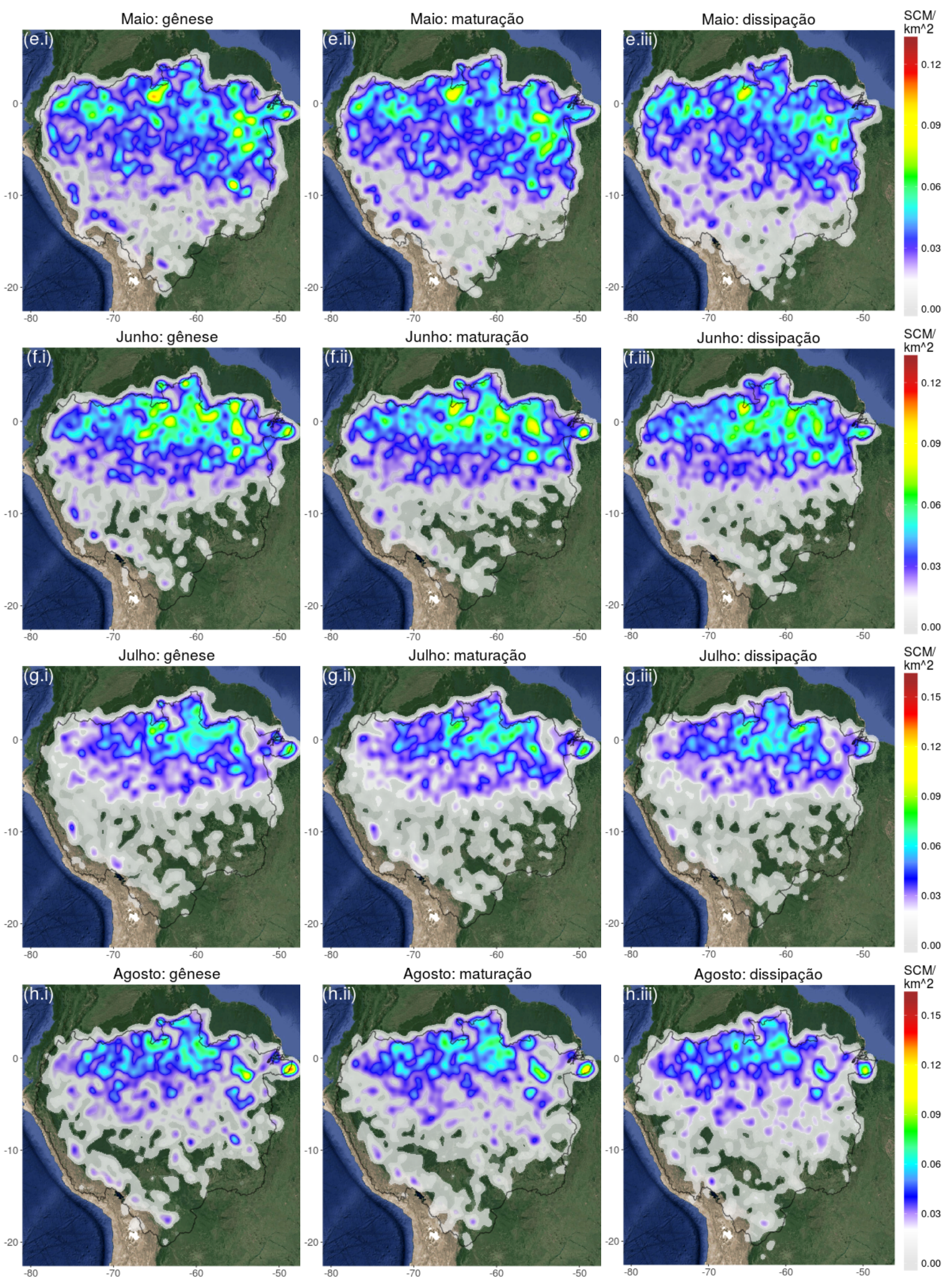

Figura 7 - Continuação da figura da página anterior. 

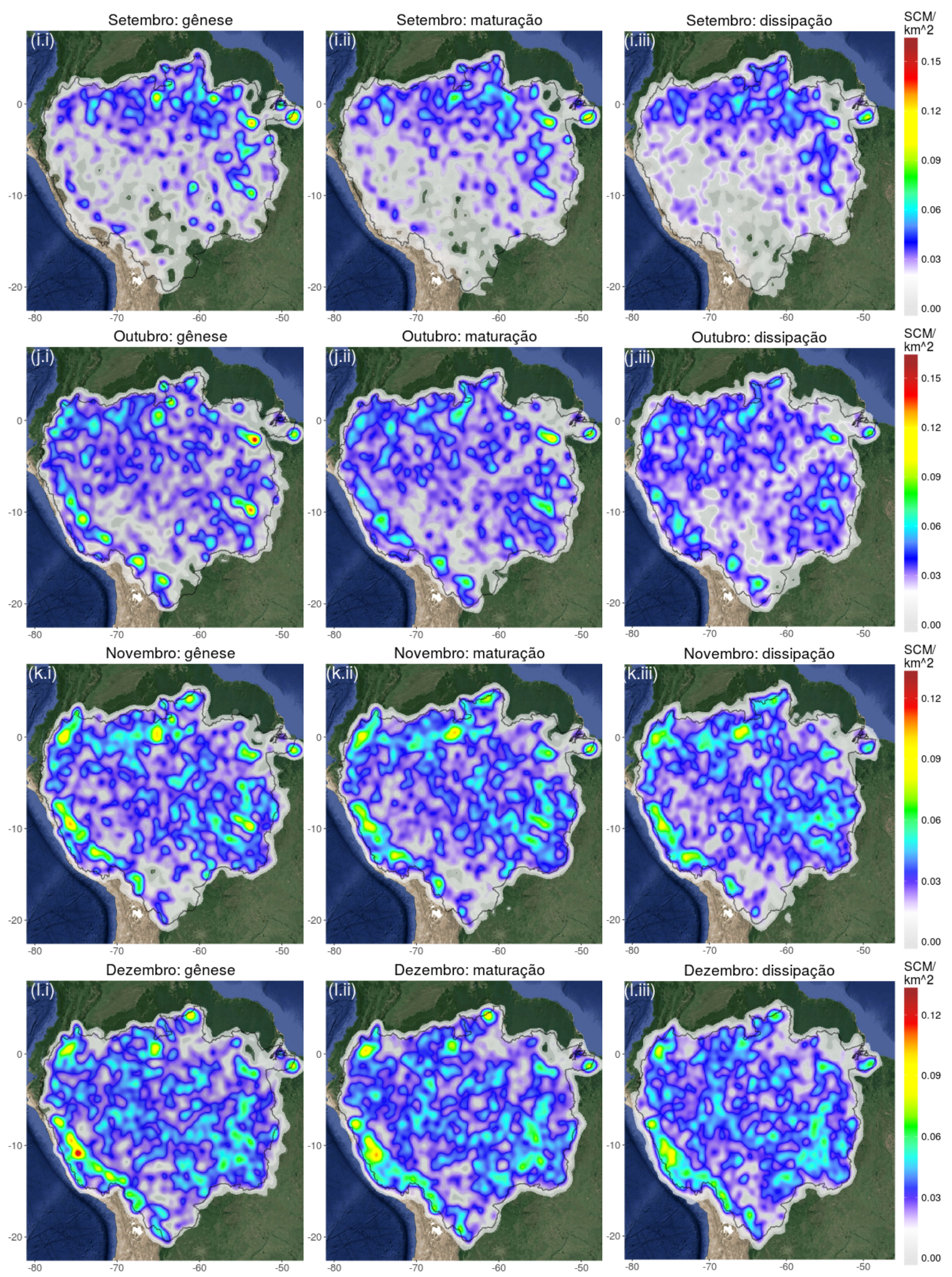

Figura 7 - Continuação da figura da página anterior. 

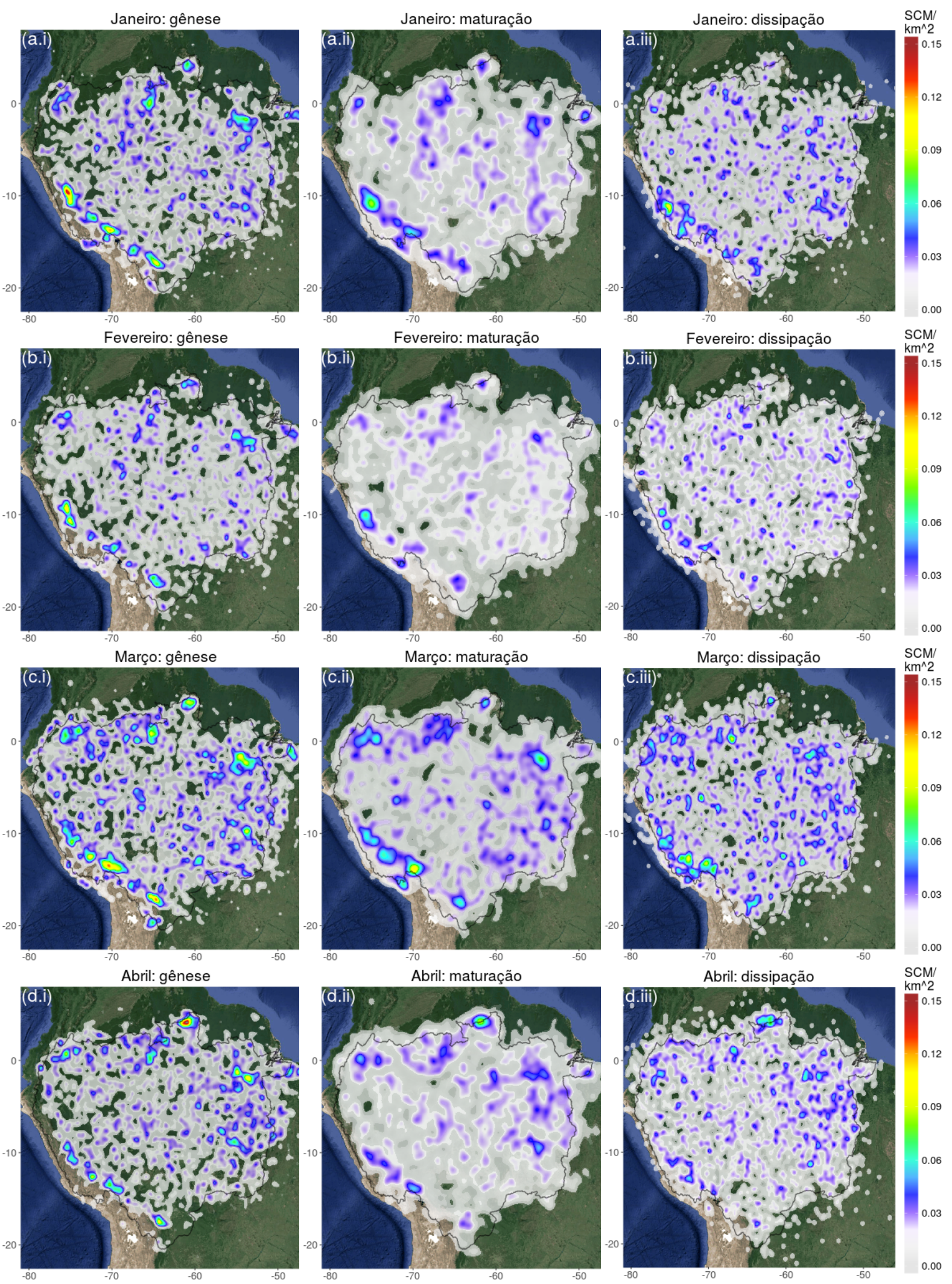

Figura 8 - Climatologia da densidade de gênese, maturação e dissipação, respectivamente, dos SCMs com longo ciclo de vida em (a.i), (a.ii) e (a.iii) janeiro; (b.i), (b.ii), (b.iii) fevereiro; (c.i), (c.ii),(c.iii) março; (d.i), (d.ii), (d.iii) abril; (e.i), (e.ii), (e.iii) maio; (f.i), (f.ii), (f.iii) junho; (g.i), (g.ii), (g.iii) julho; (h.i), (h.ii), (h.iii) agosto; (i.i), (i.ii), (i.iii) setembro; (j.i), (j.ii), (j.iii) outubro; (k.i), (k.ii), (k.iii) novembro e (l.i), (l.ii), (l.iii) dezembro. O contorno em preto indica os limites da bacia Amazônica. Período utilizado: 2000 a 2013. 

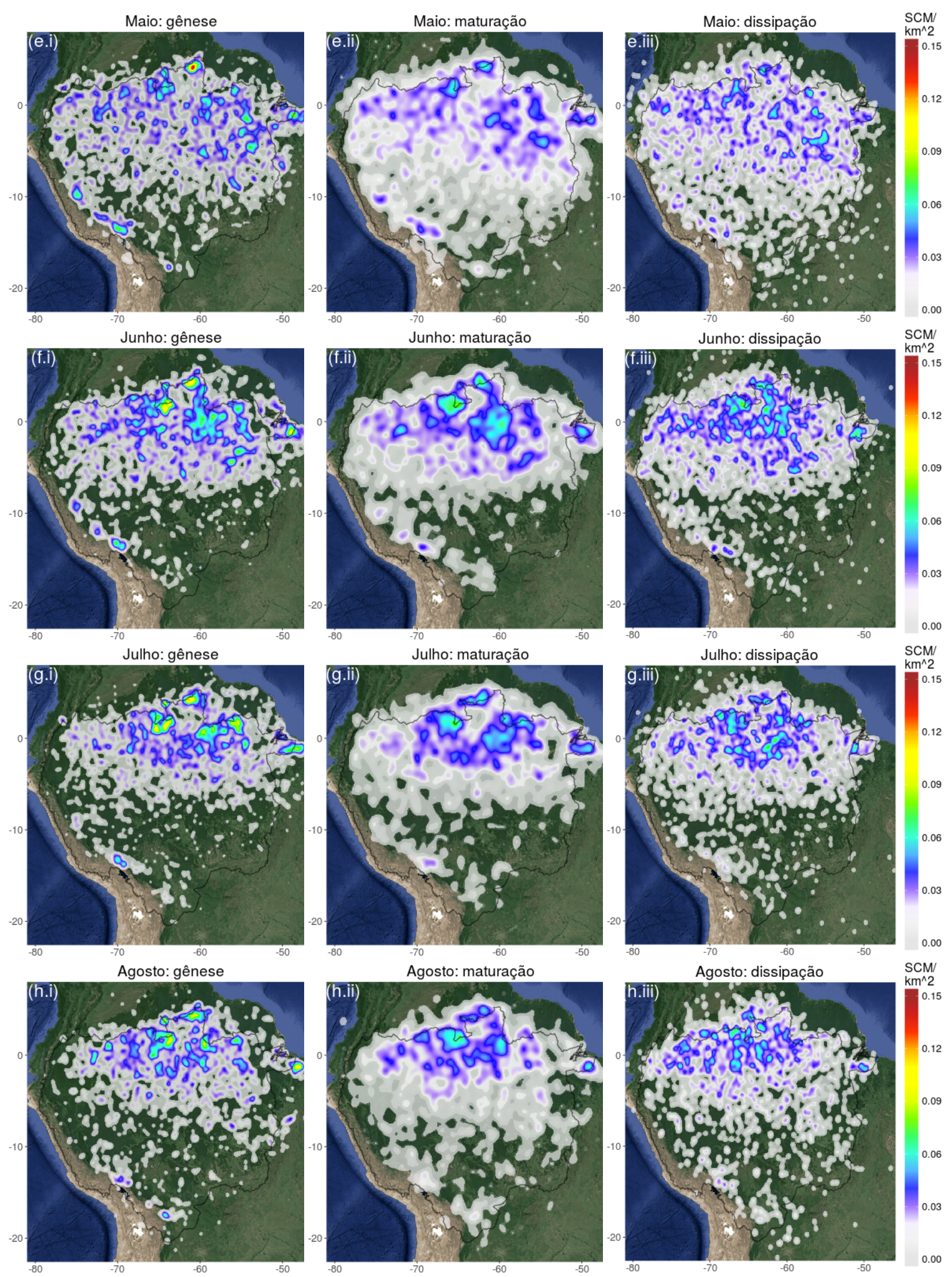

Figura 8 - Continuação da figura da página anterior. 

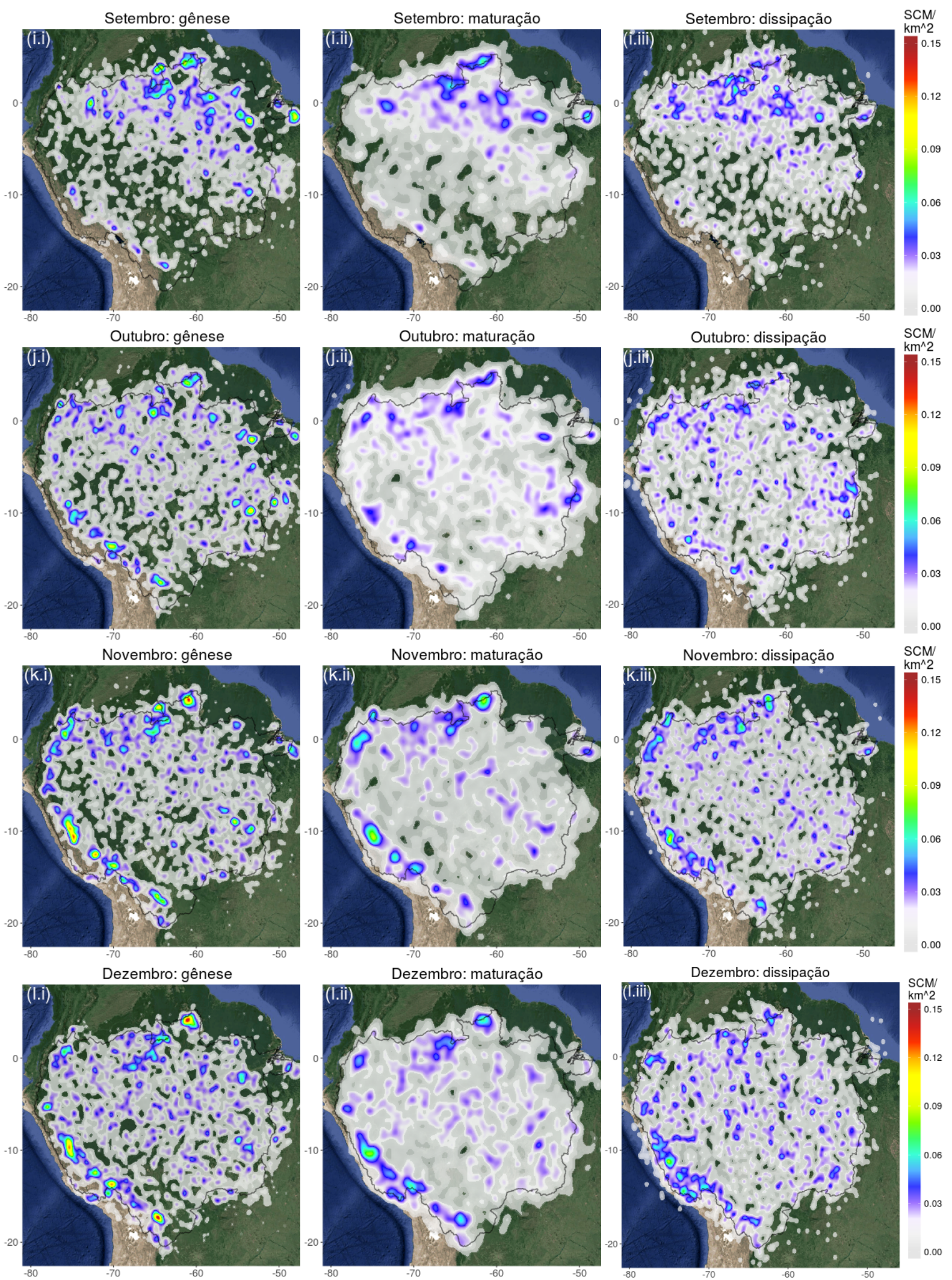

Figura 8 - Continuação da figura da página anterior. 

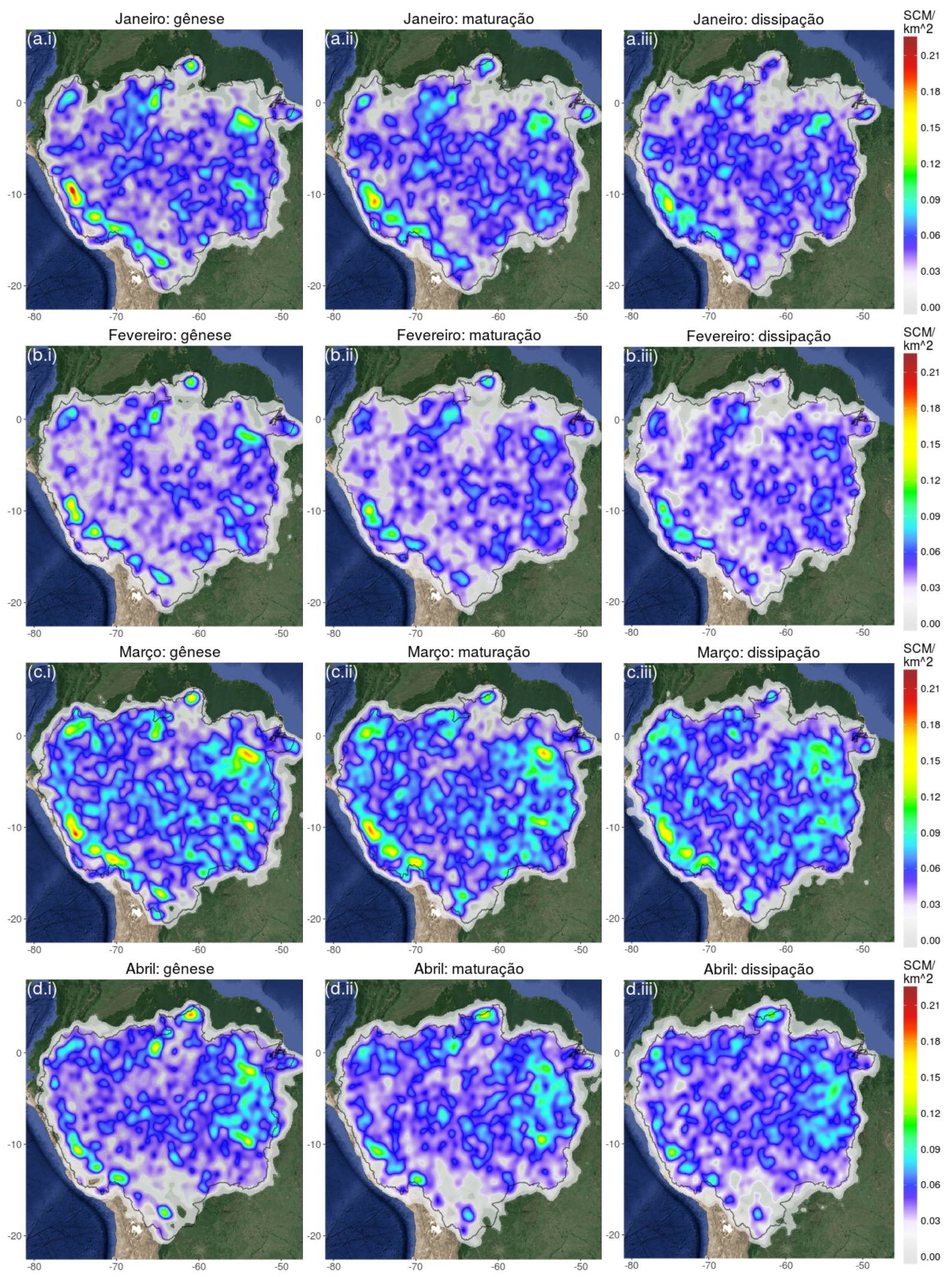

Figura 9 - Climatologia da densidade com relação à gênese, maturação e dissipação, respectivamente, de todos os SCMs em (a.i), (a.ii) e (a.iii) janeiro; (b.i), (b.ii), (b.iii) fevereiro; (c.i), (c.ii),(c.iii) março; (d.i), (d.ii), (d.iii) abril; (e.i), (e.ii), (e.iii) maio; (f.i), (f.ii), (f.iii) junho; (g.i), (g.ii), (g.iii) julho; (h.i), (h.ii), (h.iii) agosto; (i.i), (i.ii), (i.iii) setembro; (j.i), (j.ii), (j.iii) outubro; (k.i), (k.ii), (k.iii) novembro e (l.i), (l.ii), (l.iii) dezembro. O contorno em preto indica os limites da bacia Amazônica. Período utilizado: 2000 a 2013. 

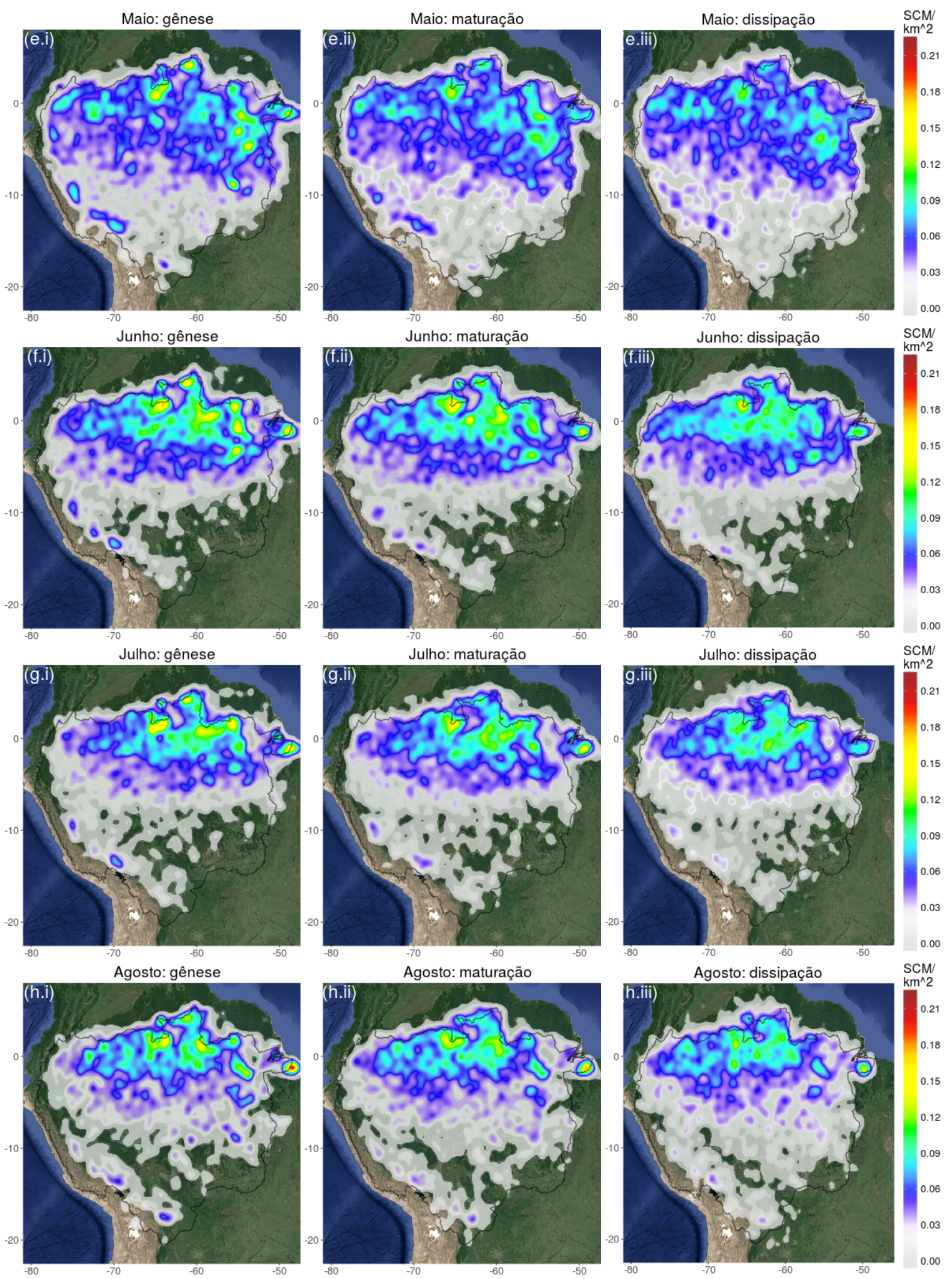

Figura 9 - Continuação da figura da página anterior. 

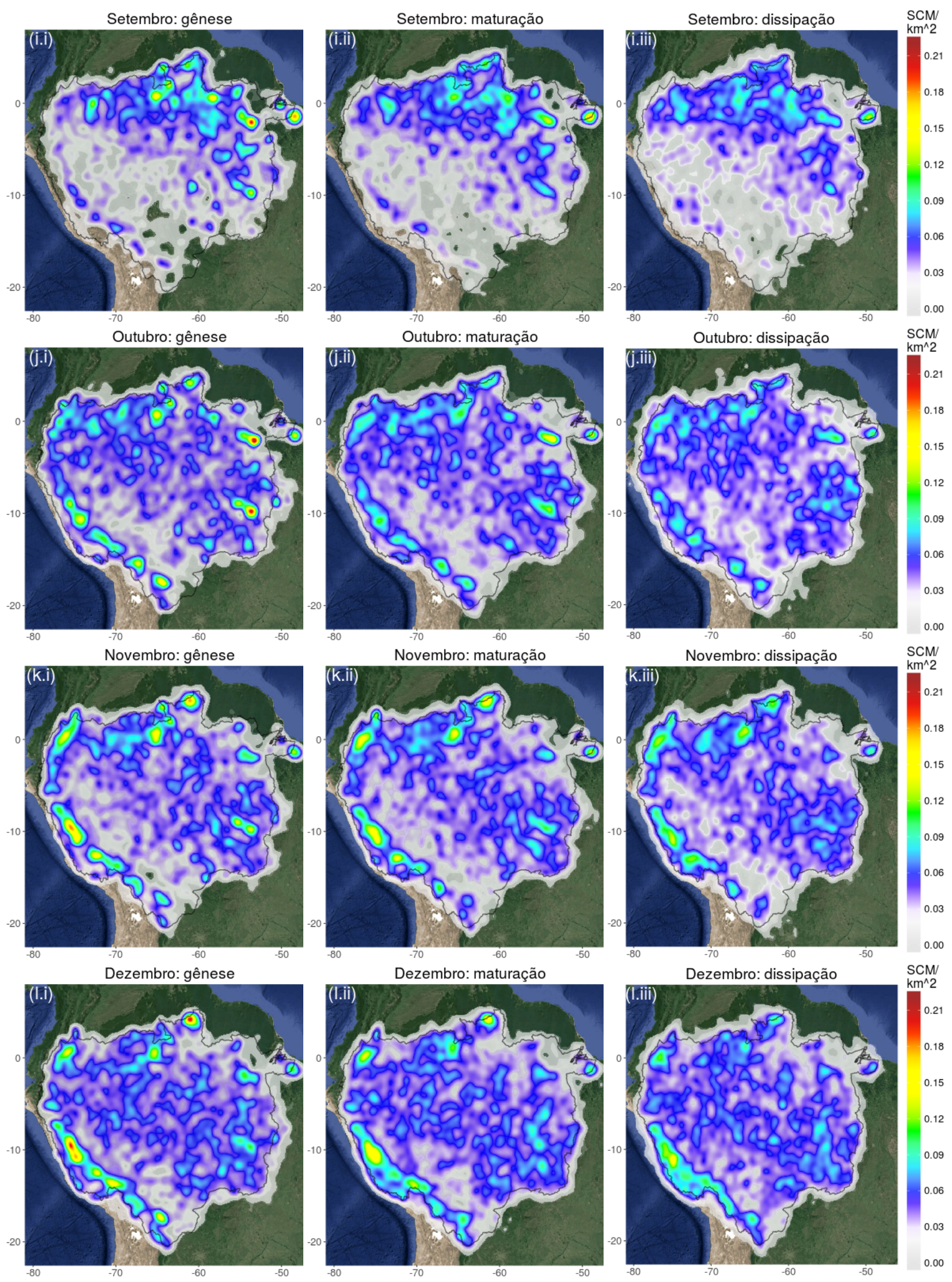

Figura 9 - Continuação da figura da página anterior. 
A velocidade média de propagação dos SCMs com curto ciclo de vida, obtida com o ForTraCC, é de $22,4 \mathrm{~km} / \mathrm{h}( \pm 7,2 \mathrm{~km} / \mathrm{h})$, e não difere muito dos SCMs de longa duração, os quais apresentam velocidade média de $21,8 \mathrm{~km} / \mathrm{h}( \pm 6,5 \mathrm{~km} / \mathrm{h})$. Pereira Filho et al. (2015) constataram que as velocidades de fase médias quando os sistemas convectivos se deslocaram para oeste são de $42,5 \mathrm{~km} / \mathrm{h}$ e de $47,5 \mathrm{~km} / \mathrm{h}$ quando eles deslocaram para leste. Machado et al. (1998) encontraram valores de 43,2 km/h sobre as Américas, embora os autores afirmam que esta foi muito variável. No mesmo estudo, os autores verificaram que o valor de $45 \mathrm{~km} / \mathrm{h}$ é um limite superior da velocidade de deslocamento do centro de massa de SCMs sem junções ou divisões. No presente trabalho sistemas que sofrem junções ou divisões ao longo do ciclo de vida não foram descartados. Em comparação com latitudes subtropicais, Sakamoto (2009) explica que a velocidade com que o sistema se move é variável, sendo a média de $36 \mathrm{~km} / \mathrm{h}( \pm 23,4$ $\mathrm{km} / \mathrm{h}$ ).

No presente trabalho, a menor velocidade encontrada comparado com a literatura pode ter ocorrido devido ao cálculo ter levado em conta todos os eventos ao longo de todo o ano e território amazônico, com junções e divisões, sem separar sistemas que deslocam para uma ou outra direção. Além disso, a velocidade foi calculada pelo ForTracc; o algoritmo considera os deslocamentos a cada passo de tempo, como explicado na Seção 3.3. As velocidades, no presente trabalho, foram obtidas também através da distância total percorrida pelos sistemas e do tempo de duração. Neste caso, foram obtidos valores levemente maiores que aquelas obtidas pelo ForTraCC, média de $26,7 \mathrm{~km} / \mathrm{h}( \pm 15 \mathrm{~km} / \mathrm{h}$ ) para sistemas de curta duração e média de $27,9 \mathrm{~km} / \mathrm{h}$ $( \pm 13,8 \mathrm{~km} / \mathrm{h})$ para sistemas com longa duração. Como as médias não diferem muito $\mathrm{e}$ os desvios padrões são maiores no segundo cálculo, foram utilizadas as velocidades calculadas pelo ForTracc, realizando uma média das velocidades de cada sistema e em seguida a velocidade média de todos os sistemas.

Pereira Filho et al. (2015) verificou que em média os SCMs que se propagam para oeste sobre a bacia Amazônica possuem deslocamentos da ordem de $500 \mathrm{~km}$ e são maiores que aqueles que se deslocam para leste. No presente trabalho, sem separar a direção de propagação dos sistemas, o deslocamento médio daqueles SCMs de longa duração foi de $275,2 \mathrm{~km}$ ( $\pm 206,2 \mathrm{~km})$, e dos SCMs de curta duração é de $106 \mathrm{~km}( \pm 64,2 \mathrm{~km})$. Estes valores variam de acordo com a época do ano, sendo que durante o inverno os deslocamentos são maiores (Figura 10). 

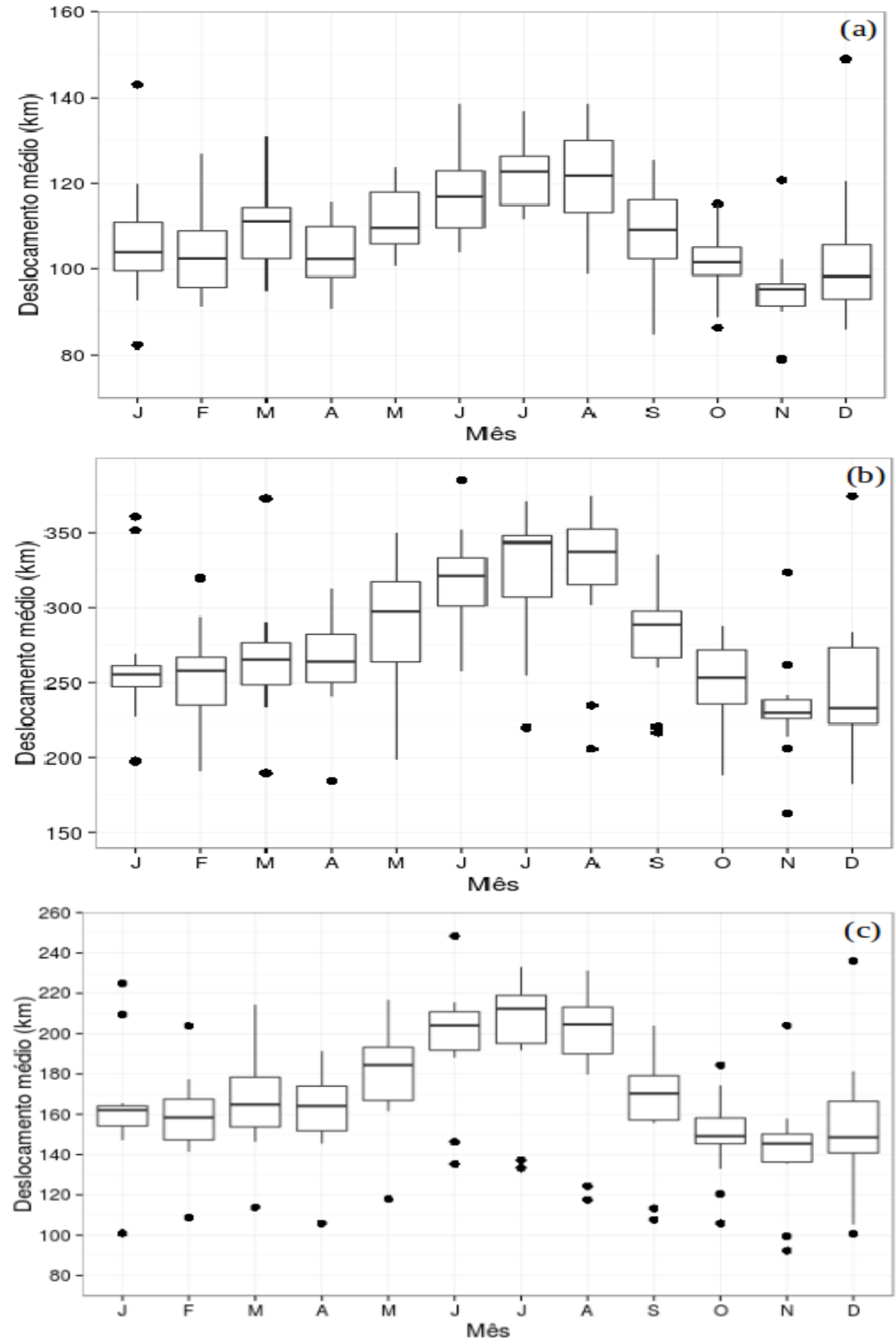

Figura 10 - Deslocamentos médios mensais dos (a) SCMs com curto tempo de vida, (b) SCMs com longo ciclo de vida e (c) todos SCMs. Período utilizado: 2000 a 2013. No total, 98743 SCMs foram considerados. 
As Figuras 11, 12 e 13 indicam a direção de propagação, o deslocamento médio e a velocidade média mensal dos SCMs de acordo com o tempo de vida. Entre novembro a março a circulação é similar, onde na região nordeste da Amazônia os sistemas tendem deslocar-se para noroeste e na região noroeste tendem a se deslocar para sudoeste. Na região central, em uma faixa zonalmente orientada entre as latitudes de $5^{\circ} \mathrm{S}$ e $12^{\circ} \mathrm{S}$ e longitudes de $50^{\circ} \mathrm{W}$ a $70^{\circ} \mathrm{W}$ os SCMs deslocam-se preferencialmente para oeste, naquele período. Na região sul, em novembro o deslocamento é pouco maior que nos meses seguintes e para leste. Em dezembro, na mesma região, os deslocamentos são que anteriormente e não há uma região preferencial evidente. Conforme visto anteriormente, no inverno os deslocamentos são maiores que durante o verão. O deslocamento naquela época do ano é para oeste na região norte da bacia Amazônica, porém na faixa oeste são desviados para o sul. No sul os deslocamentos são maiores que na parte oeste durante o inverno e os sistemas tendem deslocar-se para sudeste.

Os SCMs com longa duração apresentam maiores deslocamentos ao longo de toda a bacia Amazônica e em todos os meses do ano comparados aos de curta duração. Entretanto, durante o verão, o sul da bacia Amazônica apresenta menores deslocamentos não há uma direção preferencial de propagação. Nos meses de inverno a metade sul da bacia apresenta maiores variabilidades na velocidade, porém eles os SCMs deslocam-se para sudeste. Entre agosto e novembro, na região norte da bacia, a direção preferencial é para oeste com uma leve tendência para noroeste, porém nos outros meses é para sudoeste. 


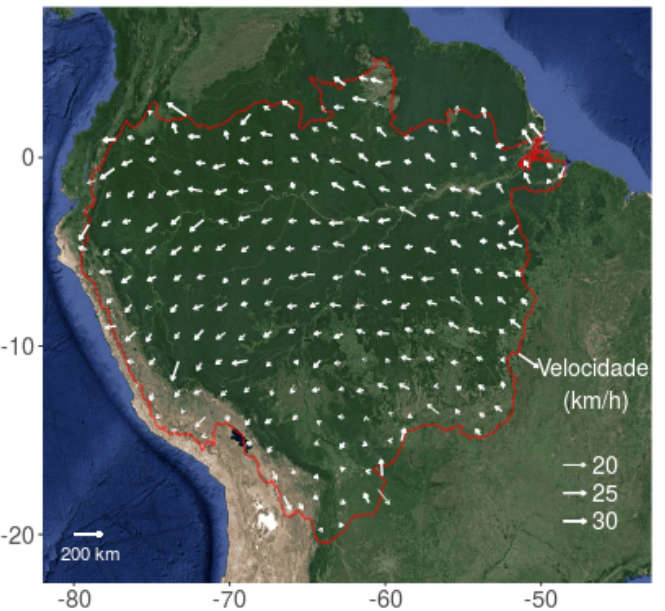

(a) Janeiro

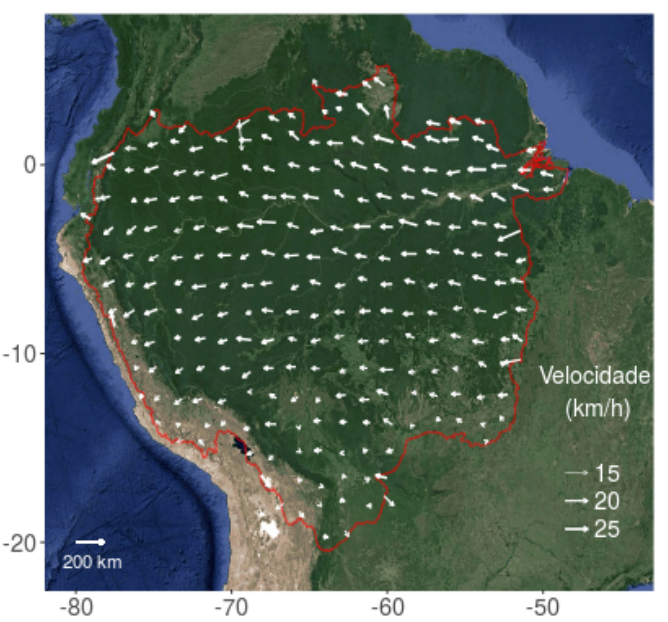

(c) Março

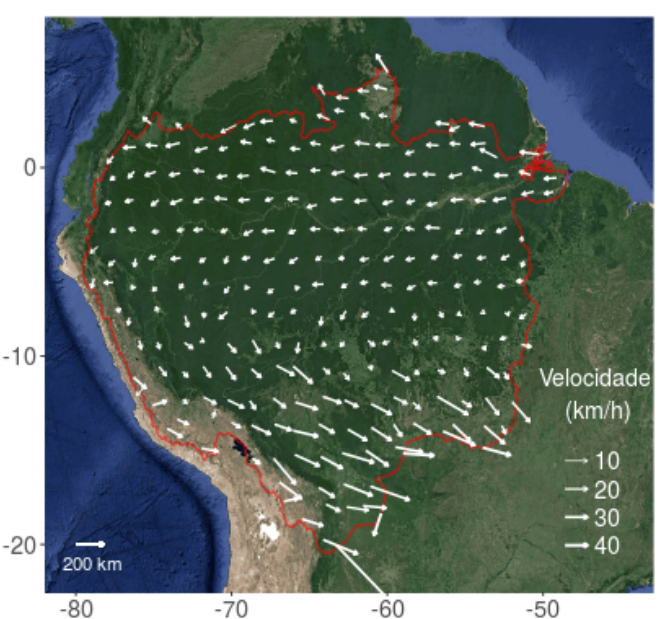

(e) Maio

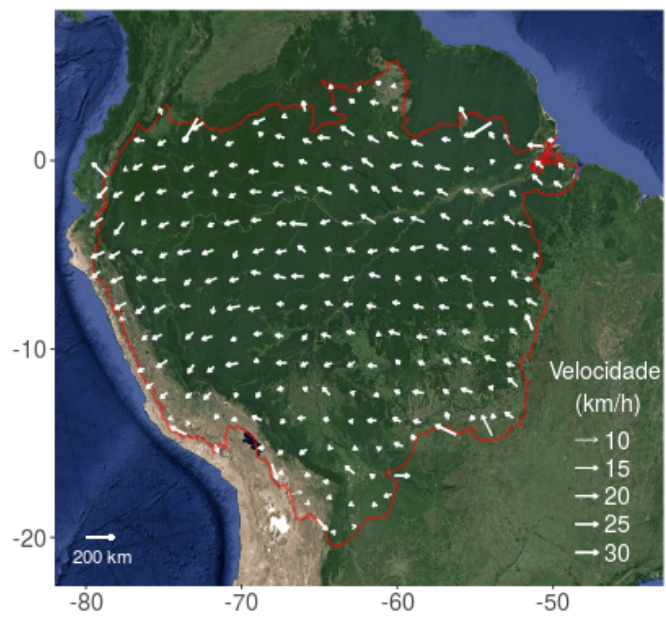

(b) Fevereiro

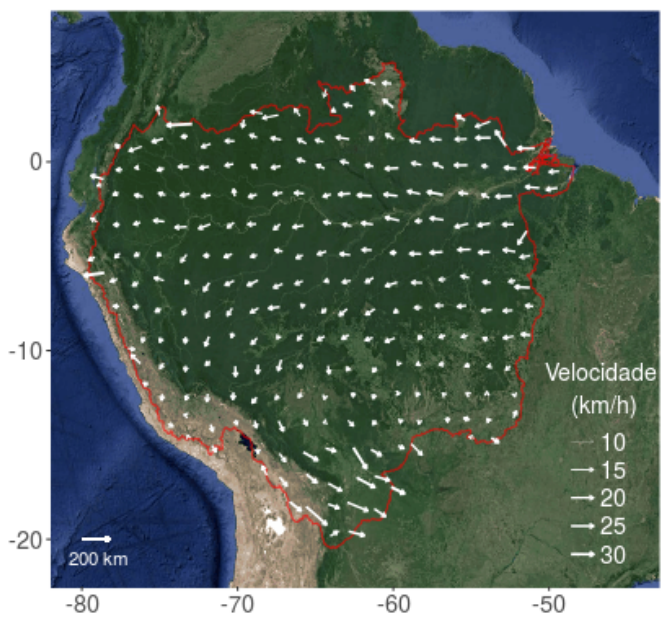

(d) Abril

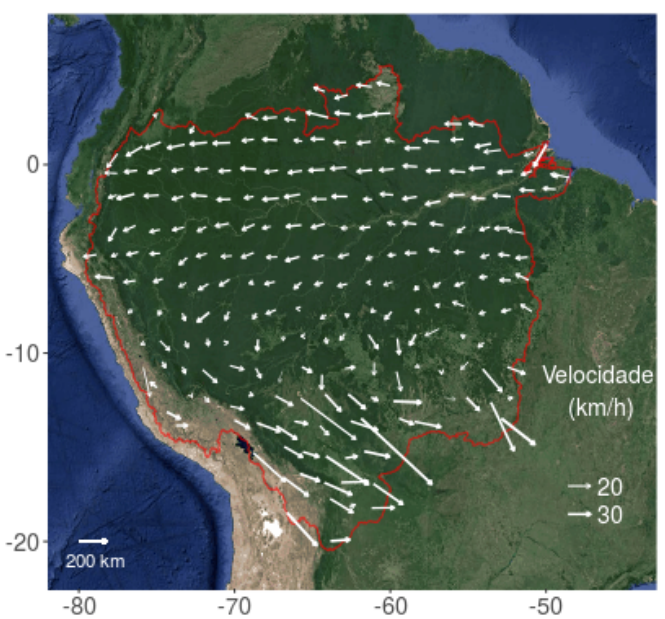

(f) Junho

Figura 11 - Climatologia da direção de propagação, deslocamentos médios e velocidade média dos SCMs com curto ciclo de vida ocorridos na bacia Amazônica. O comprimento do vetor indica o deslocamento médio e a largura indica a velocidade. Período utilizado: 2000 a 2013. 


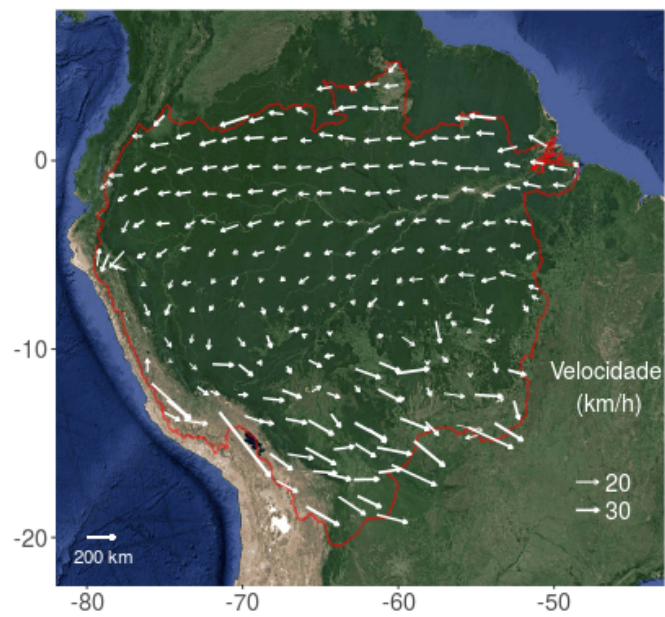

(g) Julho

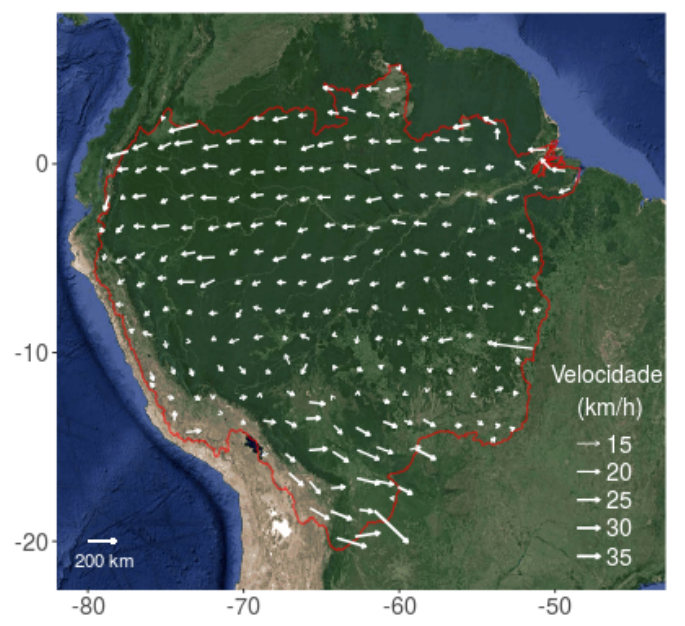

(i) Setembro

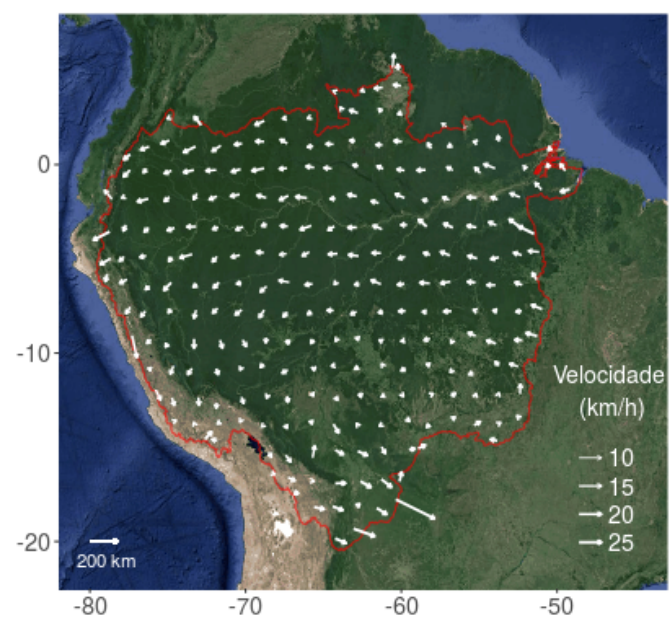

(k) Novembro

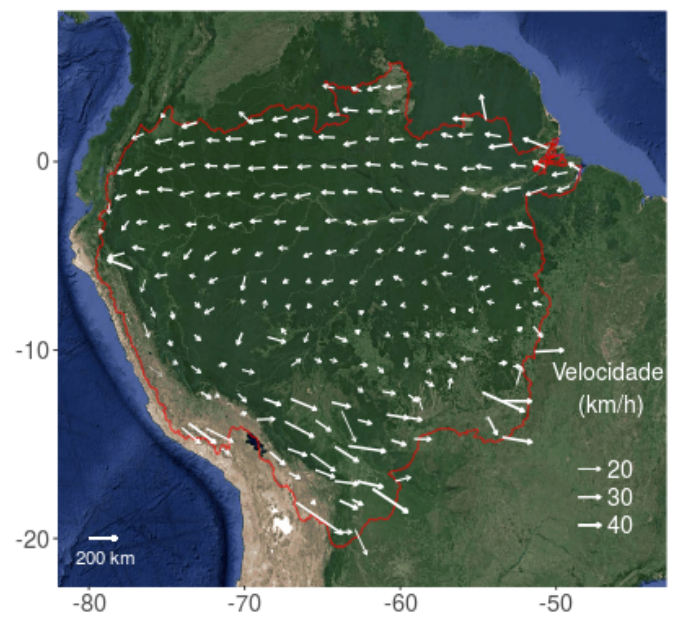

(h) Agosto

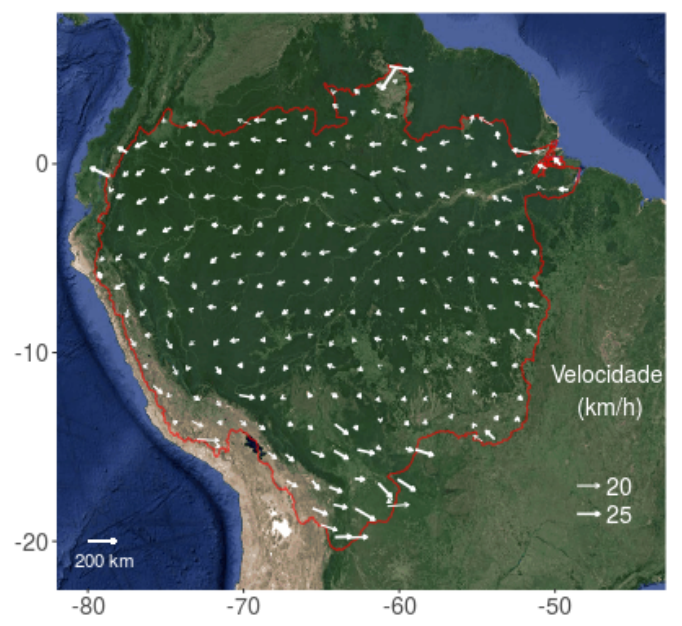

(j) Outubro

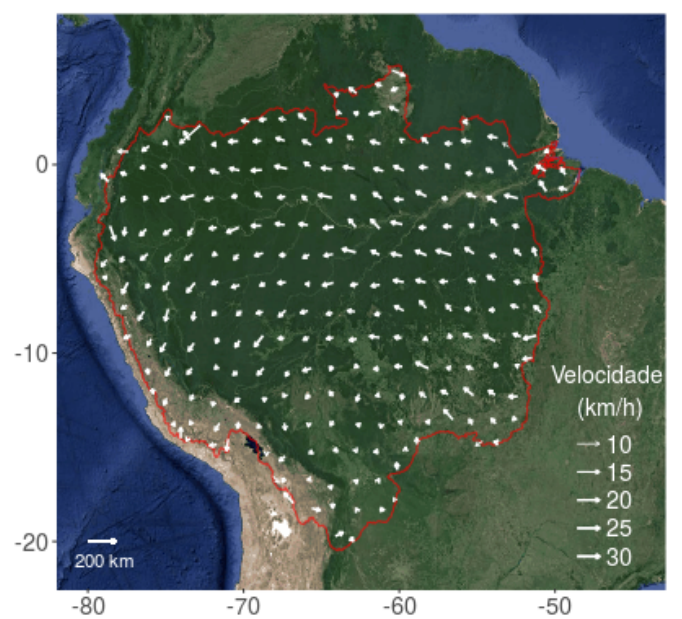

(I) Dezembro

Figura 11 - Continuação da figura da página anterior. 


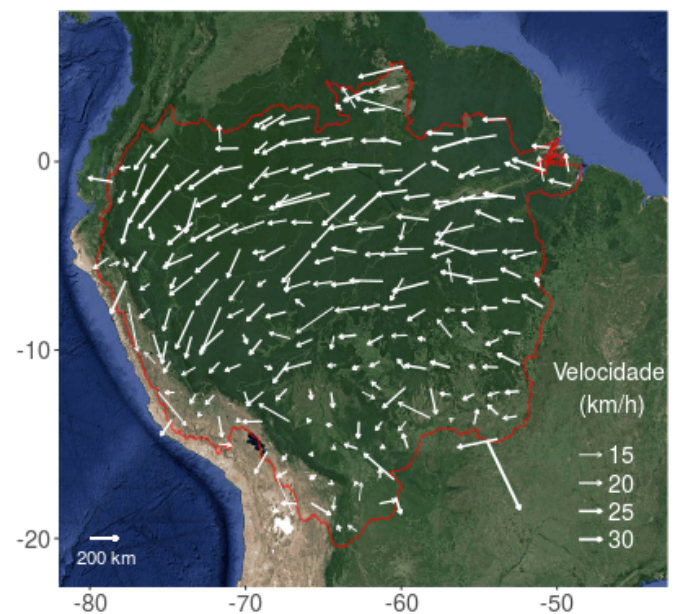

(a) Janeiro

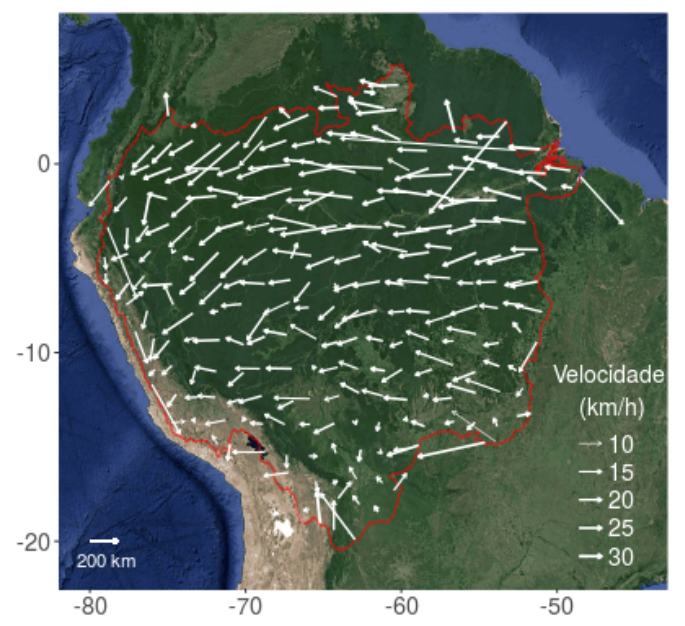

(c) Março

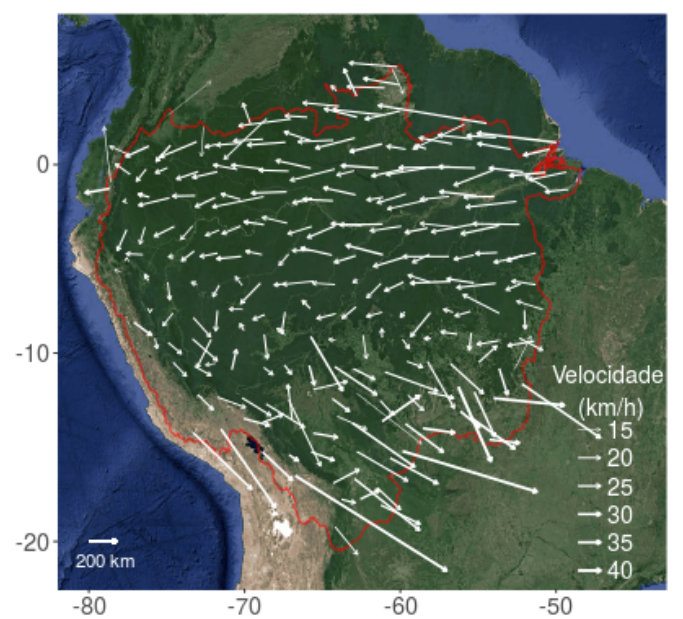

(e) Maio

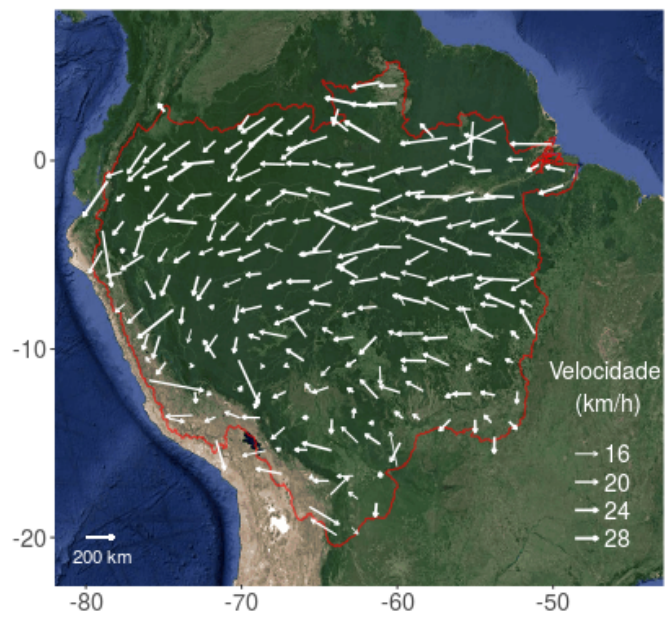

(b) Fevereiro

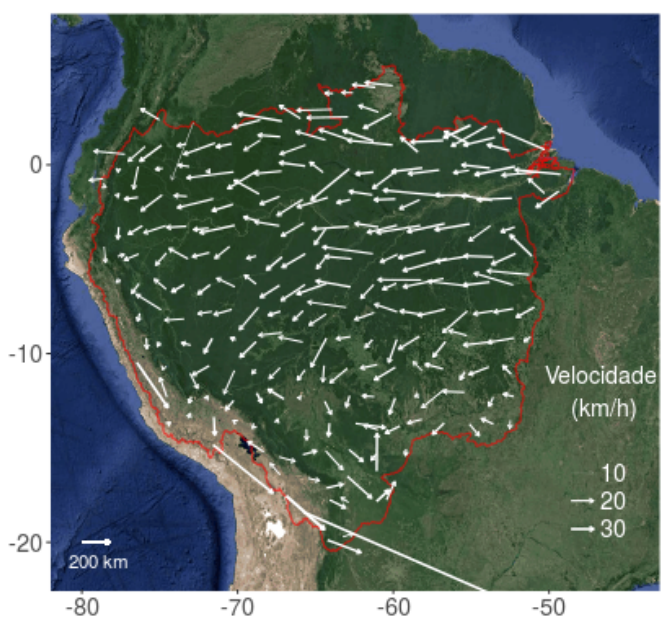

(d) Abril

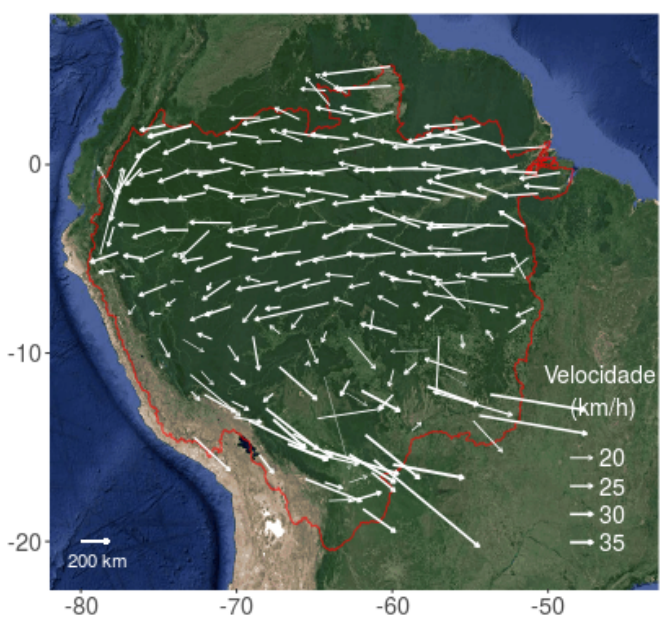

(f) Junho

Figura 12 - Climatologia da direção de propagação, deslocamentos médios e velocidade média dos SCMs com longo ciclo de vida ocorridos na bacia Amazônica. O comprimento do vetor indica o deslocamento médio e a largura indica a velocidade. Período utilizado: 2000 a 2013. 


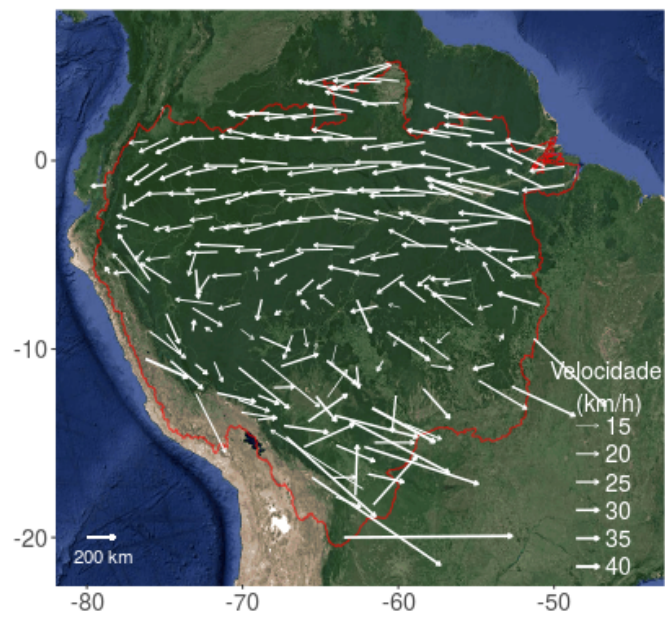

(g) Julho

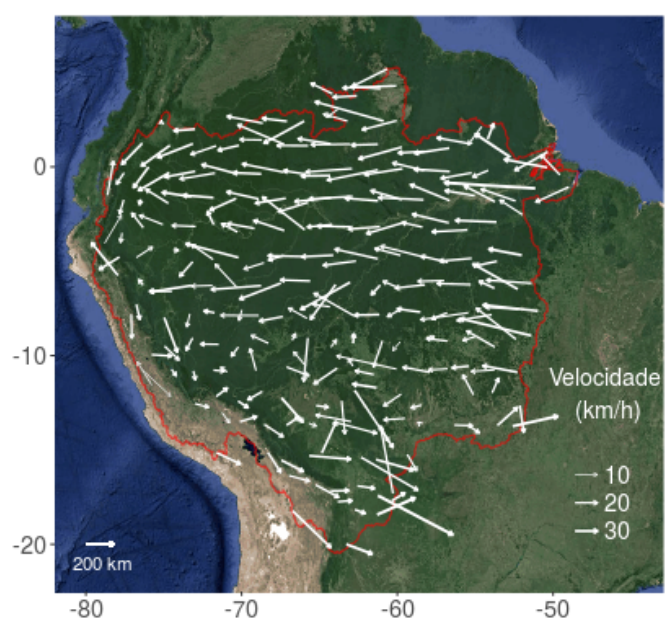

(i) Setembro

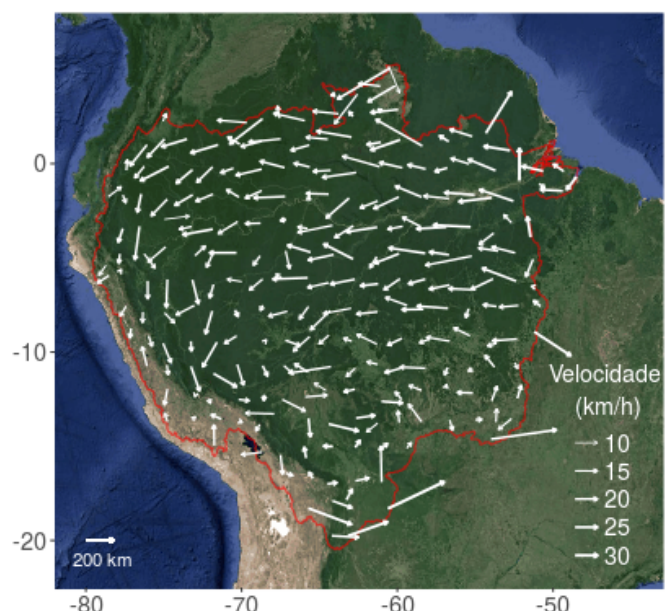

(k) Novembro

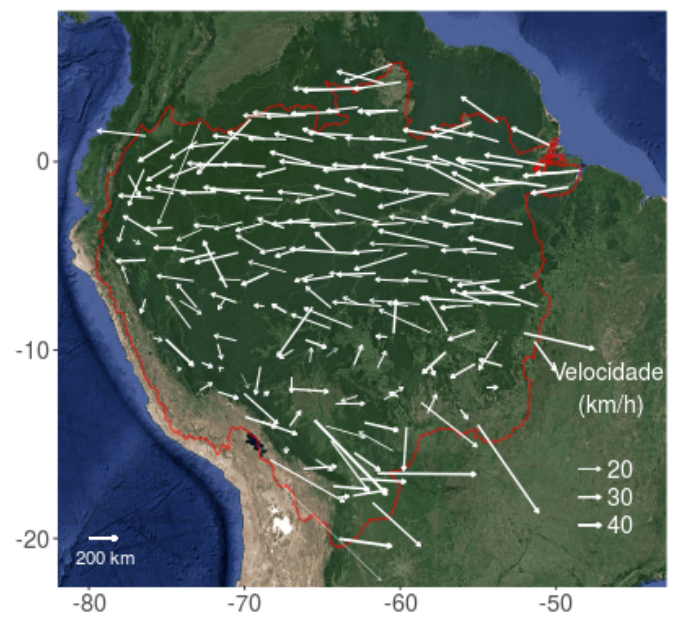

(h) Agosto

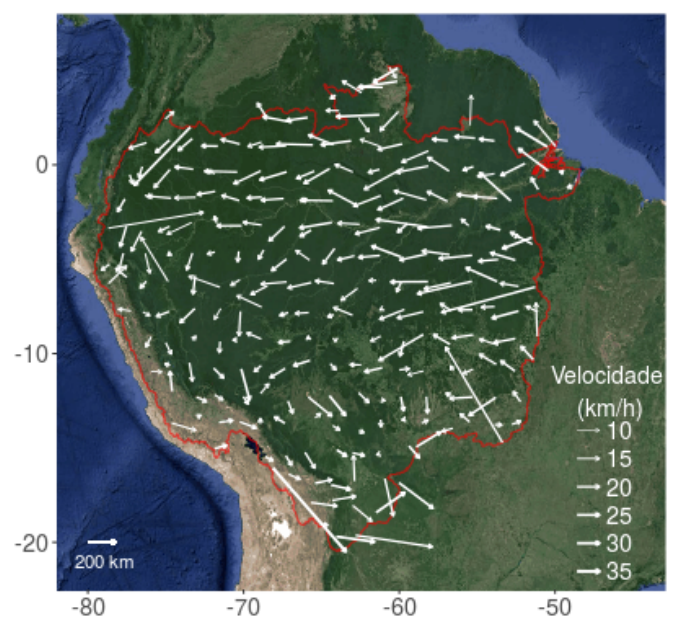

(j) Outubro

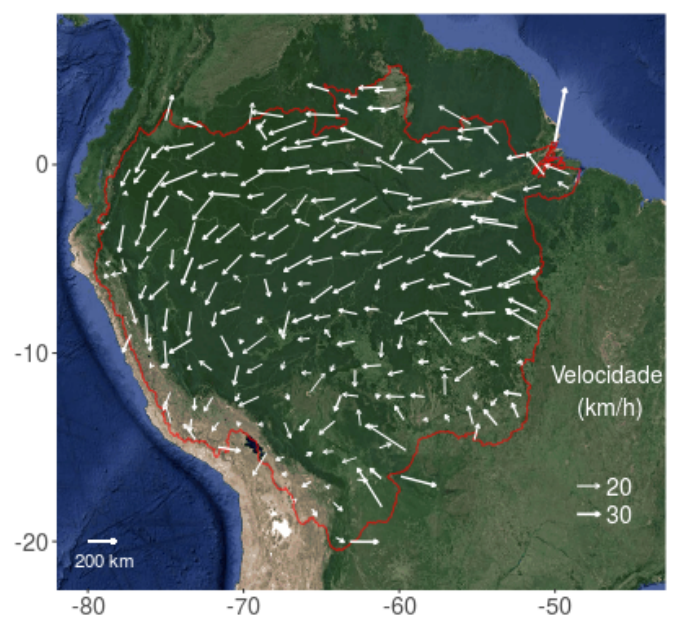

(I) Dezembro

Figura 12 - Continuação da figura da página anterior. 


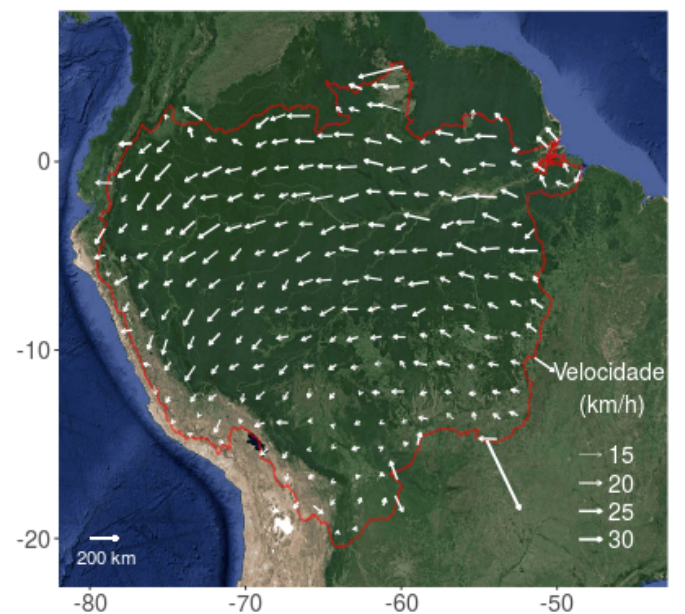

(a) Janeiro

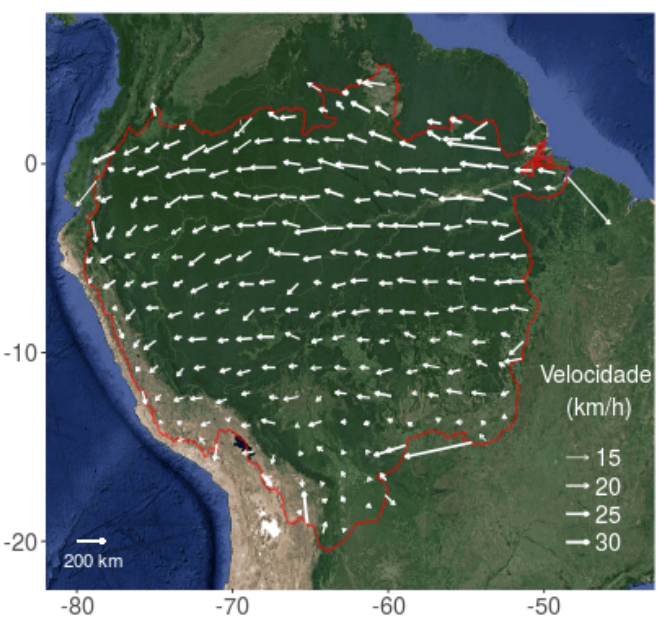

(c) Março

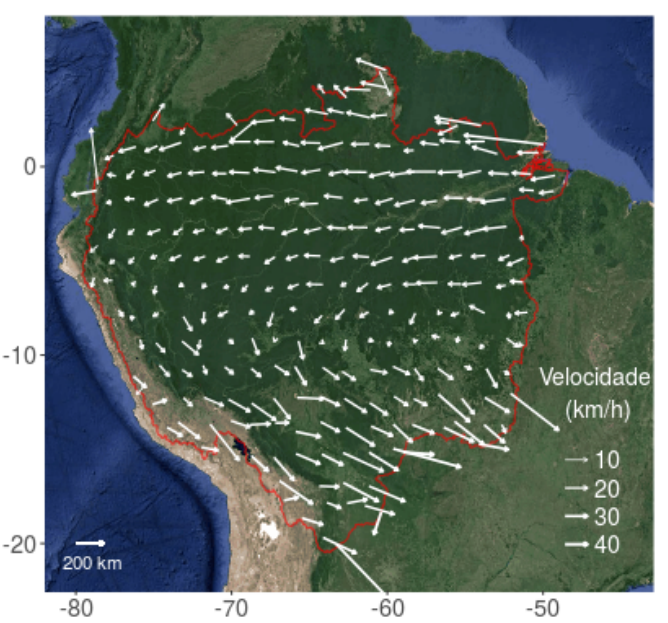

(e) Maio

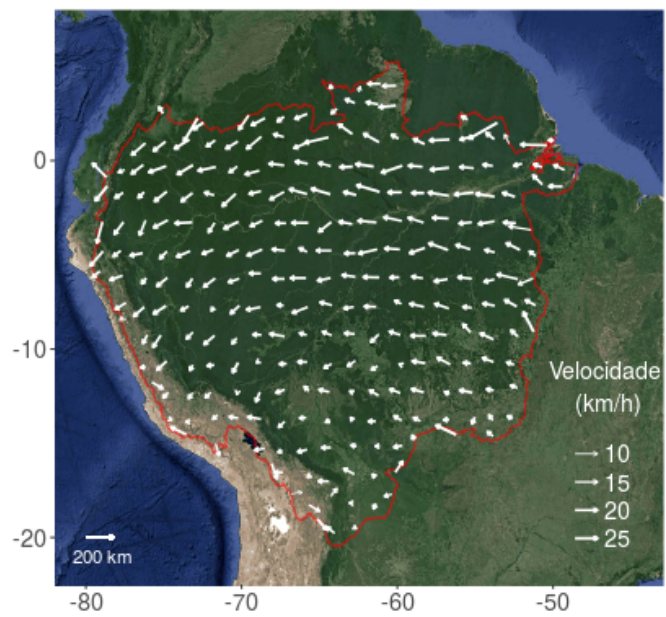

(b) Fevereiro

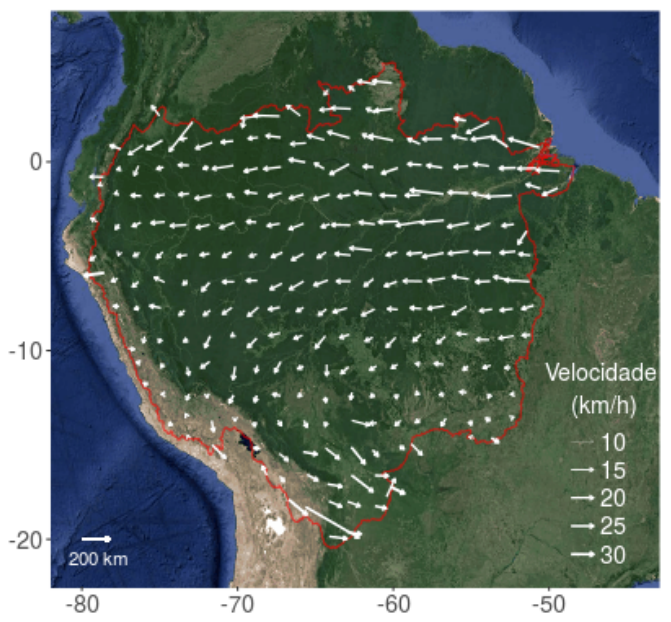

(d) Abril

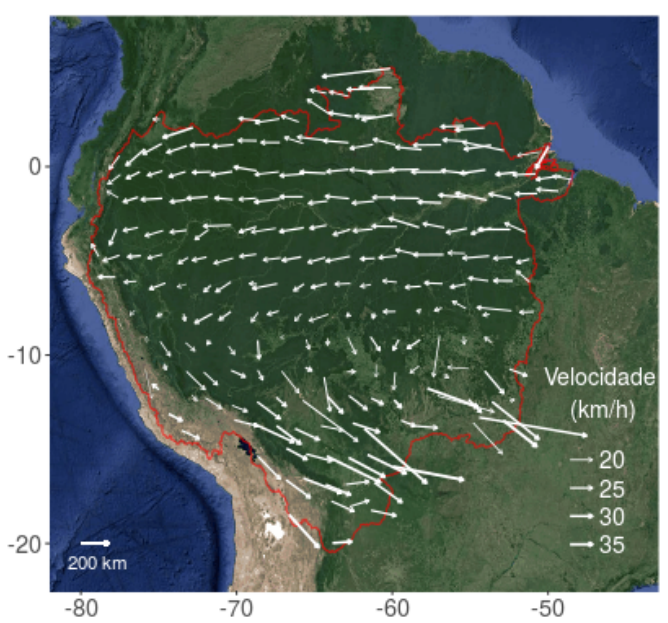

(f) Junho

Figura 13 - Climatologia da direção de propagação, deslocamentos médios e velocidade média de todos SCMs ocorridos na bacia Amazônica. O comprimento do vetor indica o deslocamento médio e a largura indica a velocidade. Período utilizado: 2000 a 2013. 


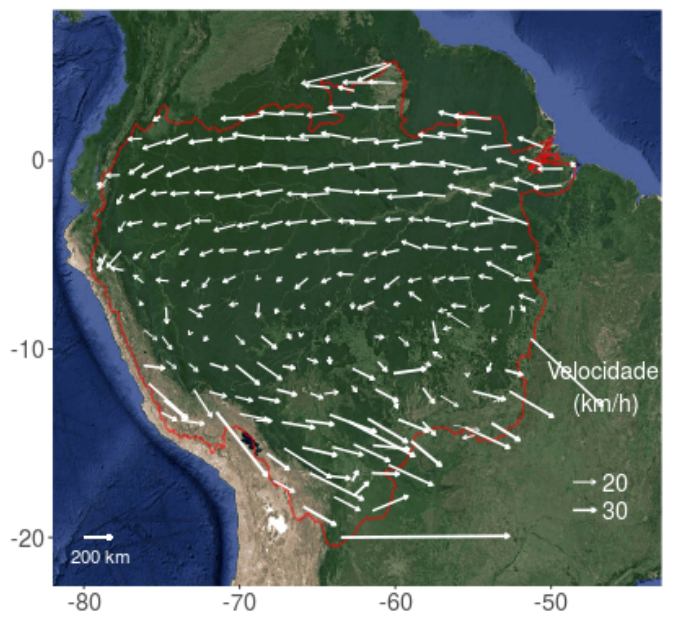

(g) Julho

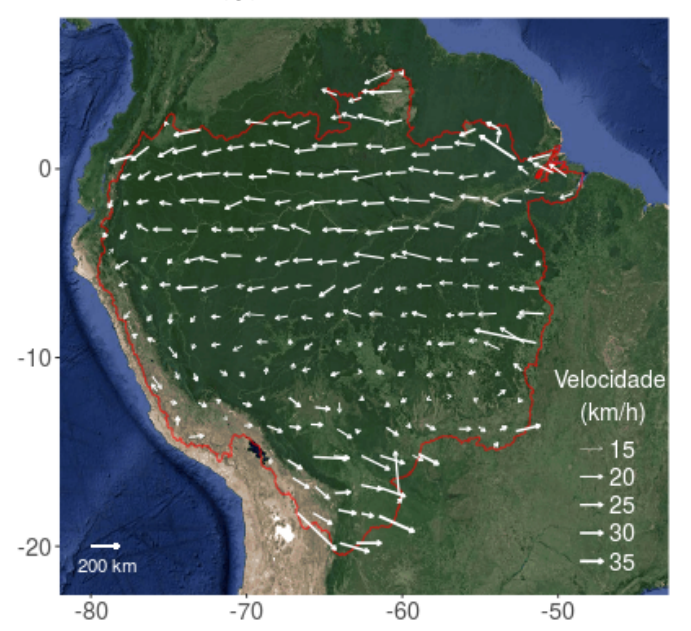

(i) Setembro

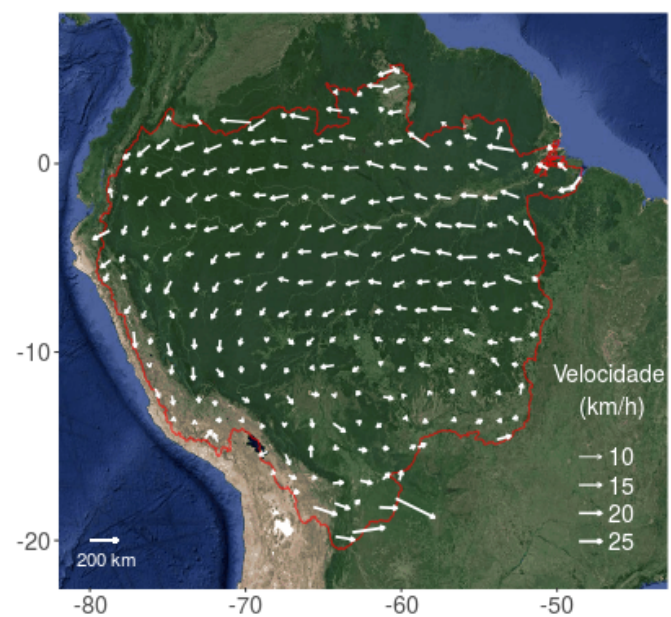

(k) Novembro

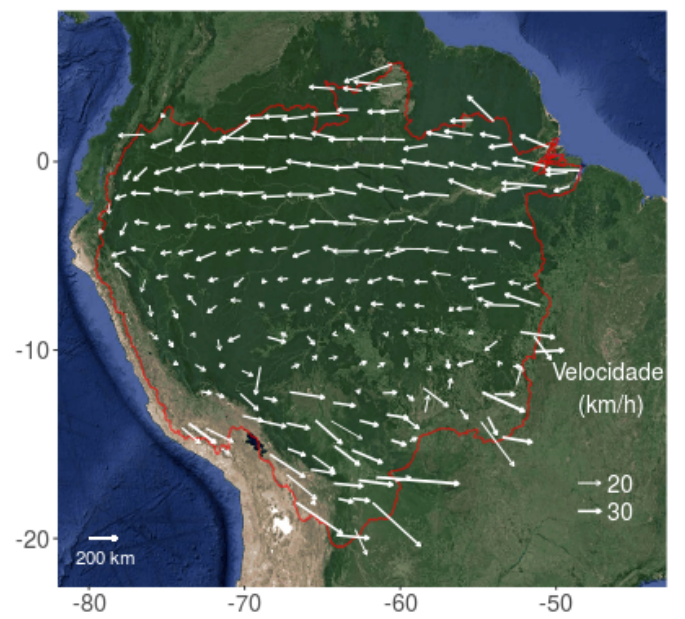

(h) Agosto

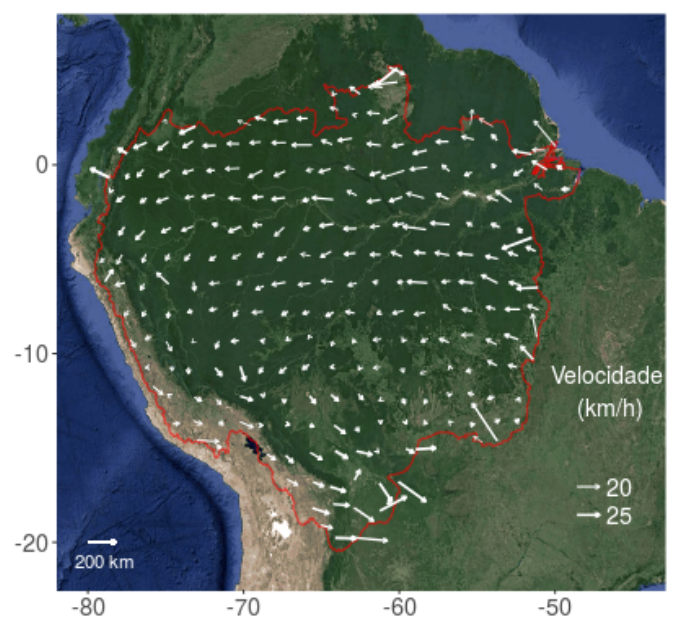

(j) Outubro

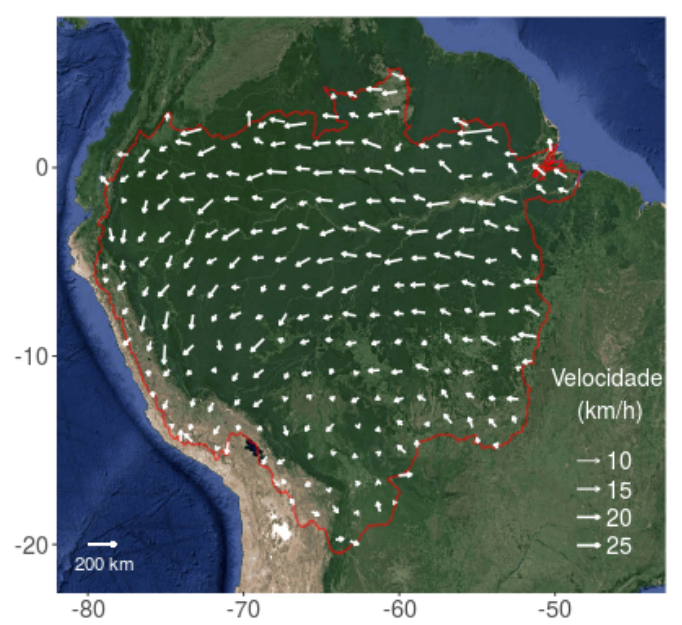

(I) Dezembro

Figura 13 - Continuação da figura da página anterior. 
Tabela 2 - Climatologia das áreas médias nas diferentes fases do ciclo de vida dos SCMs continentais e oceânicos de acordo com o tempo de duração.

\begin{tabular}{cccc}
\hline \multirow{2}{*}{ Fase } & Tempo de & \multicolumn{2}{c}{ Área média $\left(\mathbf{k m}^{\mathbf{2}}\right)$} \\
\cline { 3 - 4 } & vida & Continentais & Oceânicos \\
\hline \multirow{2}{*}{ Gênese } & Curto & 4542 & 3883 \\
& Longo & 6618 & 3916 \\
& Todos SCMs & 5580 & 3900 \\
\hline \multirow{2}{*}{ Maturação } & Curto & 15381 & 14834 \\
& Longo & 63354 & 90322 \\
& Todos SCMs & 39368 & 52578 \\
Dissipação & Curto & 6956 & 6518 \\
& Longo & 13639 & 12378 \\
& Todos SCMs & 10298 & 9448 \\
\hline \multirow{2}{*}{ Todo ciclo } & Curto & 9879 & 9053 \\
de vida & Longo & 36545 & 49976 \\
& Todos SCMs & 23212 & 29514 \\
\hline
\end{tabular}

A Tabela 2 mostra as áreas médias nas diferentes fases dos SCMs continentais e oceânicos de acordo com o tempo de vida. Os SCMs continentais com longo ciclo de vida possuem área inicial maior que os SCMs de curto ciclo de vida e na fase de maturação esta diferença aumenta para 4 vezes. A área inicial dos SCMs de longa duração é aproximadamente 3 vezes maior que o limiar de tamanho definido (2400 $\mathrm{km}^{2}$ ). Velasco e Fritsch (1987) identificaram uma alta frequência de pequenos sistemas convectivos tropicais em seu estudo, assim como Machado e Rossow (1993). Todavia, mesmo os sistemas com maiores durações possuem áreas médias muito pequenas comparadas com outras regiões. Sakamoto (2009) observou que a média da área máxima dos SCMs subtropicais continentais foi de $161600 \mathrm{~km}^{2}$. Dos SCMs estudados por Salio, Nicolini e Zipser (2007) e ocorridos entre $10^{\circ} \mathrm{S}$ e $23^{\circ} \mathrm{S}$, 35\% apresentaram área máxima acima de $150000 \mathrm{~km}^{2}$.

A área média final na fase final é maior que a área média na fase inicial, além de ser maior para sistemas de longa duração. Isto aponta para o fato de que os sistemas deixam de ser rastreados por não obedecer mais aos critérios de temperaturas de brilho estabelecidos e não necessariamente o critério de tamanho. Nesta fase, geralmente a presença de nuvens cirrus mais finas domina, indicando a dissipação dos SCMs. 


\subsubsection{SCMs oceânicos}

A média anual de ocorrências de SCMs com origem oceânica e que adentram a bacia Amazônica é 48,7 SCMs. Detalhes sobre a distribuição anual destes sistemas encontram-se na Tabela 6 no Apêndice B. A frequência relativa de ocorrência de SCMs oceânicos de longa duração é de 75\%. Deste valor, aproximadamente 10\% corresponde à durações iguais ou maiores a 24 horas (Figura 16). Logo, ao contrário dos SCMs continentais, os SCMs oceânicos possuem maiores tempos de vida. A duração média dos SCMs oceânicos é de 11,8 horas. O maior ciclo de vida encontrado foi de 69 horas e 30 minutos.

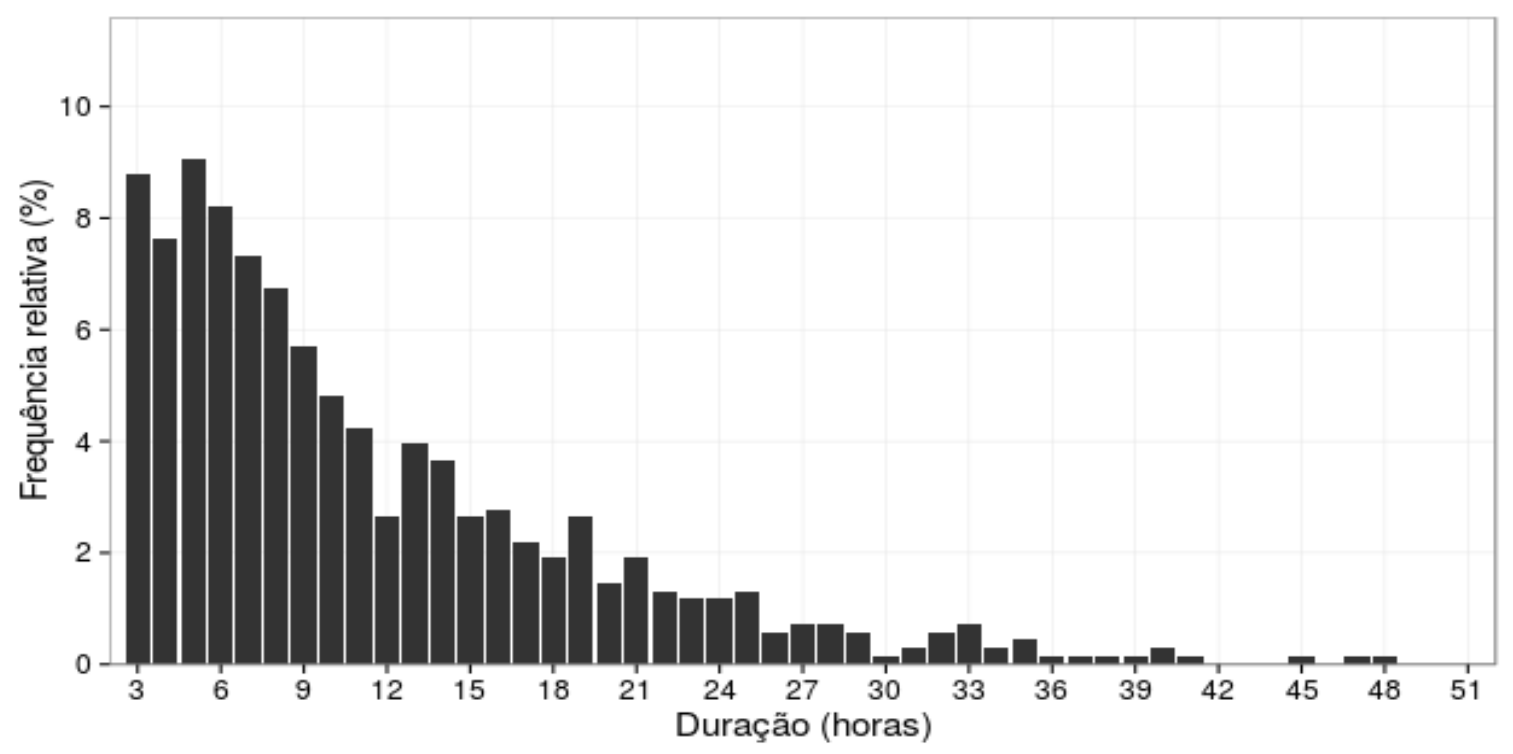

Figura 14 - Climatologia da frequência relativa (\%) dos SCMs oceânicos de acordo com seu ciclo de vida (horas). Período utilizado: 2000 a 2013. No total 682 SCMs foram considerados.

A distribuição mensal dos SCMs oceânicos mostra que a maior frequência de SCMs com curto ciclo de vida ocorre entre março e julho (Figura 15). Da mesma forma se apresentam os SCMs com longa duração, no entanto, sua frequência de gênese é máxima durante o outono, sendo que a maior ocorrência é observada em maio. Possivelmente estes SCMs possam se desenvolver e se estruturar em forma de linhas que adentram a bacia Amazônica e configuram-se em LIs, uma vez que coincide com a maior frequência de ocorrência deste tipo de SCM (COHEN; DIAS; NOBRE, 1989), porém mais investigações deveriam ser realizadas para verificar esta hipótese. 

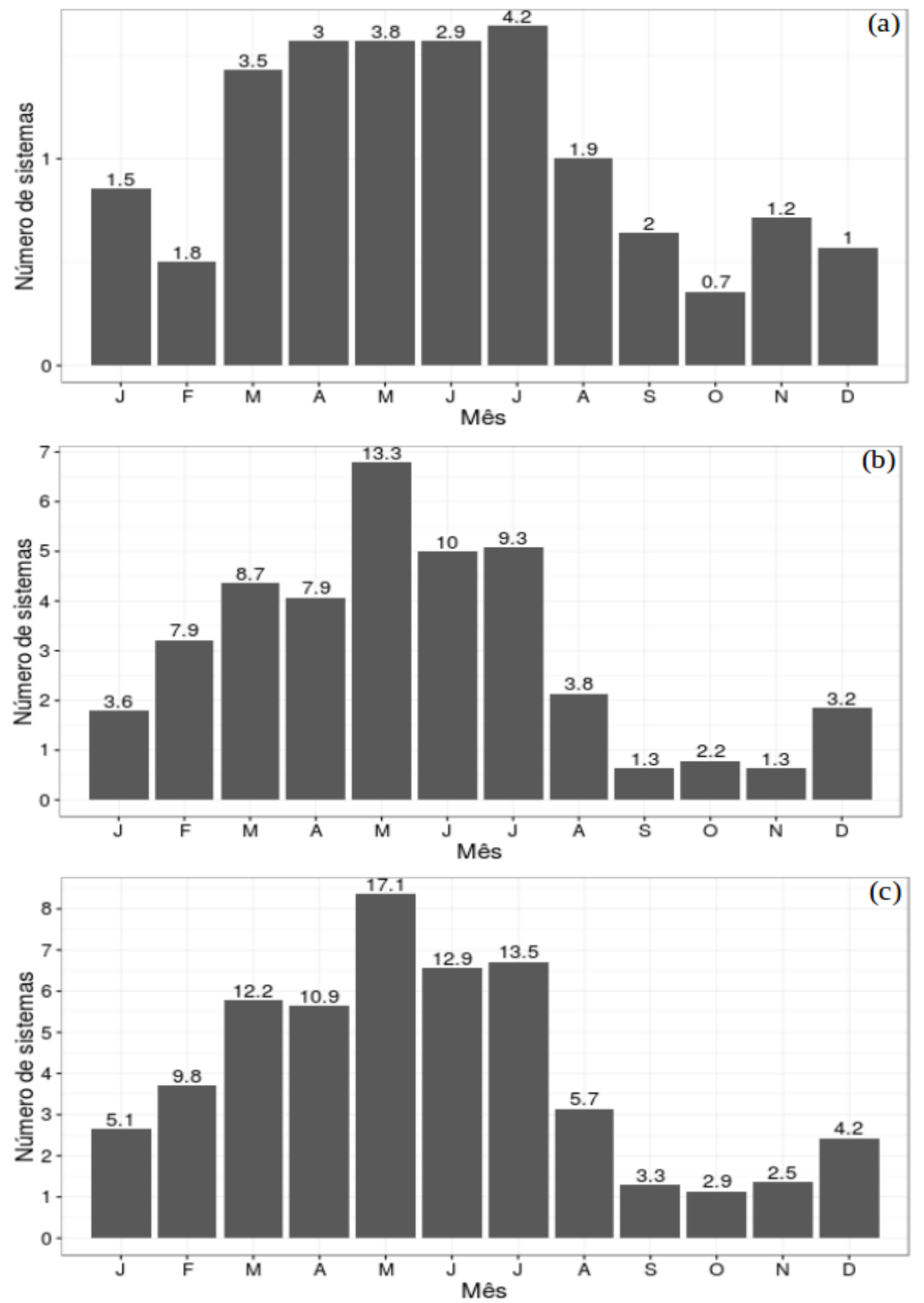

Figura 15 - Ocorrência média mensal dos SCMs oceânicos de acordo com tempo de duração. Em (a) SCMs com curto tempo de vida, (b) SCMs com longo ciclo de vida e (c) todos SCMs. Os números em cima das barras representam a frequência relativa (\%). Período utilizado: 2000 a 2013. No total 682 SCMs foram considerados. 
A hora preferencial de gênese dos SCMs oceânicos de curta duração inicia às 15 UTC e perdura até as 20 UTC, com um horário máximo às 18 UTC (Figura 16). Há um segundo período com maior atividade de gênese, entre 02 e 07 UTC, porém a frequência de ocorrência é bem menor. Os SCMs com longo tempo de vida possuem um período de maior frequência de ocorrência iniciando às 14 UTC, uma hora mais cedo que os SCMs de curta duração, e com término às 18 UTC, ou seja, duas horas mais cedo que os SCMs com curta duração. Após este período a atividade de gênese enfraquece e sofre um leve aumento a partir das 00 UTC. Às 05 UTC há um pico isolado de maior gênese.

Devido a maioria dos SCMs oceânicos terem gênese muito próxima ao continente suas características podem diferir daquelas apresentadas na literatura científica para outras regiões, onde os SCMs geralmente se formam e completam seu ciclo de vida em alto mar. No entanto, estes sistemas, apesar de terem ocorrido com uma frequência baixa (em média 4 sistemas por mês), eles possuem grandes áreas durante sua fase de maturação (Tabela 3 ) e grandes deslocamentos (Figura 19). Portanto, o impacto em termos de precipitação ou severidade destes SCMs pode ser importante para a região Amazônica.

A maturação dos SCMs oceânicos de curta duração ocorre em média após 3 horas de sua gênese e SCMs com longa duração possuem maturação após 5 horas passado sua gênese (Figura 17). Como sua gênese ocorre próxima ao continente, a maturação, na maioria dos casos, deve ocorrer sobre a região Amazônica, o que é um fator importante, uma vez que a fase de maturação pode também ser o momento de maior precipitação (MACHADO; LAURENT, 2004). A dissipação dos SCMs de curta duração é concentrada no período das 19 e 01 UTC e daqueles com longa duração entre 22 e 04 UTC.

A velocidade média de propagação dos $\mathrm{SCMs}$ oceânicos com curto tempo de vida é de $25,6 \mathrm{~km} / \mathrm{h}( \pm 7 \mathrm{~km} / \mathrm{h})$. Para os sistemas de longa duração a velocidade média é de $22,8 \mathrm{~km} / \mathrm{h}( \pm 6,3 \mathrm{~km} / \mathrm{h})$.

A maioria dos SCMs oceânicos possui gênese próxima à foz do rio Amazonas. Alguns casos de sistemas de longa duração apresentaram deslocamentos próximos à $1000 \mathrm{~km}$ e um caso isolado apresentou a distância de $1000 \mathrm{~km}$ entre a posição inicial e o continente. Apenas dois sistemas, durante os 14 anos analisados, tiveram gênese no oceano Pacífico. A Figura 19 mostra que os SCMs com curta duração não apresentam tendências nos deslocamentos ao longo do ano. A média de deslocamentos dos SCMs de curta duração é muito variável: $160 \mathrm{~km}( \pm 203 \mathrm{~km})$. O mês de outubro apresentou os menores valores (abaixo de $100 \mathrm{~km}$ ) e também foi o mês com menor número de ocorrências. Os SCMs de longa duração apresentam variabilidade sazonal nas distâncias percorridas, sendo que entre maio e julho elas são levemente maiores. A média anual de deslocamentos dos SCMs de longa duração é de $564 \mathrm{~km}( \pm 400 \mathrm{~km})$. 

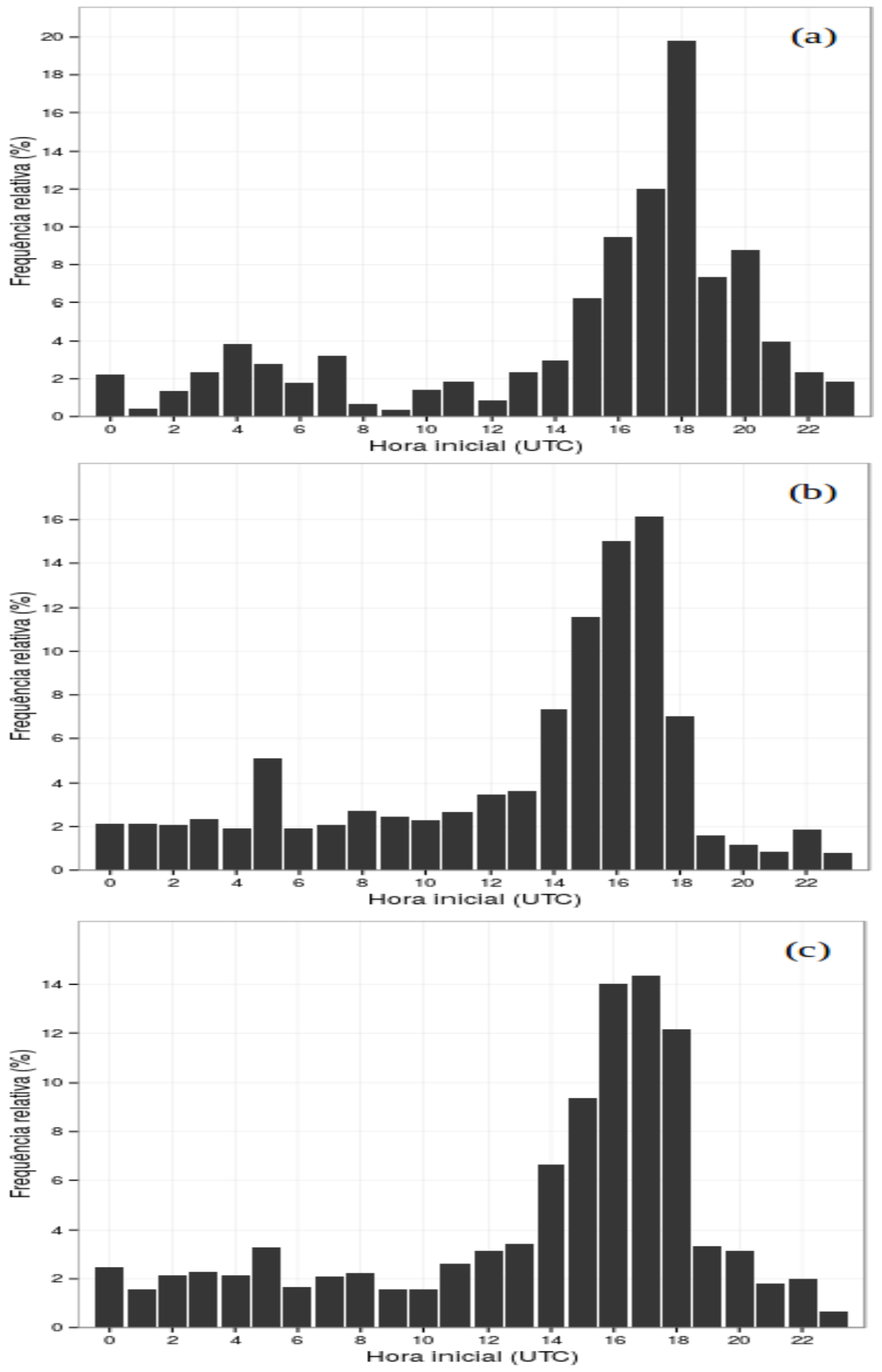

Figura 16 - Climatologia do horário de gênese dos SCMs oceânicos (a) com curto tempo de vida, (b) com longo ciclo de vida e (c) todos SCMs. Período utilizado: 2000 a 2013. No total 682 SCMs foram considerados. 

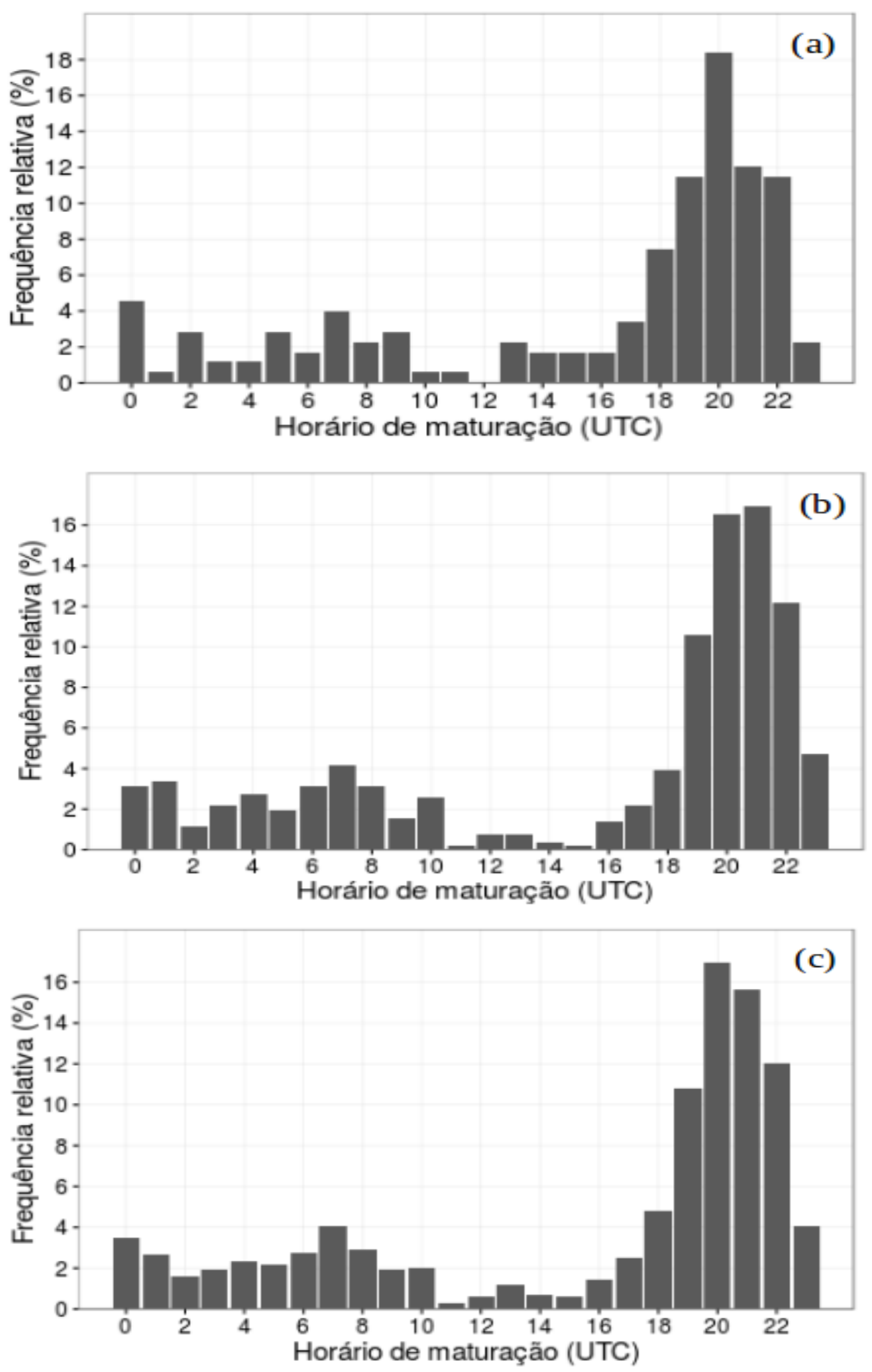

Figura 17 - Climatologia do horário de maturação dos SCMs oceânicos (a) com curto tempo de vida, (b) com longo ciclo de vida e (c) todos SCMs. Período utilizado: 2000 a 2013. No total 682 SCMs foram considerados. 

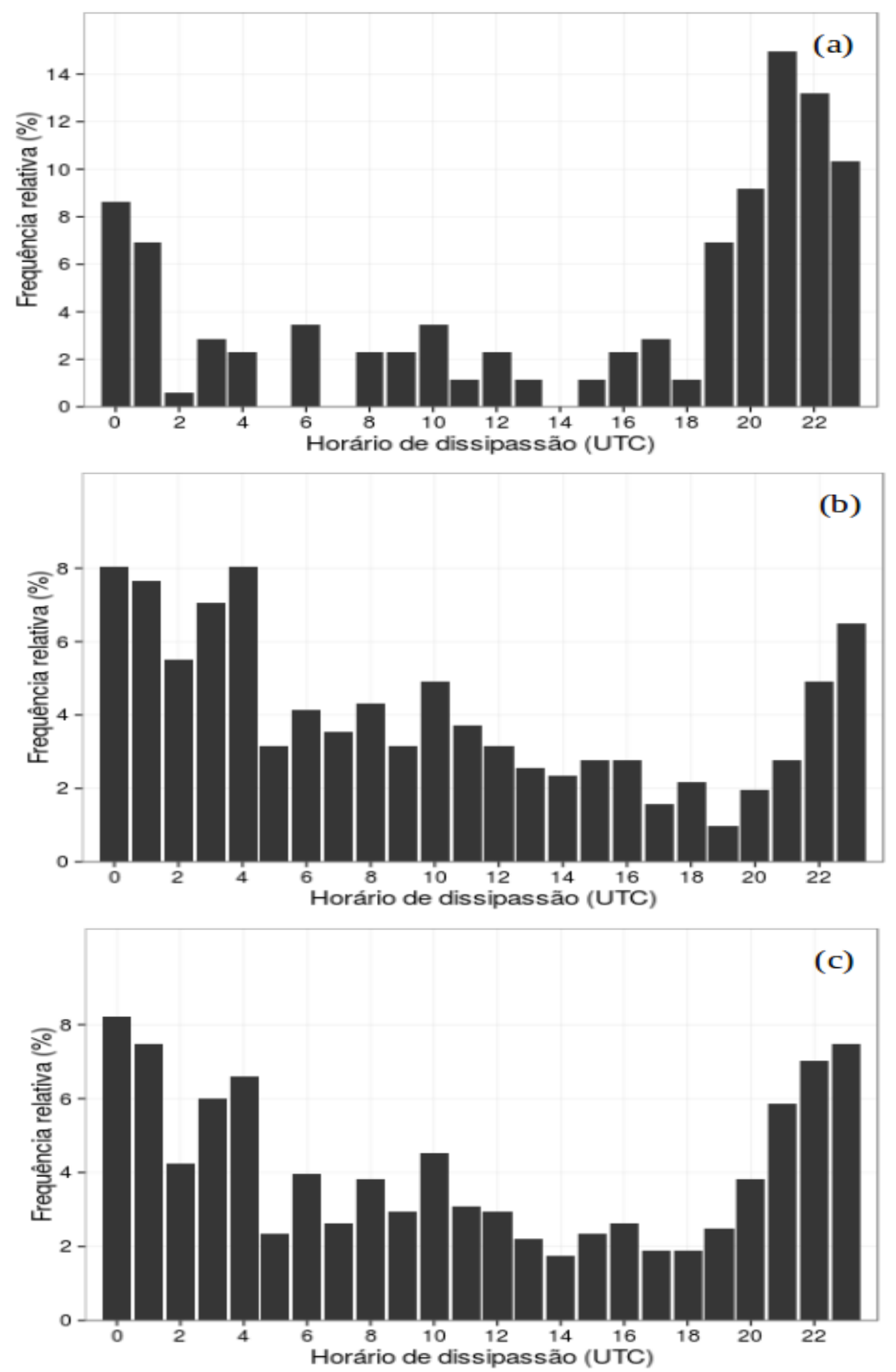

Figura 18 - Climatologia do horário de dissipação dos SCMs oceânicos (a) com curto tempo de vida, (b) com longo ciclo de vida e (c) todos SCMs. Período utilizado: 2000 a 2013. No total 682 SCMs foram considerados. 
Os SCMs oceânicos com longa duração têm área média inicial levemente maior que os de curta duração (Tabela 2), porém ambas são menores comparadas às continentais. Na maturação ocorre o inverso para os SCMs de longa duração.
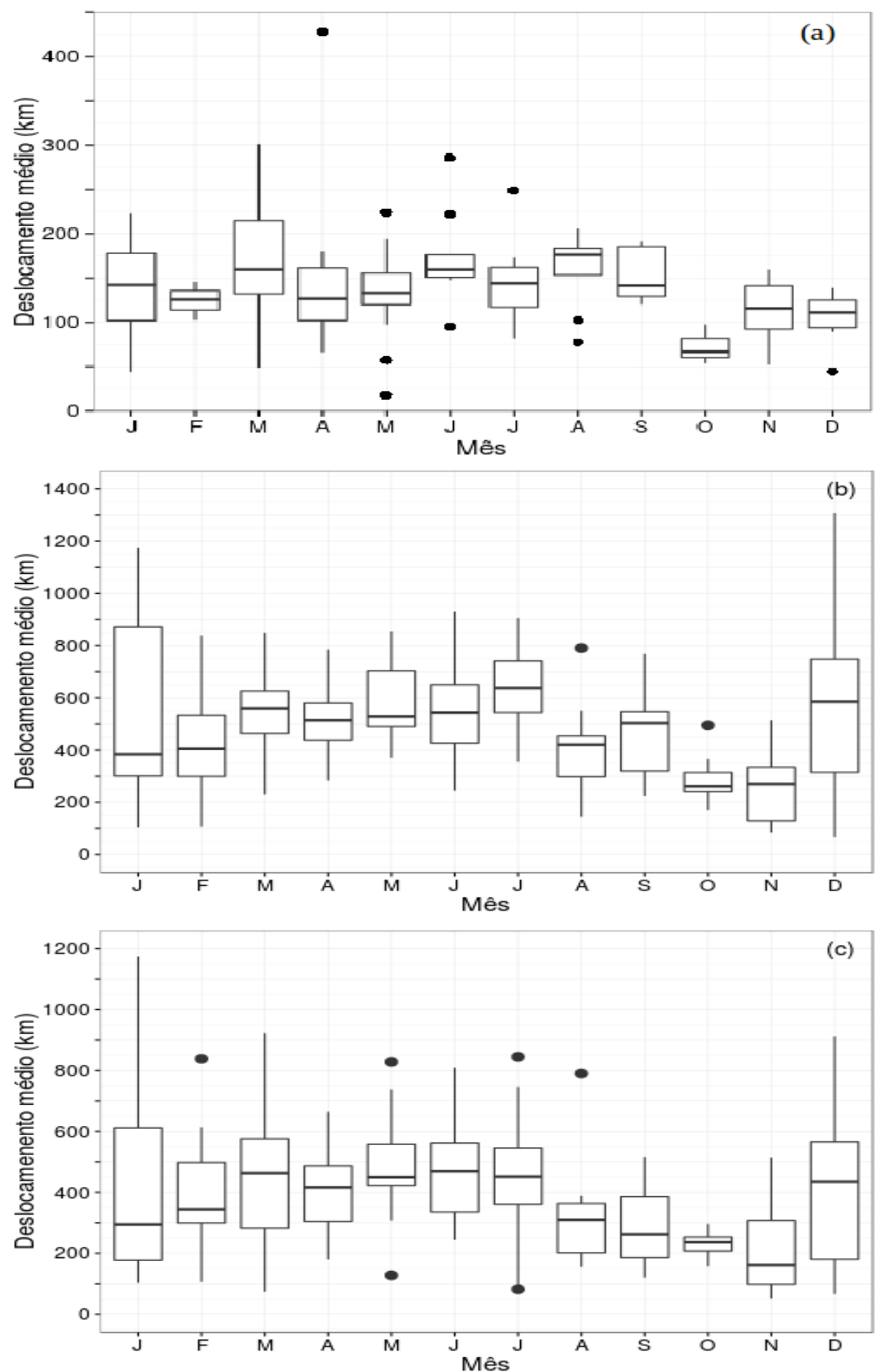

Figura 19 - Deslocamentos mensais dos SCMs oceânicos (a) com curto tempo de vida, (b) com longo ciclo de vida e (c) todos SCMs. Período utilizado: 2000 a 2013. No total 682 SCMs foram considerados. 


\subsection{SCMs ocorridos durante o projeto GOAmazon}

\subsubsection{SCMs continentais e suas características}

Foram encontrados 6137 SCMs continentais durante o período analisado, sendo que 3974 SCMs (56,3\% da média climatológica) ocorreram em 2014 e os 2163 SCMs restantes ocorreram entre janeiro e junho de 2015, representando apenas $58 \%$ do esperado para a mesma época do ano. Os sistemas com curto ciclo de vida ocorridos em 2014 representam 81,5\% do total e em 2015 representam 83,5\%. Desta forma, além de representarem um déficit de ocorrências comparado à climatologia, os SCMs ocorridos em 2014 e 2015 possuíram, em sua maioria, curta duração.

A distribuição dos SCMs de acordo com o tempo de duração encontra-se na Figura 20. Os tempos de vida médios dos SCMs, tanto em 2014 quanto em 2015, foram de 4 horas e 30 minutos. Os maiores tempos de vida registrados foram de 18 horas em 2014 e 20 horas em 2015.

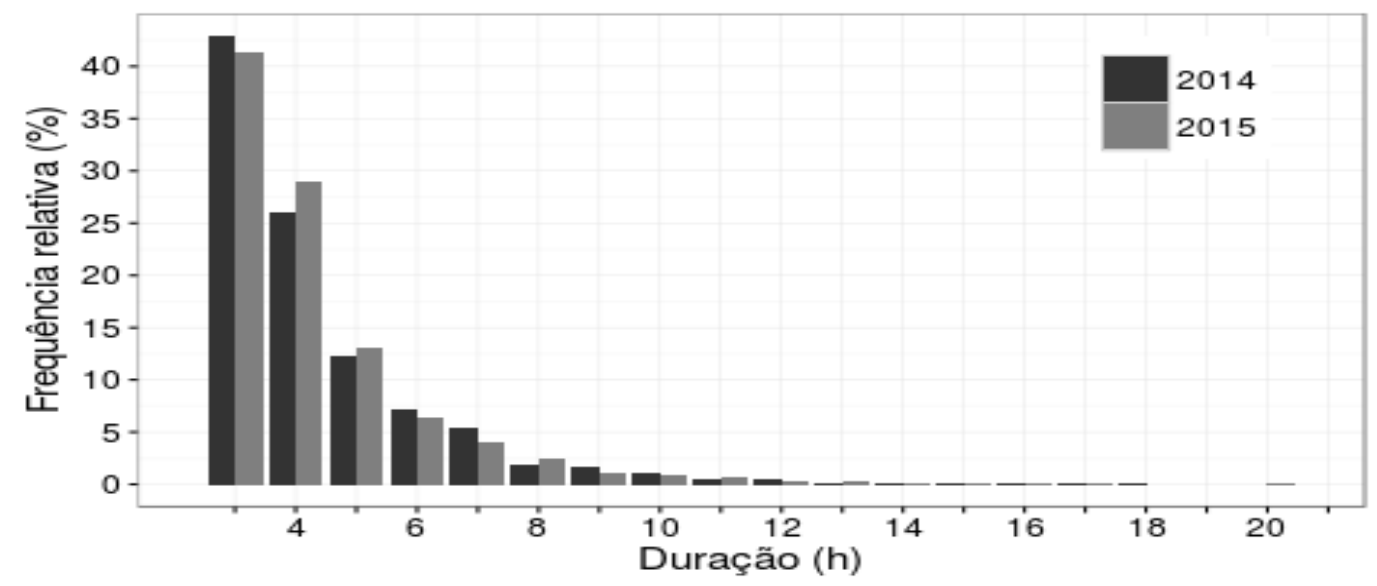

Figura 20 - Frequência relativa (\%) de SCMs continentais de acordo com o ciclo de vida (h) ocorridos durante o projeto GOAmazon.

A Figura 21 mostra a distribuição mensal dos SCMs de acordo com o tempo de vida. Ela evidencia que o padrão observado na climatologia com maior frequência de ocorrência de SCMs durante os meses mais quentes do ano, se repetiu e, portanto, as anomalias negativas na frequência de ocorrência de SCMs ocorreram distribuidamente ao longo de 2014 e no primeiro semestre de 2015.

Durante os verões de 2013/2014 e 2014/2015 padrões anômalos na circulação atmosférica enfraqueceram a Zona de Convergência do Atlântico Sul (ZCAS) e contribuíram para a ocorrência de estiagens no sudeste do Brasil e precipitações acima da média no sudeste da América do Sul (COELHO et al., 2015; SETH; FERNANDES; CAMARGO, 2015). Os trabalhos de Coelho et al. (2015) e Seth, Fernandes e Camargo (2015) mostraram duas anomalias anticiclônicas em baixos níveis próximas a América do Sul, uma posicionada sobre o oceano Pacífico e outra sobre o Atlântico. A circulação 
anticiclônica sobre o oceano Atlântico e na região das ZCAS reforçou a entrada de ventos de leste sobre o continente pelo norte da região norte do país e região nordeste. Esta circulação desviada pelos Andes em direção ao sul da América do Sul, resultou em ventos mais intensos na região do Jato de Baixos Níveis (SETH; FERNANDES; CAMARGO, 2015), o qual, por sua vez, trasporta umidade para o sudeste da América do Sul. Nestas ocasiões, Salio, Nicolini e Zipser (2007) verificaram menor ocorrência de SCMs na região tropical. Contudo, isto justificaria somente a menor ocorrência durante os verões, porém como foi visto anteriormente na Figura 21 as anomalias ocorreram distribuidamente ao longo de 2014 e 2015.

Outros mecanismos atuam na supressão da convecção amazônica e podem ter influenciado a menor ocorrência de SCMs, complementando ou mesmo intensificando o já descrito acima, como a fase positiva do El Niño-Oscilação Sul (ROPELEWSKI; HALPERT, 1987; MARENGO; HASTENRATH, 1993; GRIMM, 2003). Durante a maior parte do projeto GOAmazon ocorreram anomalias na temperatura da superfície do mar (TSM) no oceano Pacífico Equatorial Leste. Em 2014, acompanhados de anomalias positivas na TSM do Pacífico Equatorial, os ventos alísios, os quais são os maiores responsáveis pelo transporte de umidade para a região Amazônica (SATYAMURTY; COSTA; MANZI, 2012), encontraram-se desintensificados em boa parte dos meses. $O$ jato de baixos níveis em direção ao sul da América do Sul encontrou-se intensificado na maioria dos meses e anomalias negativas de precipitação são observadas sobre diferentes regiões da bacia Amazônica ao longo do ano (GREC/IAG-USP, 2014). Em 2015 houve a configuração do El Niño, que intensificou os padrões ocorridos em 2014.

Apesar disso, entre novembro de 2013 e março de 2014 a precipitação no sul da bacia Amazônica esteve acima da média climatológica, causando inundações e transtornos para as populações da Bolívia, sul da Amazônia Peruana, Acre e Rondônia (ESPINOZA et al., 2014; MARENGO et al., 2015). Embora estes maiores acumulados de precipitação terem ocorridos no sul da bacia Amazônica no início de 2014, a densidade de gênese não mostra grandes anomalias positivas naquela região (Figuras $25,26$ e 27$)$. 

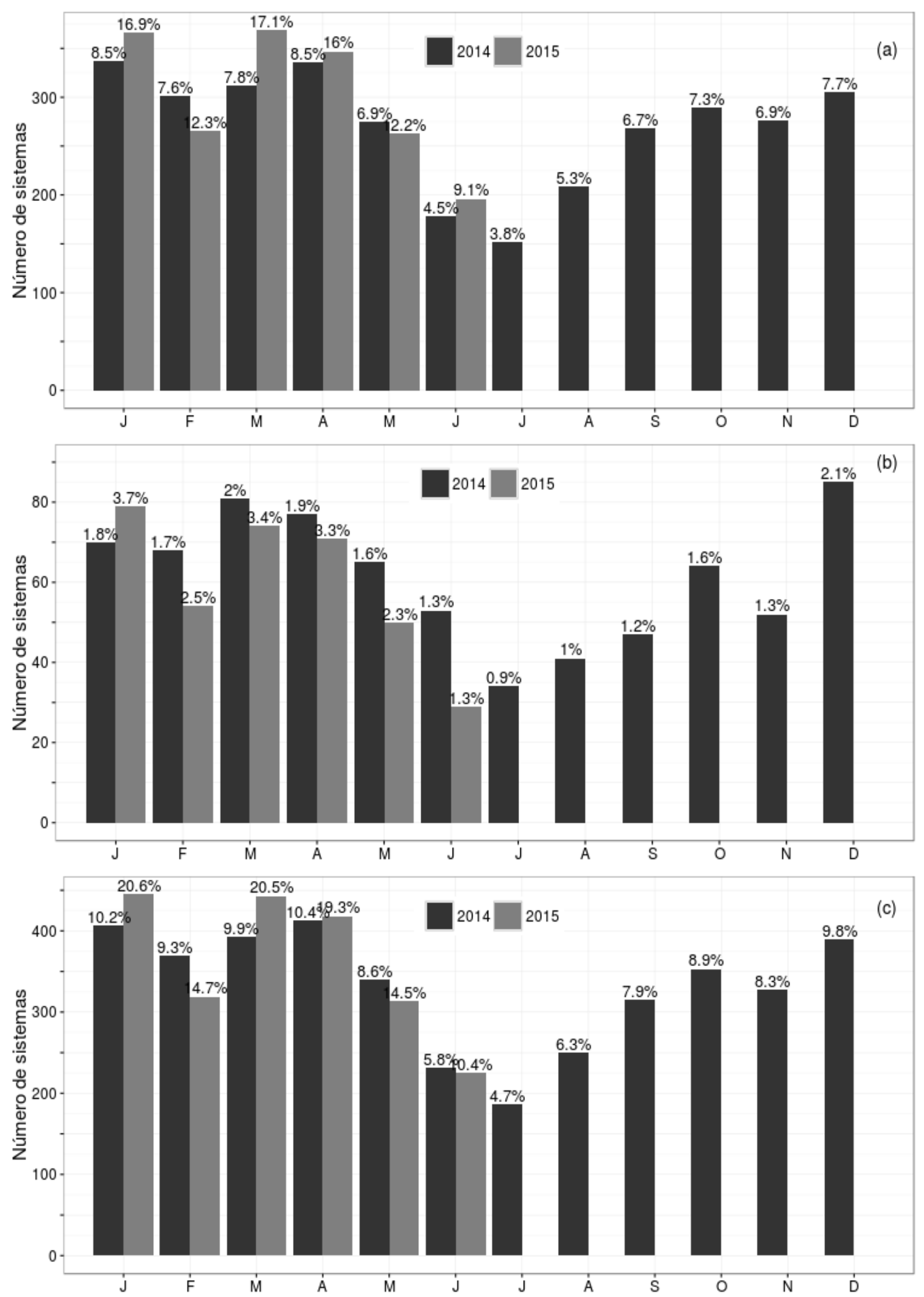

Figura 21 - Ocorrência mensal dos SCMs continentais ocorridos na bacia Amazônica em 2014 e primeiro semestre de 2015 de acordo com o tempo de vida. Em (a) SCMs de curta duração (b) SCMs de longa duração e (c) todos SCMs. Os valores sobre as barras são as frequências relativas (\%) calculadas com base em 3974 SCMs que ocorreram durante 2014 e 2163 SCMs ocorridos entre 01/01 - 30/06/2015. 
O horário de gênese dos SCMs de curta duração ocorreu preferencialmente entre as 17 UTC e 20 UTC tanto em 2014 quanto em 2015 (Figura 22), seguindo o padrão observado na climatologia. $O$ pico de maior frequência de gênese observado à 01 UTC na climatologia ocorreu às 00 UTC em 2014 e 2015. O período preferencial de gênese dos SCMs com longa duração ocorridos em 2014 iniciou às 16 UTC, como previsto pela climatologia, porém aqueles ocorridos durante 2015 tiveram período preferencial de gênese uma hora mais tarde e em ambos os anos este período teve menor duração comparado a climatologia. Um segundo pico de maior frequência ocorreu entre 02 e 05 UTC em 2014 e entre 00 UTC e 03 UTC no ano de 2015. O terceiro período de maior gênese, entre 06 e 07 UTC, observado na climatologia não ocorreu durante 2014 e 2015. No entanto, houve uma diminuição gradativa da gênese dos SCMs até as 13 UTC, horário de menor frequência de ocorrência de novos sistemas.

A Figura 23 mostra os horários da fase de maturação de acordo com o tempo de vida dos SCMs. Aqueles com curto ciclo de vida levaram em média 2 a 3 horas para atingir a fase de maturação e os de longa duração 3 a 4 horas. Em geral, os comportamentos dos SCMs ocorridos durante o período do GOAmazon foram similares a climatologia. As poucas diferenças observadas podem estar relacionadas à menor ocorrência de SCMs durante o GOAmazon em comparação com a média climatológica.

A Figura 24 mostra que a transição entre o período de mínima dissipação e máxima dissipação foi bastante abrupta para os SCMS com curta duração comparado com a climatologia. O término deste período com maior ocorrência foi mais suave. $\mathrm{A}$ dissipação dos sistemas de longa duração apresentaram comportamento muito similar à climatologia, com maior frequência entre as 00 e 04 UTC. 

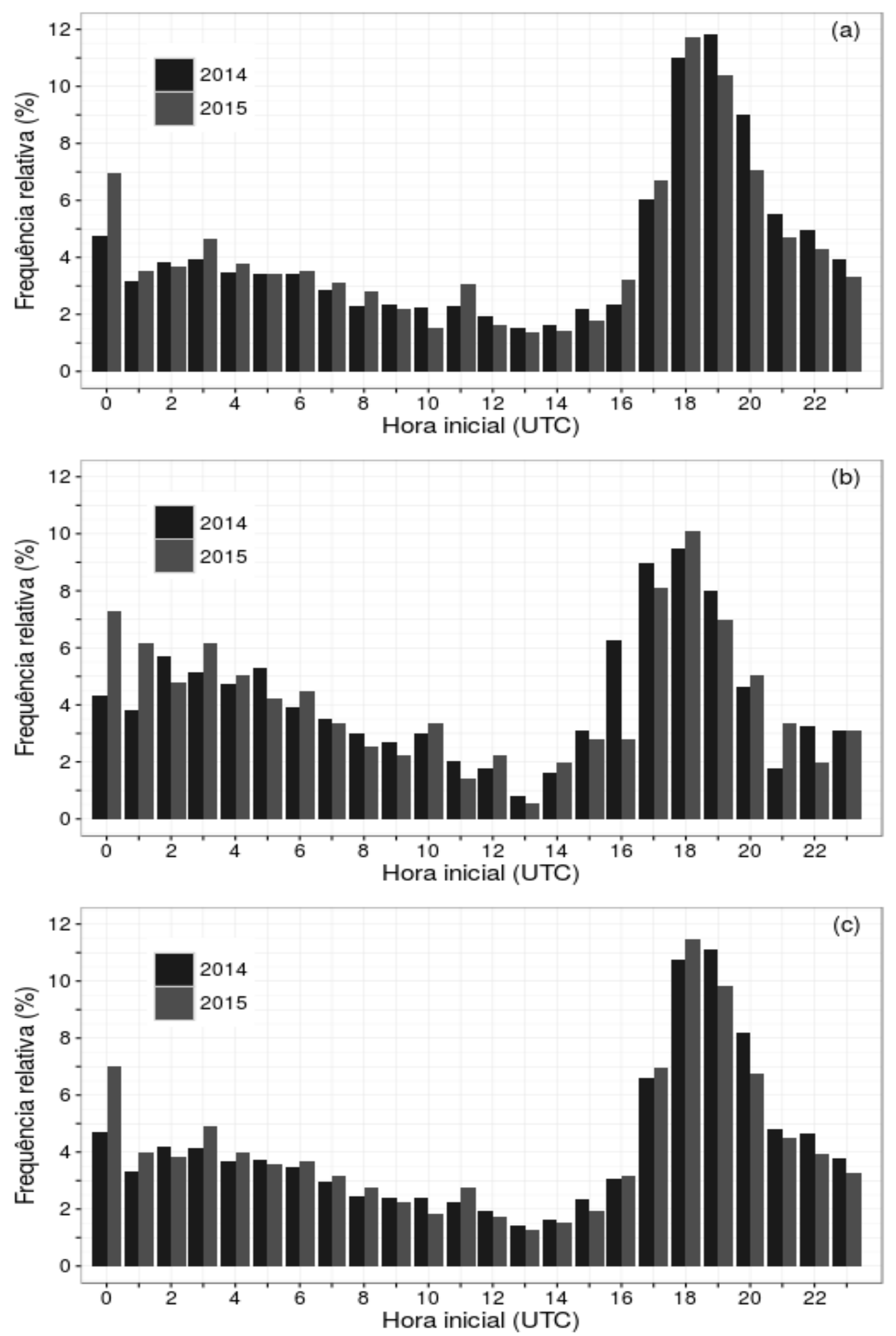

Figura 22 - Horário de gênese (UTC) dos SCMs com duração (a) SCMs com curto tempo de vida, (b) SCMs com longo ciclo de vida e (c) todos SCMs. Cada horário representa o intervalo da hora cheia mais meia hora. A frequência relativa (\%) foi calculada com base em 3974 SCMs que ocorreram durante 2014 e 2163 SCMs ocorridos entre 01/01 - 30/06/2015. 

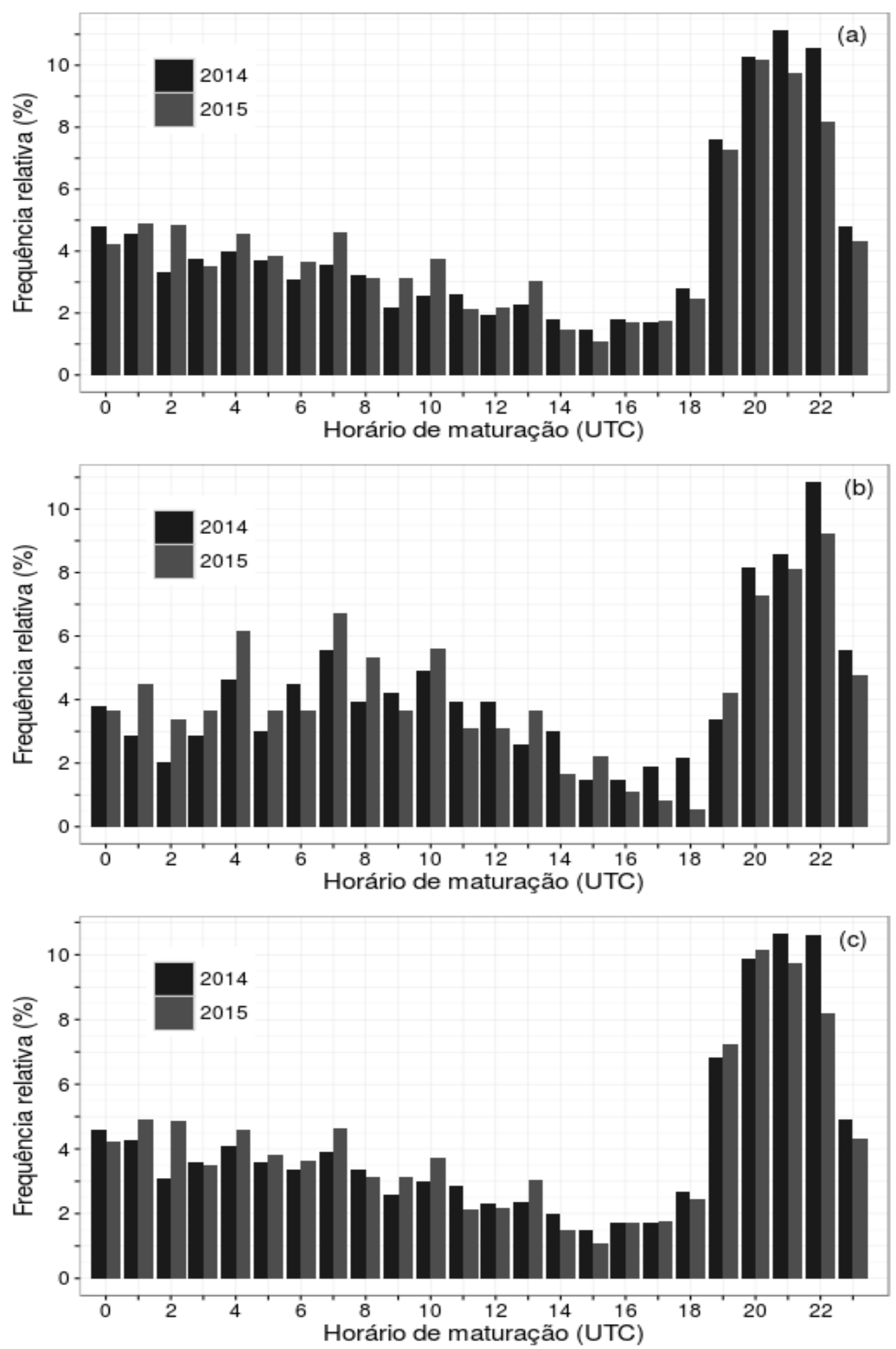

Figura 23 - Horário de maturação (UTC) dos SCMs com ciclo de vida (a) SCMs com curto tempo de vida, (b) SCMs com longo ciclo de vida e (c) todos SCMs. Cada horário representa o intervalo da hora cheia mais meia hora. A frequência relativa (\%) foi calculada com base em 3974 SCMs que ocorreram durante 2014 e 2163 SCMs ocorridos entre 01/01 - 30/06/2015. 

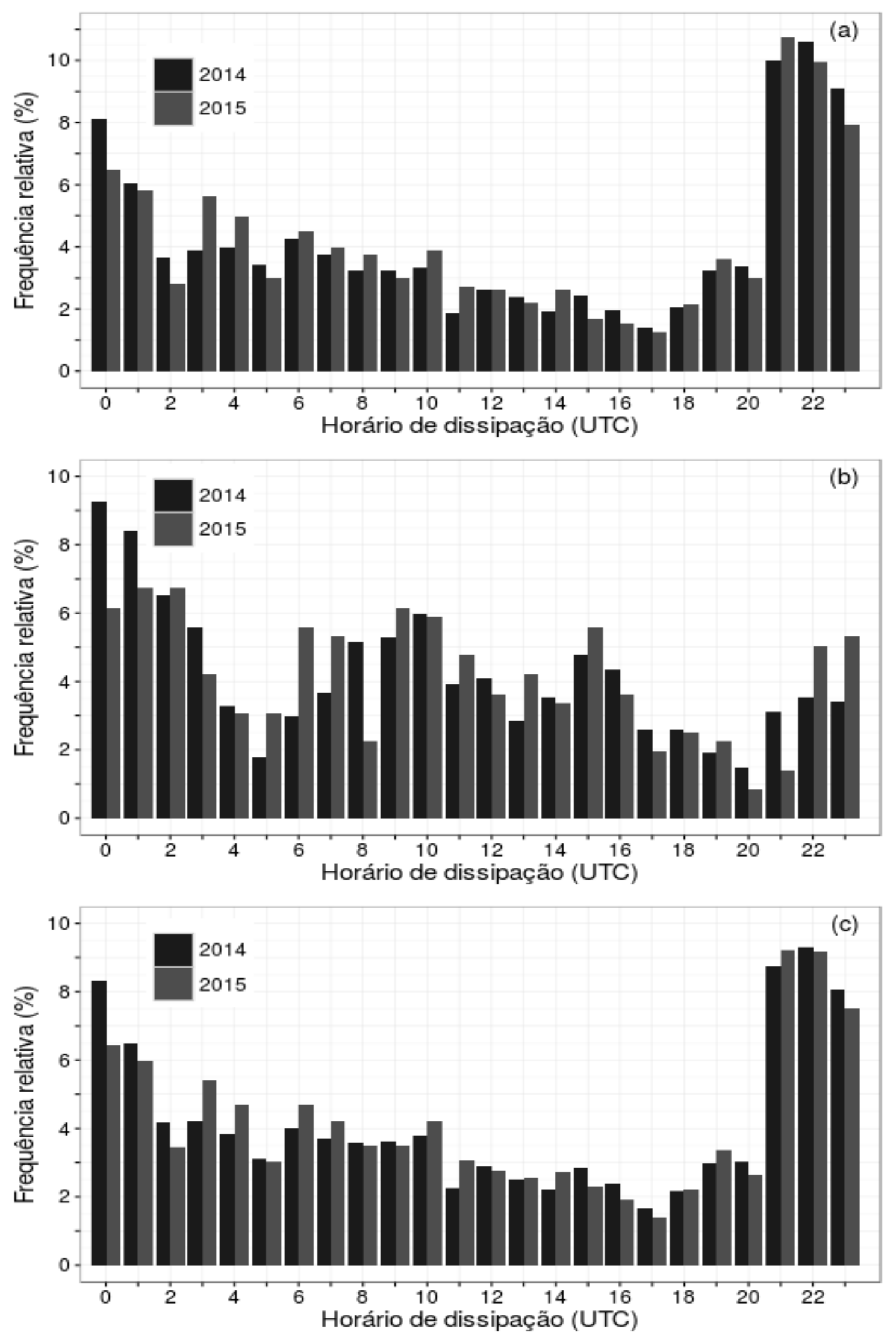

Figura 24 - Horário de dissipação (UTC) dos SCMs com ciclo de vida (a) SCMs com curto tempo de vida, (b) SCMs com longo ciclo de vida e (c) todos SCMs. Cada horário representa o intervalo da hora cheia mais meia hora. A frequência relativa (\%) foi calculada com base em 3974 SCMs que ocorreram durante $2014 \mathrm{e}$ 2163 SCMs ocorridos entre 01/01 - 30/06/2015. 
As anomalias de densidade em 2014 e 2015 não apresentaram região preferencial de ocorrência sobre a bacia Amazônica, como mostram as Figuras 25, 26, 27, 28, 29 e 30 . Anomalias negativas predominaram em todos os meses e ao longo de toda a bacia Amazônica. Anomalias positivas de densidade ocorreram em regiões pontuais ao longo da bacia e variando a posição conforme o mês.

Os SCMs com curto ciclo de vida exibem maior quantidade destas regiões pontuais de anomalias positivas comparadas aos SCMs de longo ciclo de vida. Como foi visto no início desta seção, a ocorrência de SCMs com curto ciclo de vida foi mais persistente em 2014 e 2015 sobre a bacia Amazônica que de SCMs com longa duração e ocorreu distribuidamente ao longo do tempo. Esta distribuição ao longo do tempo, ou seja, em todos os meses, observada na Figura 3 também é verificada nas Figuras de anomalia de densidade. Este fato reforça as hipóteses de que a menor ocorrência de SCMs durante o projeto GOAmazon comparado à climatologia, ocorreu devido aos fenômentos de larga escala explicados anteriormente. Este reforço se deve ao fato de que o impacto da circulação de maior escala, atuando no sentido de minimizar a convecção na Amazônia, abrange uma grande área e costumam ser persistentes.

As anomalias de densidade de maturação e dissipação, em geral, ocorreram próximas ao local da respectiva anomalia de gênese. 

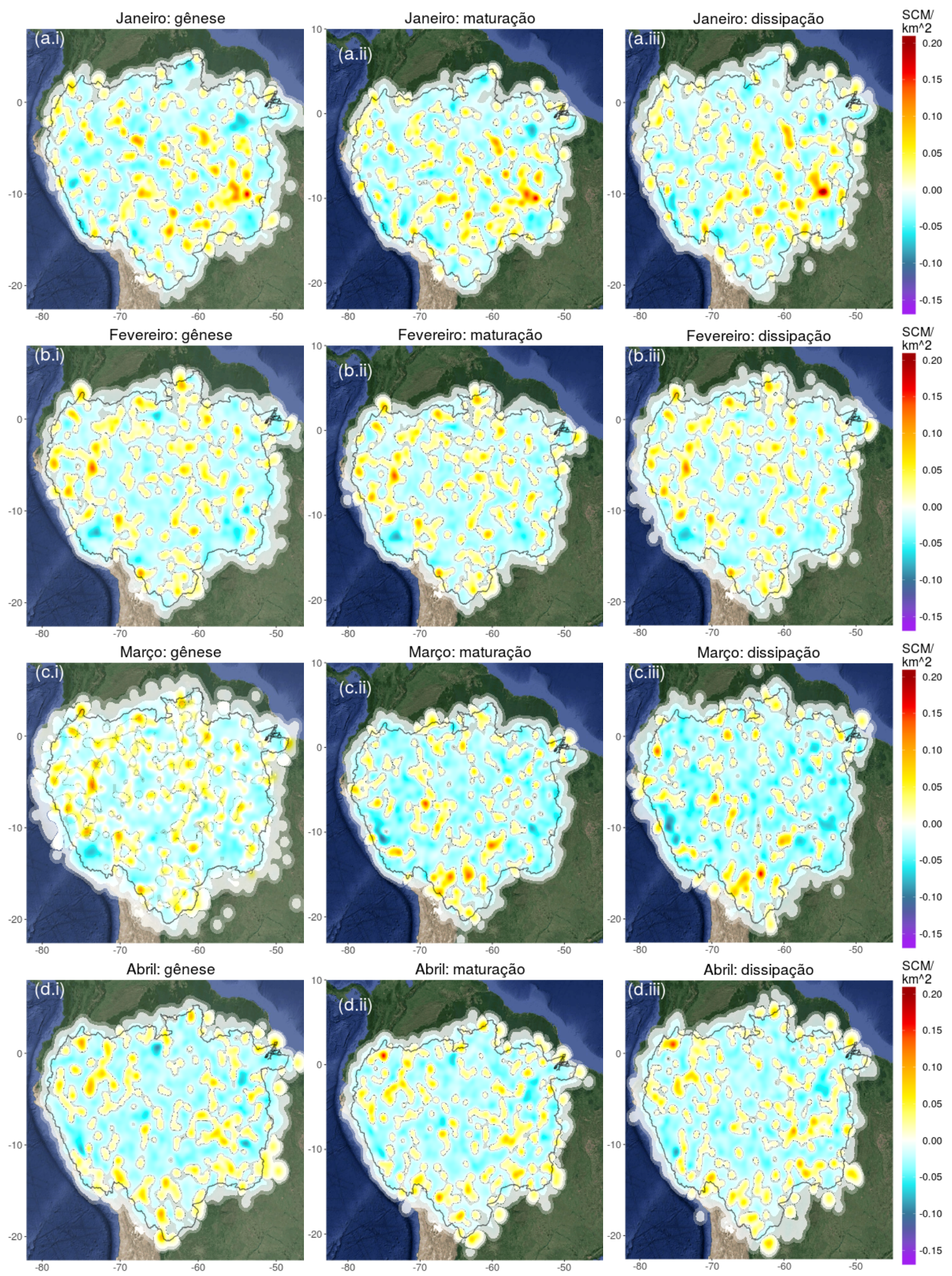

Figura 25 - Anomalias da densidade de gênese, maturação e dissipação dos SCMs com curto ciclo de vida ocorridos em 2014 sobre a bacia Amazônica. Em (a.i), (a.ii) e (a.iii) janeiro; (b.i), (b.ii), (b.iii) fevereiro; (c.i), (c.ii),(c.iii) março; (d.i), (d.ii), (d.iii) abril; (e.i), (e.ii), (e.iii) maio; (f.i), (f.ii), (f.iii) junho; (g.i), (g.ii), (g.iii) juIho; (h.i), (h.ii), (h.iii) agosto; (i.i), (i.ii), (i.iii) setembro; (j.i), (j.ii), (j.iii) outubro; (k.i), (k.ii), (k.iii) novembro e (I.i), (l.ii), (l.iii) dezembro. 

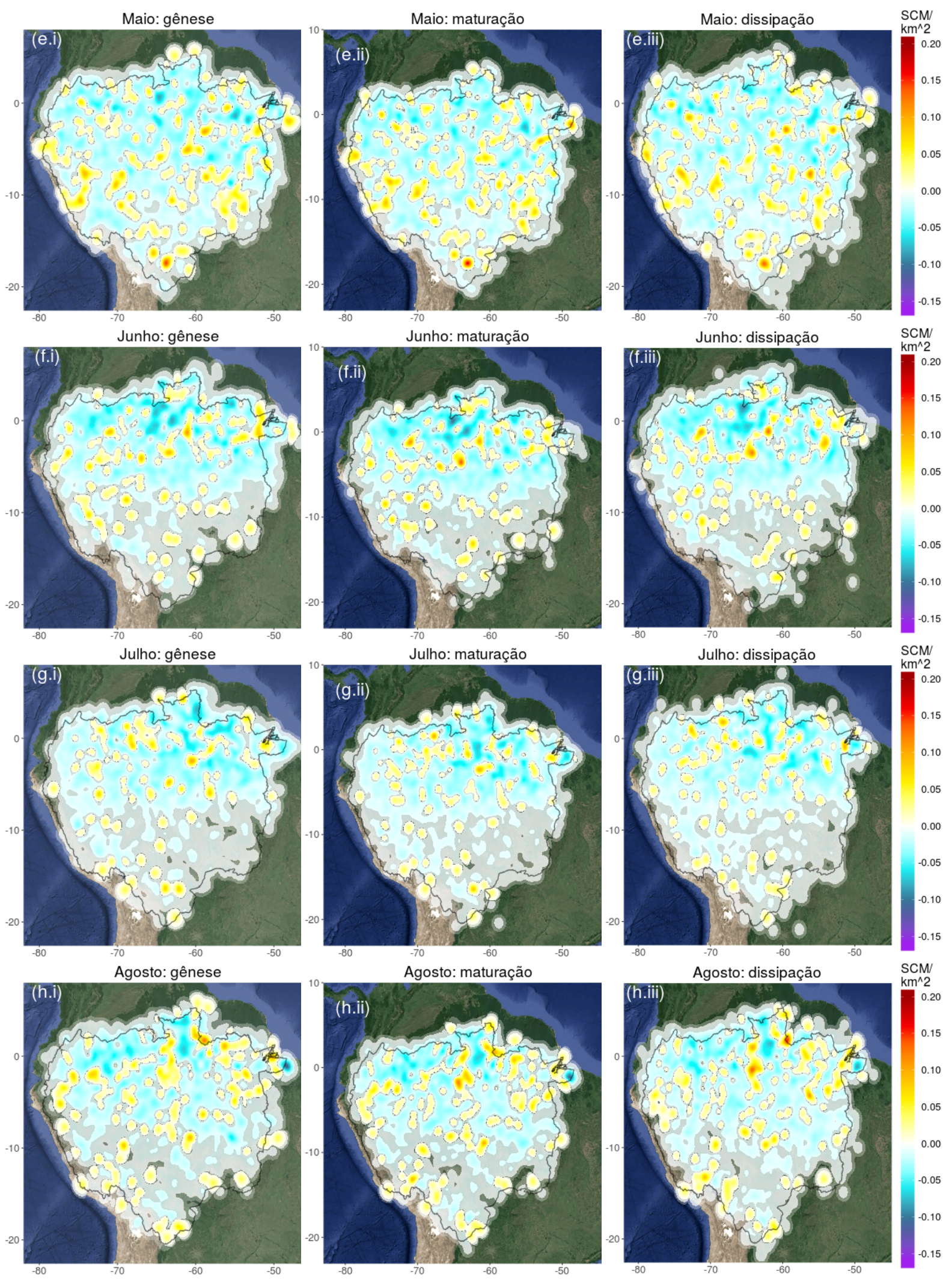

Figura 25 - Continuação da figura da página anterior. 

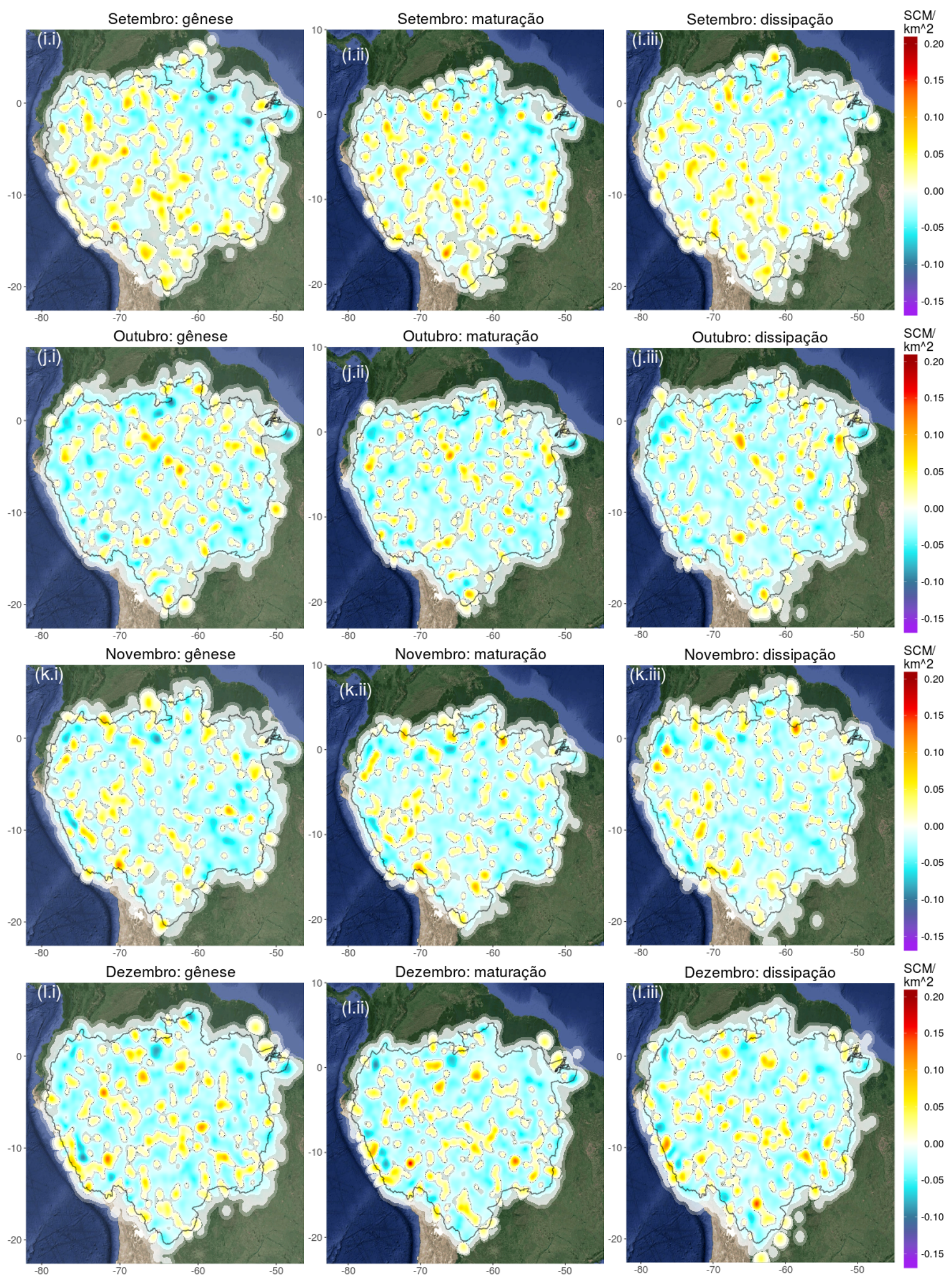

Figura 25 - Continuação da figura da página anterior. 

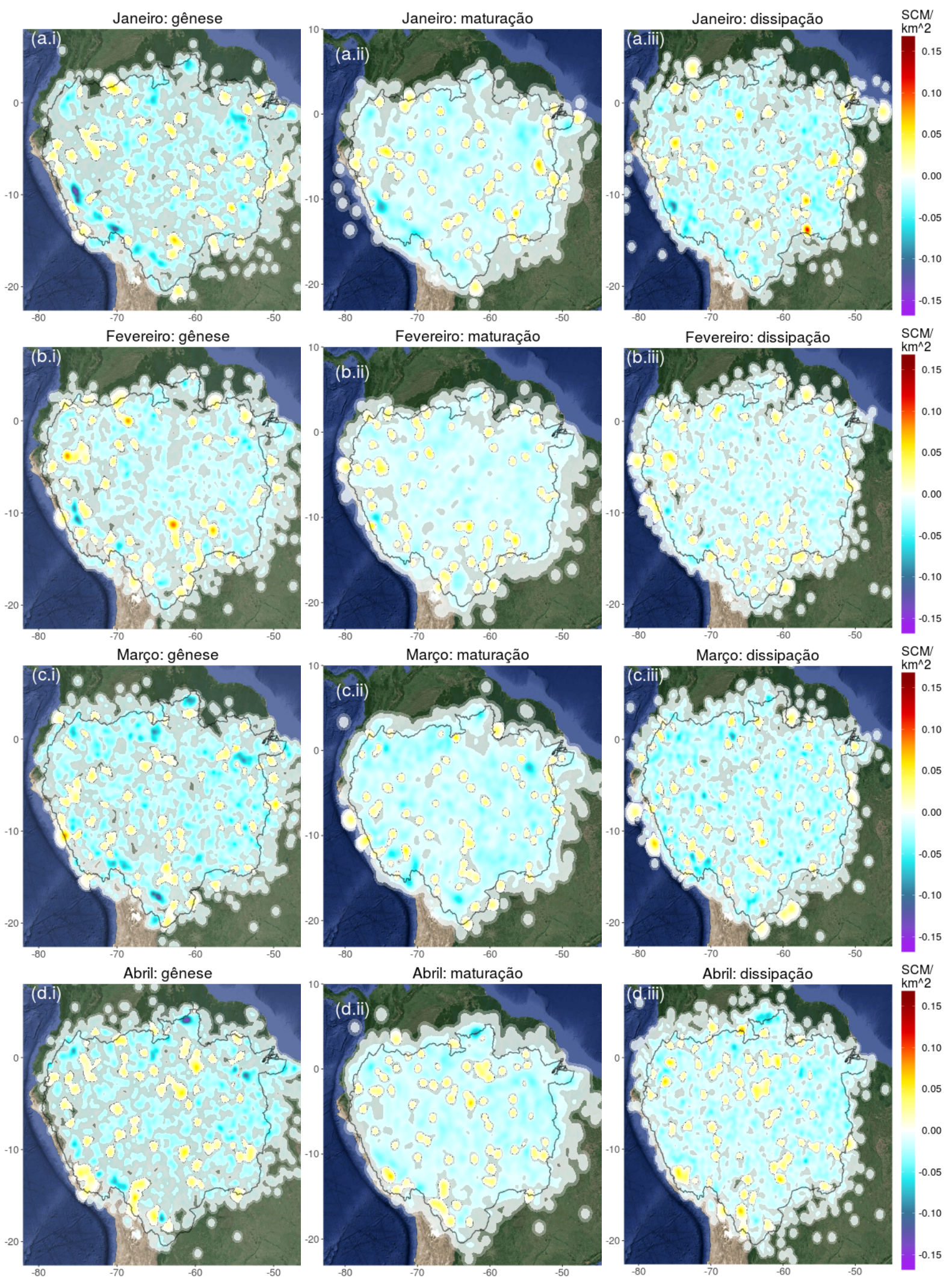

Figura 26 - Anomalias da densidade de gênese, maturação e dissipação dos SCMs com longo ciclo de vida ocorridos em 2014 sobre a bacia Amazônica. Em (a.i), (a.ii) e (a.iii) janeiro; (b.i), (b.ii), (b.iii) fevereiro; (c.i), (c.ii),(c.iii) março; (d.i), (d.ii), (d.iii) abril; (e.i), (e.ii), (e.iii) maio; (f.i), (f.ii), (f.iii) junho; (g.i), (g.ii), (g.iii) juIho; (h.i), (h.ii), (h.iii) agosto; (i.i), (i.ii), (i.iii) setembro; (j.i), (j.ii), (j.iii) outubro; (k.i), (k.ii), (k.iii) novembro e (I.i), (I.ii), (I.iii) dezembro. 

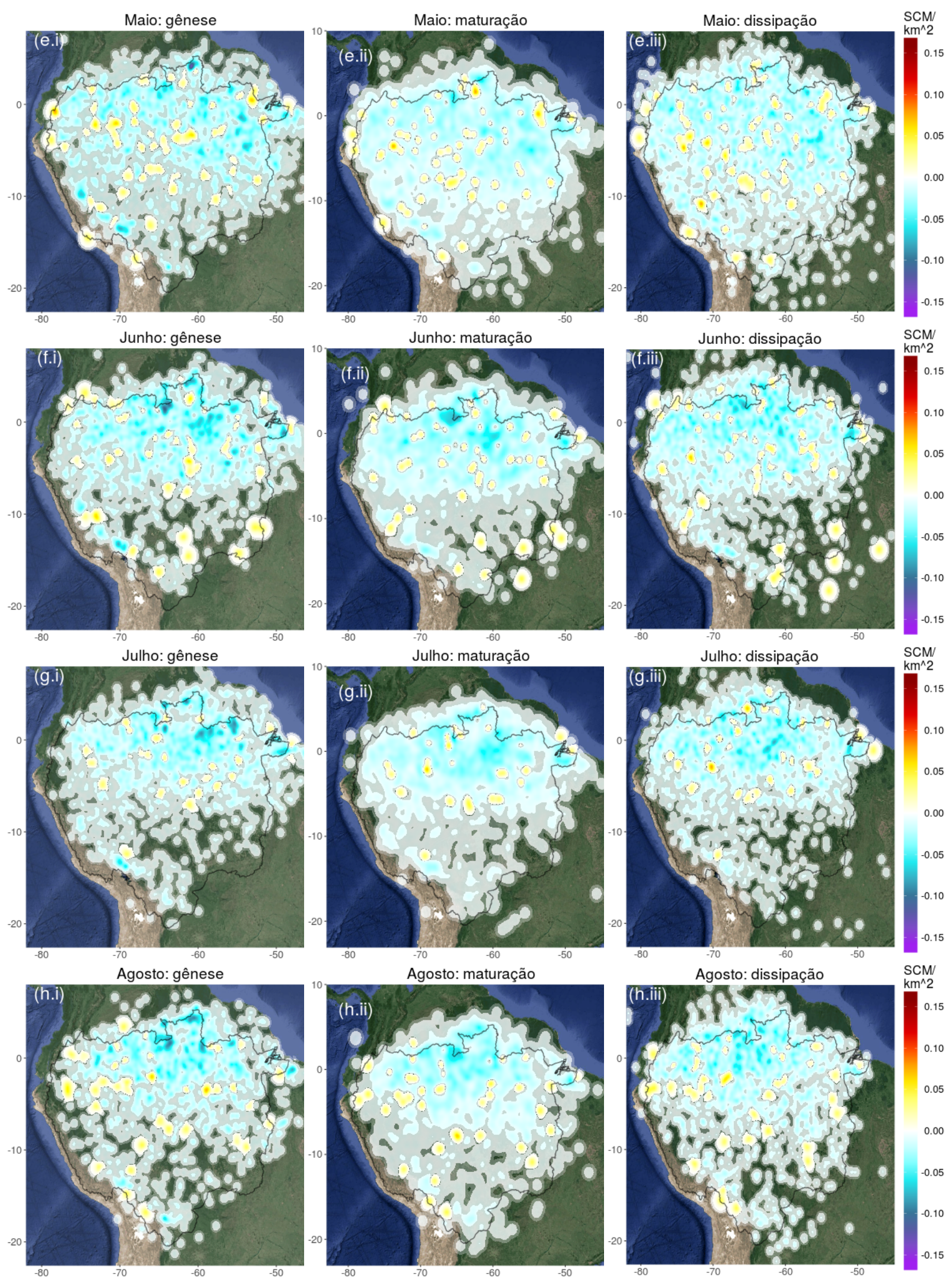

Figura 26 - Continuação da figura da página anterior. 

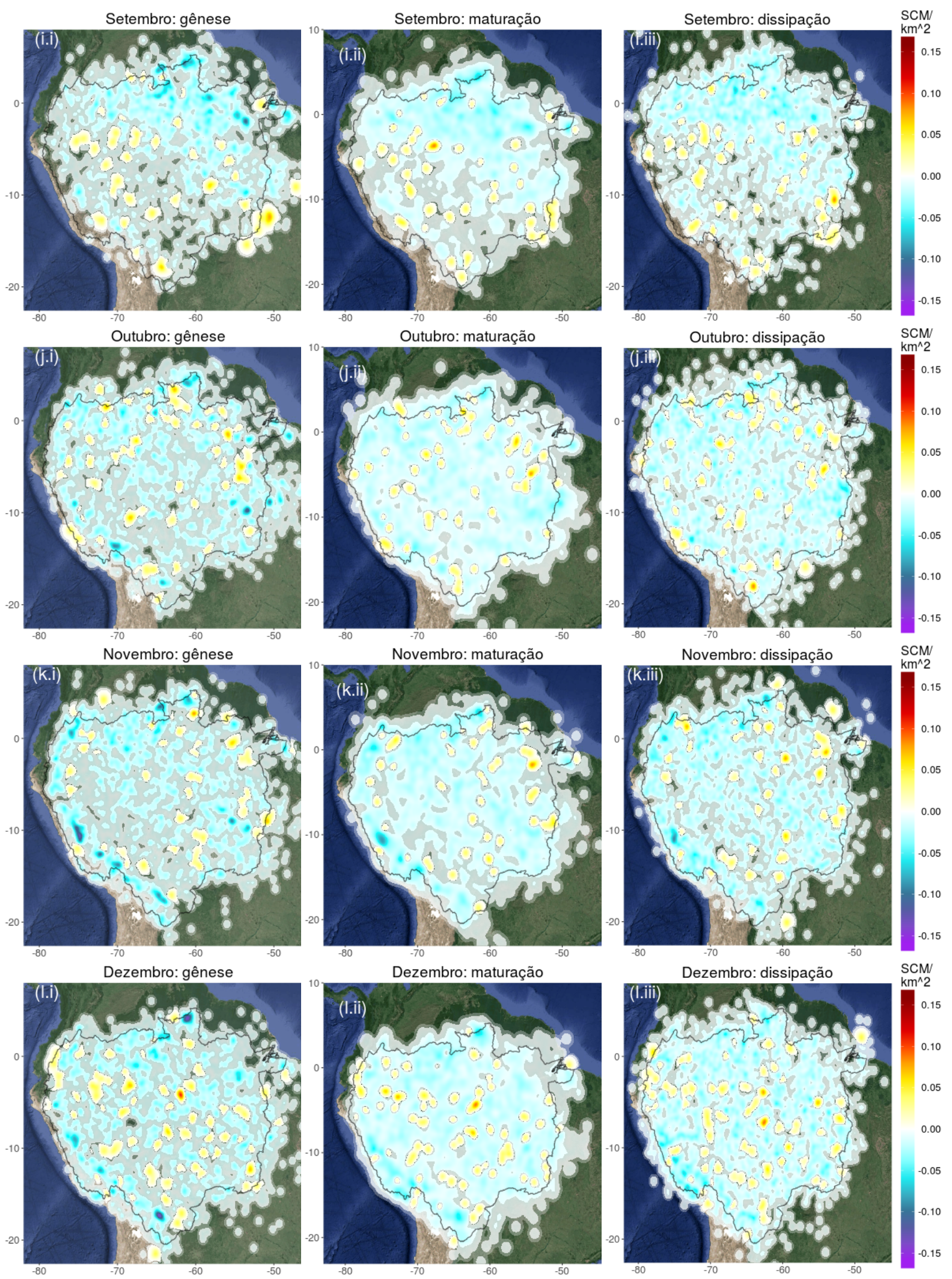

Figura 26 - Continuação da figura da página anterior. 

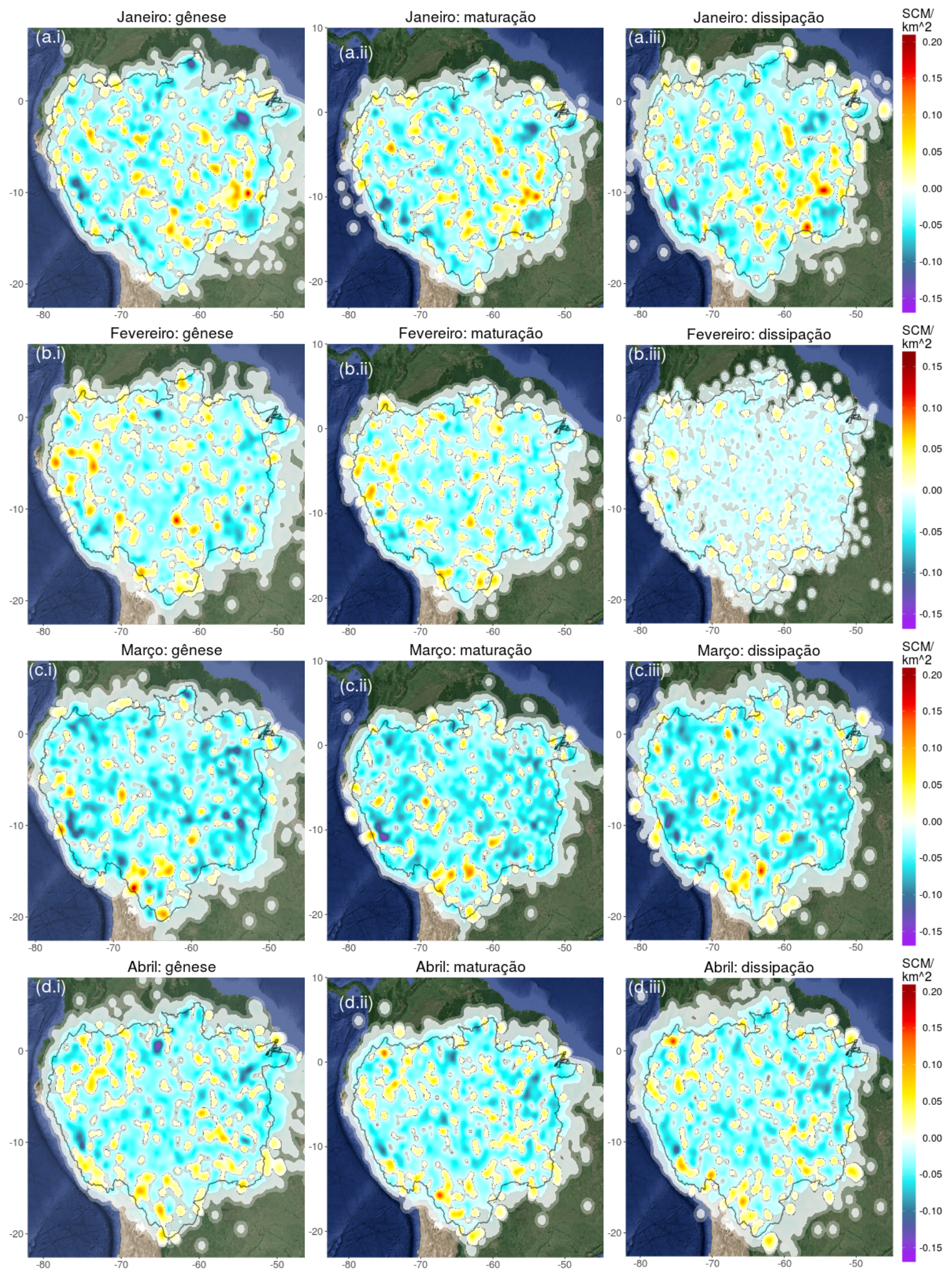

Figura 27 - Anomalias da densidade de gênese, maturação e dissipação de todos os SCMs ocorridos em 2014 sobre a bacia Amazônica. Em (a.i), (a.ii) e (a.iii) janeiro; (b.i), (b.ii), (b.iii) fevereiro; (c.i), (c.ii),(c.iii) março; (d.i), (d.ii), (d.iii) abril; (e.i), (e.ii), (e.iii) maio; (f.i), (f.ii), (f.iii) junho; (g.i), (g.ii), (g.iii) julho; (h.i), (h.ii), (h.iii) agosto; (i.i), (i.ii), (i.iii) setembro; (j.i), (j.ii), (j.iii) outubro; (k.i), (k.ii), (k.iii) novembro e (l.i), (l.ii), (l.iii) dezembro. 

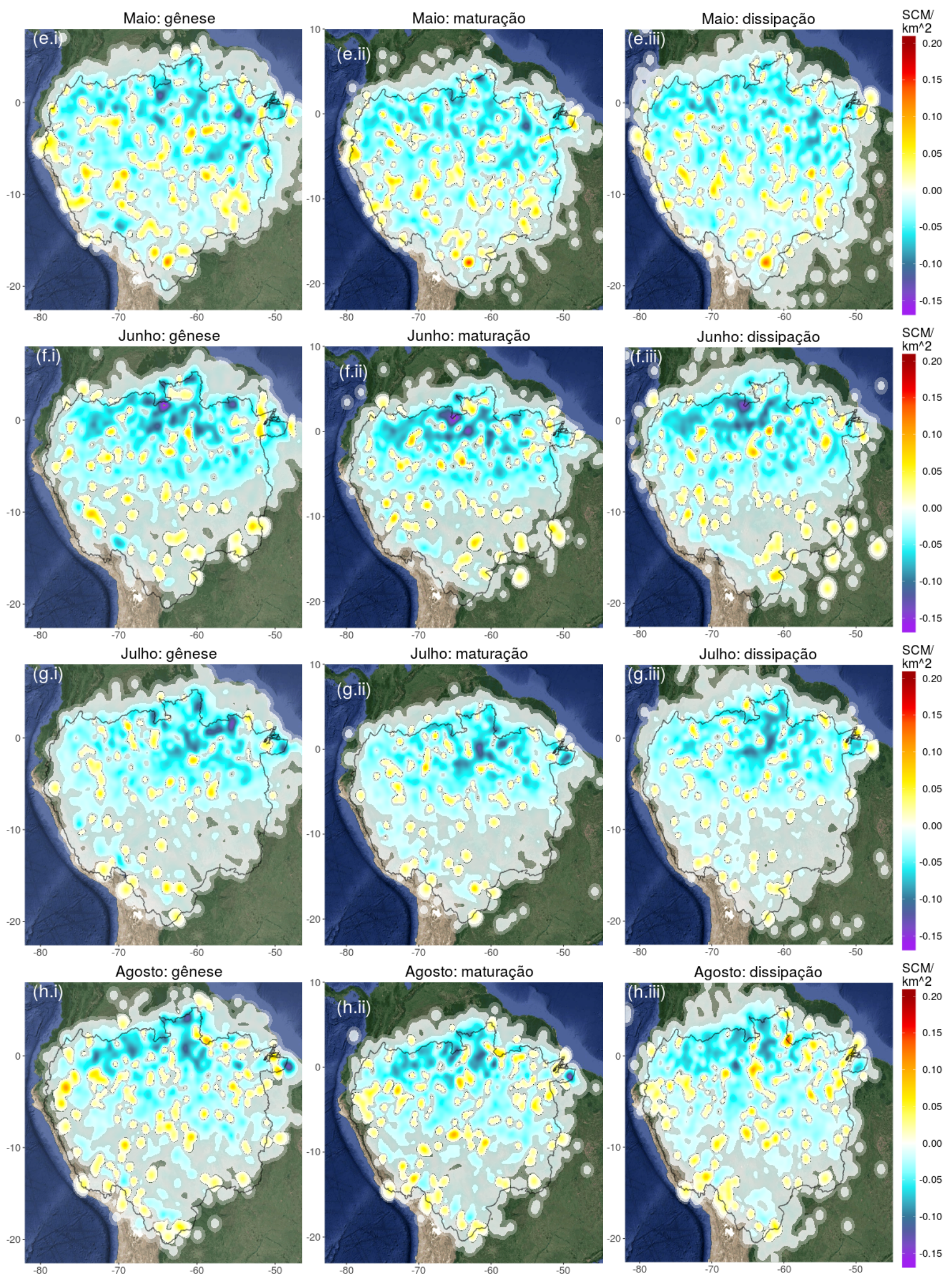

Figura 27 - Continuação da figura da página anterior. 

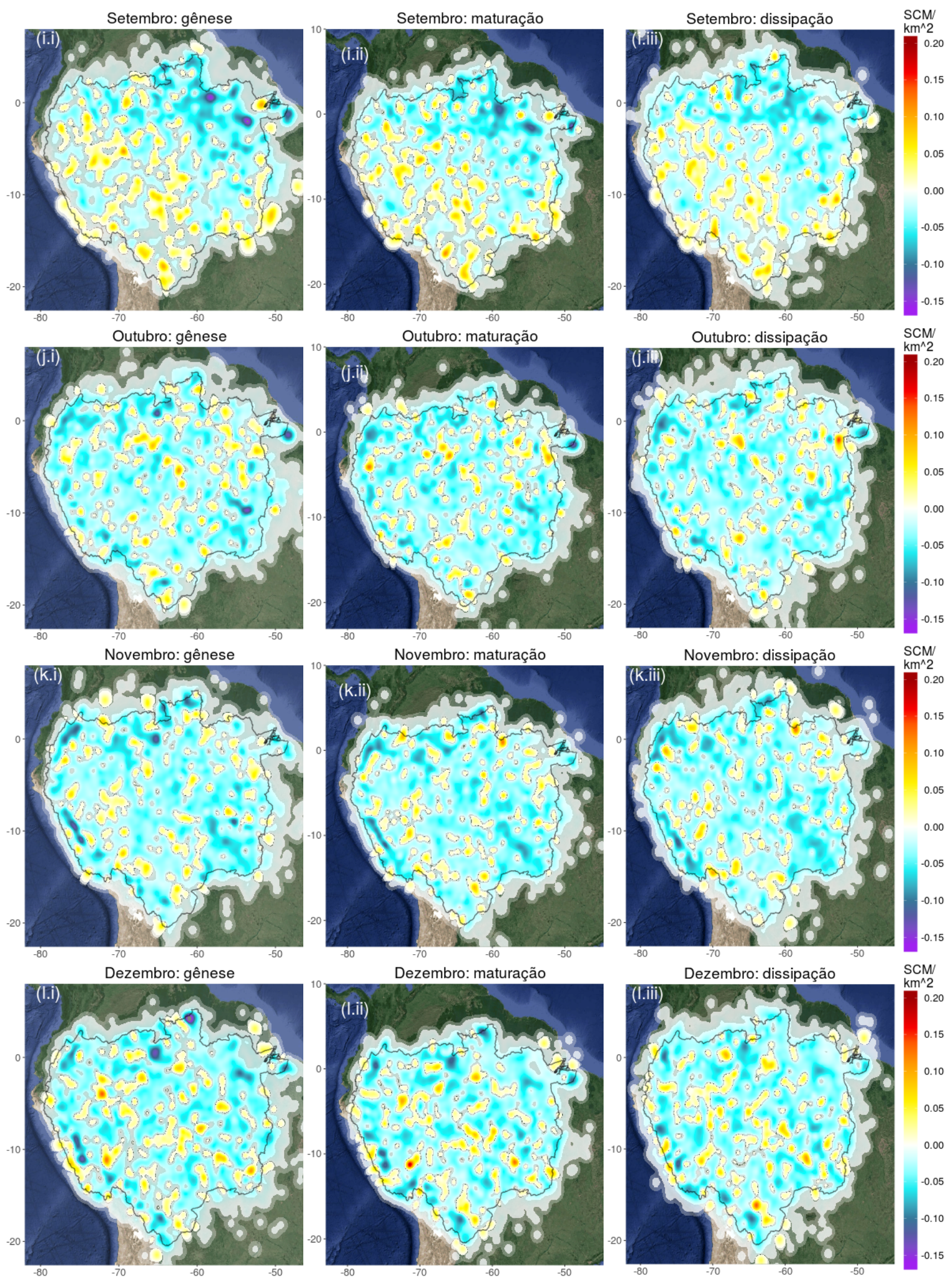

Figura 27 - Continuação da figura da página anterior. 

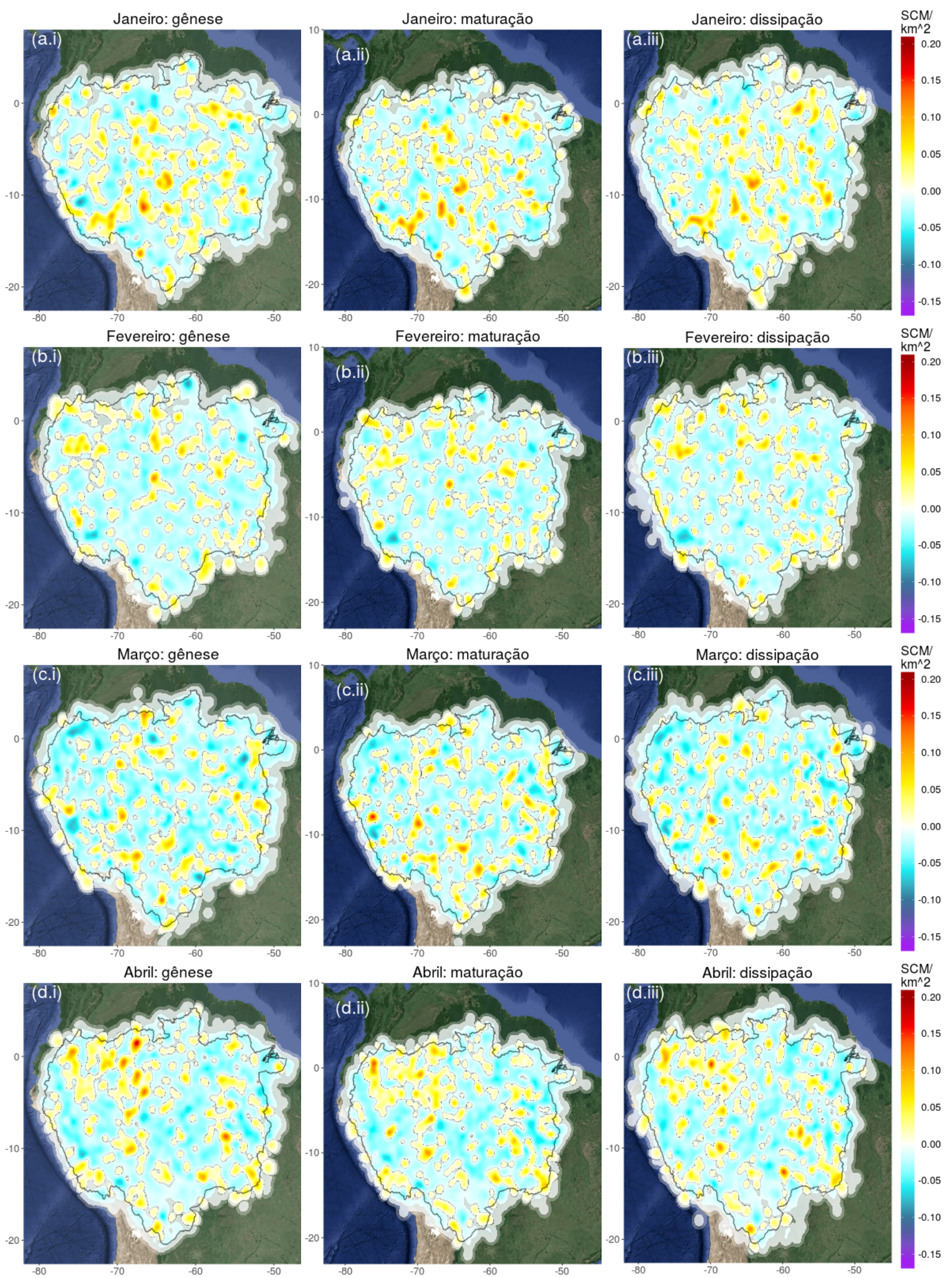

Figura 28 - Anomalias da densidade de gênese, maturação e dissipação dos SCMs com curto ciclo de vida ocorridos em 2015 sobre a bacia Amazônica. Em (a.i), (a.ii) e (a.iii) janeiro; (b.i), (b.ii), (b.iii) fevereiro; (c.i), (c.ii),(c.iii) março; (d.i), (d.ii), (d.iii) abril; (e.i), (e.ii), (e.iii) maio; (f.i), (f.ii), (f.iii) junho; (g.i), (g.ii), (g.iii) juIho; (h.i), (h.ii), (h.iii) agosto; (i.i), (i.ii), (i.iii) setembro; (j.i), (j.ii), (j.iii) outubro; (k.i), (k.ii), (k.iii) novembro e (l.i), (l.ii), (I.iii) dezembro. 

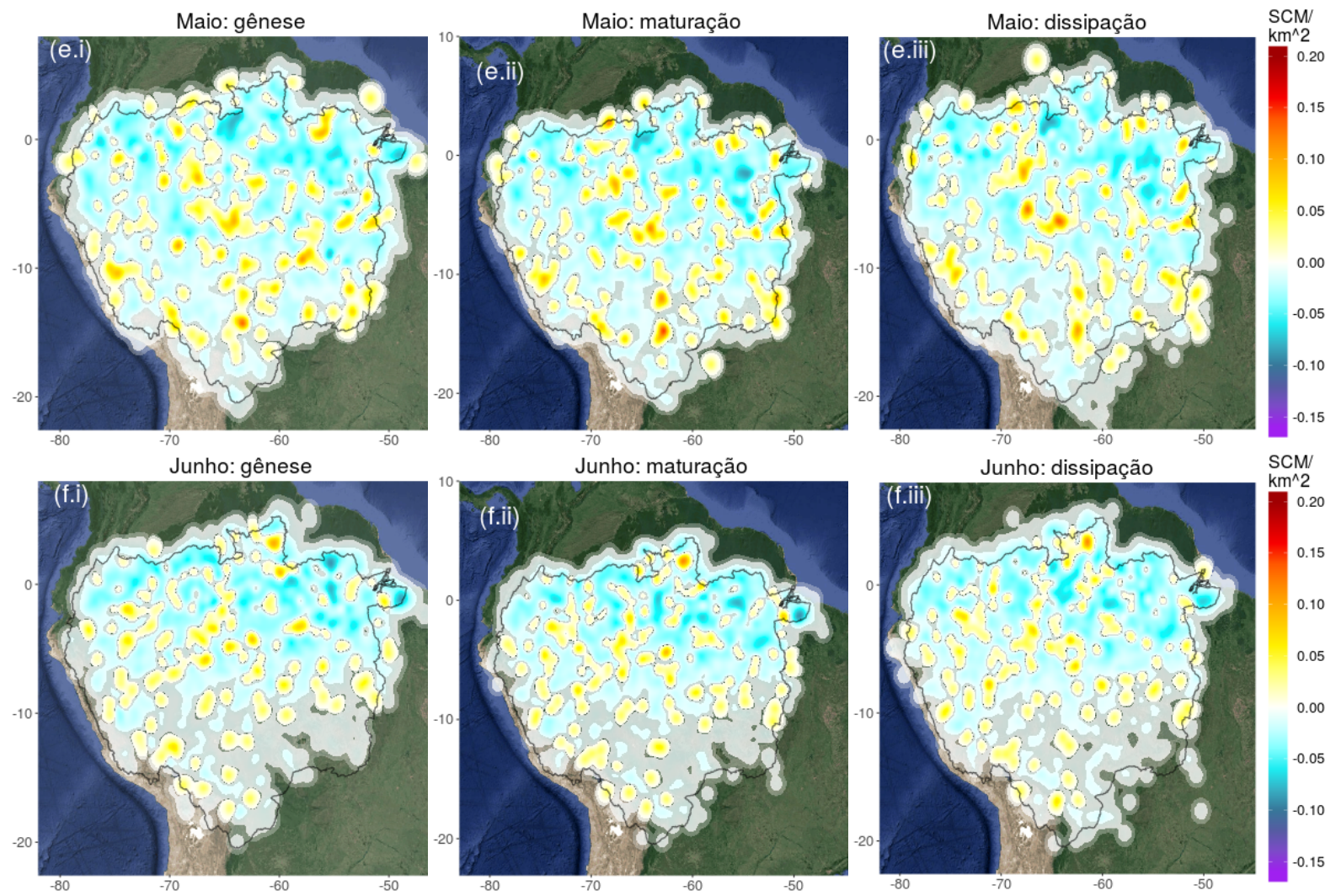

Figura 28 - Continuação da figura da página anterior. 

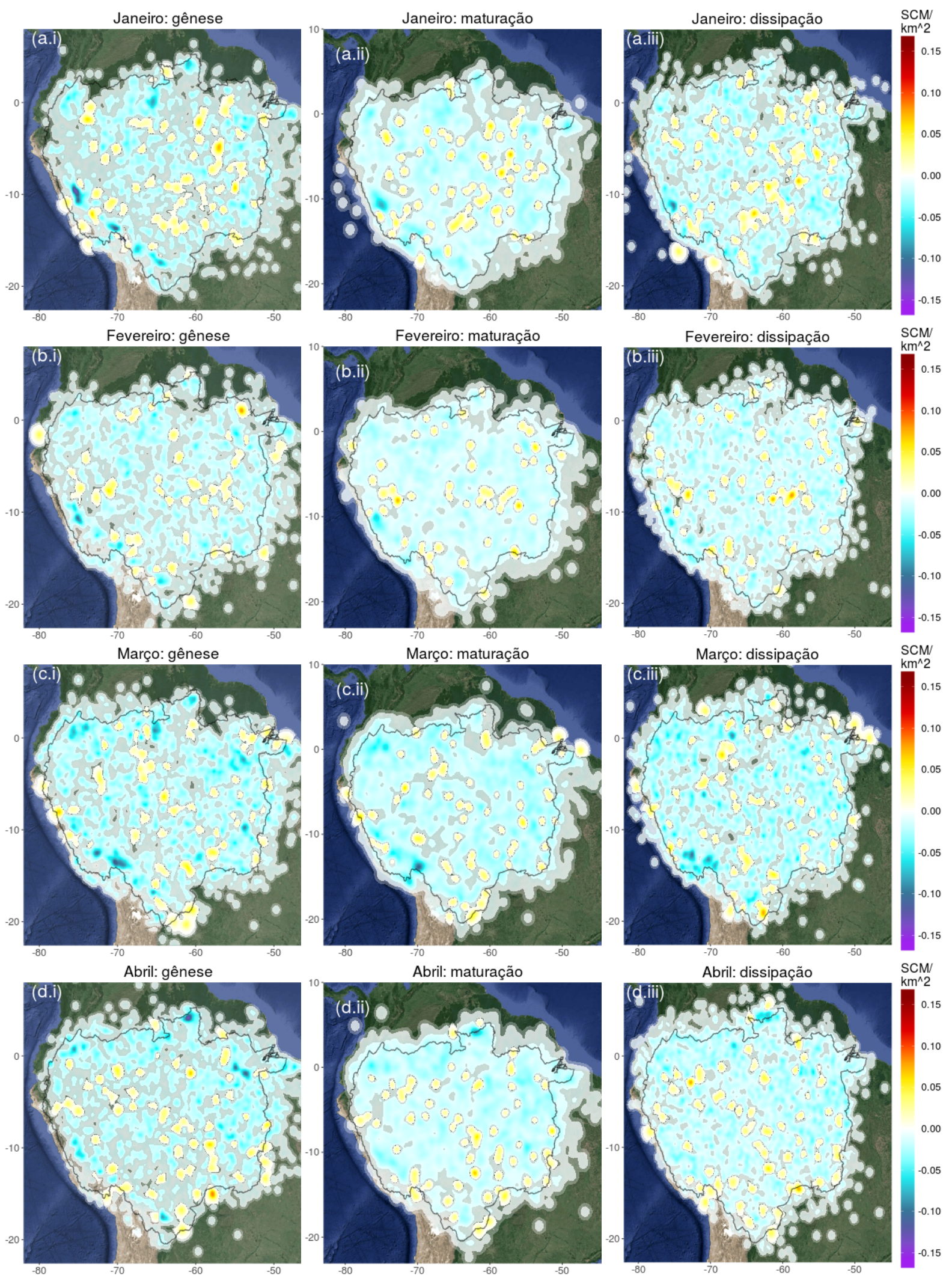

Figura 29 - Anomalias da densidade de gênese, maturação e dissipação dos SCMs com longo ciclo de vida ocorridos em 2015 sobre a bacia Amazônica. Em (a.i), (a.ii) e (a.iii) janeiro; (b.i), (b.ii), (b.iii) fevereiro; (c.i), (c.ii),(c.iii) março; (d.i), (d.ii), (d.iii) abril; (e.i), (e.ii), (e.iii) maio; (f.i), (f.ii), (f.iii) junho; (g.i), (g.ii), (g.iii) juIho; (h.i), (h.ii), (h.iii) agosto; (i.i), (i.ii), (i.iii) setembro; (j.i), (j.ii), (j.iii) outubro; (k.i), (k.ii), (k.iii) novembro e (I.i), (I.ii), (I.iii) dezembro. 

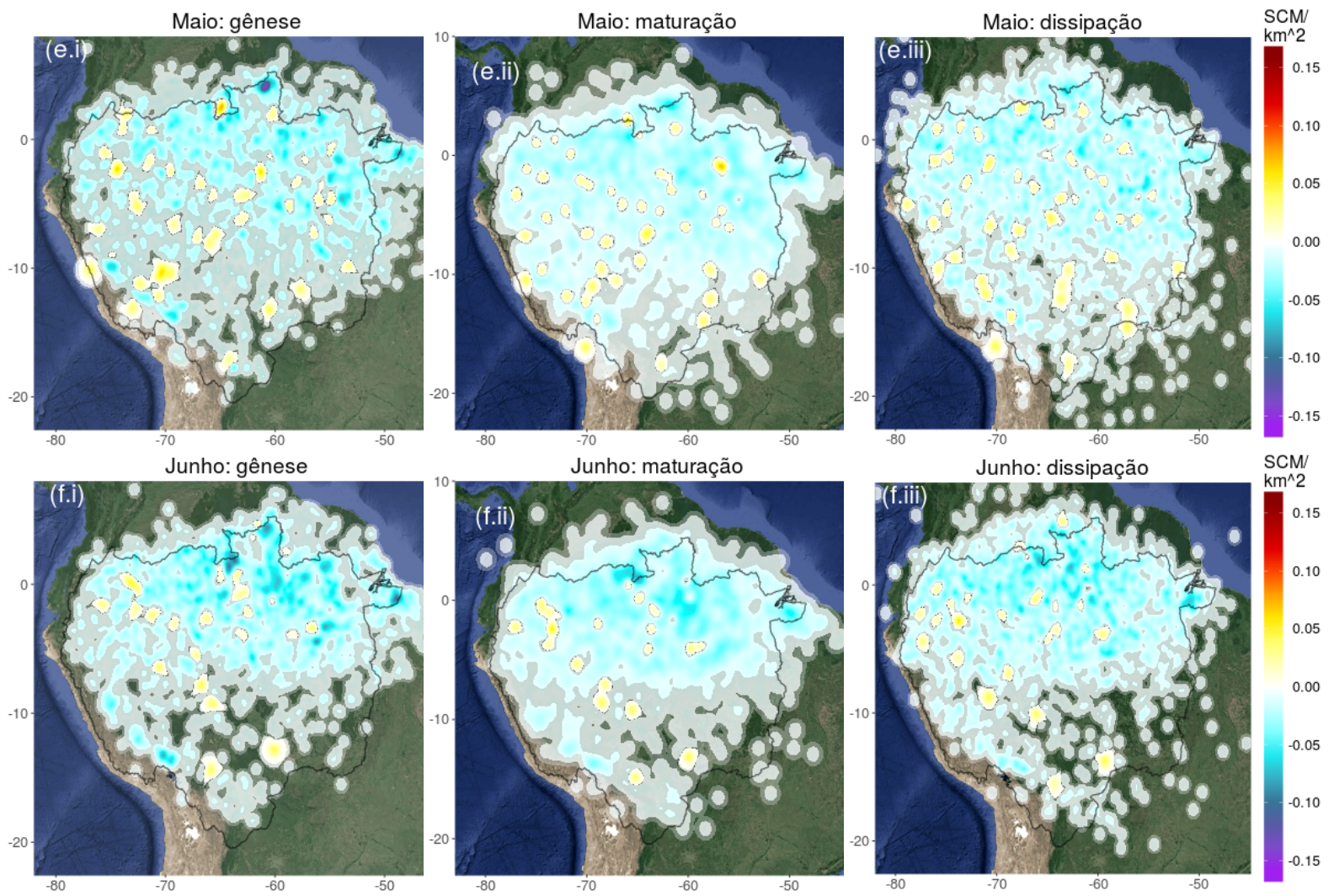

Figura 29 - Continuação da figura da página anterior. 

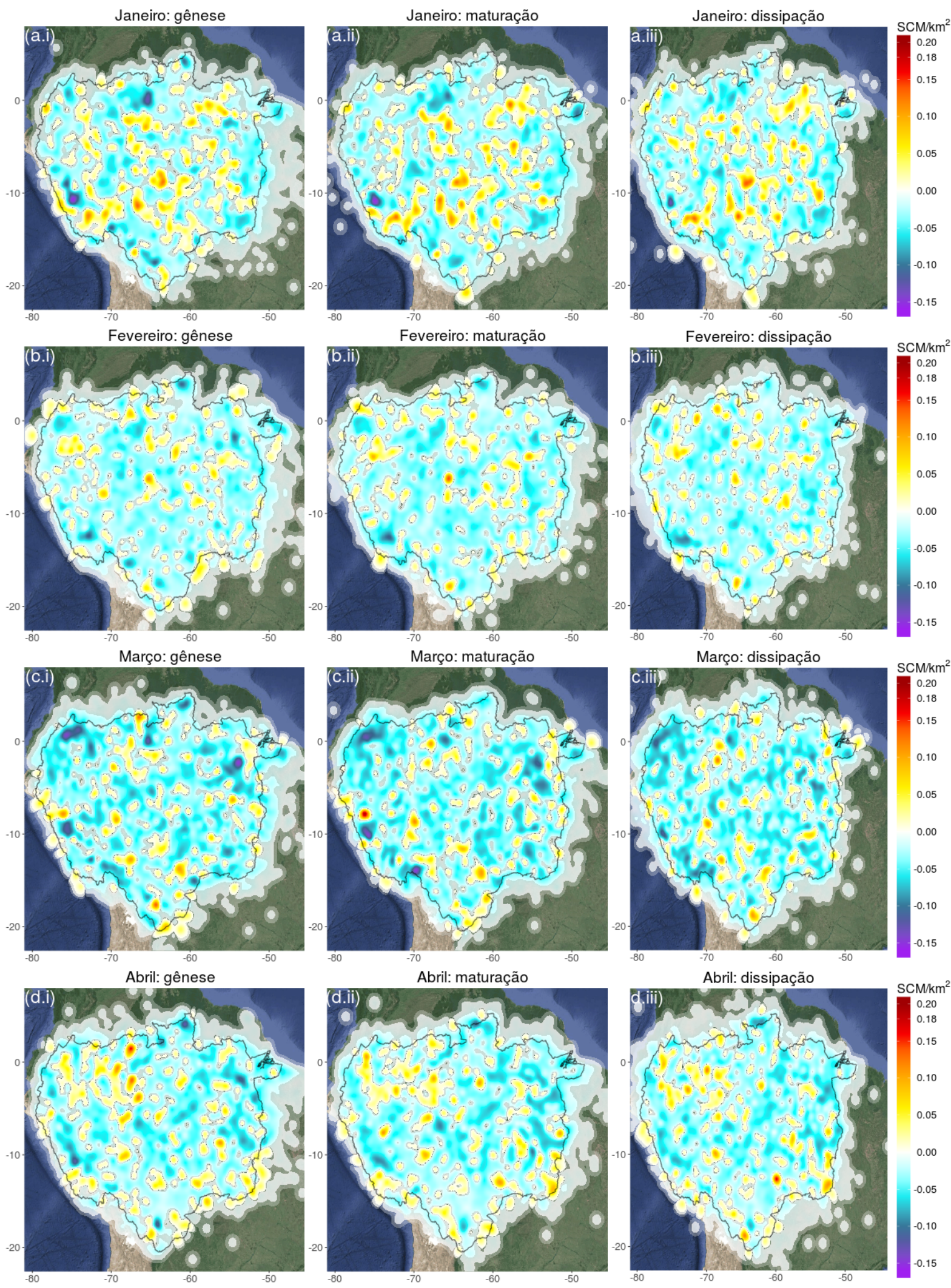

Figura 30 - Anomalias da densidade de gênese, maturação e dissipação de todos os SCMs ocorridos entre 01/01 a 30/06/2015 sobre a bacia Amazônica. Em (a.i), (a.ii) e (a.iii) janeiro; (b.i), (b.ii), (b.iii) fevereiro; (c.i), (c.ii),(c.iii) março; (d.i), (d.ii), (d.iii) abril; (e.i), (e.ii), (e.iii) maio; (f.i), (f.ii), (f.iii) junho; (g.i), (g.ii), (g.iii) julho; (h.i), (h.ii), (h.iii) agosto; (i.i), (i.ii), (i.iii) setembro; (j.i), (j.ii), (j.iii) outubro; (k.i), (k.ii), (k.iii) novembro e (I.i), (I.ii), (I.iii) dezembro. 

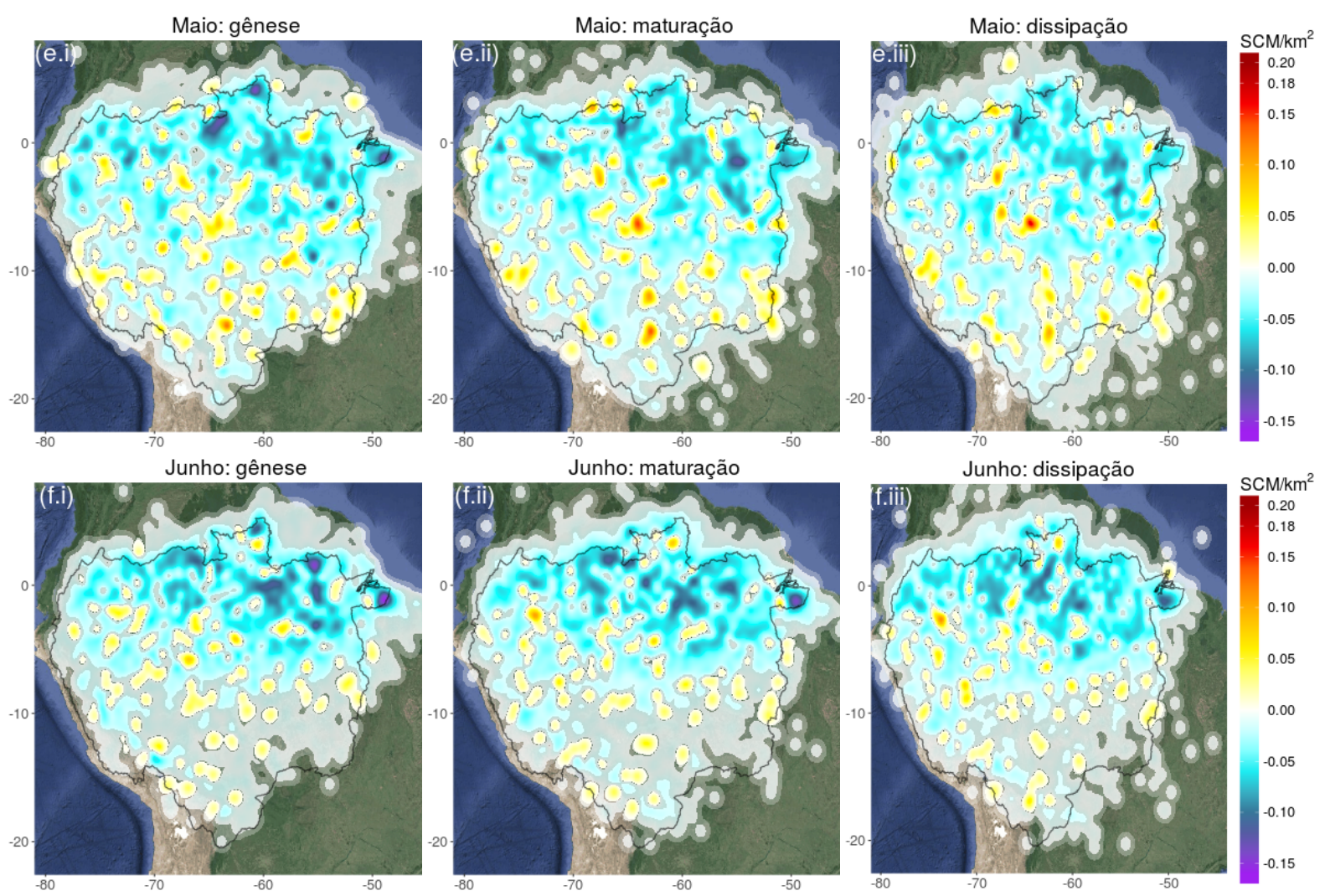

Figura 30 - Continuação da figura da página anterior.

A velocidade média dos SCMs ocorridos durante o GOAmazon foi menor que o observado na climatologia. Em 2014 a velocidade média dos sistemas de curta duração foi de $14,8 \mathrm{~km} / \mathrm{h}$ e em 2015 foi de $15 \mathrm{~km} / \mathrm{h}$, ambos tiveram desvio padrão de $5,3 \mathrm{~km} / \mathrm{h}$. A velocidade média dos SCMs de longa duração: em 2014 foi de $15 \mathrm{~km} / \mathrm{h}( \pm 4,5 \mathrm{~km} / \mathrm{h})$ e em 2015 foi de $14,6 \mathrm{~km} / \mathrm{h}( \pm 4,1 \mathrm{~km} / \mathrm{h})$.

O deslocamento médio dos SCMs de curta duração ocorridos em 2014 foi de 89 km ( $\pm 53,6$ km) e dos SCMs de longa duração foi de 194,1km ( \pm 121 km). Em 2015 o deslocamento médio dos sistemas com curto tempo de vida foi 91,8 km ( $\pm 59,6 \mathrm{~km}) \mathrm{e}$ de longo ciclo de vida foi $190 \mathrm{~km}( \pm 124,3 \mathrm{~km})$.

Devido à baixa ocorrência de SCMs em 2014 e 2015 comparado com a climatologia, observamos nas 31, 32, 33, 34, 35 e 36 que as direções de propagação dos SCMs são mais desorganizadas ao longo da bacia Amazônica. Apesar disso, os SCMs seguiram a tendência de ter menores deslocamentos durante o verão comparado ao inverno e para oeste na metade norte da bacia Amazônica e para leste na parte sul. Os SCMs com longo ciclo de vida ocorridos durante o GOAmazon tiveram maiores deslocamentos comparados aos SCMs de curta duração ocorridos no mesmo período. 


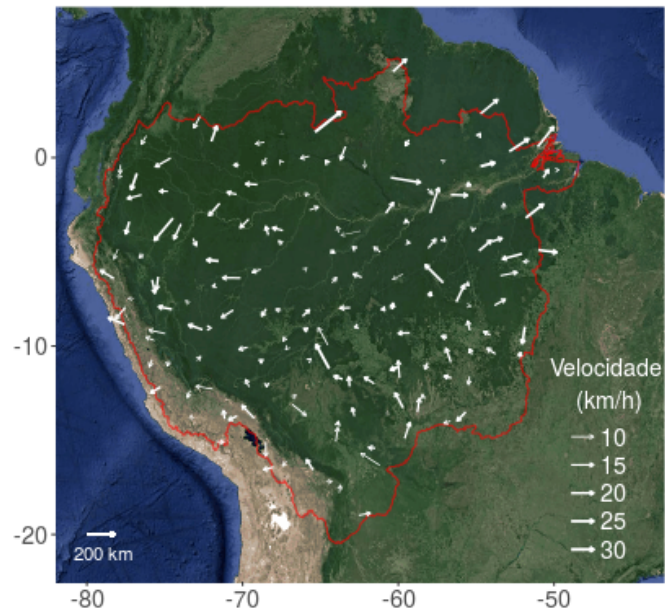

(a) Janeiro

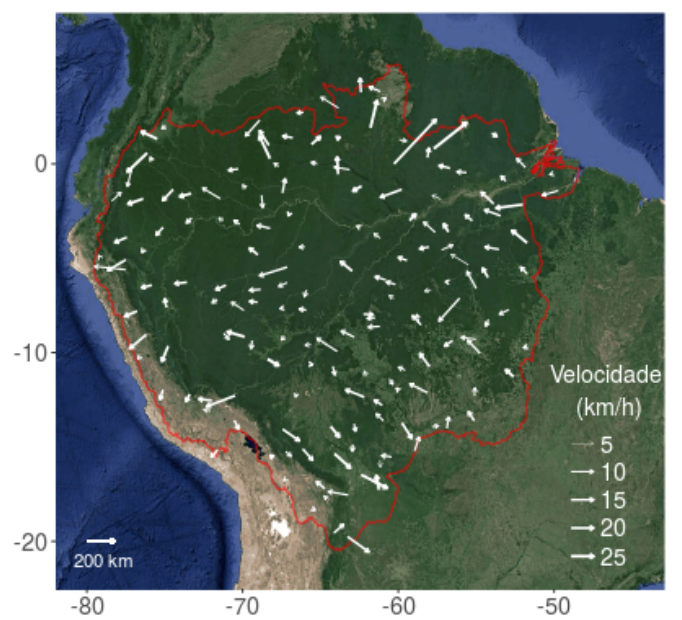

(c) Março

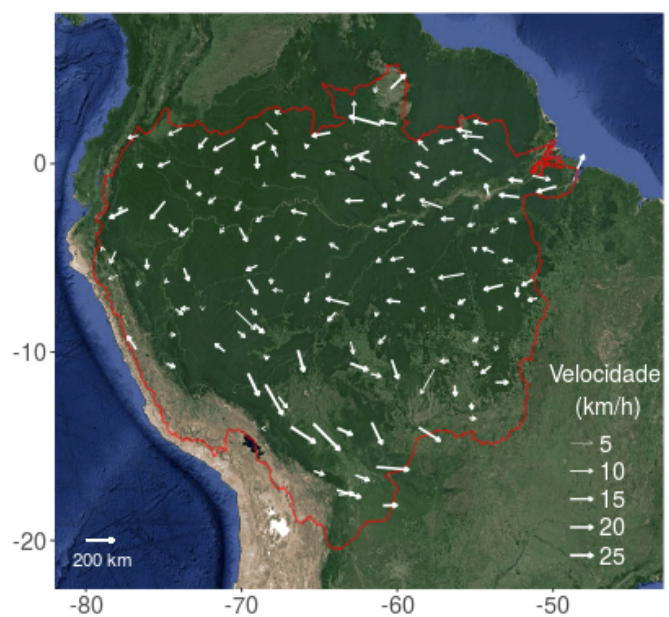

(e) Maio

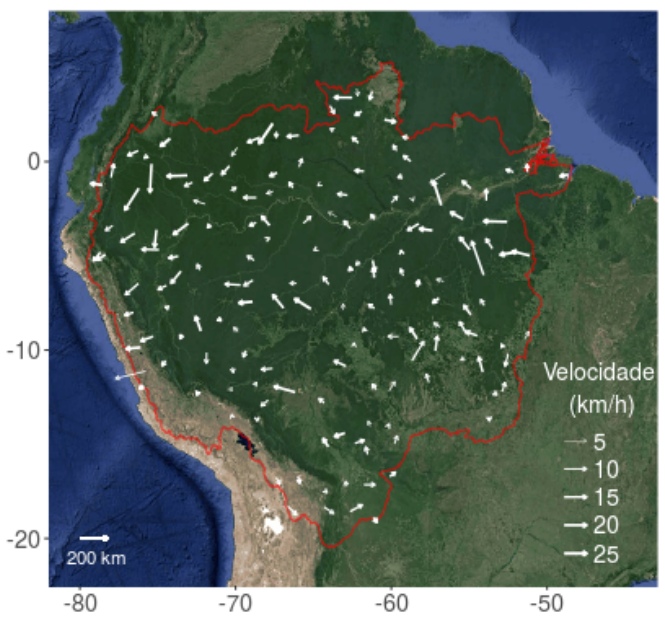

(b) Fevereiro

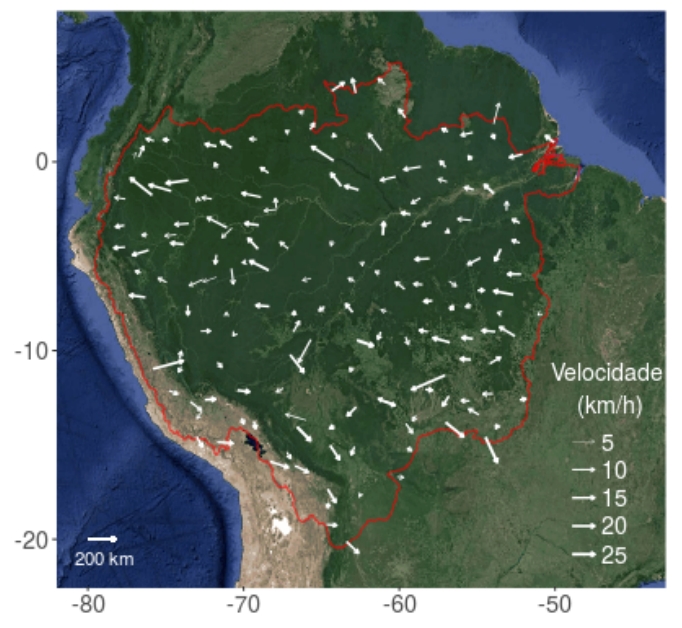

(d) Abril

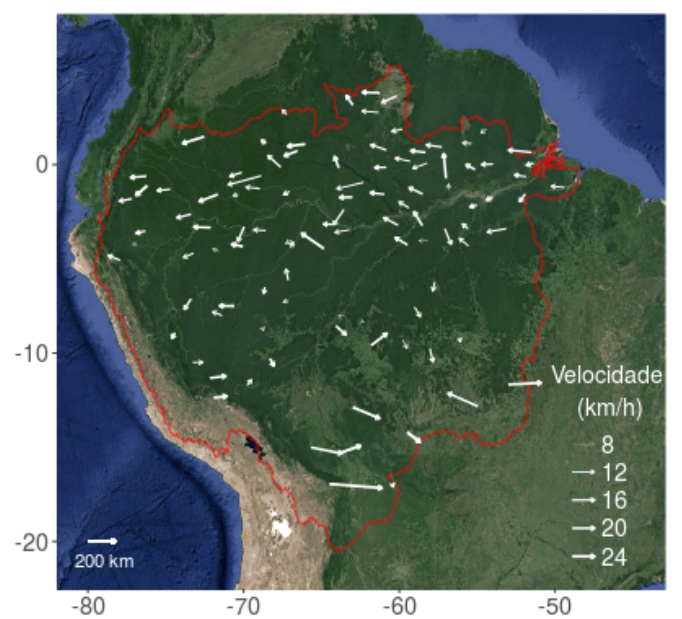

(f) Junho

Figura 31 - Direção de propagação, deslocamentos médios e velocidade média dos SCMs com curto ciclo de vida ocorridos na bacia Amazônica em 2014. O comprimento do vetor indica o deslocamento médio e a largura indica a velocidade. 


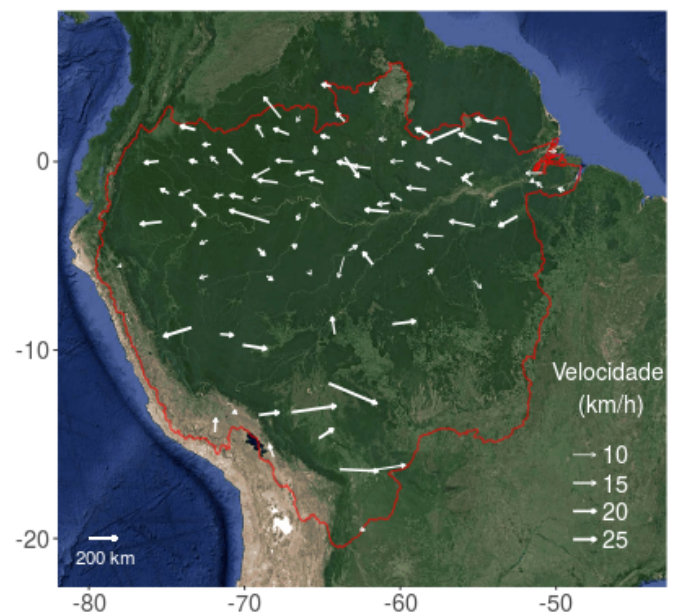

(g) Julho

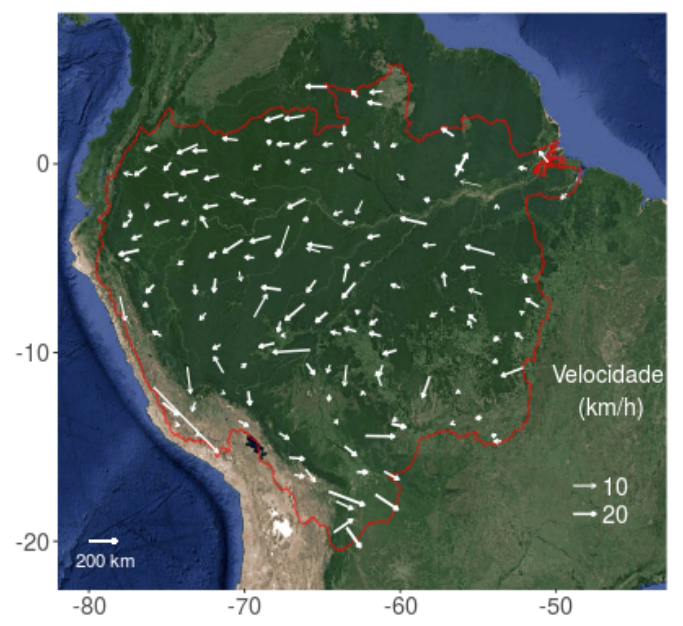

(i) Setembro

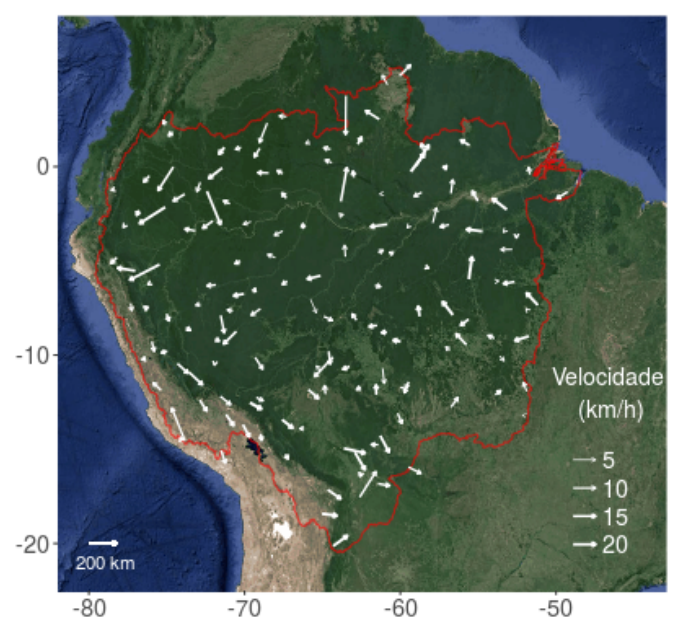

(k) Novembro

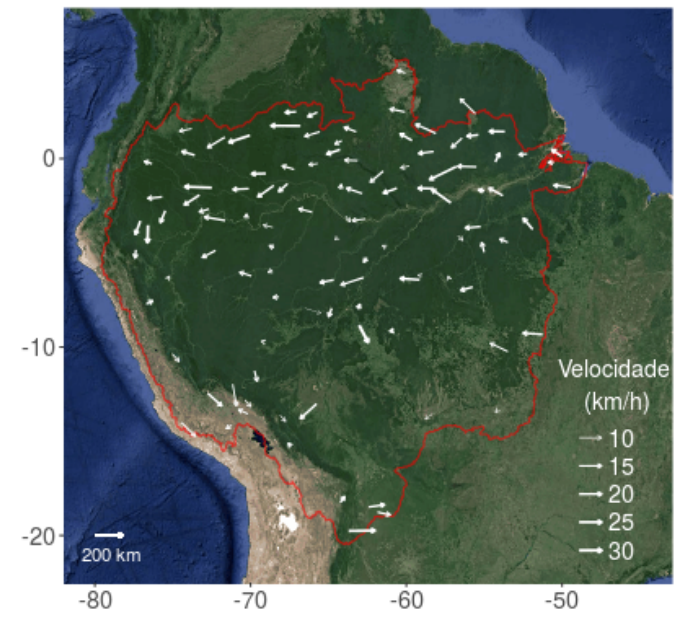

(h) Agosto

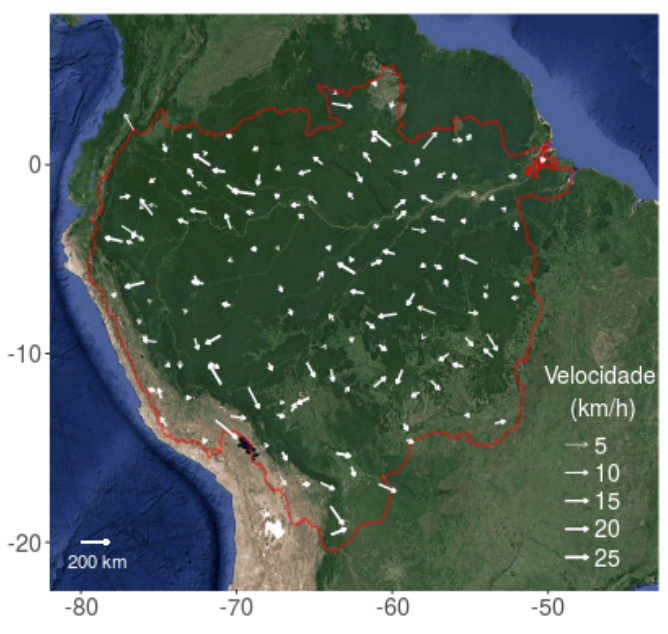

(j) Outubro

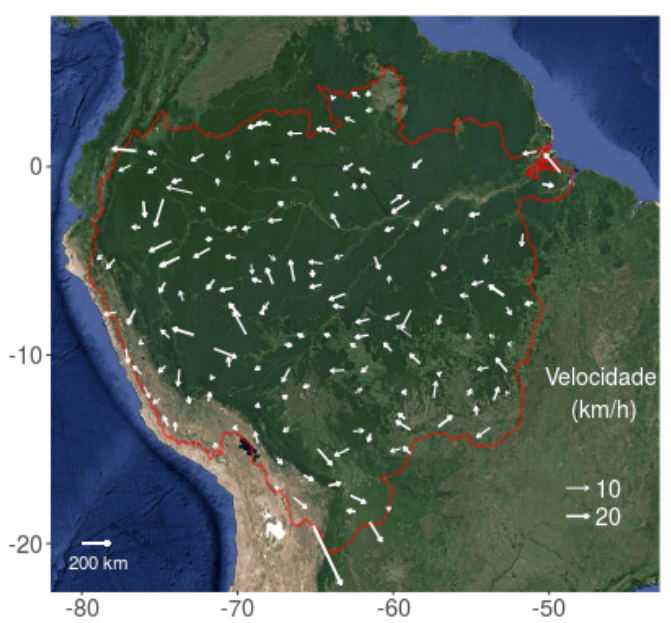

(I) Dezembro

Figura 31 - Continuação da figura da página anterior. 


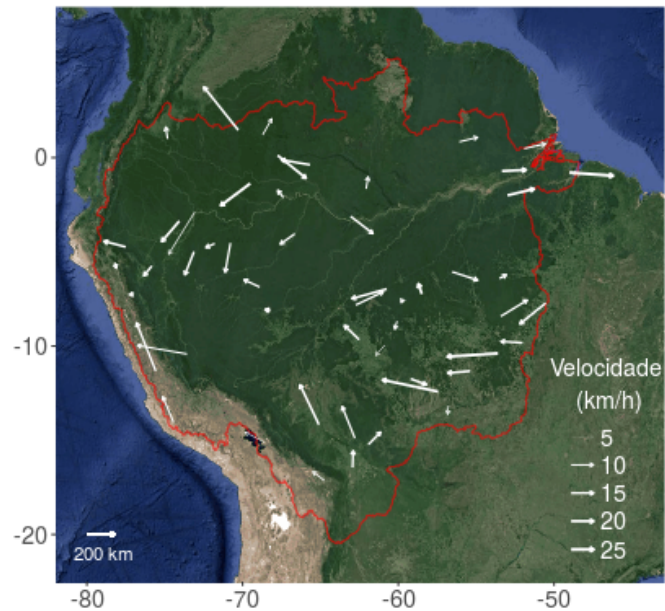

(a) Janeiro

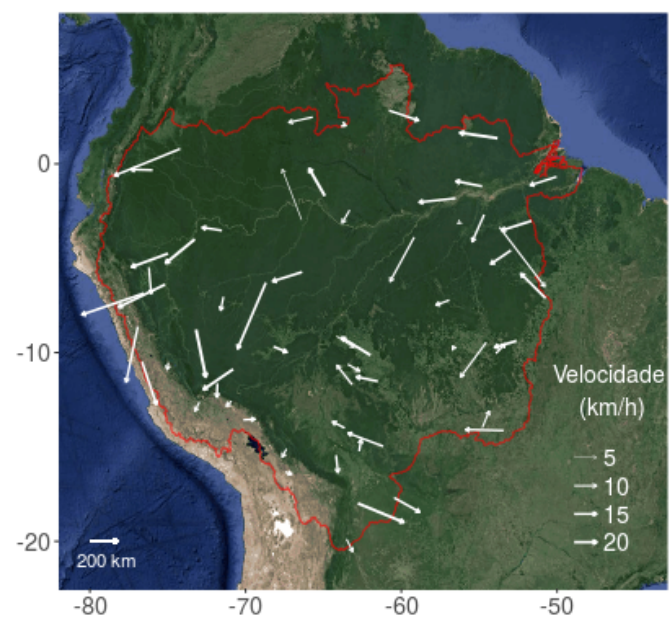

(c) Março

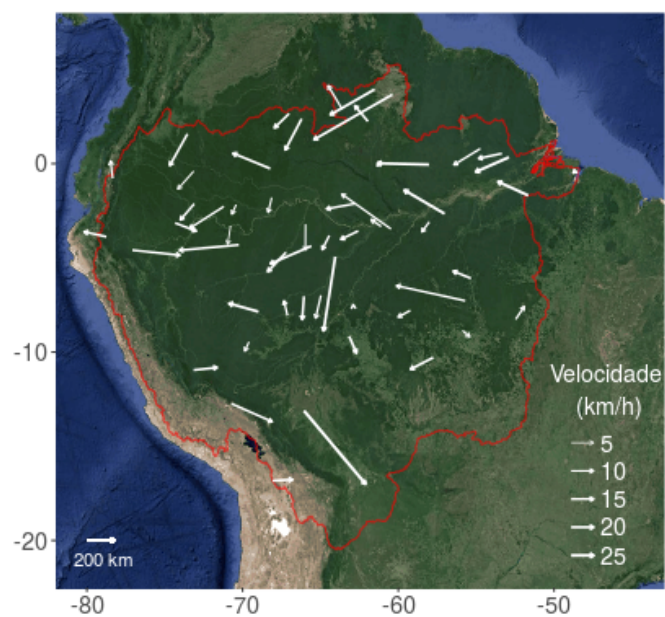

(e) Maio

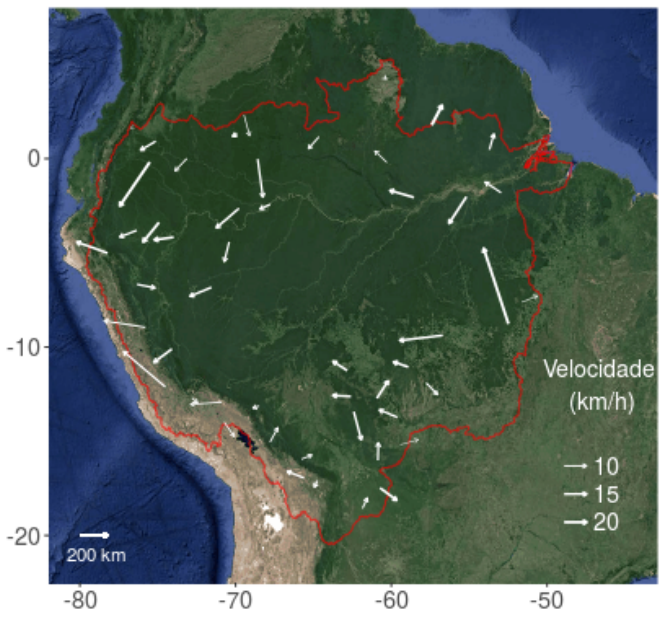

(b) Fevereiro

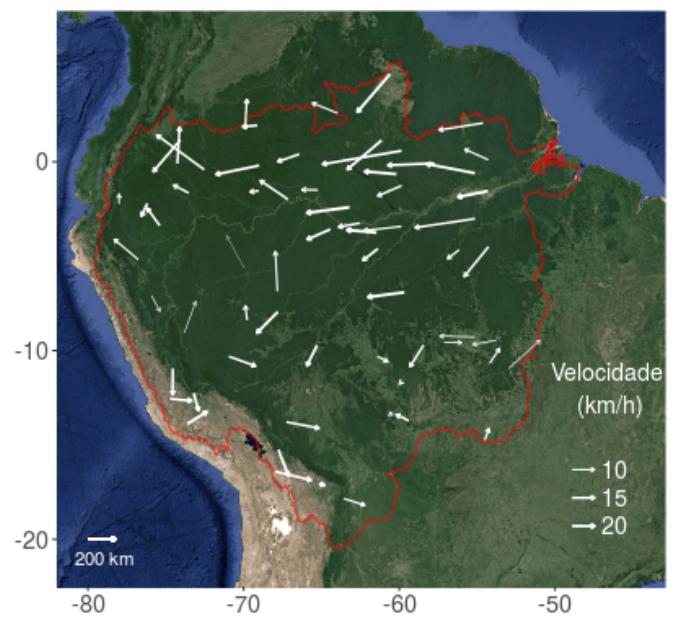

(d) Abril

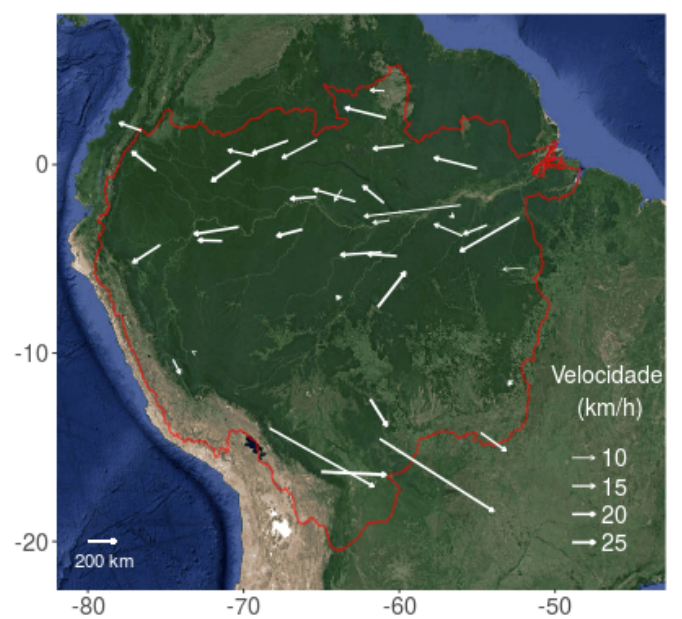

(f) Junho

Figura 32 - Direção de propagação, deslocamentos médios e velocidade média dos SCMs com longo ciclo de vida ocorridos na bacia Amazônica em 2014. O comprimento do vetor indica o deslocamento médio e a largura indica a velocidade. 


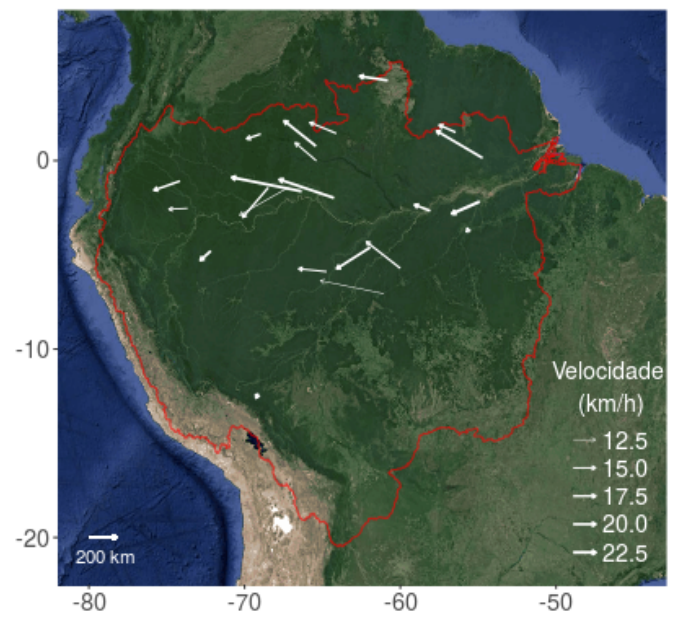

(g) Julho

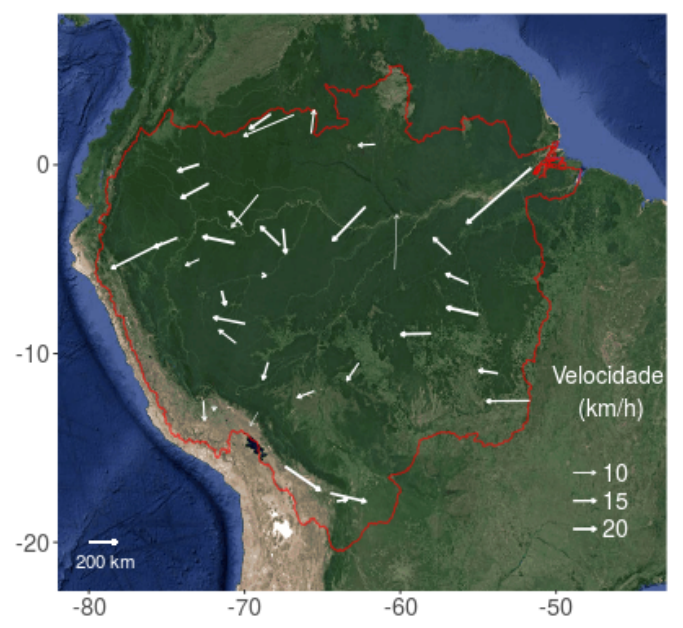

(i) Setembro

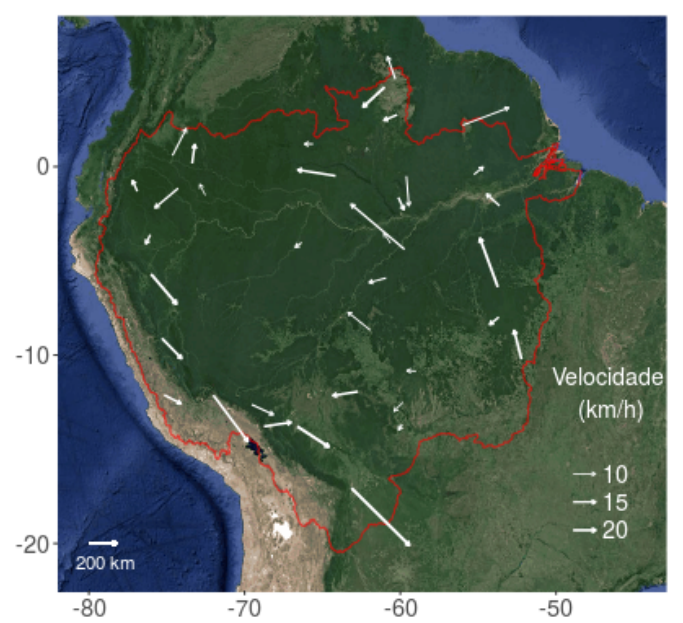

(k) Novembro

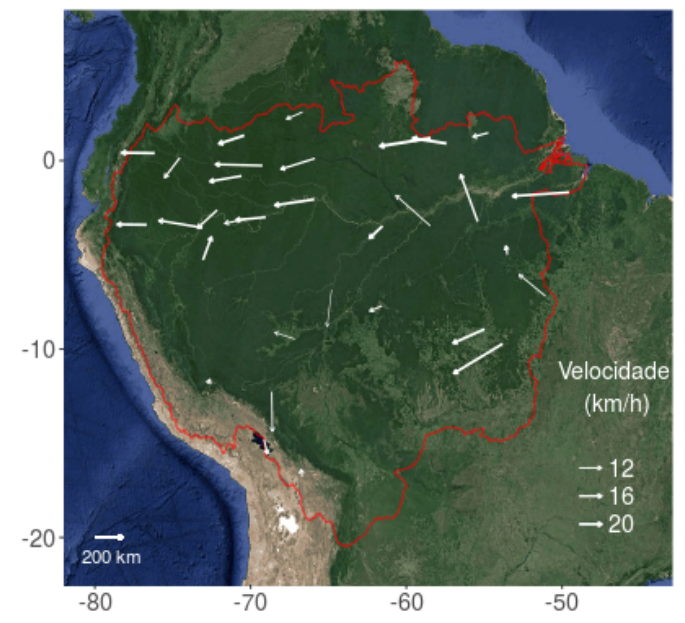

(h) Agosto

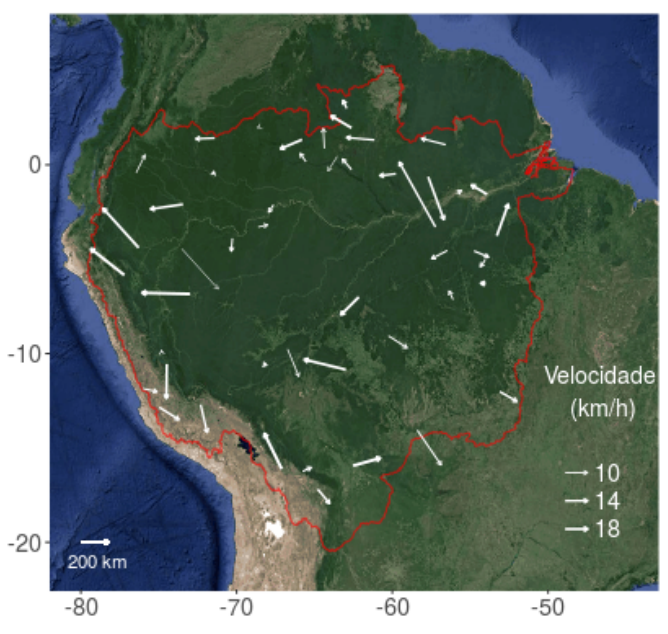

(j) Outubro

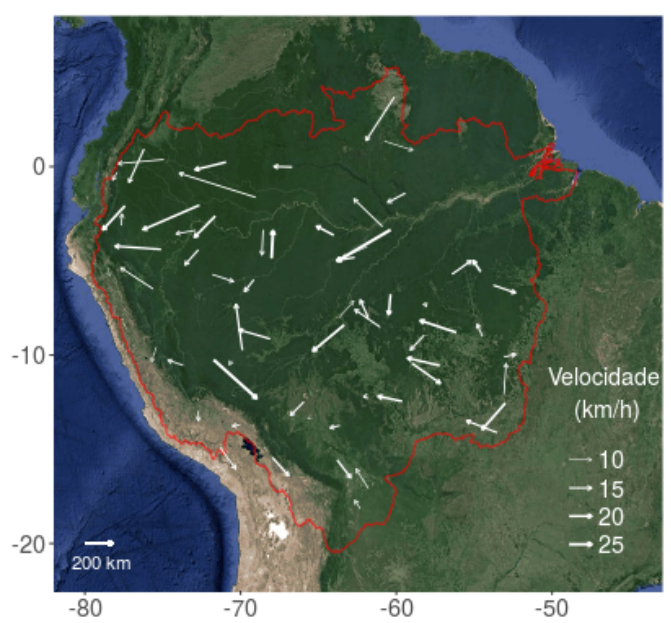

(I) Dezembro

Figura 32 - Continuação da figura da página anterior. 


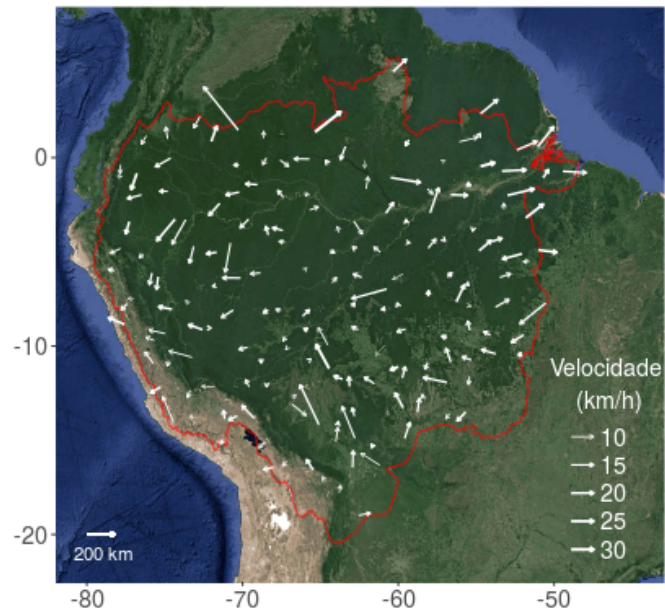

(a) Janeiro

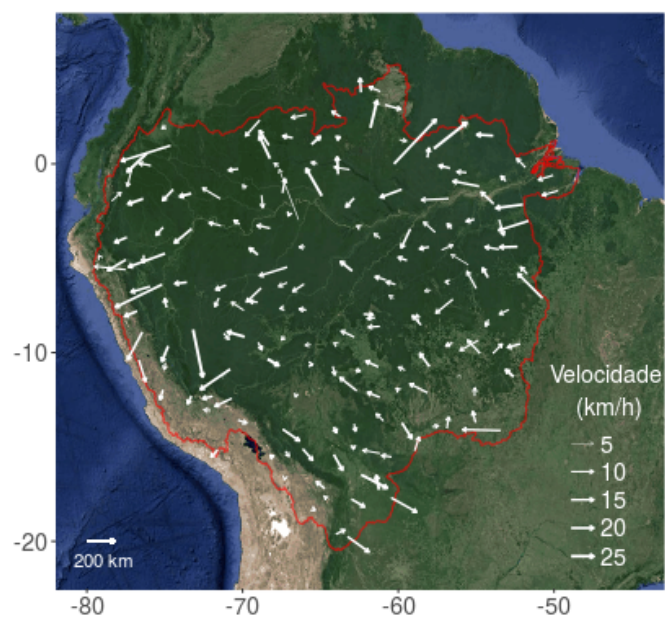

(c) Março

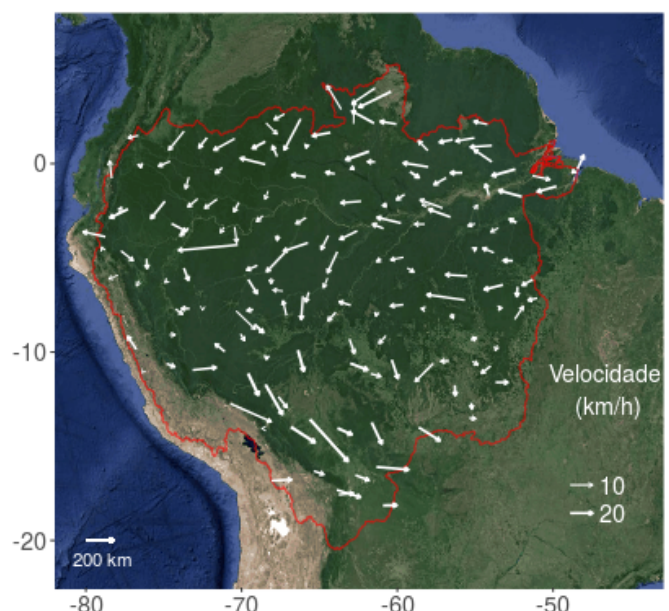

(e) Maio

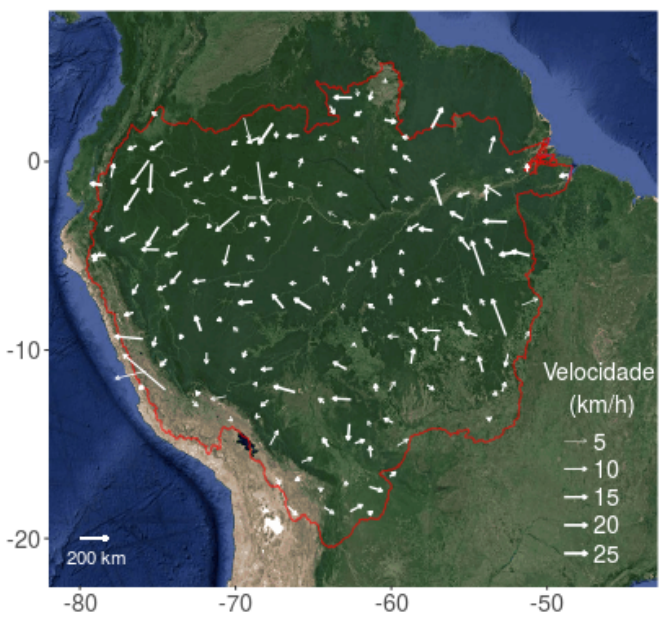

(b) Fevereiro

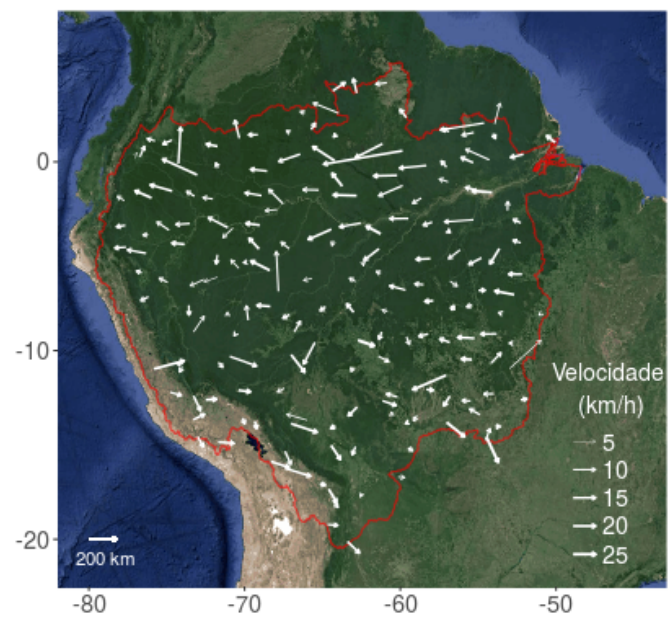

(d) Abril

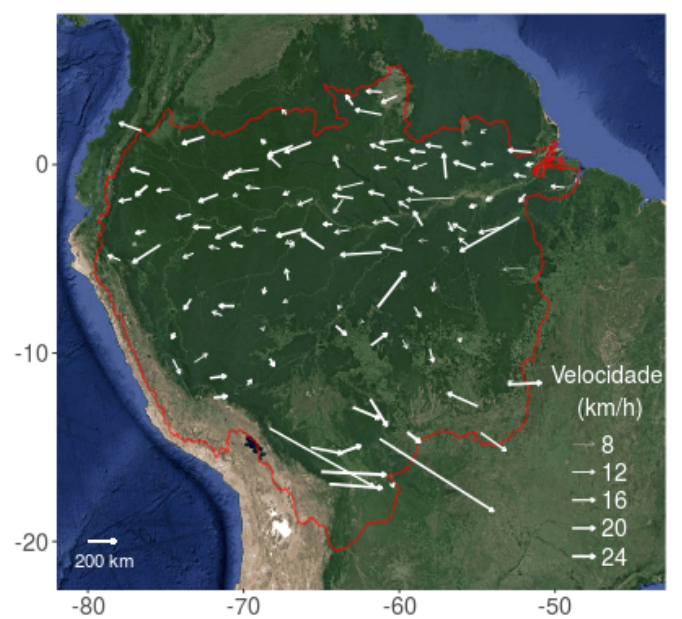

(f) Junho

Figura 33 - Direção de propagação, deslocamentos médios e velocidade média de todos SCMs ocorridos na bacia Amazônica em 2014. O comprimento do vetor indica o deslocamento médio e a largura indica a velocidade. 


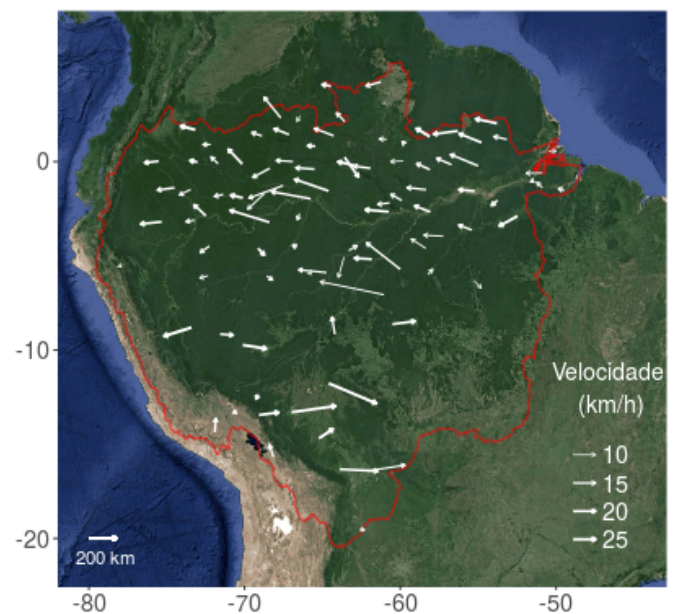

(g) Julho

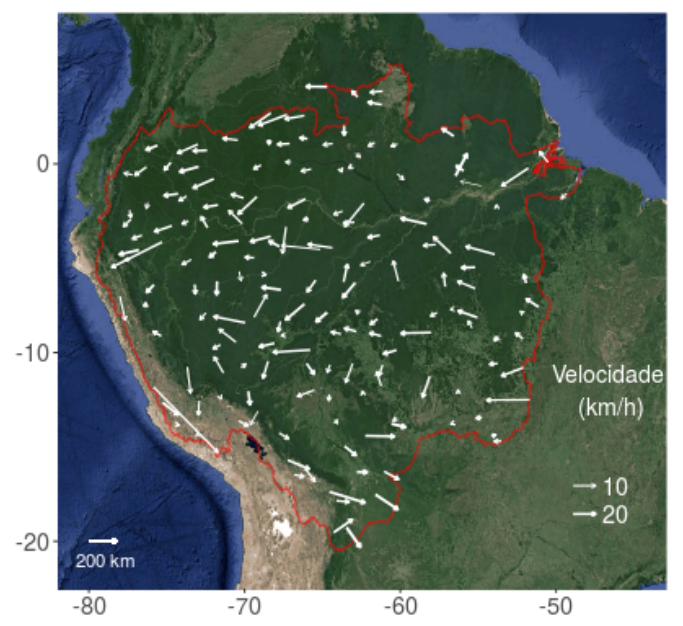

(i) Setembro

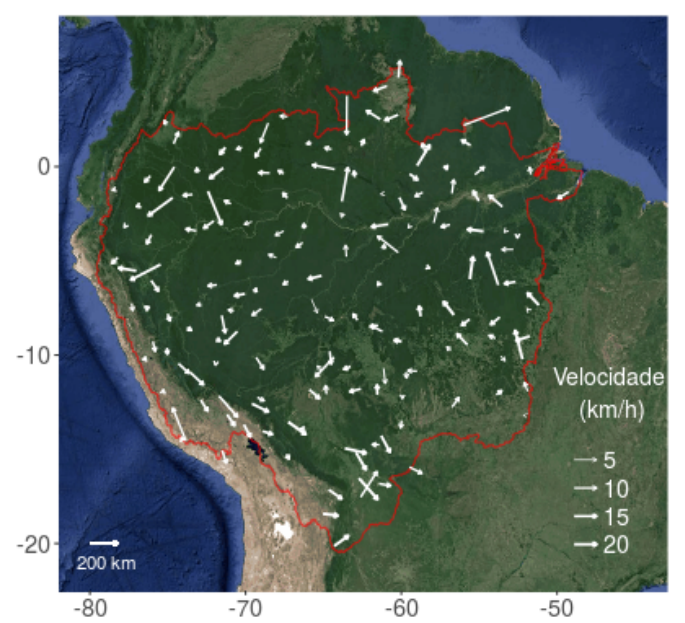

(k) Novembro

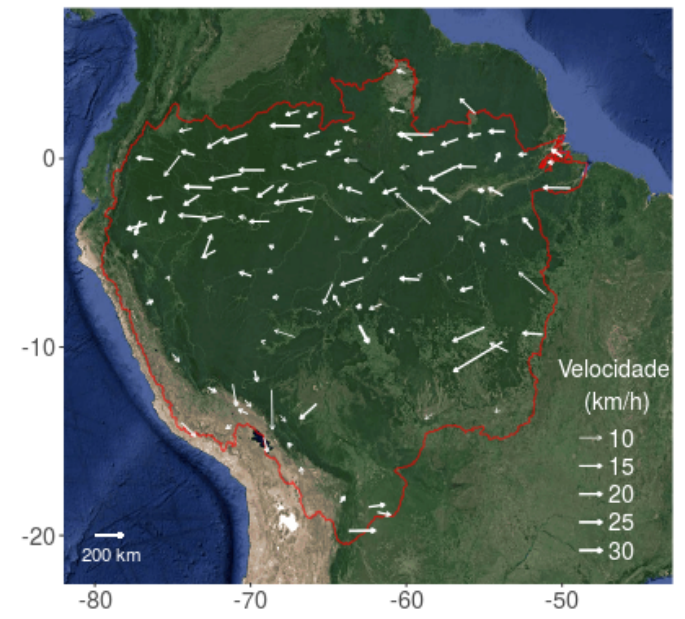

(h) Agosto

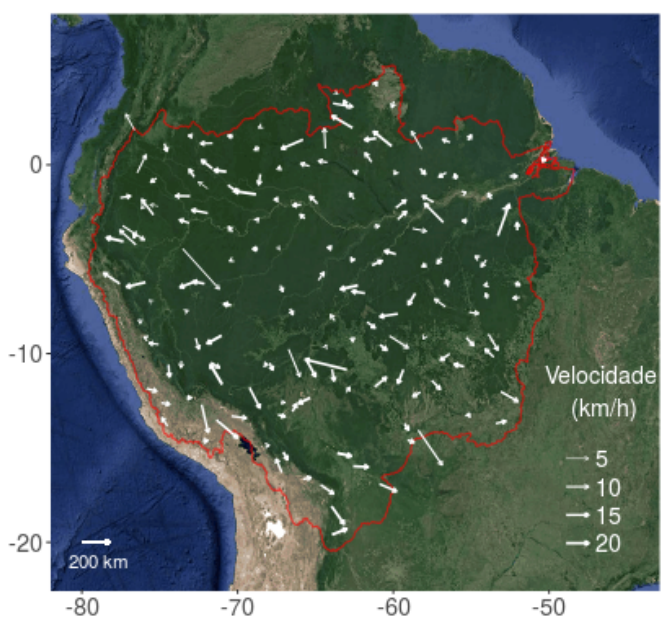

(j) Outubro

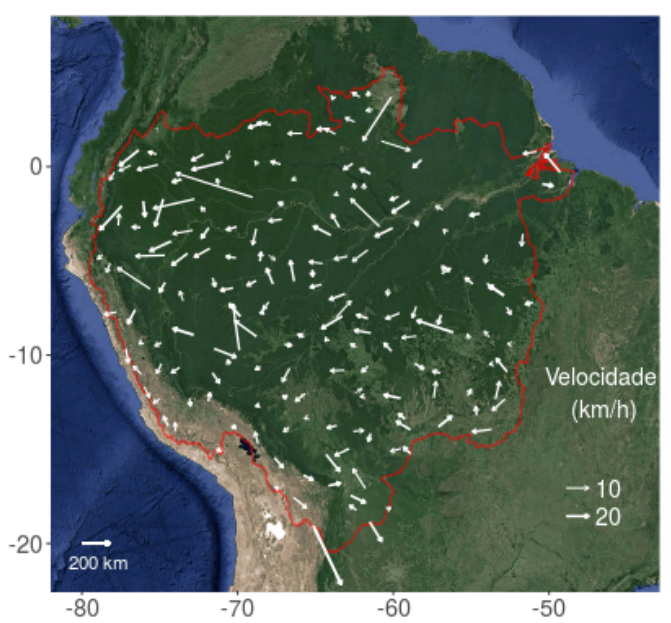

(I) Dezembro

Figura 33 - Continuação da figura da página anterior. 


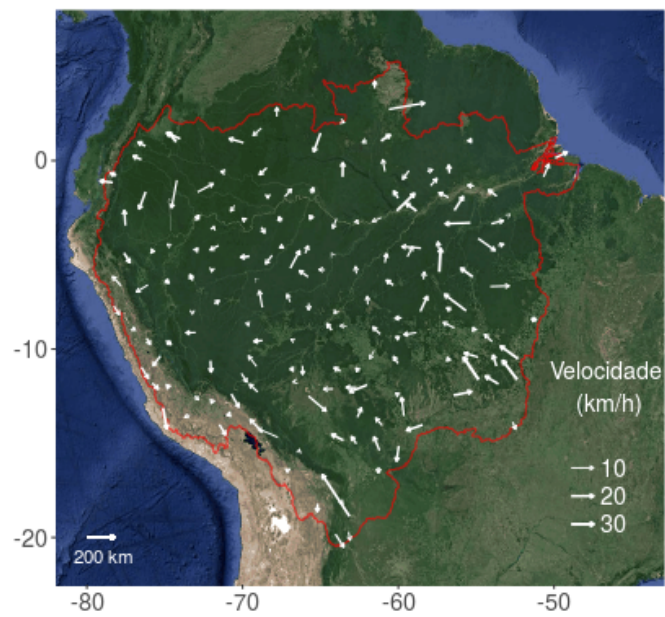

(a) Janeiro

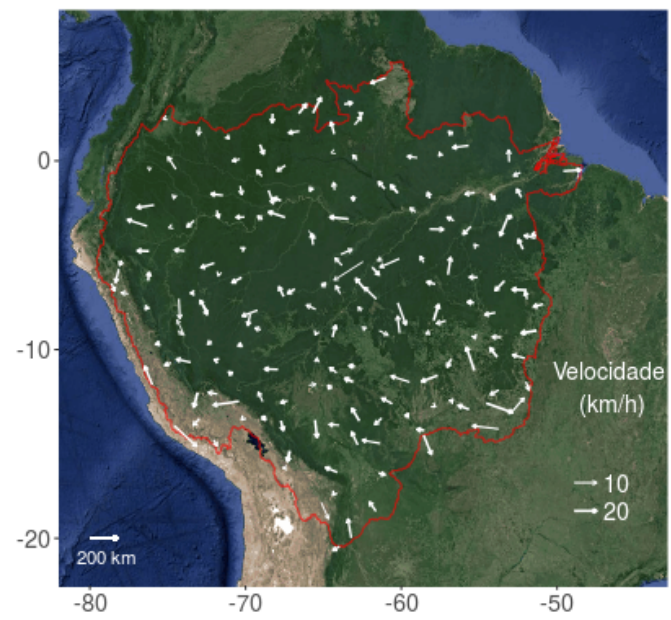

(c) Março

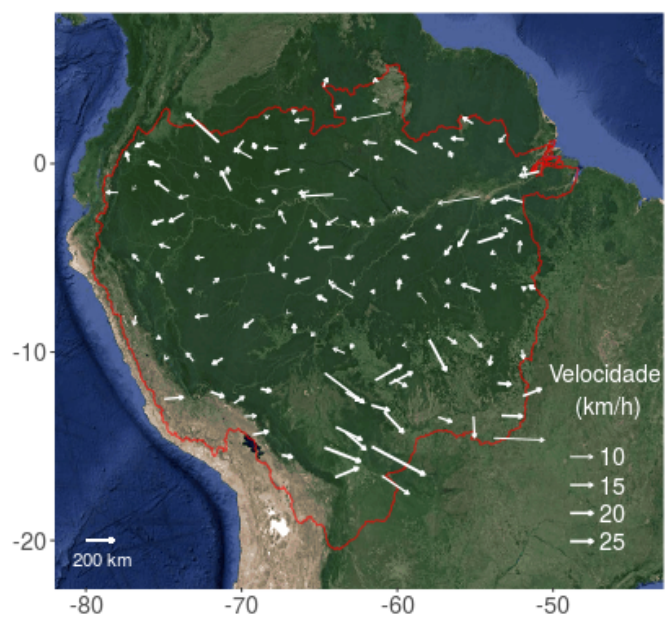

(e) Maio

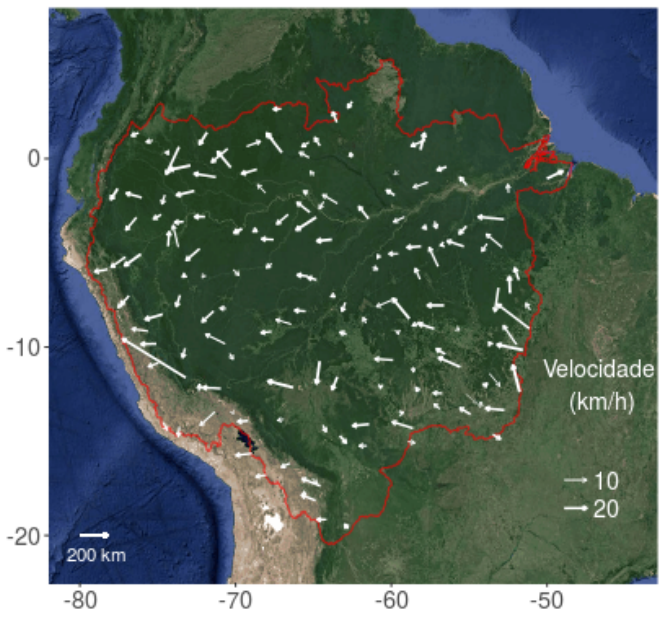

(b) Fevereiro

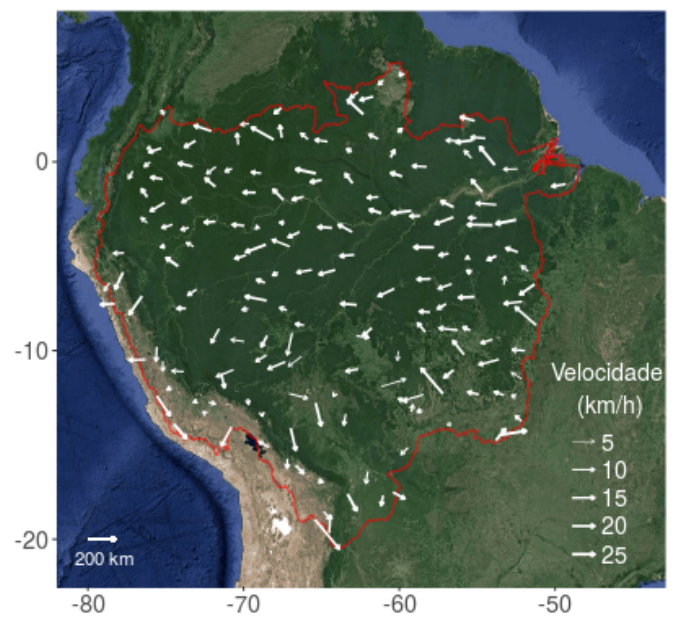

(d) Abril

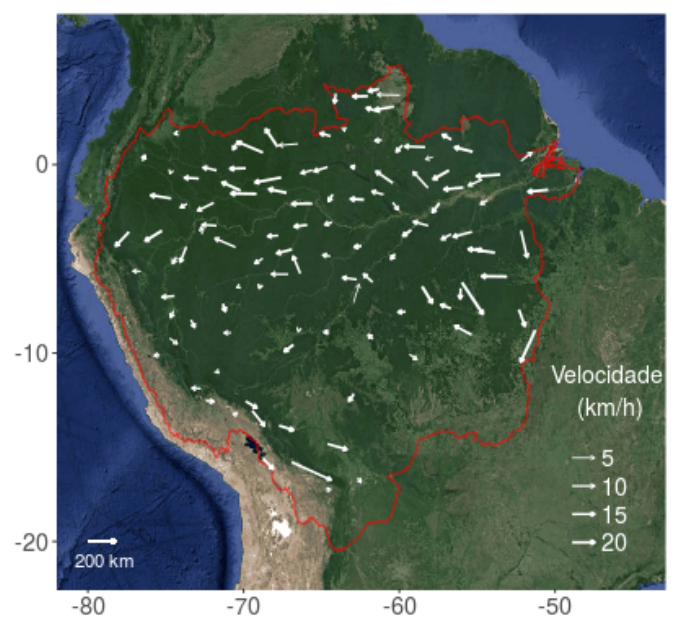

(f) Junho

Figura 34 - Direção de propagação, deslocamentos médios e velocidade média dos SCMs com curto ciclo de vida ocorridos na bacia Amazônica em 2015. O comprimento do vetor indica o deslocamento médio e a largura indica a velocidade. 


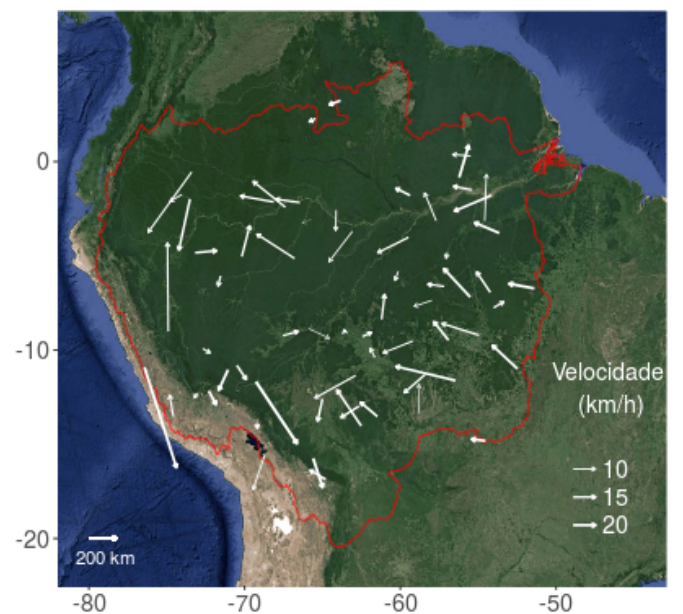

(a) Janeiro

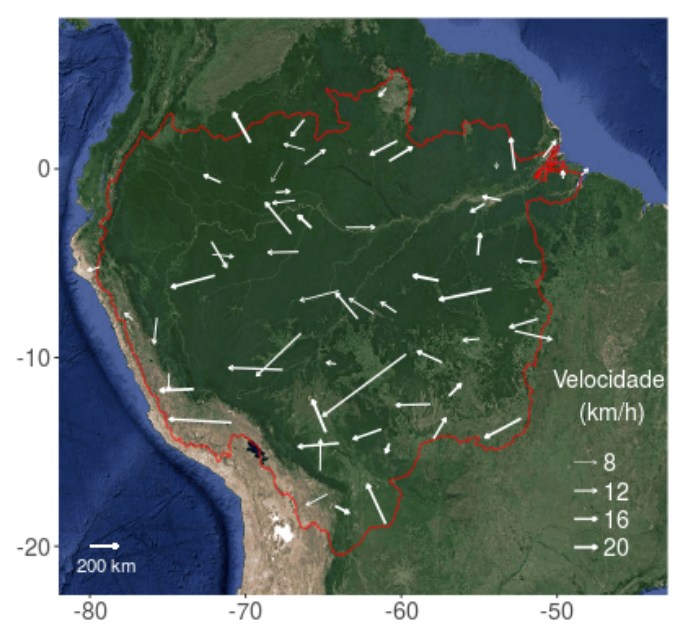

(c) Março

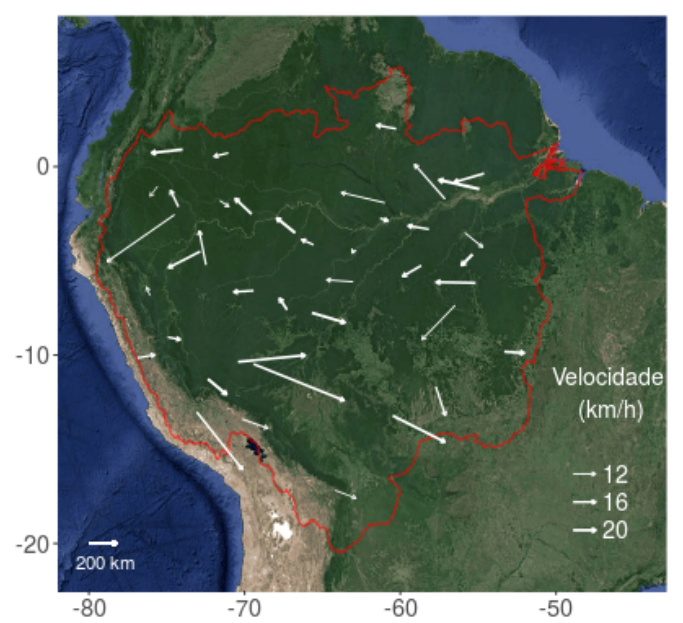

(e) Maio

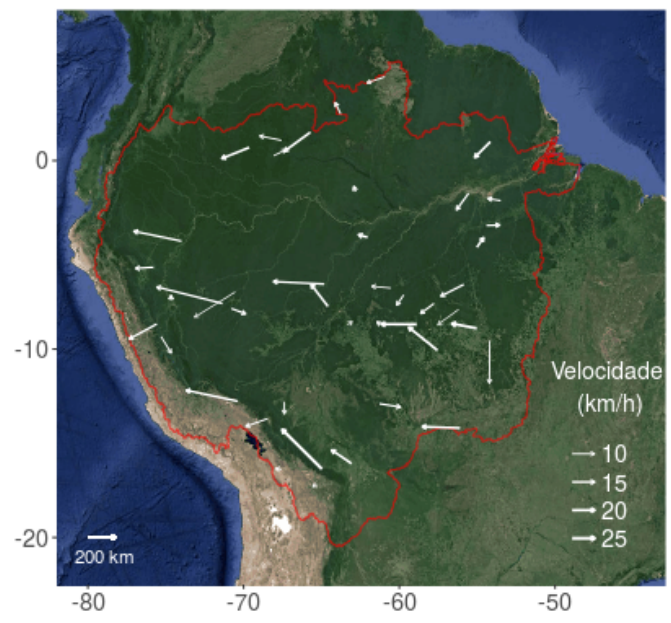

(b) Fevereiro

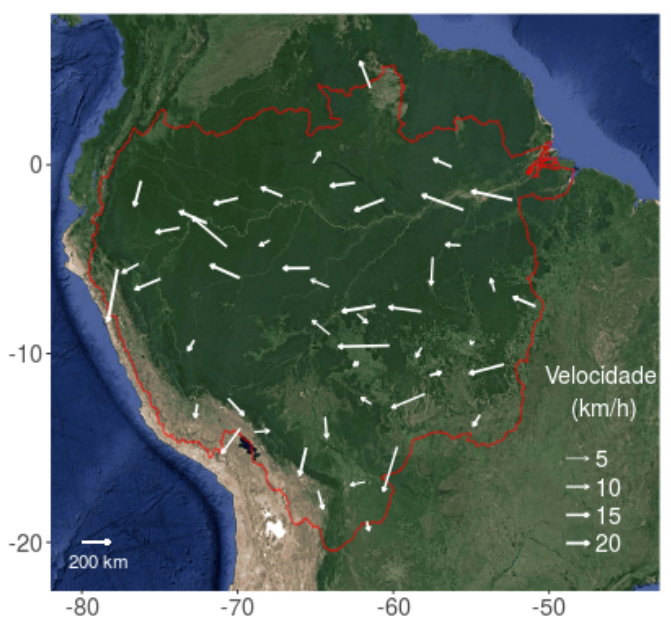

(d) Abril

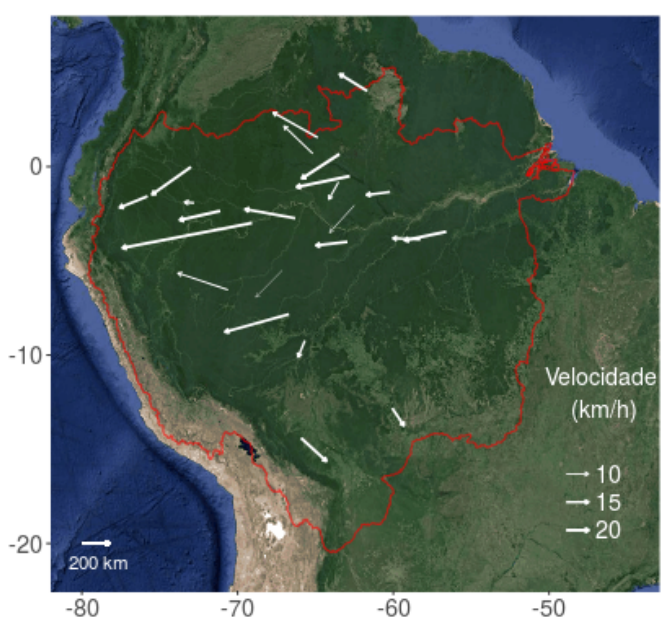

(f) Junho

Figura 35 - Direção de propagação, deslocamentos médios e velocidade média dos SCMs com longo ciclo de vida ocorridos na bacia Amazônica em 2015. O comprimento do vetor indica o deslocamento médio e a largura indica a velocidade. 


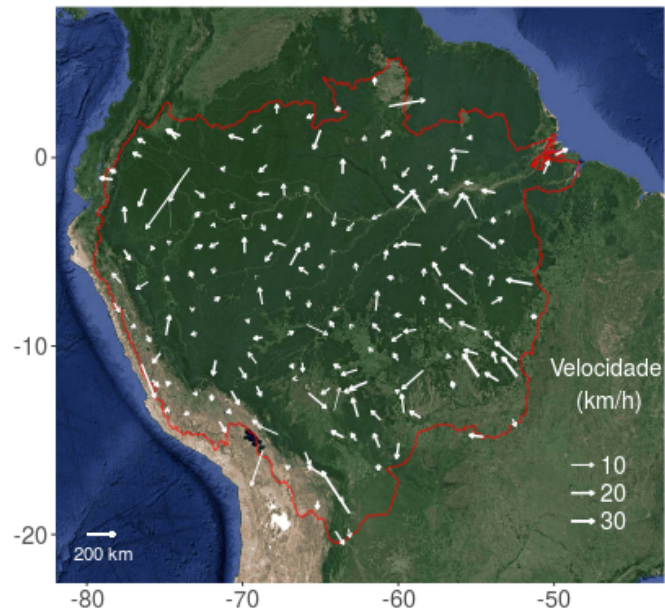

(a) Janeiro

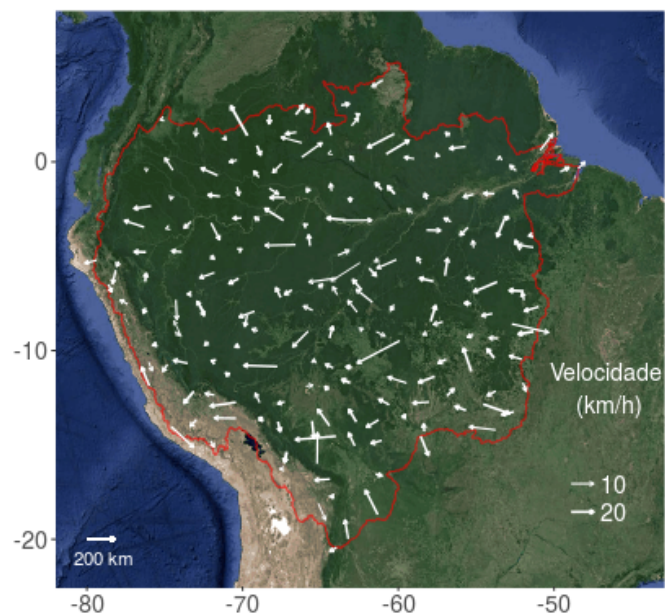

(c) Março

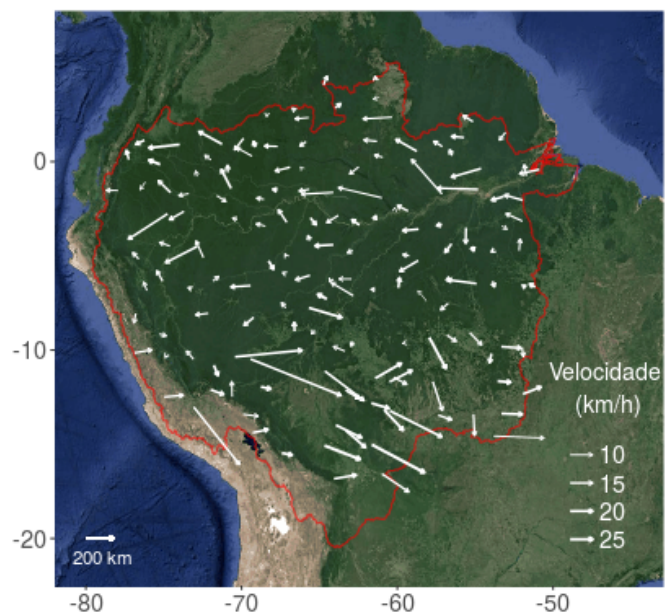

(e) Maio

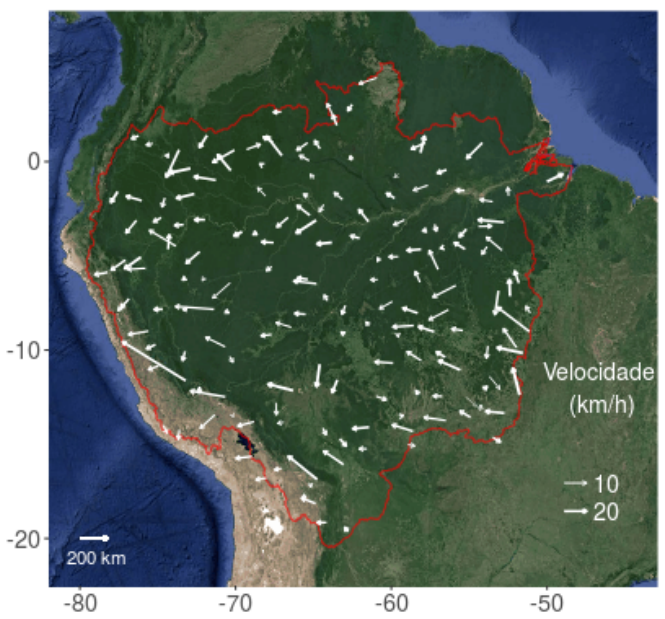

(b) Fevereiro

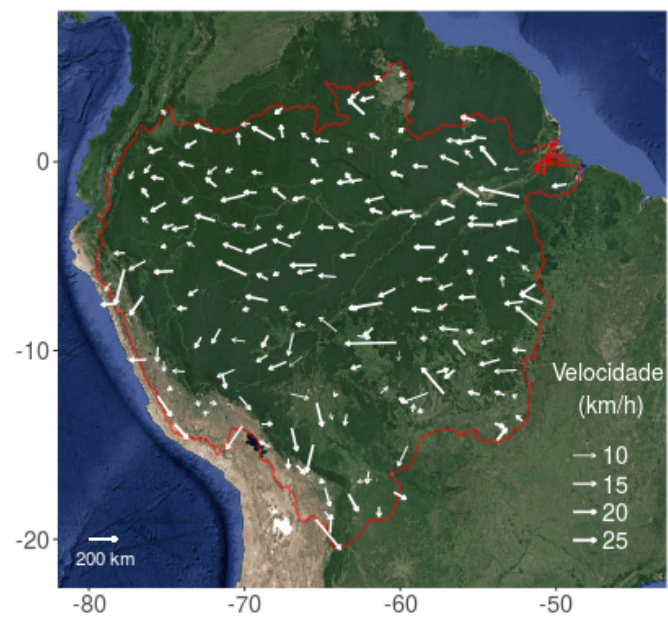

(d) Abril

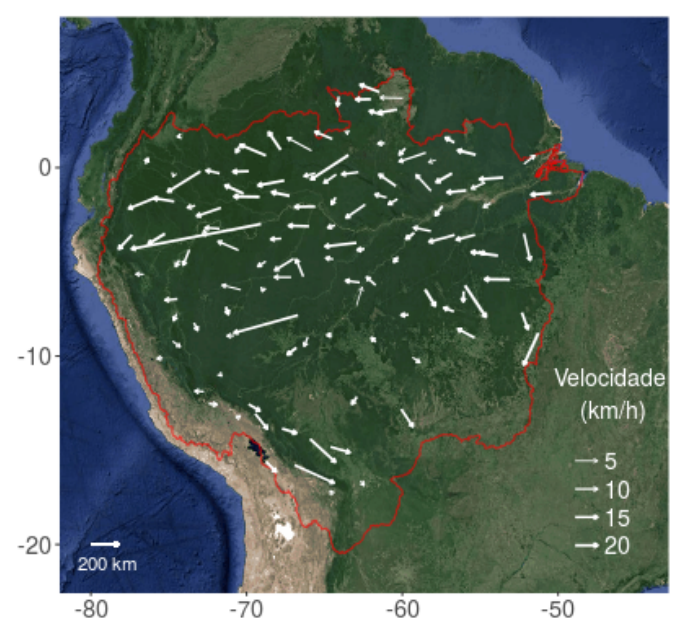

(f) Junho

Figura 36 - Direção de propagação, deslocamentos médios e velocidade média de todos SCMs ocorridos na bacia Amazônica em 2015. O comprimento do vetor indica o deslocamento médio e a largura indica a velocidade. 
Tabela 3 - Áreas médias nas diferentes fases do ciclo de vida de acordo com o tempo de duração dos SCMs continentais e oceânicos ocorridos durante o projeto GOAmazon.

\begin{tabular}{cccccc}
\hline \multirow{2}{*}{ Fase } & Tempo de & \multicolumn{4}{c}{ Área média $\left(\mathbf{k m}^{\mathbf{2}}\right)$} \\
\cline { 3 - 6 } & vida & \multicolumn{2}{c}{ Continentais } & \multicolumn{2}{c}{ Oceânicos } \\
\cline { 3 - 6 } & & $\mathbf{2 0 1 4}$ & $\mathbf{2 0 1 5}$ & $\mathbf{2 0 1 4}$ & $\mathbf{2 0 1 5}$ \\
\hline \multirow{3}{*}{ Gênese } & Curto & 3725 & 4046 & 3387 & 2904 \\
& Longo & 4494 & 4325 & 3938 & - \\
& Todos SCMs & 4109 & 4186 & 3663 & 2904 \\
\hline \multirow{3}{*}{ Maturação } & Curto & 12215 & 13036 & 15856 & 31456 \\
& Longo & 36193 & 35300 & 48244 & - \\
& Todos SCMs & 24204 & 24168 & 32050 & 31456 \\
\hline \multirow{2}{*}{ Dissipação } & Curto & 6298 & 6804 & 6887 & 25976 \\
& Longo & 11549 & 12779 & 13566 & - \\
\hline \multirow{2}{*}{ Todo ciclo } & Todos SCMs & 8923 & 9791 & 10226 & 25976 \\
de vida & Curto & 7897 & 8385 & 9813 & 18441 \\
& Longo & 19300 & 18724 & 23496 & - \\
\hline & Todos SCMs & 13597 & 13554 & 16654 & 18441 \\
\hline
\end{tabular}

Os SCMs de longa duração ocorridos durante o GOAmazon apresentaram, em média, maior área durante as fases inicial, maturação e final que os sistemas de curta duração, similar à climatologia. Com relação à sazonalidade, áreas médias não apresentaram grandes variações, exceto com relação as médias das áreas máximas, onde no período de inverno eles tiveram áreas levemente menores comparado com os outros meses (não mostradas aqui).

\subsubsection{SCMs oceânicos e suas características}

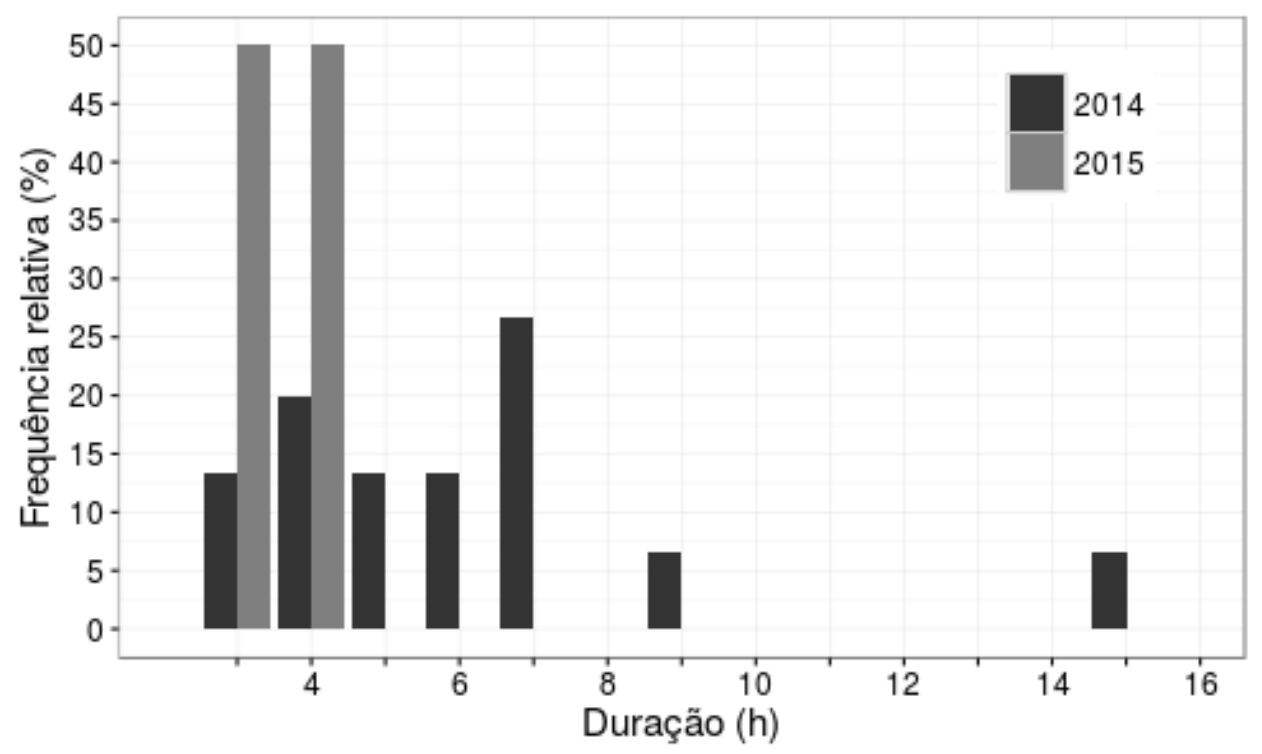

Figura 37 - Frequência relativa (\%) de SCMs oceânicos de acordo com o ciclo de vida (h) ocorridos durante o projeto GOAmazon. 
A ocorrência de SCMs oceânicos em 2014 foi de 15 sistemas, correspondendo à $30,8 \%$ da climatologia anual, e em 2015 ocorreram somente 2 (4,1\% da climatologia). O tempo de vida médio dos SCMs oceânicos ocorridos durante o GOAmazon foi menor que a climatologia. Em 2014 a duração média foi de 6,4 horas e em 2015 a média foi de 3,7 horas, enquanto que a climatologia apresenta 11,8 horas. O maior tempo de vida observado foi de 15 horas e 30 minutos em 2014 (Figura 37).

Os horários de gênese, maturação e dissipação dos SCMs oceânicos de acordo com o tempo de vida ocorridos em 2014 encontram-se na Figura 38. Os dois SCMs ocorridos em 2015 tiveram curto ciclo de vida e as gêneses ocorreram às 05 e 16 UTC. A maturação em ambos os casos ocorreu 1 hora após a gênese e a dissipação foi às 08 e 2030 UTC, respectivamente.

A velocidade média de propagação dos sistemas de curta duração ocorridos em 2014 foi de $15,9 \mathrm{~km} / \mathrm{h}( \pm 2,5 \mathrm{~km} / \mathrm{h})$ e a velocidade média dos SCMs de longa duração ocorridos no mesmo ano foi de 20,6 km/h ( $\pm 5,4 \mathrm{~km} / \mathrm{h})$. Em 2015 a velocidade média foi de $12,4 \mathrm{~km} / \mathrm{h}( \pm 3,5 \mathrm{~km} / \mathrm{h})$. Em ambos os anos as velocidades médias foram menores que a climatologia. O deslocamento médio dos SCMs de curta duração ocorridos em 2014 foi de 110,7 km ( $\pm 36,8 \mathrm{~km})$ e de longa duração 266,5 km ( $\pm 136,2 \mathrm{~km})$. Em 2015 o deslocamento médio dos SCMs foi de $89,4 \mathrm{~km}$ ( $\pm 16 \mathrm{~km})$.

As áreas médias dos SCMs oceânicos ocorridos durante o GOAmazon encontramse na Tabela 3. A média das áreas iniciais foram muito similares à climatologia. Os SCMs de longa duração em 2014 apresentaram média das áreas na fase de maturação bem abaixo da climatologia e em 2015, os SCMs com curto ciclo de vida apresentaram a média da área na fase de maturação muito maior que a climatologia. O mesmo aconteceu na fase de dissipação para os SCMs de curto ciclo de vida ocorridos em 2015 e para aqueles com longo ciclo de vida ocorridos em 2014. 

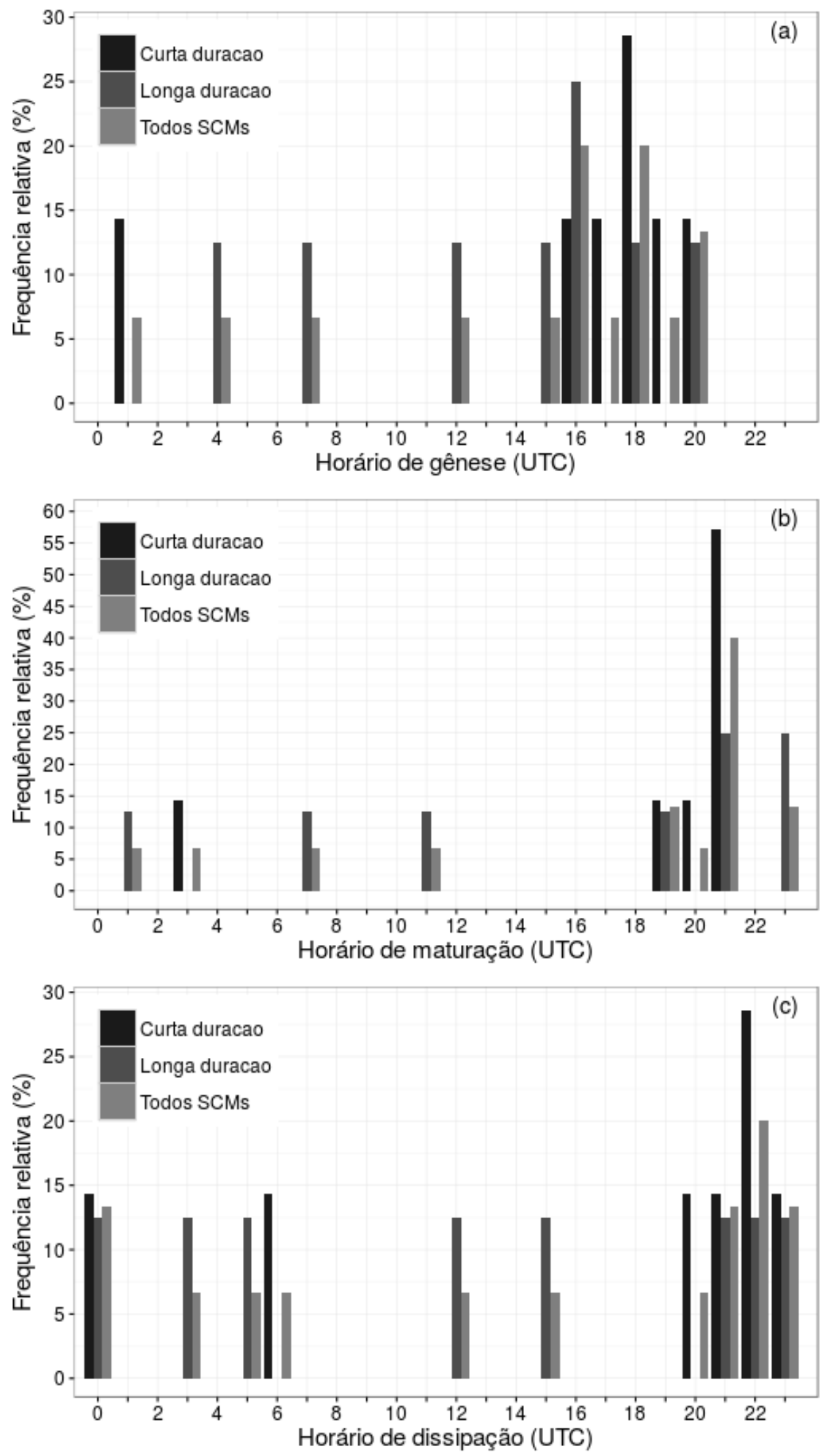

Figura 38 - Horário de (a) gênese, (b) maturação e (c) dissipação dos SCMs oceânicos ocorridos em 2014 de acordo com o tempo de vida. Cada horário representa o intervalo da hora cheia mais meia hora. 


\subsection{SCMs ocorridos próximos às estações do GOAmazon}

Foram detectados 21 SCMs sobre a região das estações do projeto GOAmazon (Figura 1) no período analisado. As localizações destes sistemas e suas direções de propagação podem ser observados na Figura 39. Como pode ser visto, nenhum deles teve origem oceânica. A média dos deslocamentos foi $249 \mathrm{~km}$ e o máximo deslocamento ocorreu para sudoeste e apresentou $690 \mathrm{~km}$ (SCM de número 6). A velocidade média dos SCMs foi de $15 \mathrm{~km} / \mathrm{h}$, a velocidade máxima de $23,3 \mathrm{~km} / \mathrm{h}$ e a mínima de 7,5 km/h. A maioria dos SCMs, 9 deles, teve deslocamento para noroeste, 8 para sudoeste, 3 para sudeste e 1 para nordeste. Mais detalhes encontram-se na Tabela 4.

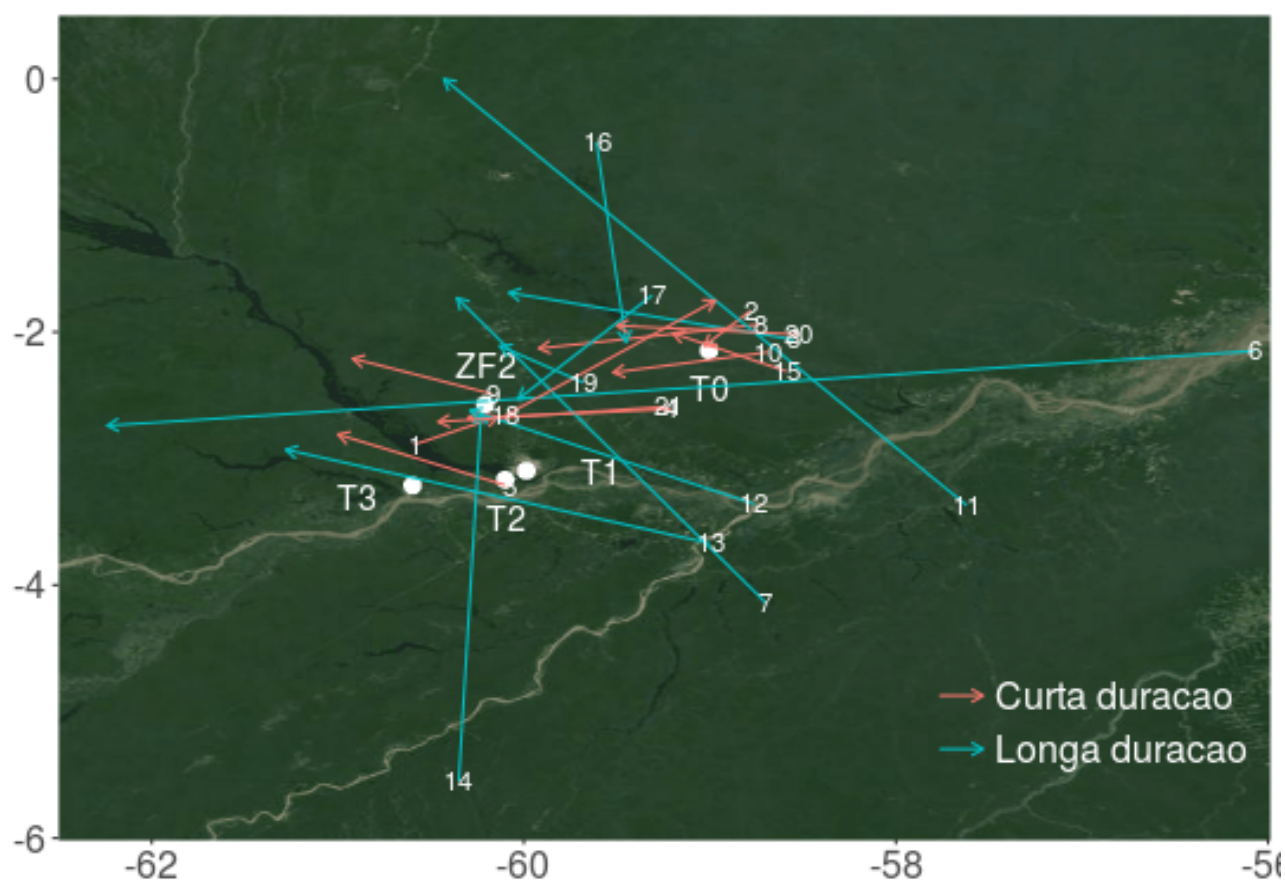

Figura 39 - Localização e deslocamentos dos SCMs ocorridos próximo às estações do GOAmazon de acordo com o tempo de vida. Os SCMs são identificados através do número no início de cada seta (Tabela 4). O início da seta indica a posição inicial do SCM, a ponta da seta indica a posição final e sua inclinação indica a direção de deslocamento. As estações de coleta de dados do GOAmazon estão indicadas por círculos brancos fechados. 


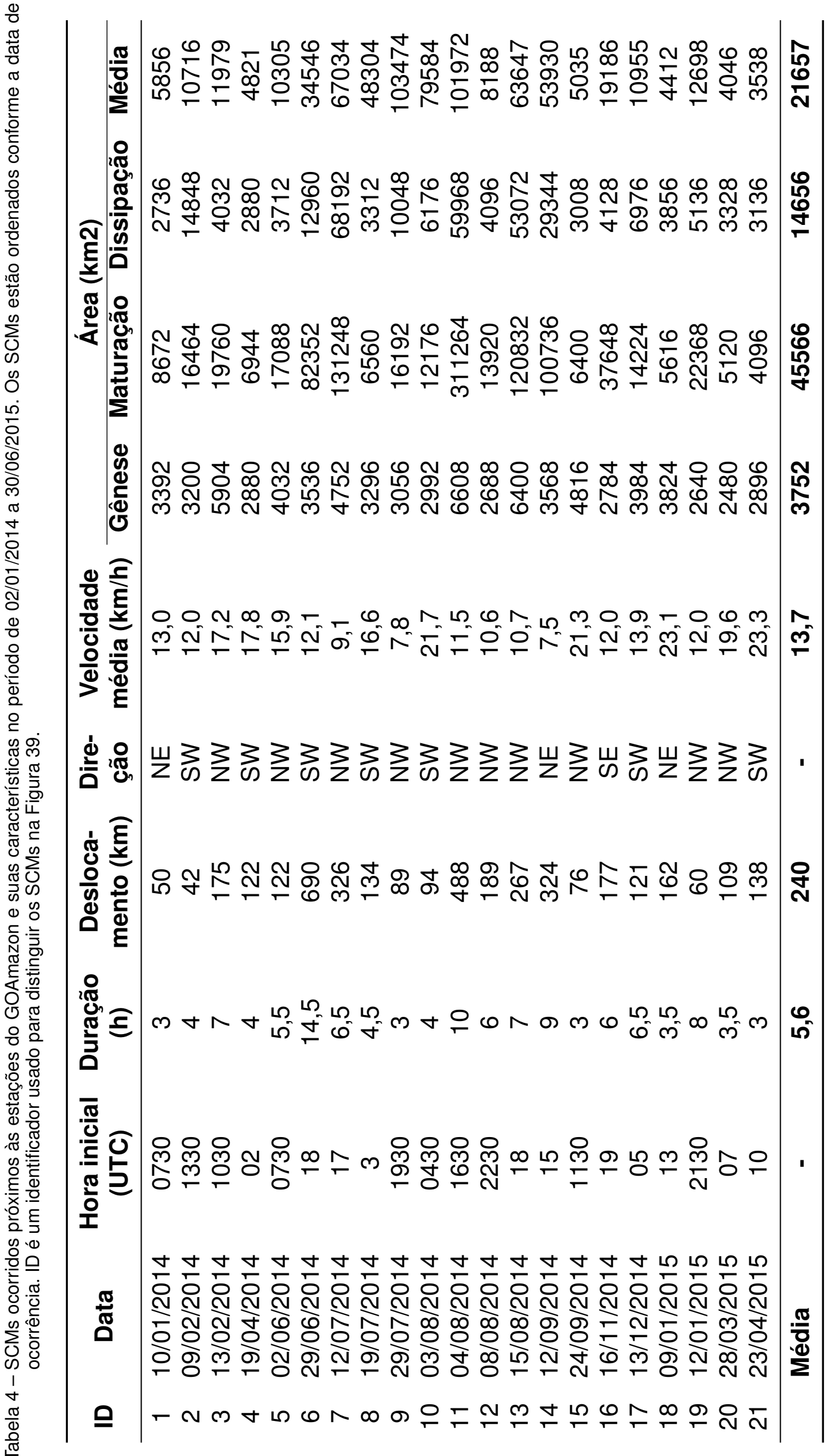




\subsubsection{Análise sinótica e das condições dinâmicas e termodinâmicas observadas}

As análises sinóticas a seguir estão focadas em descrever e identicar os fenômenos sinóticos que atuaram como pré-condicionantes, auxiliando na formação, manutenção até a dissipação dos SCMs ocorridos na parte central da região Amazônica, onde as estações do projeto GOAmazon estiveram situadas durante o projeto. Para isso, buscou-se analisar o primeiro horário precedente à fase inicial do SCM, os horários durante seu ciclo de vida e um horário posterior à sua dissipação nos níveis de 250 $\mathrm{hPa}, 500 \mathrm{hPa}, 700 \mathrm{hPa}$ e $1000 \mathrm{hPa}$. Contudo, o presente texto traz um resumo das condições observadas, abordando os horários citados conforme a necessidade.

Juntamente com a análise sinótica, foram verificadas as condições de instabilidade termodinâmica nos eventos estudados. Nascimento (2005) explica que os índices de instabilidade indicam o potencial que as tempestades têm para se tornarem severas. Neste sentido, o autor indica que na presença de cisalhamento vertical do vento, por exemplo, o desenvolvimento de perturbações de pressão dinâmicas dentro de células convectivas é favorecido e que estas perturbações contribuem na intensificação das acelerações de correntes verticais dentro das nuvens. Embora o autor explique que estes índices estão voltados para a verificação de severidade de tempestades em médias latitudes e que há necessidade de expandir o conhecimento e aplicação destes parâmetros para outras regiões do país que não só as de médias latitudes, eles serão analisados no presente trabalho para verificar as condições de instabilidade em que os SCMs estiveram embebidas. Portanto, o foco não é investigar a severidade, mas somente as condições termodinâmicas que foram observadas durante o projeto GOAmazon, comparando os parâmetros quando houve ocorrências de SCMs próximo às estações de coleta de dados e na ausência destas. Desta forma, os índices de instabilidade observados durante a ocorrência dos SCMs analisados foram comparados com a correspondente média do horário e do mês em que o ocorreu. Por exemplo, se o SCM ocorreu em 10/01/2014 e teve gênese as 02 UTC, os índices encontrados nos horários próximos à ocorrência deste sistema (no caso 00 e 06 UTC) foram comparados com a média dos índices de instabilidade nos mesmos horários do mês de janeiro.

A Figura 40 mostra a média mensal e horária de cada índice termodinâmico calculado de acordo com o local onde a radiossondagem foi obtida (Manacapuru - sítio T3 do GOAmazon e Manaus - Aeroporto de Ponta Pelada, SBMN), excluindo os 21 dias em que houve ocorrência de SCMs próximos às estações do GOAmazon. Os índices de instabilidade correspondentes a cada um dos 21 eventos encontram-se na Figura 40. Informações adicionais sobre características de cada SCM encontram-se na Tabela 4 e Figura 39. 


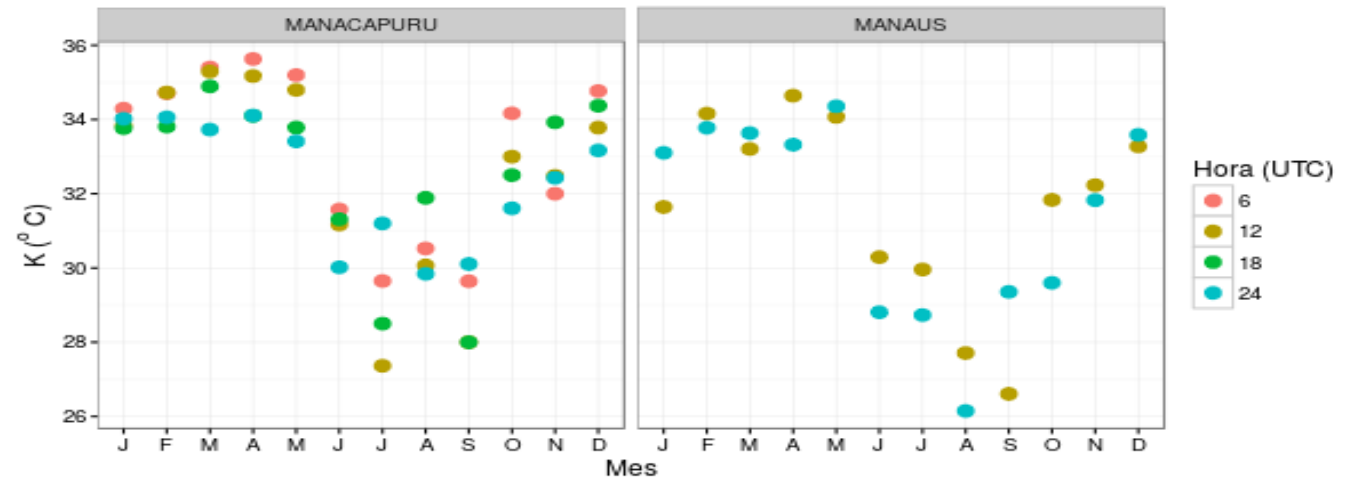

(a) Índice $\mathrm{K}\left({ }^{\circ} \mathrm{C}\right)$

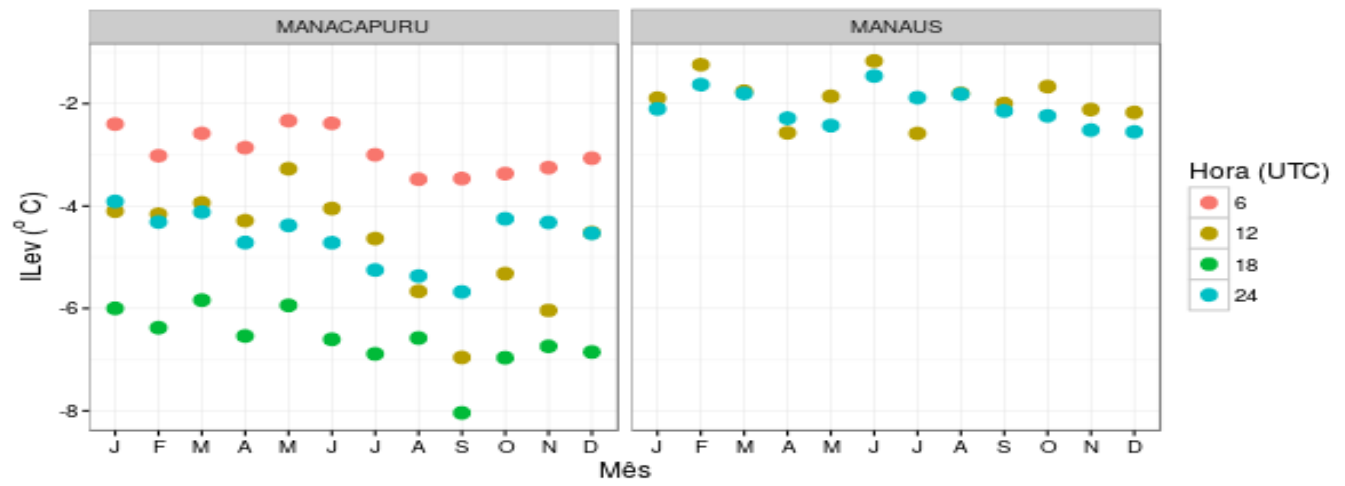

(b) Índice de Levantamento $\left({ }^{\circ} \mathrm{C}\right)$

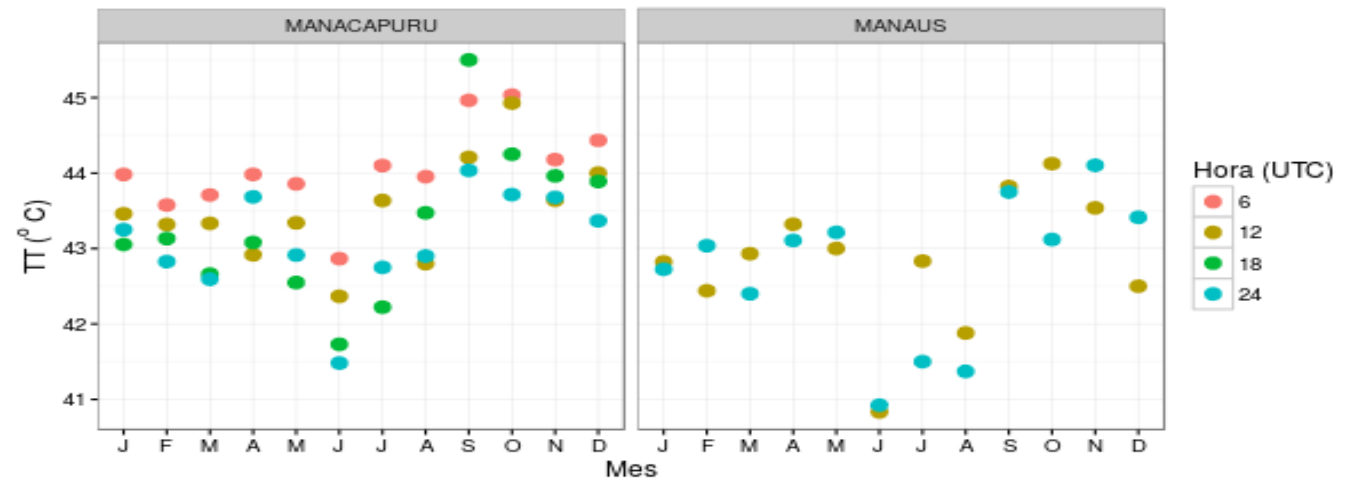

(c) Total Totals $\left({ }^{\circ} \mathrm{C}\right)$

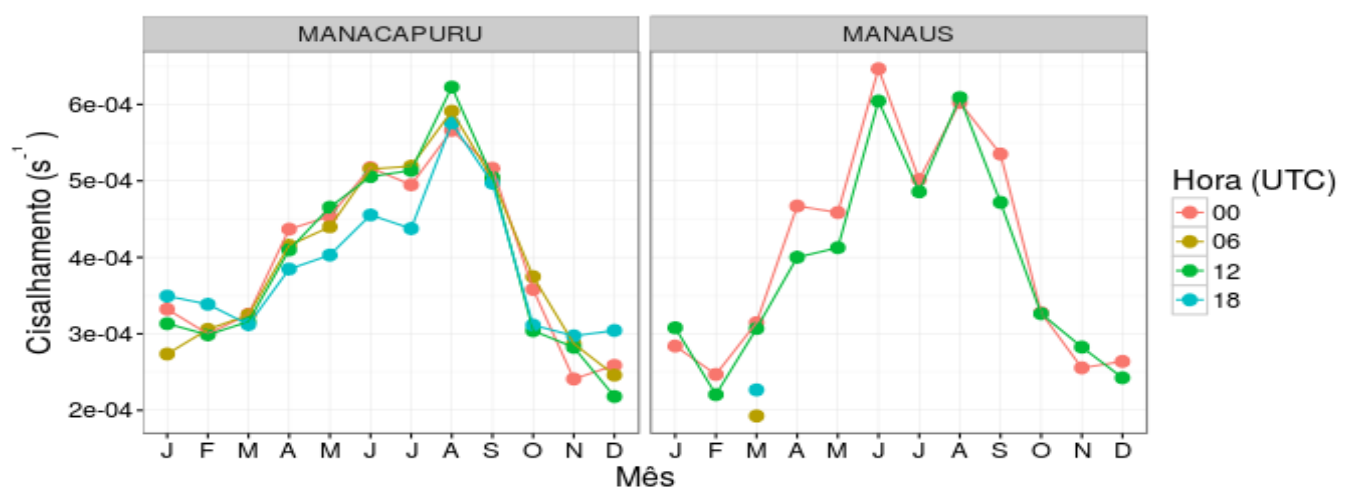

(f) Cisalhamento $\left(\mathrm{s}^{-1}\right)$

Figura 40 - Média mensal e horária dos índices de instabilidade calculados usando dados de radiossondagens lançadas em Manaus - SBMN (2014) e Manacapuru - T3 (2014 e 01/01-30/02/2015). 


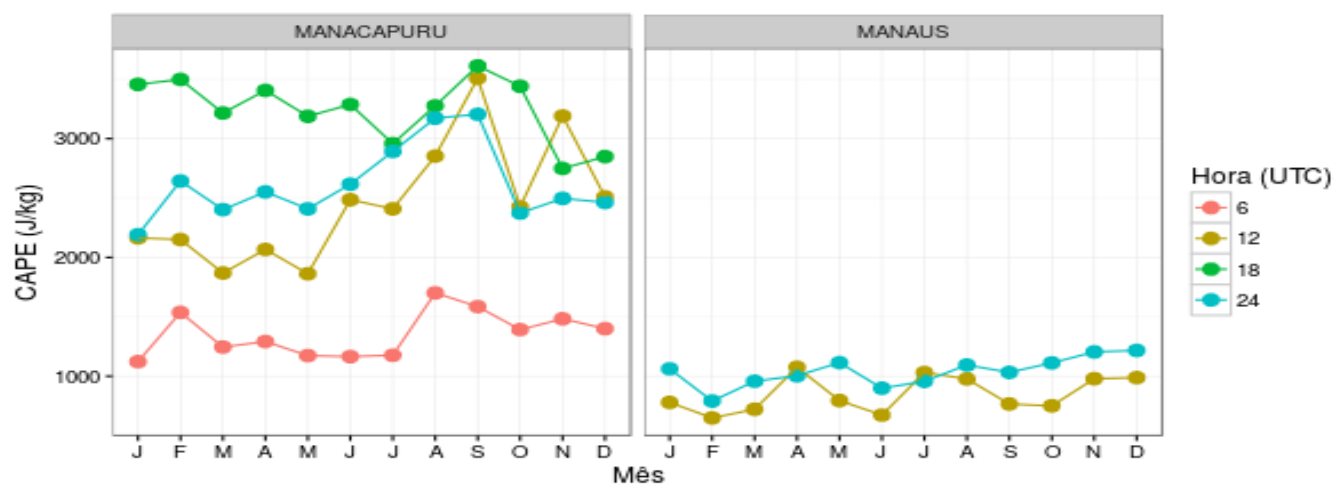

(d) CAPE $(\mathrm{J} / \mathrm{kg})$

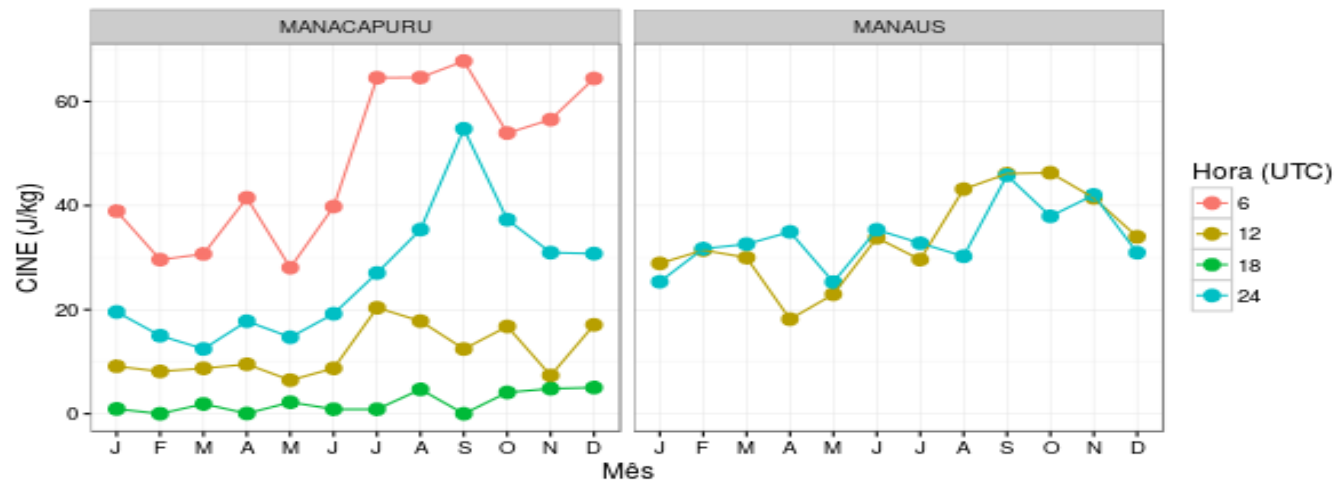

(e) CINE (J/kg)

Figura 40 - Continuação da figura da página anterior.

De um modo geral, os índices calculados mostraram menor instabilidade em Manaus comparada a Manacapuru. A média mensal do índice $\mathrm{K}$, apresentada na Figura 40 (a), mostra que em Manaus e Manacapuru estes índices são bastante parecidos, tanto na intensidade, variando cerca de $2^{\circ} \mathrm{C}$, quanto no padrão, onde durante o verão este índice fica acima de $33^{\circ} \mathrm{C}$ na maioria dos horários e no inverno tem uma leve diminuição e fica em torno de 28 a $29^{\circ} \mathrm{C}$, voltando aumentar durante a primavera. Este padrão sazonal apresentado pelo índice $\mathrm{K}$ ocorre, pois ele tende apresentar valores relativamente mais baixos quando existe intrusão de ar seco em níveis baixos e médio (NASCIMENTO, 2005).

O índice de levantamento aprensenta em torno de $-2^{\circ} \mathrm{C}$ em Manaus ao longo do ano nos horários das 12 e 00 UTC, com uma leve tendência de diminuição (aumento de instabilidade) na primavera. Em Manacapuru, nos mesmos horários os valores ficam ao redor de $-4^{\circ} \mathrm{C}$, porém as 18 UTC a instabilidade aumenta ficando abaixo de $-6^{\circ} \mathrm{C}$.

$\mathrm{O}$ índice total totals em Manacapuru, assim como os demais descritos anteriormente, apresenta valores de instabilidade levemente maiores comparado à Manaus.

Os valores de cisalhamento variaram bastante ao longo do ano, porém entre os horários não houve muitas diferenças exceto as 18 UTC no final do outono e início do inverno, onde o cisalhamento foi levemente menor que nos demais horários em 
Manacapuru. O cisalhamento em Manacapuru apresentou um pico de maior intensidade em agosto em todos os horários e seu valor foi bastante aproximado nos mesmos. Manaus teve o mesmo pico no horário das 00 e das 12 UTC, porém em julho novamente ocorreu um pico de maior cisalhamento.

A média mensal da CAPE apresentou altas variações entre horários (no caso de Manacapuru) e localidades, porém pouco variação nas diferentes estações do ano. Muitos fatores influenciam no valor da CAPE: a diferença entre a temperatura da parcela de ar ascendente e do ar ambiente, níveis em que se encontram o NCE e o NEL e a escolha da parcela de ar ascendente, além do entranhamento de ar ambiente em torno da tempestade e presença de hidrometeoros (HOUZE, 1993). A CINE, por outro lado, foi mais elevada em Manaus que em Manacapuru e teve uma tendência de aumento no final do inverno até dezembro. Em Manacapuru a CINE as 06 UTC foi a mais alta observada ao longo de todo o ano e juntamente com o horário das 00 UTC teve uma tendência de aumento a partir do inverno.

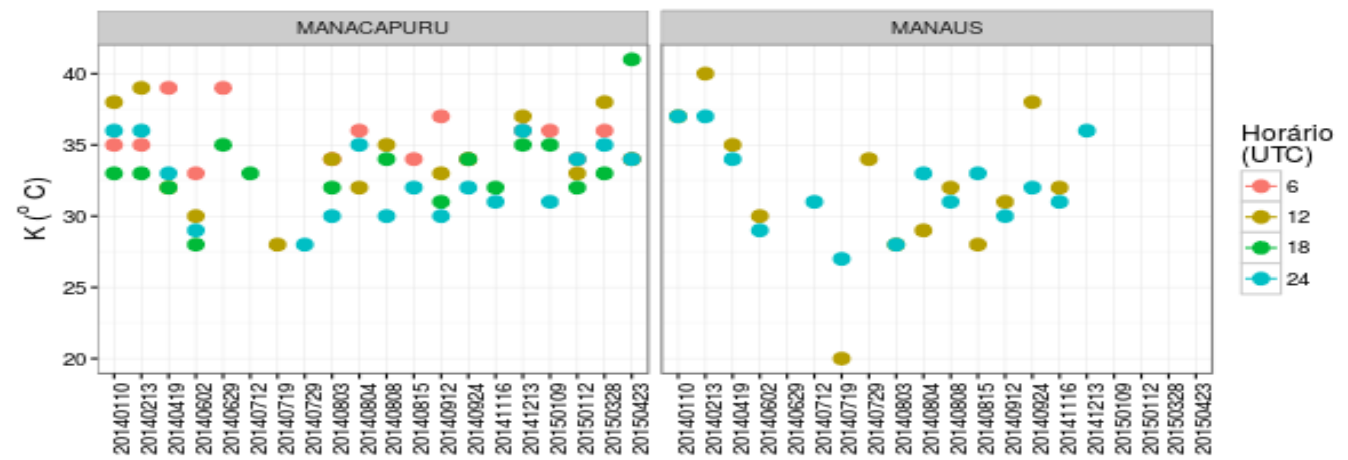

(a) Índice $\mathrm{K}\left({ }^{\circ} \mathrm{C}\right)$

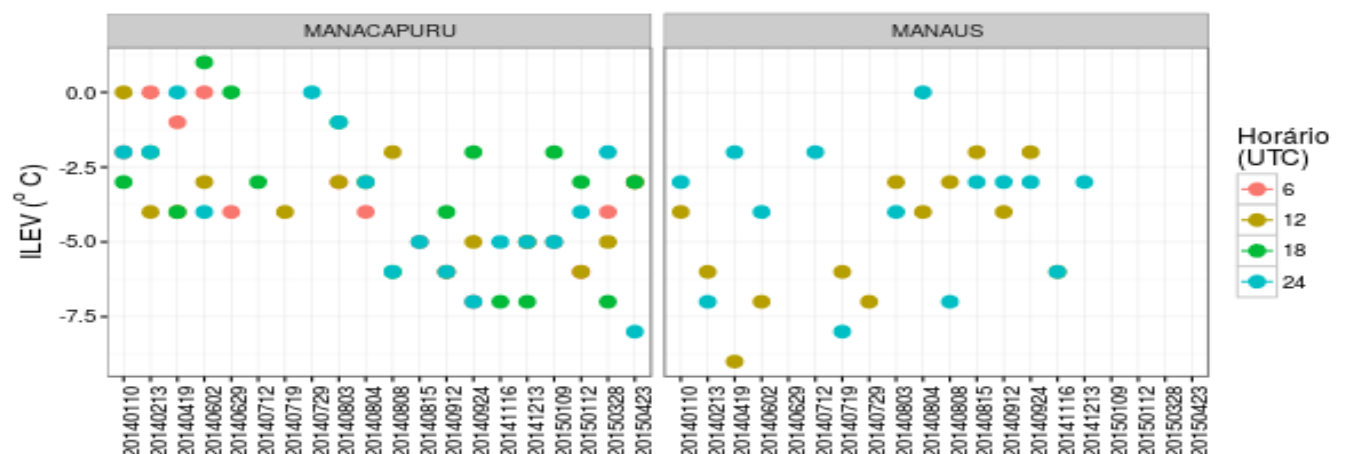

(b) Índice de Levantamento $\left({ }^{\circ} \mathrm{C}\right)$

Figura 41 - Índices de instabilidade de acordo com o horário e estação de lançamento da radiossonda. 


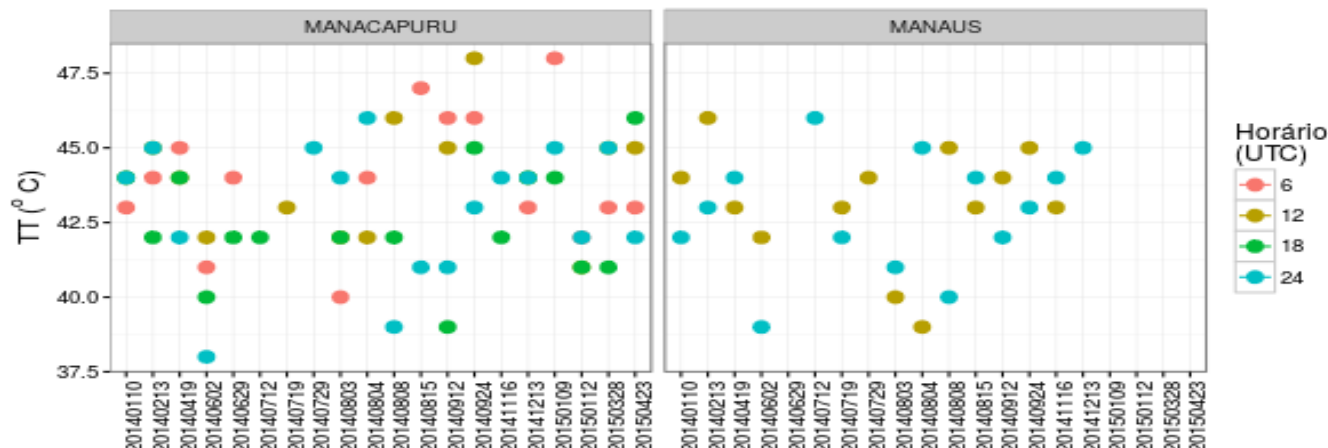

(c) Total Totals $\left({ }^{\circ} \mathrm{C}\right)$

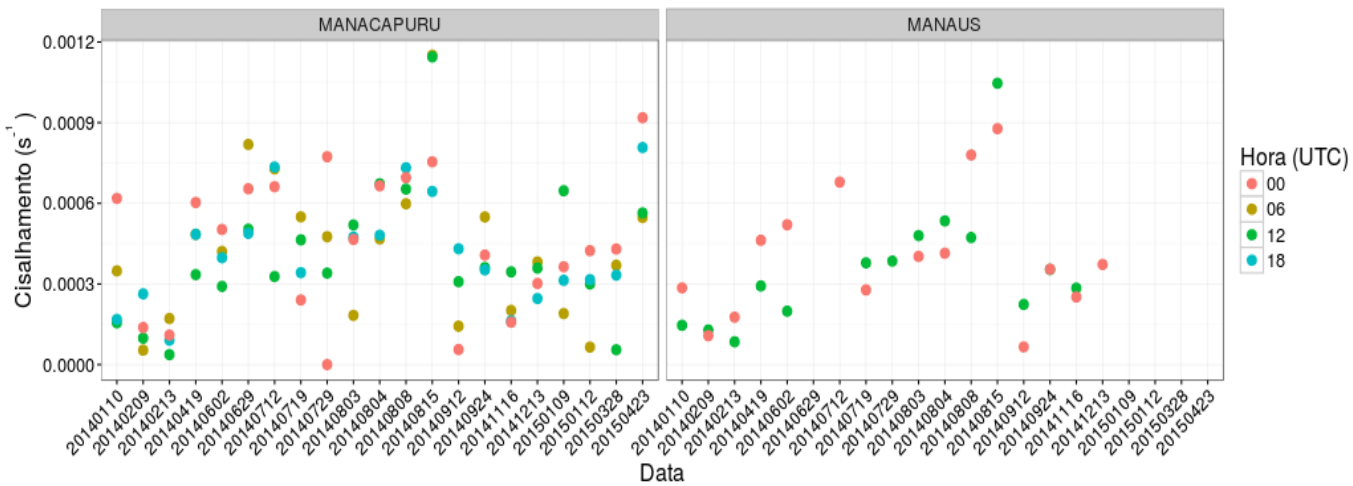

(d) Cisalhamento $\left(\mathrm{s}^{-1}\right)$

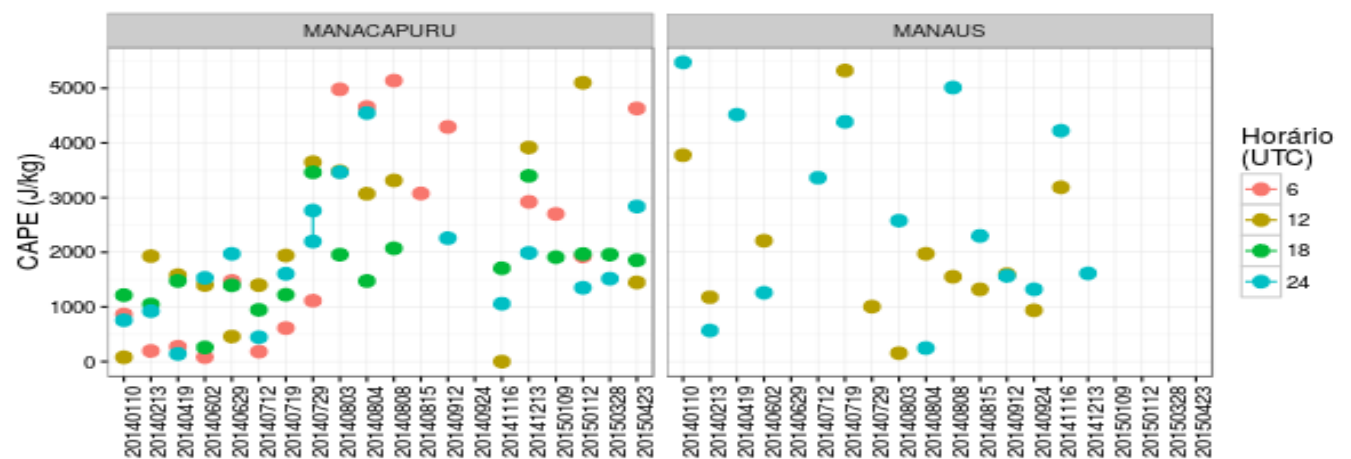

(e) CAPE (J/kg)
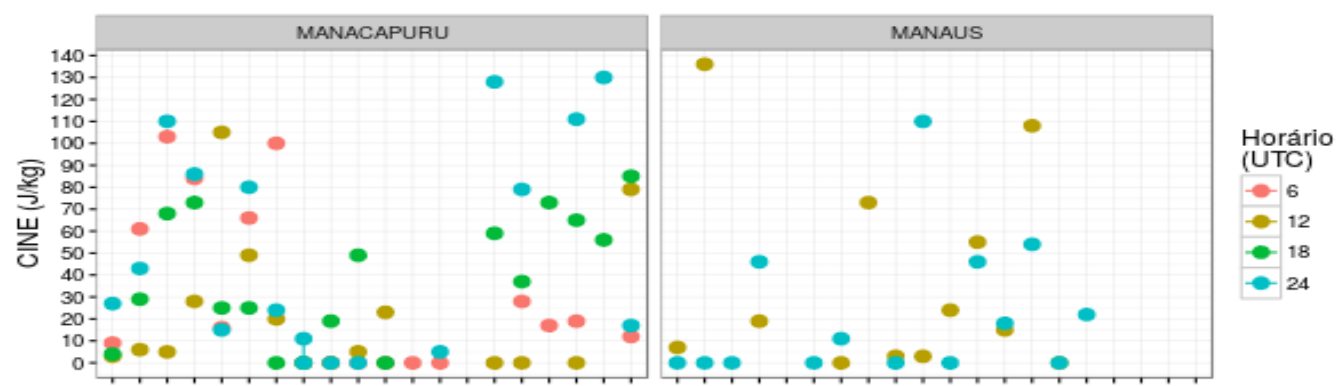

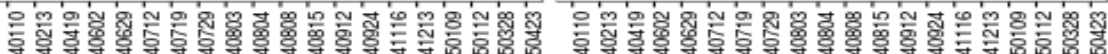

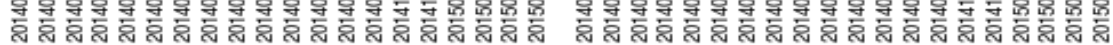

(f) $\operatorname{CINE}(\mathrm{J} / \mathrm{kg})$

Figura 41 - Continuação da figura da página anterior. 


\section{0/01/2014 - horário de gênese: 0730 UTC}

A carta sinótica em altos níveis $(250 \mathrm{hPa})$ mostra difluência no escoamento sobre o noroeste da bacia Amazônica (Figura 42 (a)). Esta difluência é causada pela atuação conjunta de um anticiclone centrado sobre o oceano Pacífico em aproximadamente $19^{\circ} \mathrm{S} / 76^{\circ} \mathrm{W}$ e um Vórtice Ciclônico de Altos Níveis (VCAN), localizado à leste do anticiclone e centrado entre o norte de Minas Gerais e o sul da Bahia. A partir desta região há um cavado com eixo se estendendo em direção ao sul do Pará e do Amazonas. A difluência mencionada gera divergência de massa em altos níveis a qual resulta em convergência em baixos níveis.

Desta forma, o padrão de divergência em altos níveis descrito anteriormente aliado à termodinâmica favorável, observada através dos índices de instabilidade, atuaram na formação do SCM observado. Apesar desta combinação de fatores favoráveis, o sistema teve curto tempo de vida, por outro lado, observou-se bastante atividade convectiva nas imagens de satélite apresentadas na Figura 43.

A Figura 44 mostra as principais condições de tempo ocorridas no dia 10/01/2014 em Manacapuru. A figura mostra que houve precipitação associada a este sistema e aumento na velocidade do vento, acompanho de queda na pressão atmosférica, com ápices no momento da maturação (0930 UTC). Porém, os maiores registros de precipitação observados neste dia ocorreram após a dissipação daquele SCM e estão associados ao sistema formado ao sul da região de dissipação do SCM analisado (Figura 43 (c)).

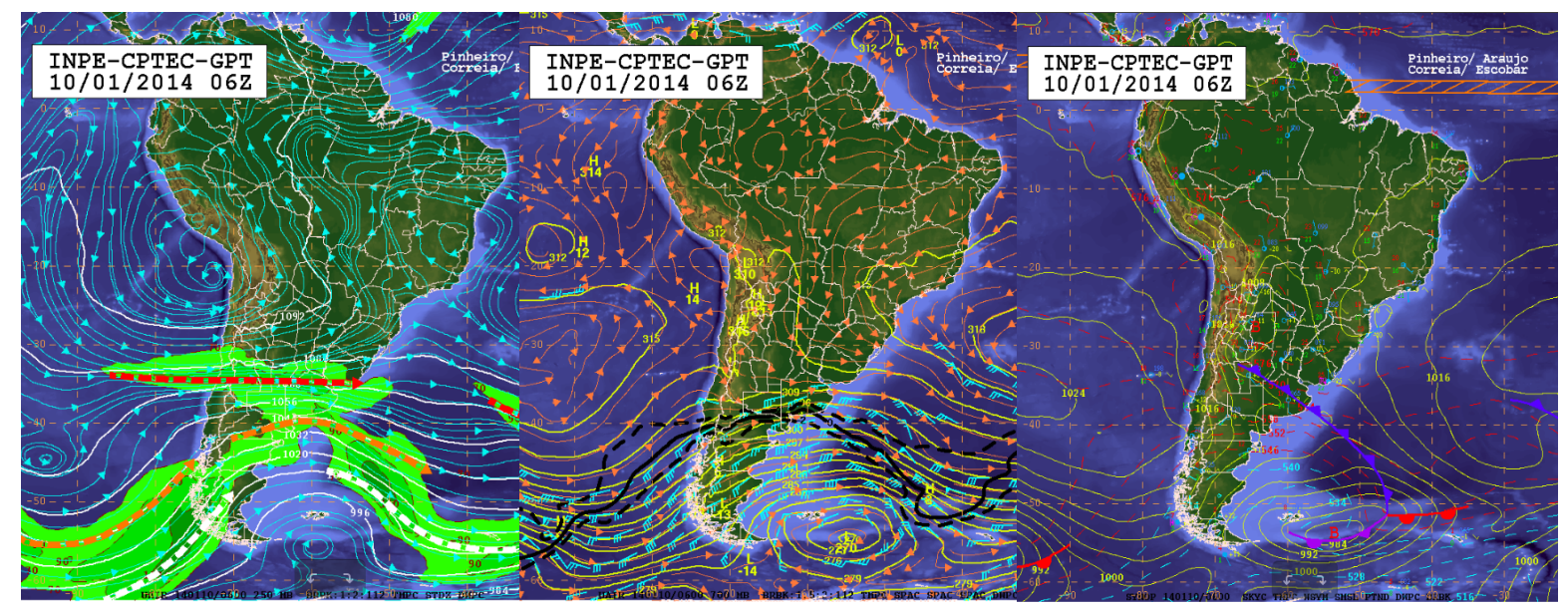
(a) $250 \mathrm{hPa}$
(b) $700 \mathrm{hPa}$
(c) Superfície

Figura 42 - Cartas sinóticas do dia 10/01/2014 - 06 UTC em (a) $250 \mathrm{hPa}$, (b) $700 \mathrm{hPa}$ e (c) superfície. Fonte: CPTEC/INPE. 


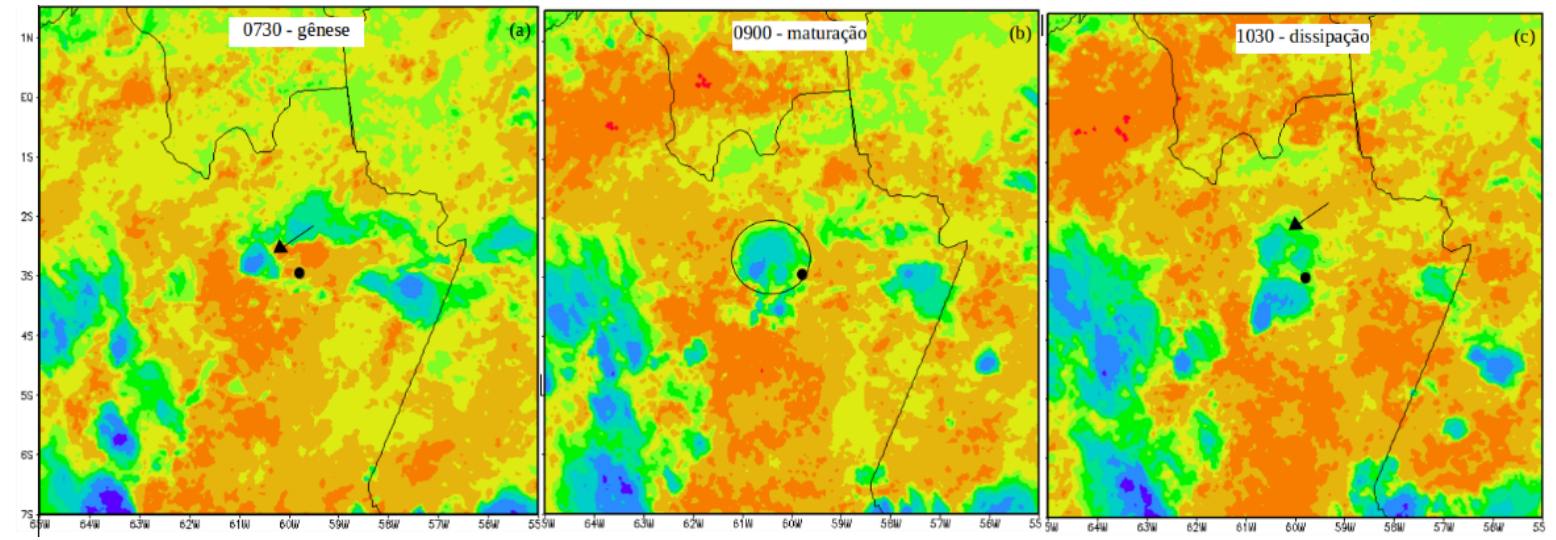

Figura 43 - Imagens de satélite do canal infravermelho em 10/01/2014. Fase de (a) gênese - 0730 UTC, (b) maturação - 0900 UTC e (c) dissipação - 1030 UTC.
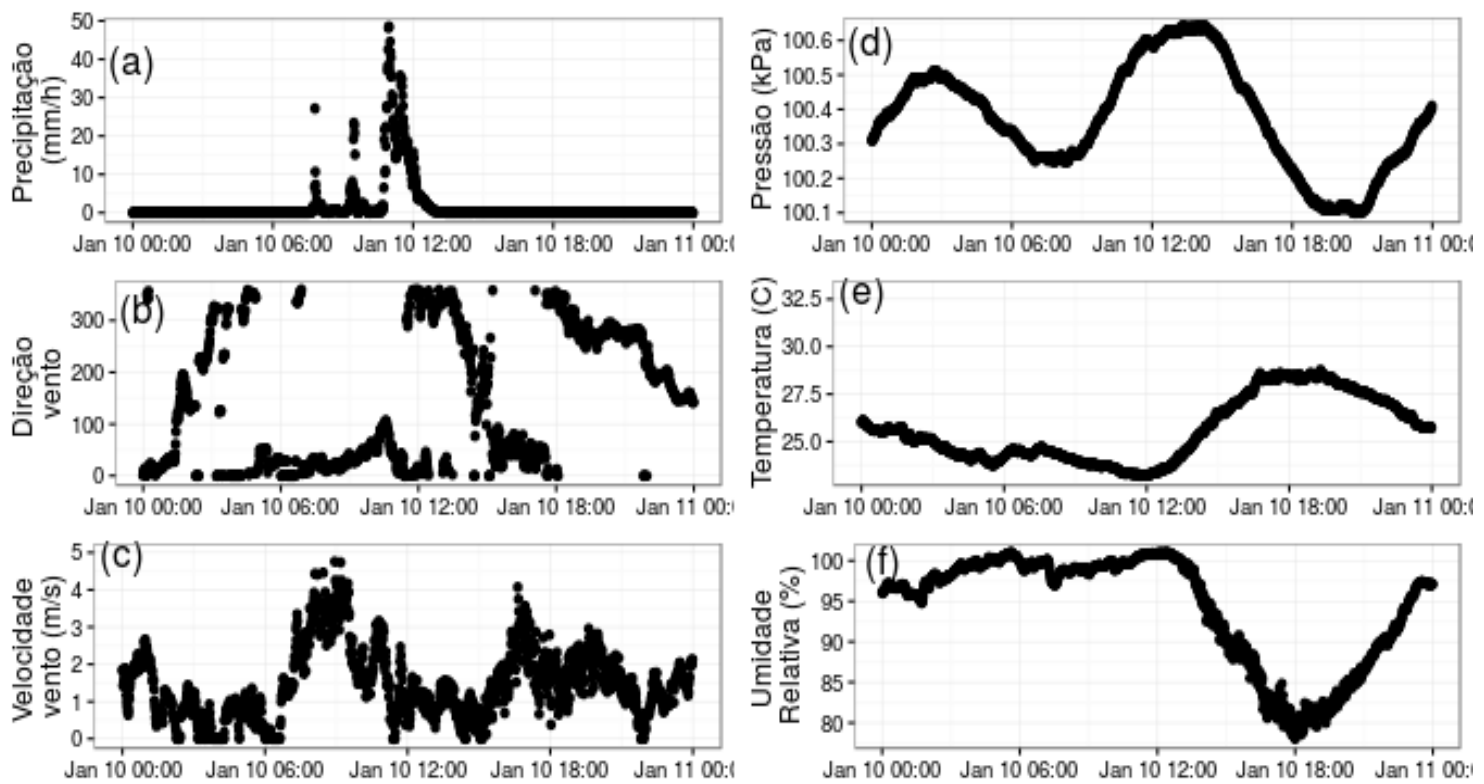

Figura 44 - Condições de tempo na estação de coleta de dados meteorológicos T3, localizada em Manacapuru, Amazonas em 10/01/2014. Em (a) precipitação (mm), (b) direção do vento $\left(^{\circ}\right)$, (c) velocidade do vento $(\mathrm{m} / \mathrm{s}),(\mathrm{d})$ pressão atmosférica $(\mathrm{kPa}),(\mathrm{e})$ temperatura do $\operatorname{ar}\left({ }^{\circ} \mathrm{C}\right),(\mathrm{f})$ umidade relativa $(\%)$.

\section{9/02/2014 - horário de gênese: 1330 UTC}

A combinação das circulações de um VCAN, centrado entre São Paulo e Minas Gerais e uma ampla área anticiclônica atuando entre o oceano Pacífico, norte da Bolívia, Peru, Rondônia e Acre, observado as 12 UTC em altos níveis, gerou difluência no escoamento sobre a região norte do Brasil (Figura 45 (a)). Esta difluência observada em $250 \mathrm{hPa}$, favoreceu a divergência de massa em altos níveis e convergência em baixos níveis. $\mathrm{Em} 700 \mathrm{hPa}$, os ventos alísios adentraram o continente próximos a $0^{\circ}$ com velocidades entre 37 e $46 \mathrm{~km} / \mathrm{h}$, aproximadamente (Figura 45 (b)). Estes ventos são responsáveis pelo transporte de umidade do oceano Atlântico Tropical para o continente sul-americano. As 06 UTC a ZCIT estava ligeiramente a norte da posição encontrada as 12 UTC e os ventos alísios eram mais fracos. No horário das 18 UTC, posterior à dissipação do SCM, o vento em baixos níveis havia desintensificado. 
Através da análise de imagens de satélite anteriores e posteriores ao horário de formação e dissipação do SCM, percebe-se que a atividade convectiva na região estava bastante presente no dia 09/02/2014. O SCM aqui investigado surgiu após o momento de dissipação de outro sistema que se deslocava desde o Pará até o Amazonas. Por isso, é possível observar temperaturas de brilho mais baixas próximas ao recém iniciado SCM na Figura 46 (a). Este sistema evoluíu sem deslocar-se muito da região de origem e teve dissipação uma hora após a fase de maturação. No momento de sua dissipação a área não havia diminuído muito, conforme mostram as imagens e a Tabela 4. Este SCM ficou localizado ao norte da estação T3 e, portanto, a precipitação observada na estação deve ser devido à outro sistema ou nuvem isolada (Figura 47).

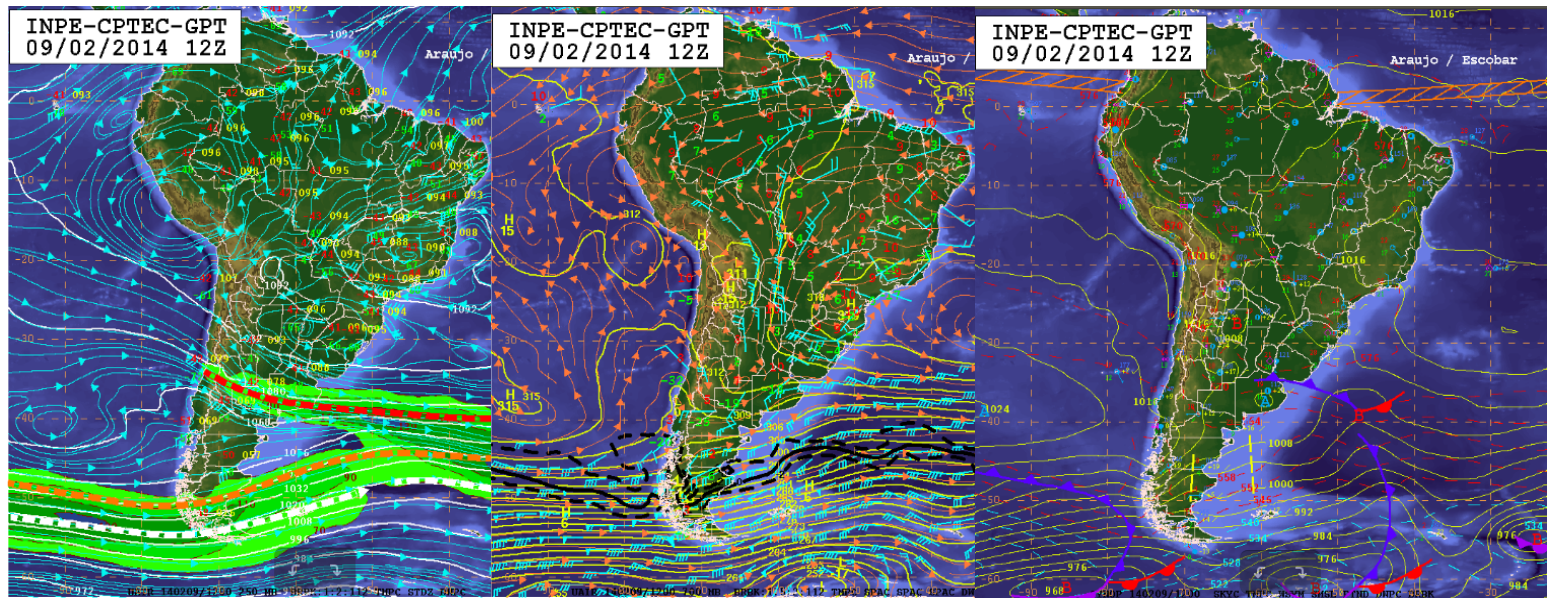

(a) $250 \mathrm{hPa}$

(b) $700 \mathrm{hPa}$

(c) Superfície

Figura 45 - Cartas sinóticas do dia 09/02/2014 - 12 UTC em (a) 250 hPa, (b) 700 hPa e (c) superfície. Fonte: CPTEC/INPE.
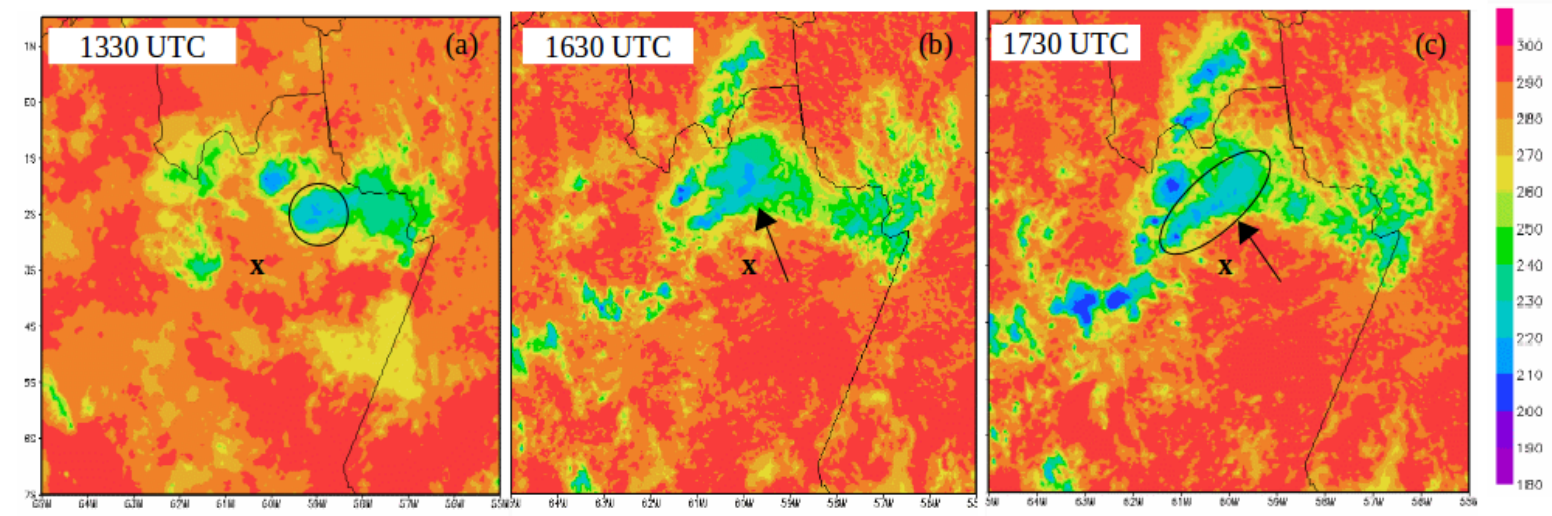

Figura 46 - Imagens de satélite do canal infravermelho em 09/02/2014 na fase de (a) gênese - 1330 UTC, (b) maturação - 1630 UTC e (c) dissipação - 1730 UTC. 

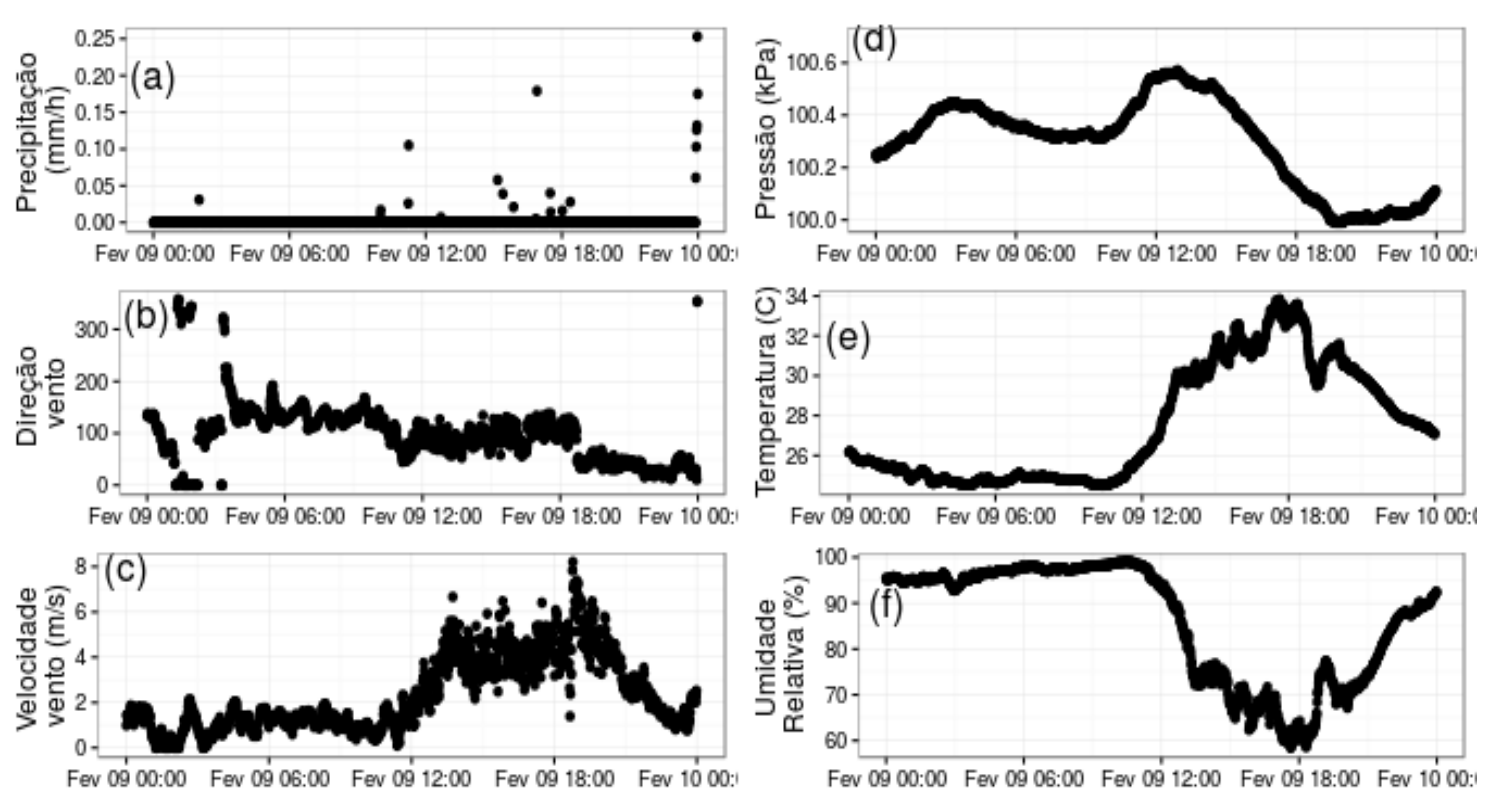

Figura 47 - Condições de tempo na estação de coleta de dados meteorológicos T3, localizada em Manacapuru, Amazonas em 09/02/2014. Em (a) precipitação $(\mathrm{mm})$, (b) direção do vento $\left(^{\circ}\right)$, (c) velocidade do vento $(\mathrm{m} / \mathrm{s})$, (d) pressão atmosférica $(\mathrm{kPa}),(\mathrm{e})$ temperatura do $\operatorname{ar}\left({ }^{\circ} \mathrm{C}\right)$, (f) umidade relativa $(\%)$.

\section{3/02/2014 - horário de gênese: 1030 UTC}

O escoamento em altos níveis mostra um anticiclone localizado em $14^{\circ} \mathrm{S} / 84^{\circ} \mathrm{W}$ que associado à um VCAN, cujo centro está localizado sobre o litoral da região Sudeste do Brasil, gera difluência com consequente divergência em altos níveis e convergência de umidade dos níveis mais baixos, favorecendo a convecção e formação de nuvens sobre a região do GOAmazon (Figura 48 (a)). A carta de superfície mostra a ZCIT localizada em $0^{\circ}$ e a análise em $700 \mathrm{hPa}$ mostra os ventos alísios direcionados para 0 continente, transportando umidade do oceano Atlântico Tropical para a região norte do país e vizinhanças. Entre as 06 UTC e as 12 UTC eles se intensificaram, porém as 18 UTC os alísios diminuem a intensidade. Os índices apresentados na Figura 41 mostraram instabilidade as 12 UTC, que associada com a dinâmica favorável permitiu a formação do SCM observado.

A evolução das imagens de satélite apresentadas na Figura 49 e a Figura 39 mostram o SCM formado próximo à estação T0, ao nordeste de Manaus. Seu deslocamento ao longo do ciclo de vida foi para norte, se distanciando das regiões de coleta de dados do GOAmazon. A Figura 50 mostra que não houve variação nas condições de tempo na estação T3 associado à este evento. 


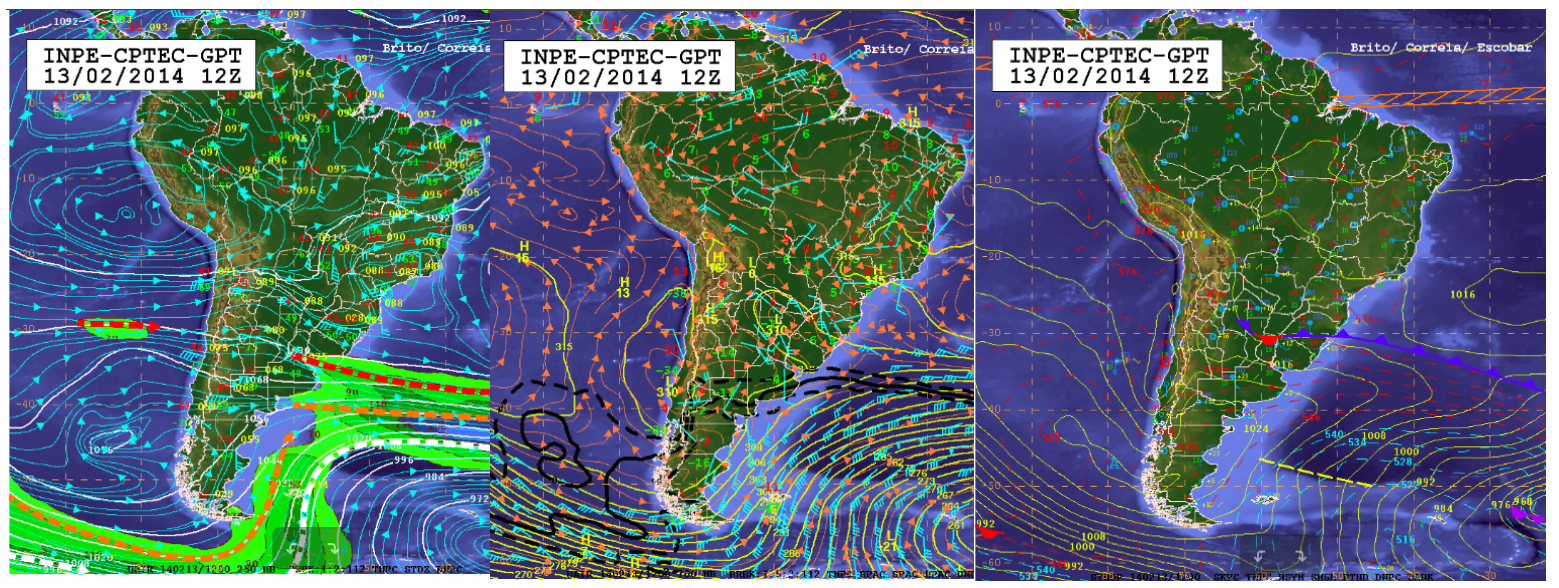

(a) $250 \mathrm{hPa}$

(b) $700 \mathrm{hPa}$

(c) Superfície

Figura 48 - Cartas sinóticas do dia 13/02/2014 - 12 UTC (a) 250 hPa, (b) 700 hPa e (c) superfície. Fonte: CPTEC/INPE.
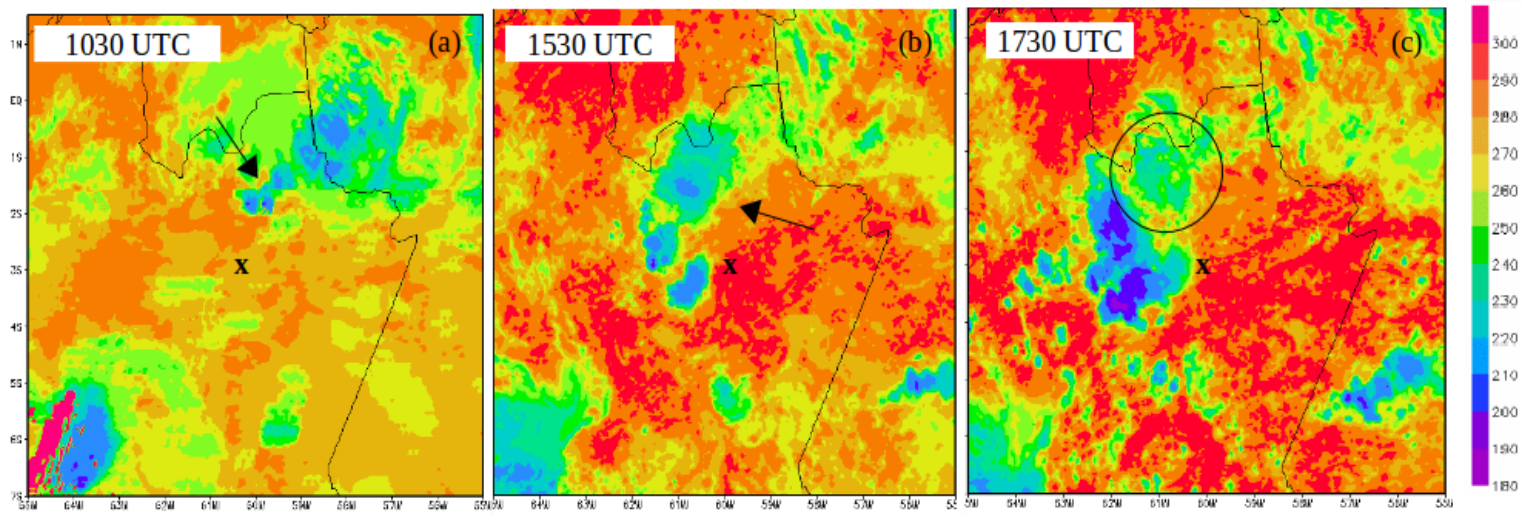

Figura 49 - Imagens de satélite do canal infravermelho em 13/02/2014 na fase de (a) gênese - 1030 UTC, (b) maturação - 1530 UTC e (c) dissipação - 1730 UTC.
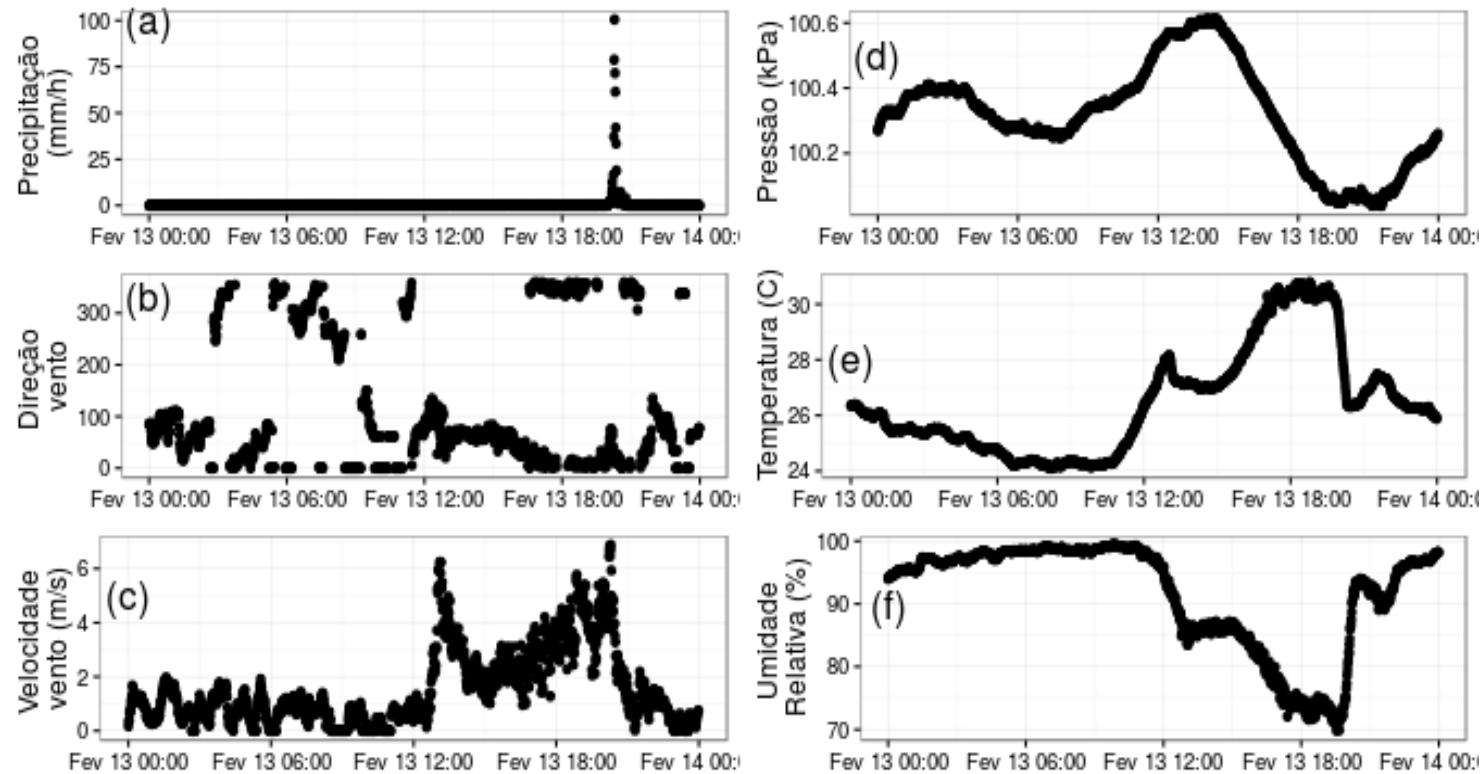

Figura 50 - Condições de tempo na estação de coleta de dados meteorológicos T3, localizada em Manacapuru, Amazonas no dia 13/02/2014. Em (a) precipitação (mm), (b) direção do vento $\left(^{\circ}\right)$, (c) velocidade do vento $(\mathrm{m} / \mathrm{s}),(\mathrm{d})$ pressão atmosférica $(\mathrm{kPa}),(\mathrm{e})$ temperatura do ar $\left({ }^{\circ} \mathrm{C}\right),(\mathrm{f})$ umidade relativa $(\%)$. 


\section{9/04/2014 - horário de gênese: 02 UTC}

Uma circulação anticiclônica em altos níveis com centro localizado entre o sul de Maranhão e norte de Tocantins predominou nas cartas analisadas (Figura 51). Associada à ela, ocorreu difluência sobre o norte do Pará e nordeste do Amazonas, que combinada aos ventos de leste em baixos níveis adentrando o continente favoreceram a convecção sobre a região Amazônica. A ZCIT apresentou dois ramos, sendo um localizado ligeiramente ao norte do Equador e outro ao sul, mais próximo ao nordeste brasileiro.

O SCM teve gênese ao norte da estação T1, localizada em Manaus, e ao longo do seu ciclo de vida se deslocou para oeste (Figura 52). Portanto, não houve precipitação associada àquele SCM e mudanças de tempo na estação T3 (Figura 53).

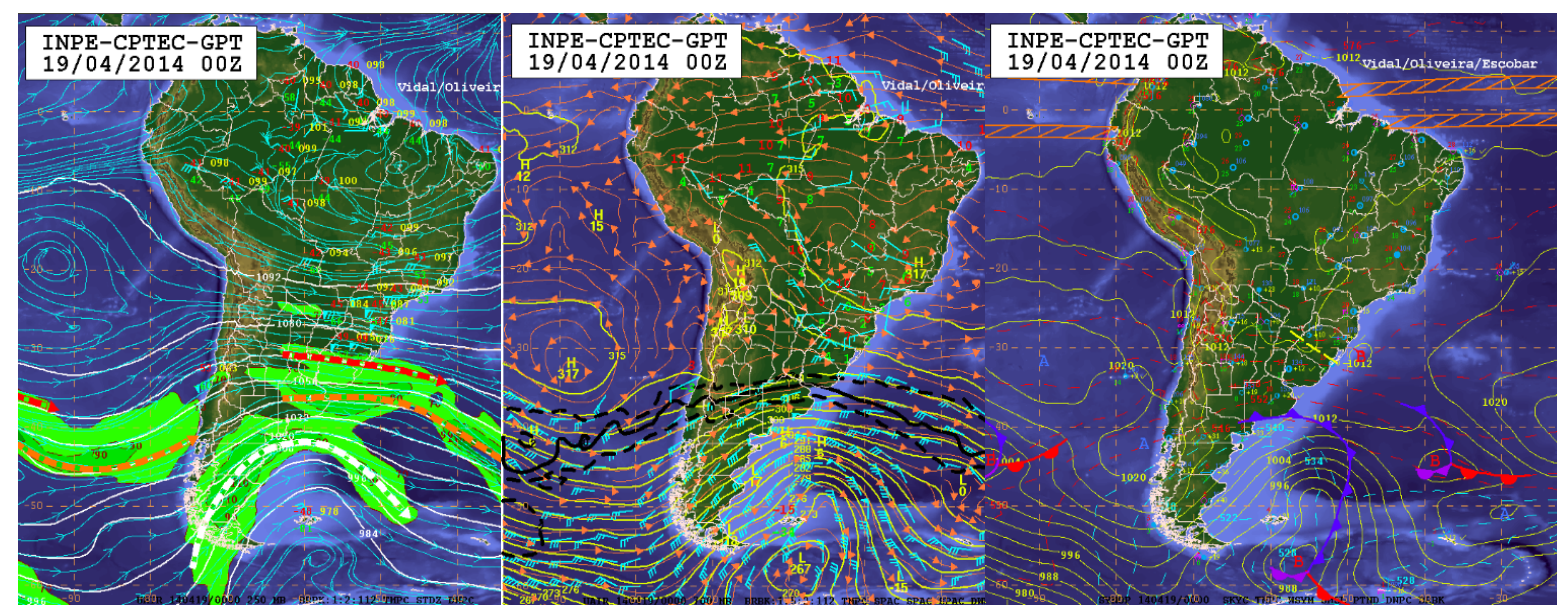
(a) $250 \mathrm{hPa}$
(b) $700 \mathrm{hPa}$
(c) Superfície

Figura 51 - Cartas sinóticas do dia 19/04/2014 - 00 UTC (a) 250 hPa, (b) 700 hPa e (c) superfície. Fonte: CPTEC/INPE.
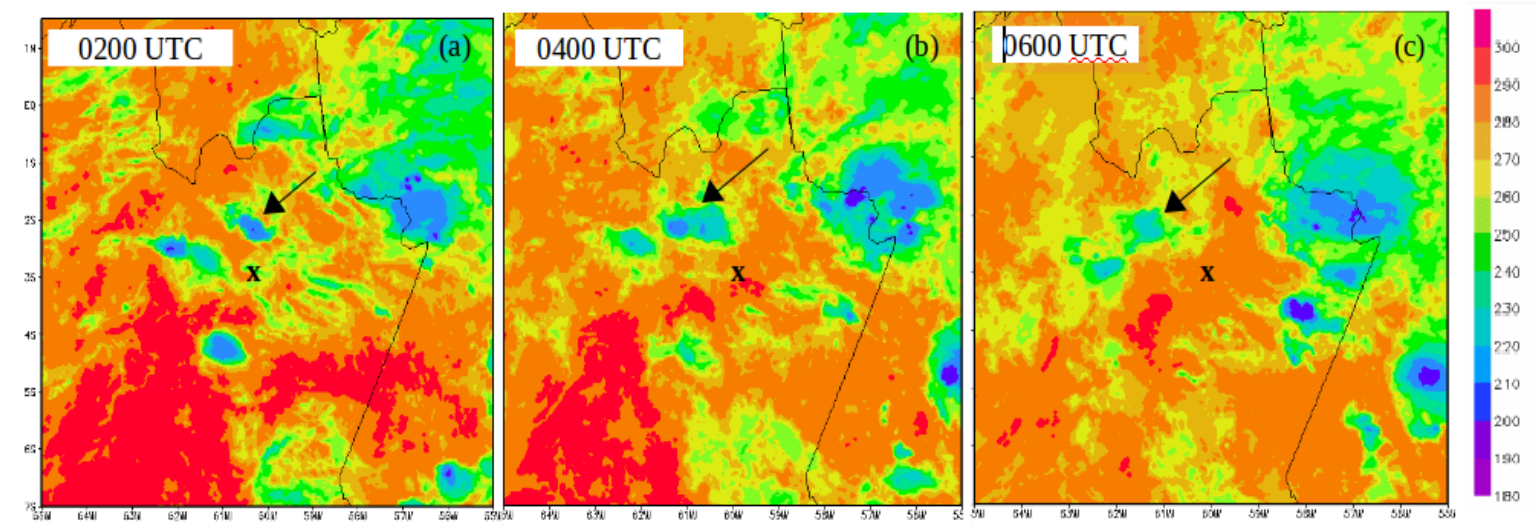

Figura 52 - Imagens de satélite do canal infravermelho em 19/04/2014 na fase de (a) gênese - 0200 UTC, (b) maturação - 0400 UTC e (c) dissipação - 0600 UTC. 

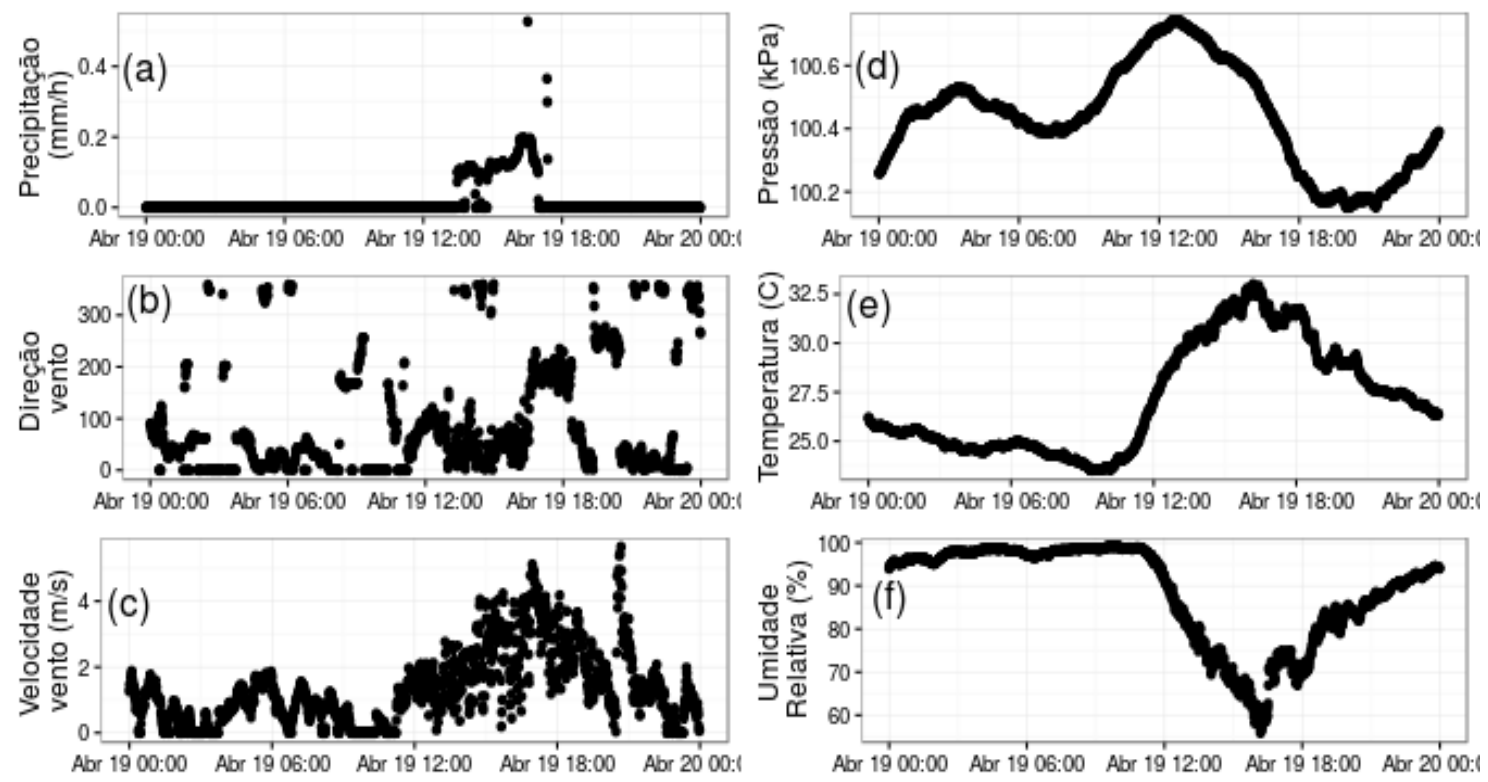

Figura 53 - Condições de tempo na estação de coleta de dados meteorológicos T3, localizada em Manacapuru, Amazonas no dia 19/04/2014. Em (a) precipitação $(\mathrm{mm})$, (b) direção do vento $\left({ }^{\circ}\right)$, (c) velocidade do vento $(\mathrm{m} / \mathrm{s}),(\mathrm{d})$ pressão atmosférica $(\mathrm{kPa}),(\mathrm{e})$ temperatura do $\operatorname{ar}\left({ }^{\circ} \mathrm{C}\right),(\mathrm{f})$ umidade relativa $(\%)$.

\section{2/06/2014 - horário de gênese: 0730 UTC}

As cartas sinóticas das 00 UTC e 06 UTC em 250 hPa mostraram padrão de circulação anticiclônico alongado sobre a região norte da América do Sul, apresentando dois centros, um localizado em $10^{\circ} \mathrm{S} / 50^{\circ} \mathrm{W}$ e o outro em aproximadamente $0^{\circ} / 40^{\circ} \mathrm{W}$ (Figura 54). Ao sul desta circulação aparecem o Jato Subtropical (JST) e o Jato Polar. As cartas em superfície mostram o predomínio de uma frente estacionária atuando na Bolívia, passando pela região centro-oeste do Brasil até o sudoeste de São Paulo. A ZCIT está posicionada em aproximadamente $2^{\circ} \mathrm{N}$ e ventos de leste encontram-se zonalmente orientados sobre o Amazonas.

Apesar de ter gêsene próximo à estação T3, este sistema se deslocou para oeste durante seu ciclo de vida (Figuras 55 (a), (b) e (c)) e não chegou causar mudanças no tempo na estação (Figura 56). A partir das 12 UTC observa-se variações nas condições atmosféricas apresentadas em Figura 56, onde o vento passa a soprar de leste com intensidade fraca (entre 2 a $6 \mathrm{~m} / \mathrm{s}$ ) ocorreram poucos milímetros de precipitação por algumas horas. Toda essa mudança deve ter ocorrido por algum sistema muito pequeno, pois não é possível observá-lo nas imagens de satélite. 


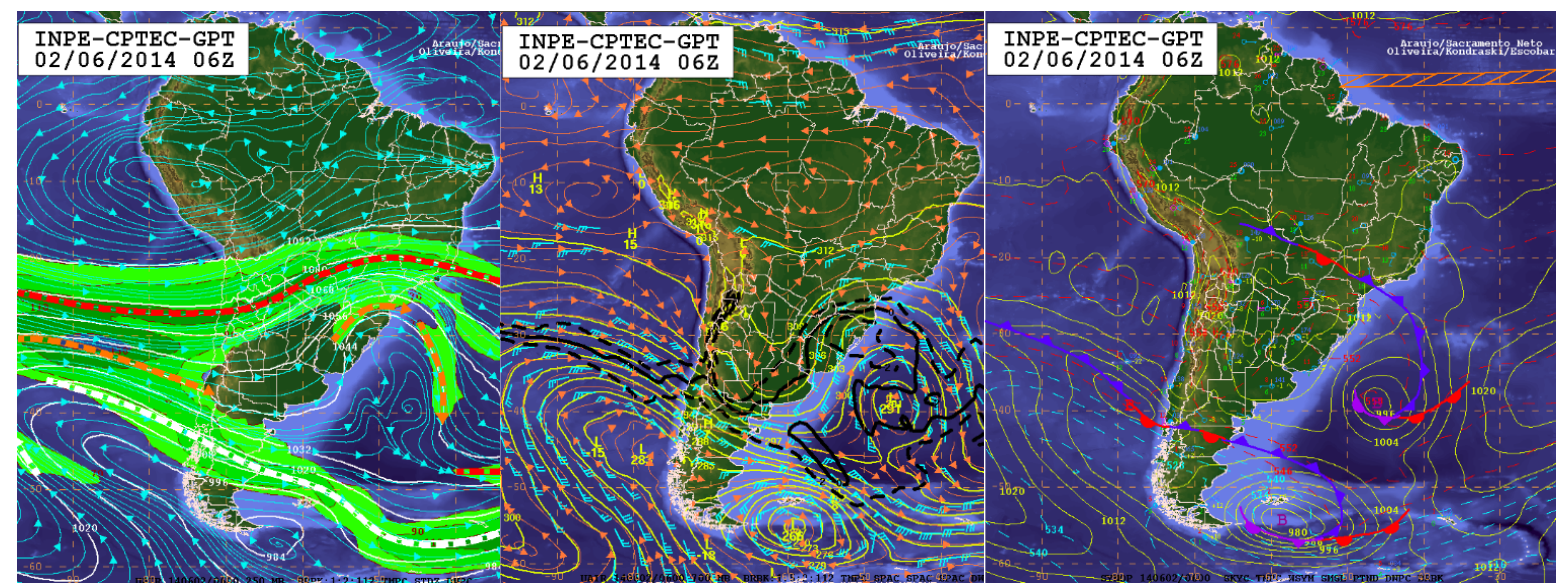

(a) $250 \mathrm{hPa}$

(b) $700 \mathrm{hPa}$

(c) Superfície

Figura 54 - Cartas sinóticas do dia 02/06/2014 - 06 UTC (a) 250 hPa, (b) 700 hPa e (c) superfície. Fonte: CPTEC/INPE.
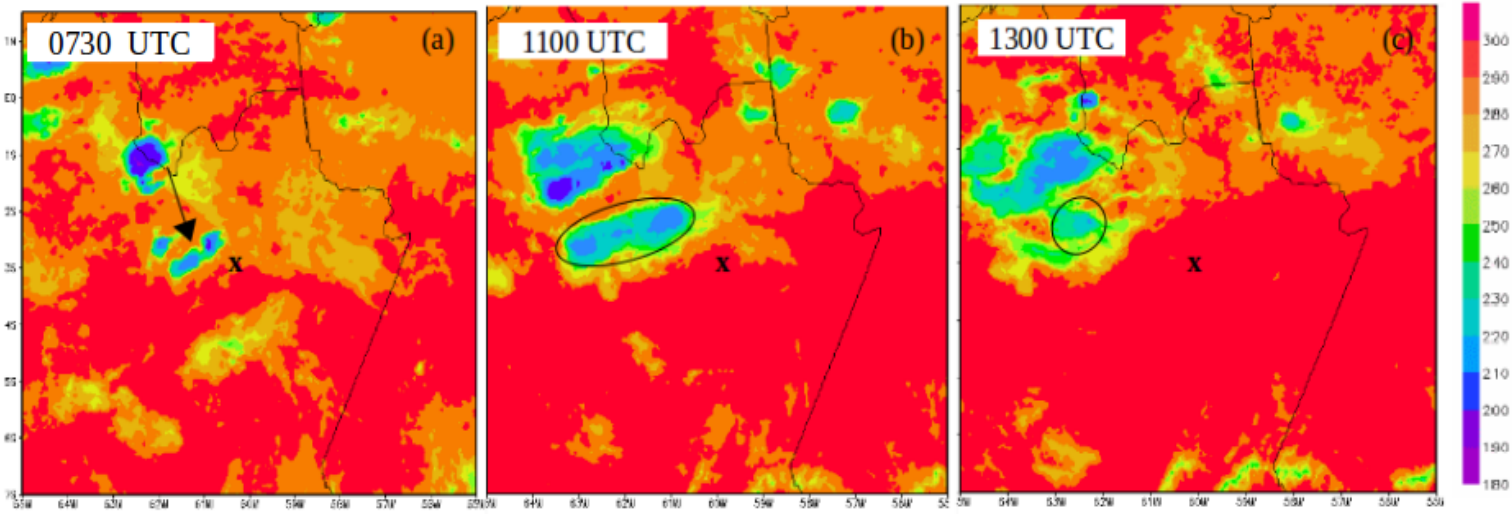

Figura 55 - Imagens de satélite do canal infravermelho em 02/06/2014 na fase de (a) gênese - 0730 UTC, (b) maturação - 1100 UTC e (c) dissipação - 1300 UTC.
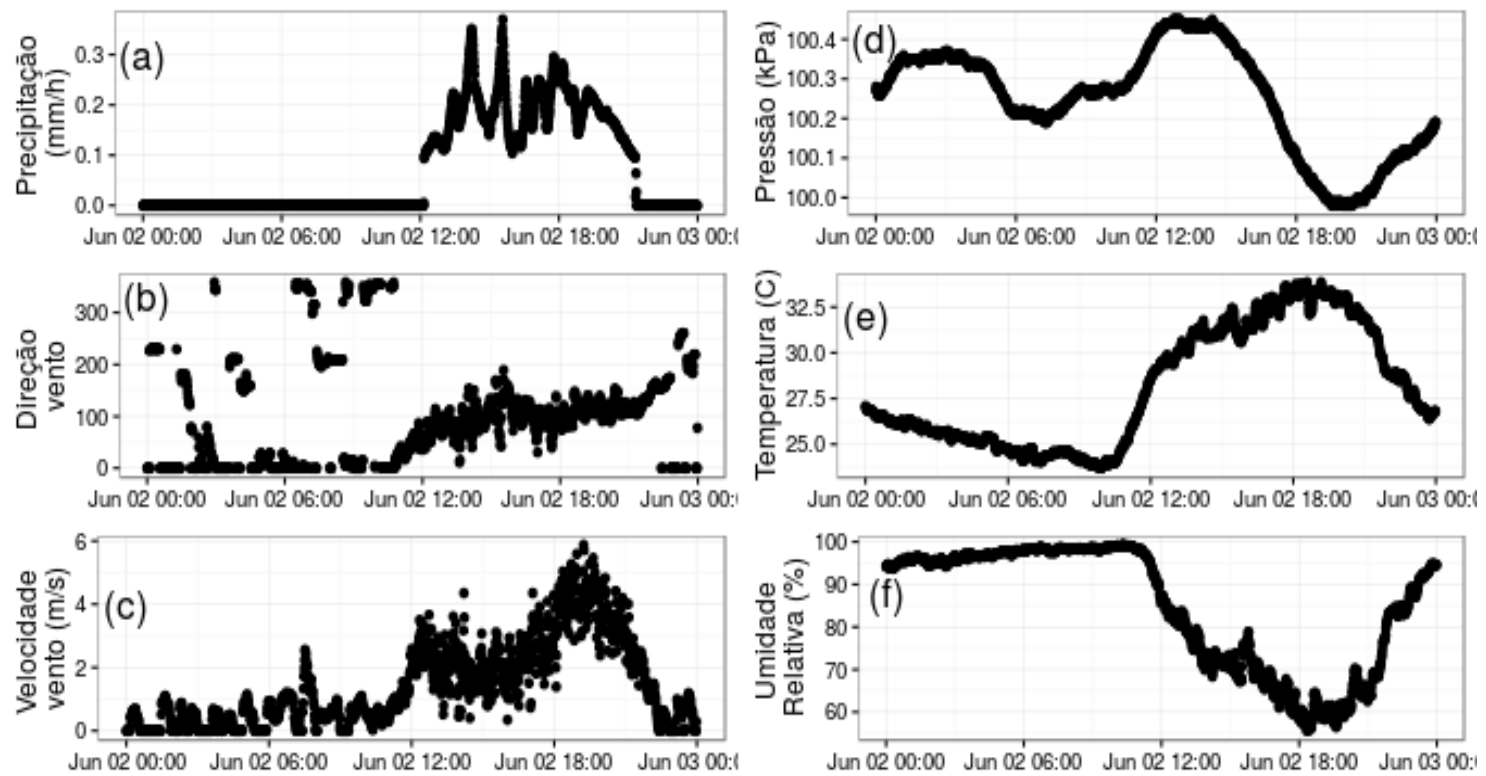

Figura 56 - Condições de tempo na estação de coleta de dados meteorológicos T3, localizada em Manacapuru, Amazonas no dia 02/06/2014. Em (a) precipitação (mm), (b) direção do vento $\left(^{\circ}\right)$, (c) velocidade do vento $(\mathrm{m} / \mathrm{s}),(\mathrm{d})$ pressão atmosférica $(\mathrm{kPa}),(\mathrm{e})$ temperatura do ar $\left({ }^{\circ} \mathrm{C}\right),(\mathrm{f})$ umidade relativa $(\%)$. 


\section{9/06/2014 - horário de gênese: 18 UTC}

Em altos níveis observa-se uma região de alta pressão com a parte central posicionada em $10^{\circ} \mathrm{S}$ e $80^{\circ} \mathrm{W}$, se estendendo sobre o sul do Amazonas (Figura 57). Ligeiramente ao sul desta região de mais alta pressão, o JST avança desde o oceano Pacífico para o continente sul-americano, curvando-se para norte ao cruzar a Cordilheira dos Andes em direção ao oceano Atlântico. Um anticiclone posicionado em torno de $20^{\circ} \mathrm{S}$ no Atlântico, próximo ao continente influencia o escoamento sobre o continente a partir do nordeste brasileiro até a região norte do país em baixos níveis. Este escoamento contribui no transporte de umidade para essas regiões. Em superfície observa-se o ramo estacionário de um sistema frontal no sul do Amazonas, passando pelo centro-oeste do Brasil, onde segue com ramo frio entre o norte de São Paulo e sul de Minas Gerais e Atlântico adjacente até o ciclone extratropical, centrado no litoral gaúcho em estágio de dissipação. A carta das 18 UTC também mostra o ramo quente associado à este sistema se acoplando a outro sistema frontal no Atlântico, longe da área de estudo. A ZCIT oscila em torno de $06^{\circ} \mathrm{N}$ e $07^{\circ} \mathrm{N}$ sobre o oceano Atlântico em todas as cartas analisadas.

A precipitação ocorrida próxima as 00 UTC do dia 30 na estação T3 (Figura 59) não esteve relacionada ao sistema analisado, pois este teve ciclo de vida ao norte daquela estação (Figura 58).

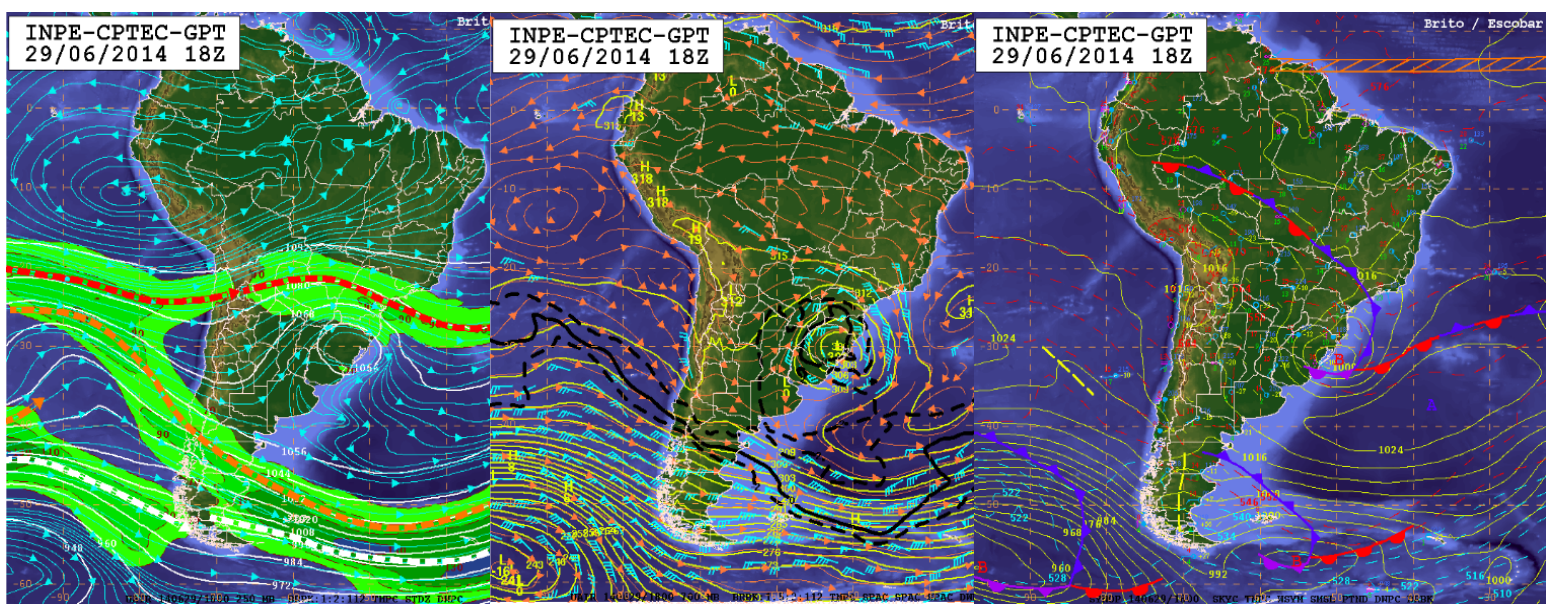
(a) $250 \mathrm{hPa}$
(b) $700 \mathrm{hPa}$
(c) Superfície

Figura 57 - Cartas sinóticas do dia 29/06/2014 - 18 UTC (a) 250 hPa, (b) 700 hPa e (c) superfície. Fonte: CPTEC/INPE. 

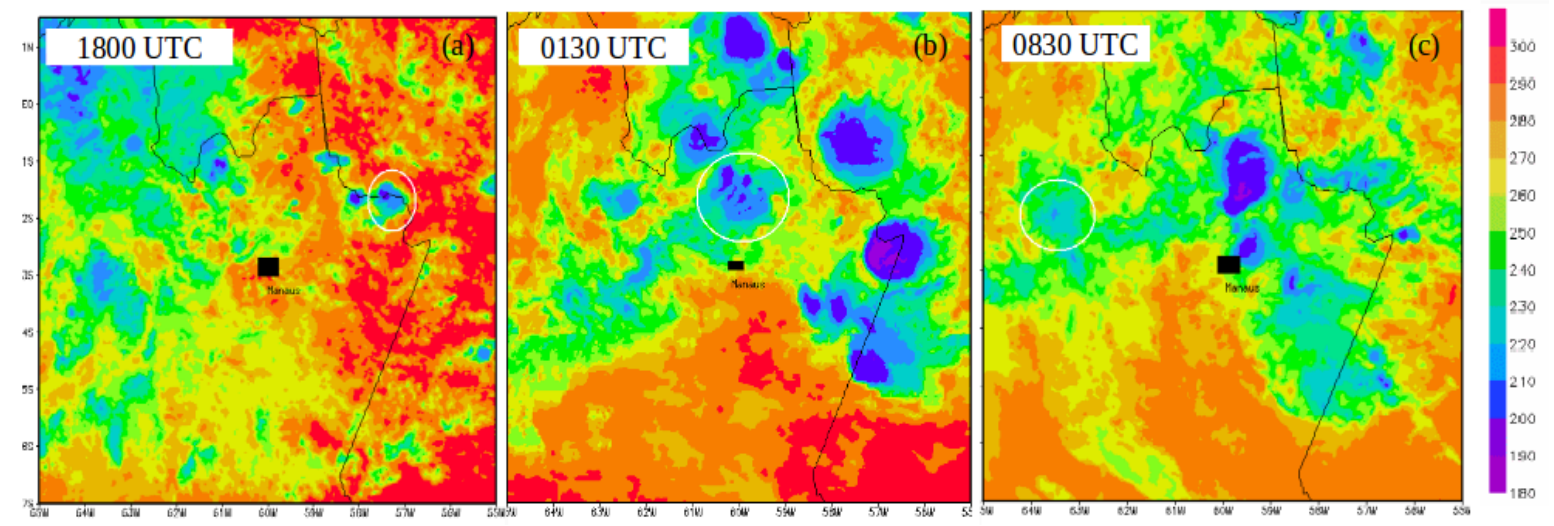

Figura 58 - Imagens de satélite do canal infravermelho em 29 e 30/06/2014 na fase de (a) gênese - 1800 UTC, (b) maturação - 0130 UTC e (c) dissipação - 0830 UTC.
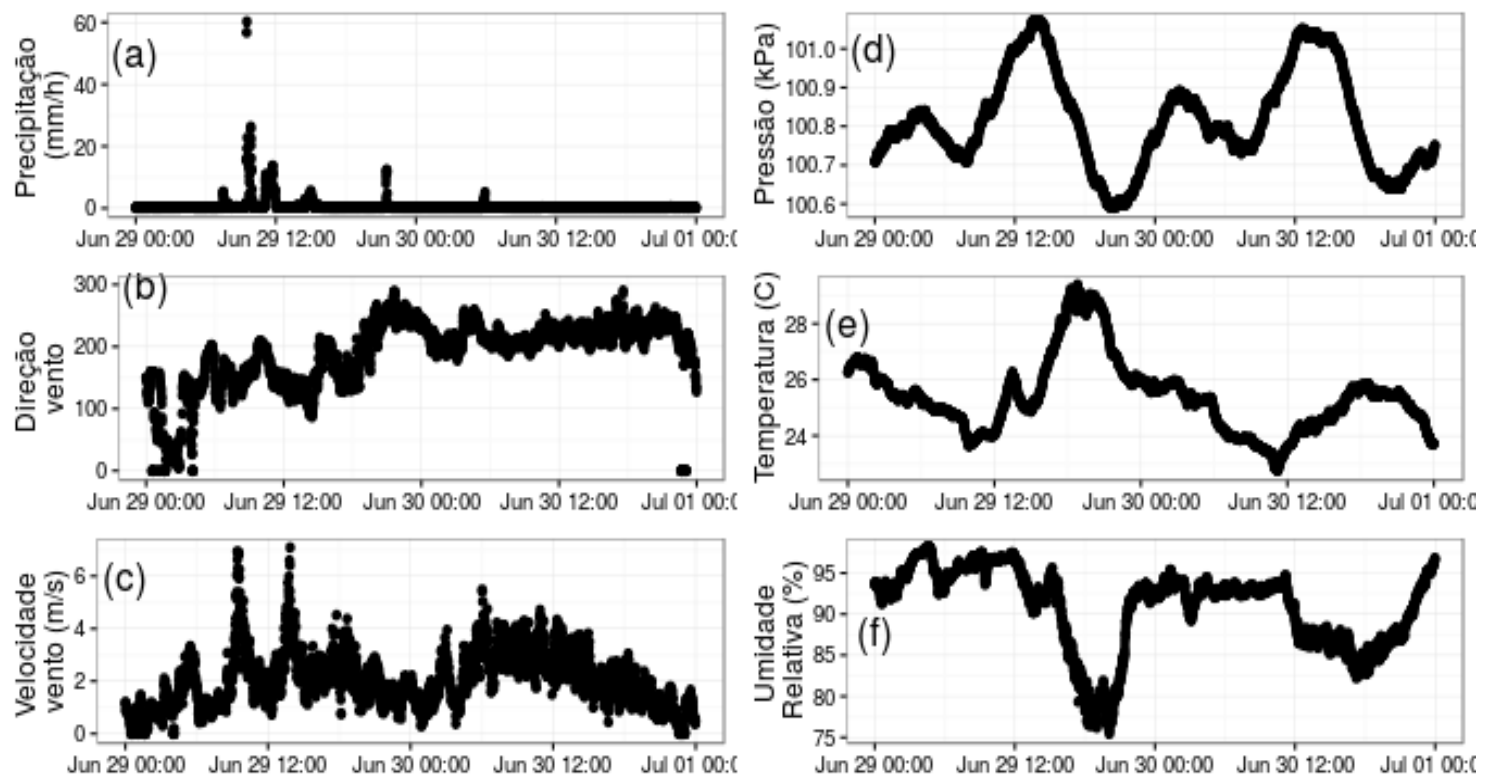

Figura 59 - Condições de tempo na estação de coleta de dados meteorológicos T3, localizada em Manacapuru, Amazonas nos dias 29 e 30/06/2014. Em (a) precipitação $(\mathrm{mm})$, (b) direção do vento $\left(^{\circ}\right)$, (c) velocidade do vento $(\mathrm{m} / \mathrm{s}),(\mathrm{d})$ pressão atmosférica $(\mathrm{kPa}),(\mathrm{e})$ temperatura do $\operatorname{ar}\left({ }^{\circ} \mathrm{C}\right)$, (f) umidade relativa $(\%)$.

\section{2/07/2014 - horário de gênese: 17 UTC}

Observa-se um escoamento de noroeste em altos níveis sobre o Amazonas, com leve difluência sobre o norte da Bolívia (Figura 60). A entrada dos ventos alísios pelo nordeste com intensidade de $46,3 \mathrm{~km} / \mathrm{h}$ ao norte do Amazonas, contribui com o aumento de umidade na região. Neste dia houve bastante cisalhamento do vento, $7 \cdot 10^{-4} \mathrm{~s}^{-1}$, do vento comparado com a média $\left(4 \cdot 10^{-4} \mathrm{~s}^{-1}\right)$ e com os dias anterios. Os demais indicadores de instabilidade apresentaram resultados bastante similares aos outros dias analisados.

A Figura 62 mostra a evolução deste sistema ao longo do ciclo de vida. Este sistema teve gênese a sudeste de Manacapuru e se deslocou para oeste. Ao norte da região das estações existiram outros sistemas concomitantes ao analisado aqui e 
no momento da maturação, as 18 UTC, quando o sistema passou sobre a estação localizada em Manacapuru, houve um alto valor de precipitação na estação $(150 \mathrm{~mm} / \mathrm{h})$ acompanhada de rajada de vento relativamente mais alto que os demais horários (Figura 61).

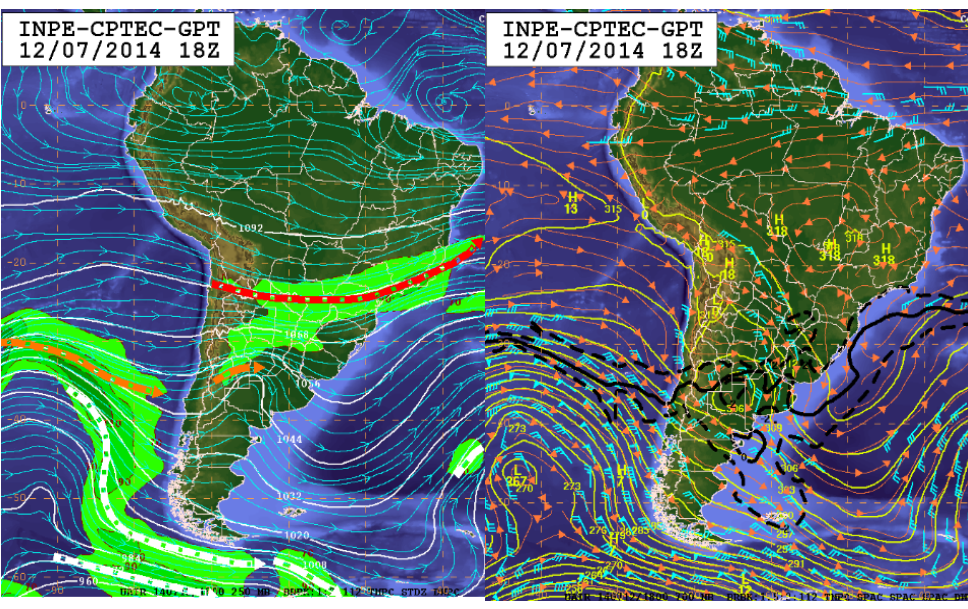

(a) $250 \mathrm{hPa}$

(b) $700 \mathrm{hPa}$

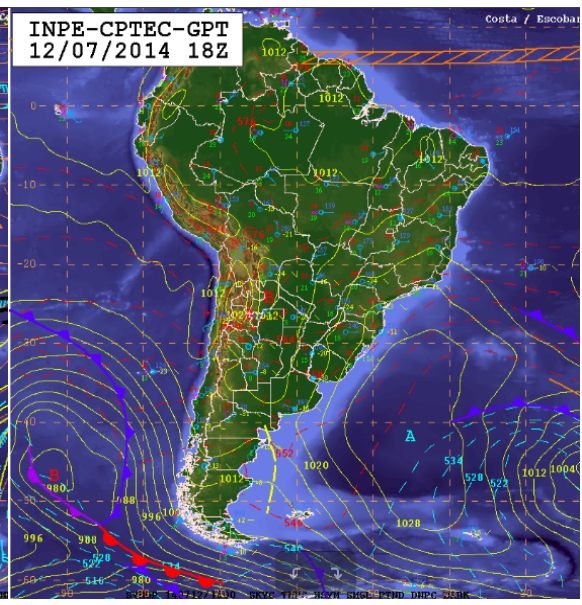

(c) Superfície

Figura 60 - Cartas sinóticas do dia 12/07/2014 - 18 UTC (a) 250 hPa, (b) 700 hPa e (c) superfície. Fonte: CPTEC/INPE.
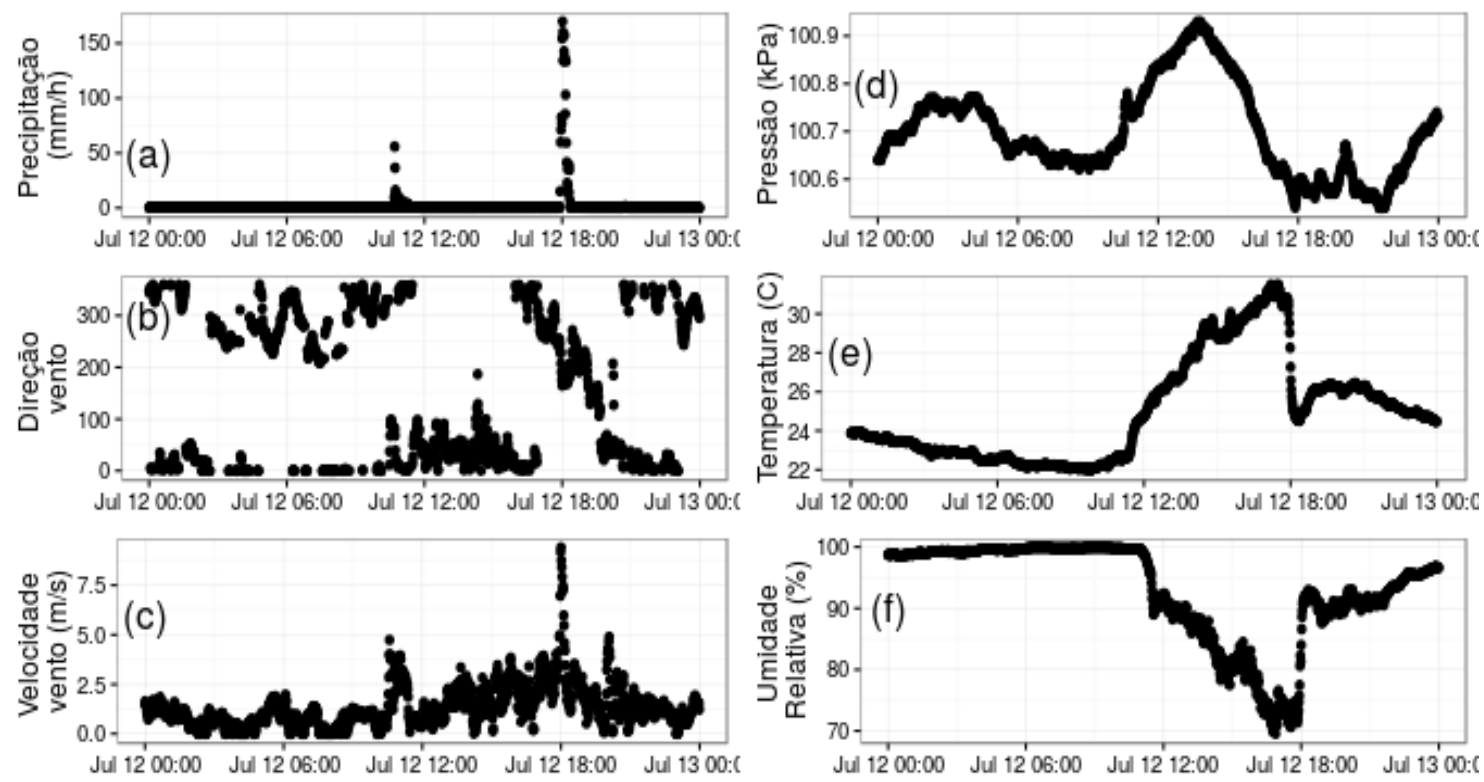

Figura 61 - Condições de tempo na estação de coleta de dados meteorológicos T3, localizada em Manacapuru, Amazonas no dia 12/07/2014. Em (a) precipitação $(\mathrm{mm})$, (b) direção do vento ${ }^{\circ}$ ), (c) velocidade do vento $(\mathrm{m} / \mathrm{s}),(\mathrm{d})$ pressão atmosférica $(\mathrm{kPa}),(\mathrm{e})$ temperatura do $\operatorname{ar}\left({ }^{\circ} \mathrm{C}\right),(\mathrm{f})$ umidade relativa $(\%)$. 

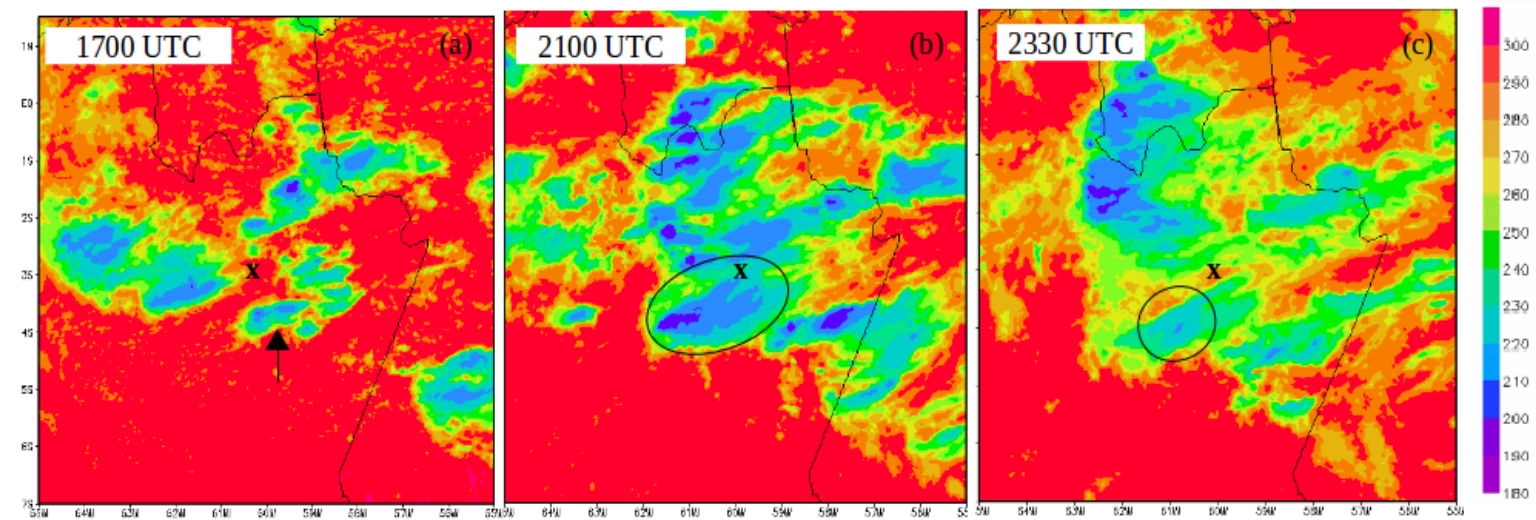

Figura 62 - Imagens de satélite do canal infravermelho em 12/07/2014 na fase de (a) gênese - 1700 UTC, (b) maturação - 2100 UTC e (c) dissipação - 2330 UTC.

\section{9/07/2014 - horário de gênese: 03 UTC}

Nos campos de $250 \mathrm{hPa}$ há difluência sobre o Amazonas, resultante de um escoamento de oeste combinado com um de nordeste (Figura 63). Este último ocorrendo em associação à uma região de alta pressão sobre o litoral do Maranhão. Em $850 \mathrm{hPa}$ ocorre confluência do escoamento entre os ventos alísios e ventos de sul sobre a região sudeste do Amazonas. Esta combinação entre difluência em altos níveis que gera divergência e consequente convergência de massa de baixos níveis, com a confluência em baixos níveis e favorecimento de mais umidade proveniente do Atlântico Tropical, formaram um ambiente propício para a ocorrência do SCM observado.

O sinal de precipitação observada na Figura 65 não foi devido ao SCM analisado, pois este se formou e teve deslocamento ao norte de Manacapuru (Figura 64), além disso, o acumulado de precipitação foi muito baixo, ao redor de $2 \mathrm{~mm}$ durante a ocorrência do sistema.

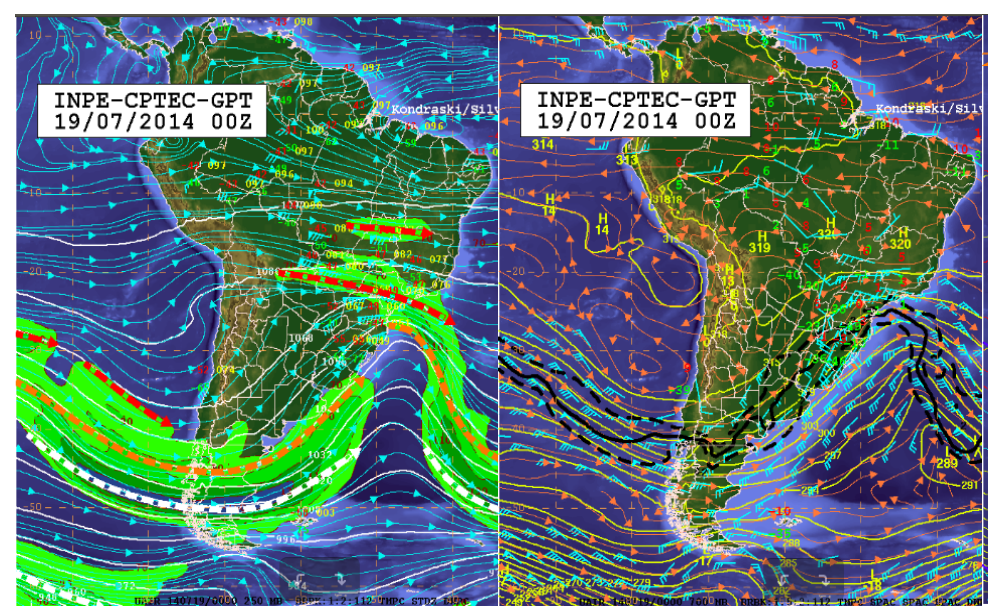

(a) $250 \mathrm{hPa}$ (b) $700 \mathrm{hPa}$

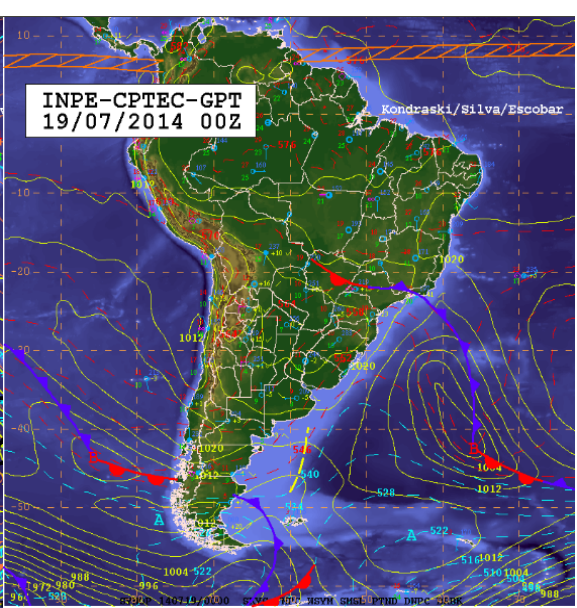

(c) Superfície

Figura 63 - Cartas sinóticas do dia 19/07/2014 - 00 UTC (a) 250 hPa, (b) 700 hPa e (c) superfície. Fonte: CPTEC/INPE. 

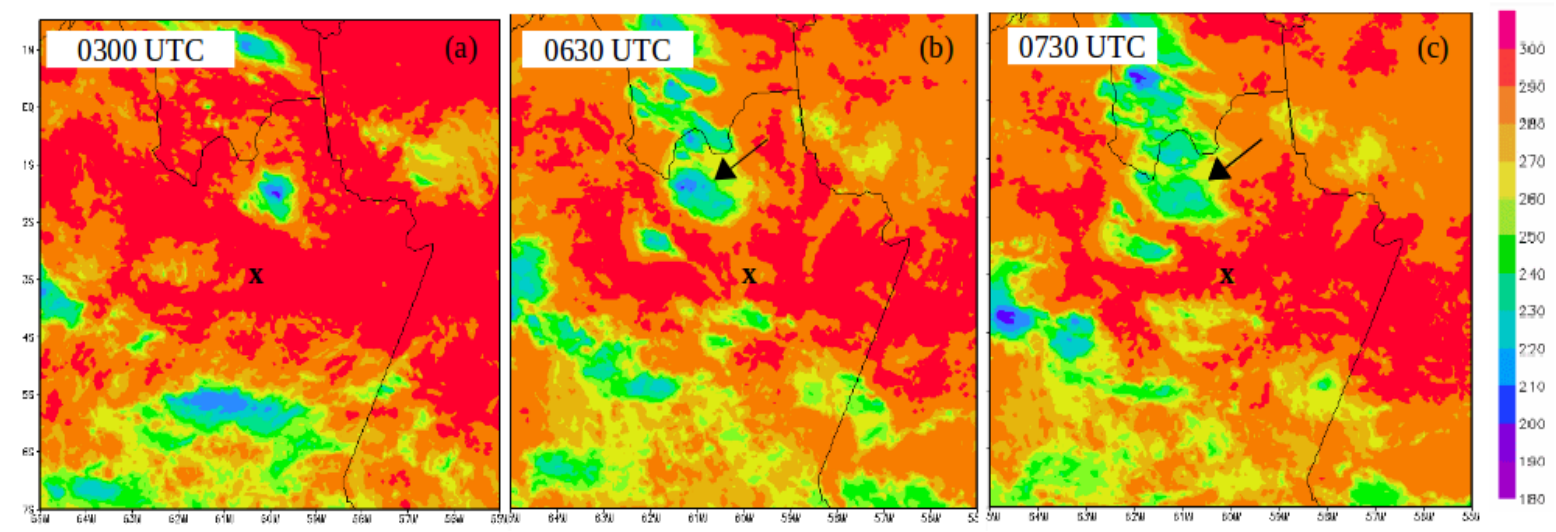

Figura 64 - Imagens de satélite do canal infravermelho em 19/07/2014 na fase de (a) gênese - 0300 UTC, (b) maturação - 0630 UTC e (c) dissipação - 0730 UTC.
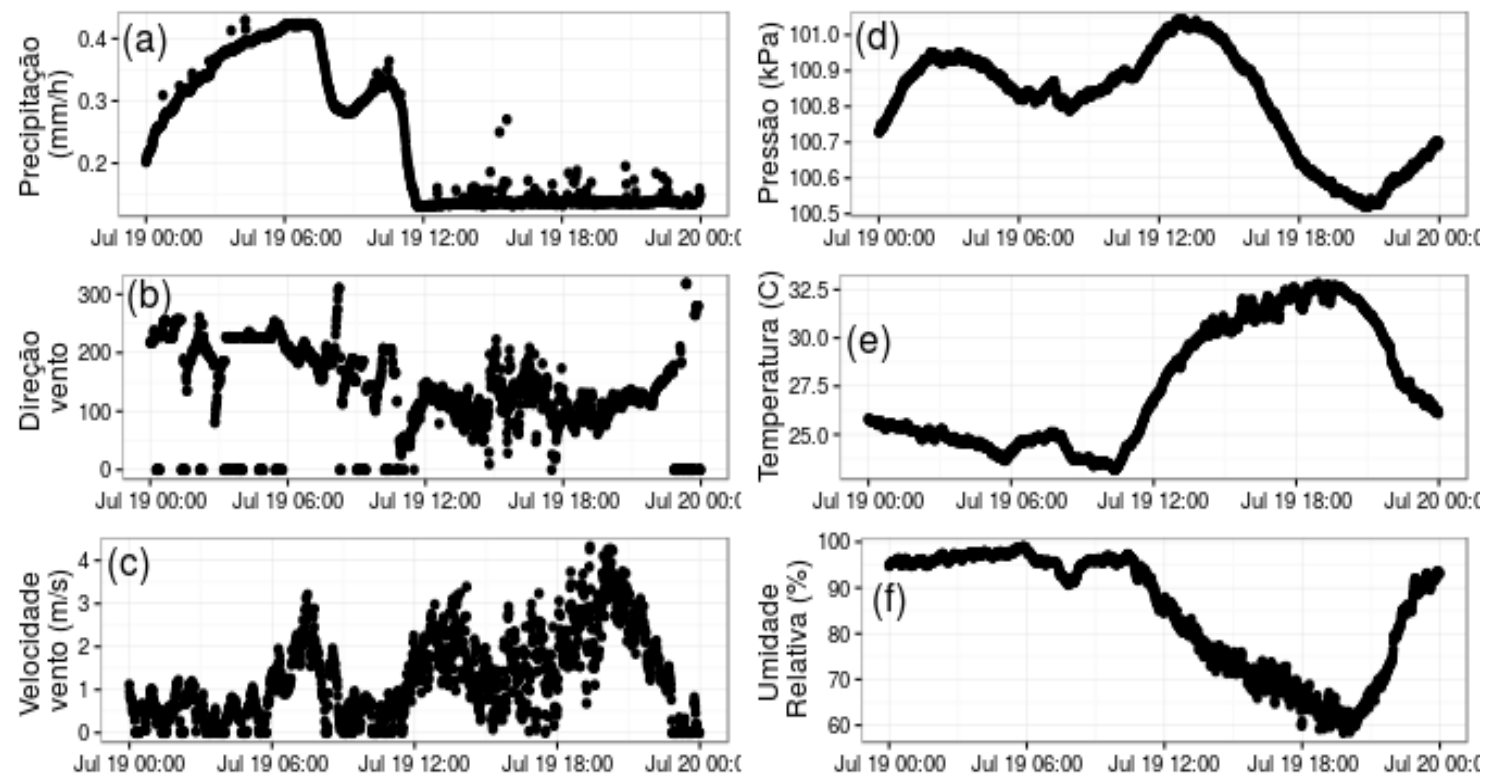

Figura 65 - Condições de tempo na estação de coleta de dados meteorológicos T3, localizada em Manacapuru, Amazonas no dia 19/07/2014. Em (a) precipitação $(\mathrm{mm})$, (b) direção do vento $\left(^{\circ}\right)$, (c) velocidade do vento $(\mathrm{m} / \mathrm{s})$, (d) pressão atmosférica $(\mathrm{kPa}),(\mathrm{e})$ temperatura do $\operatorname{ar}\left({ }^{\circ} \mathrm{C}\right),(\mathrm{f})$ umidade relativa $(\%)$.

\section{9/07/2014 - horário de gênese: 1930 UTC}

Observa-se um anticiclone sobre oceano Pacífico com centro posicionado em aproximadamente $04^{\circ} \mathrm{S} / 95^{\circ} \mathrm{W}$. À leste deste anticiclone há o eixo de um amplo cavado que se estende desde o noroeste do Pará até o Mato Grosso. A associação destes dois padrões de escoamento causam difluência de massa em toda faixa oeste do Amazonas, provocando divergência em altos níveis e convergência em baixos níveis. Em $700 \mathrm{hPa}$ observa-se ventos de oeste intensos de $46,3 \mathrm{~km} / \mathrm{h}$ e de leste atuando sobre a região Norte. As imagens de satélite mostram bastante atividade convectiva no momento da ocorrência do SCM aqui analisado (Figura 67). Este sistema não se deslocou muito da sua posição inicial $(55,7 \mathrm{~km})$ e teve curto tempo de vida (3 horas). As condições de tempo observadas na Figura 68 estão associadas ao sistema que se desenvolveu ao sul do analisado aqui e deslocou sobre as estações T0 e T3. 


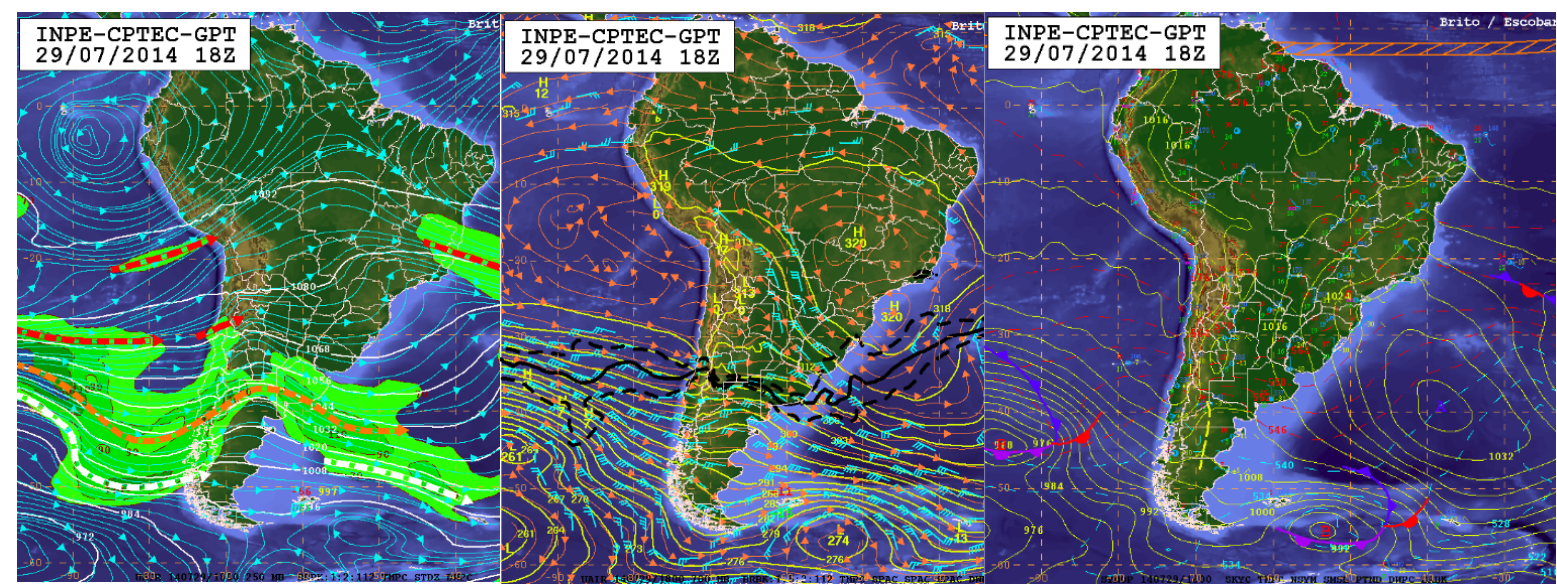

(a) $250 \mathrm{hPa}$

(b) $700 \mathrm{hPa}$

(c) Superfície

Figura 66 - Cartas sinóticas do dia 29/07/2014 - 00 UTC (a) 250 hPa, (b) 700 hPa e (c) superfície. Fonte: CPTEC/INPE.
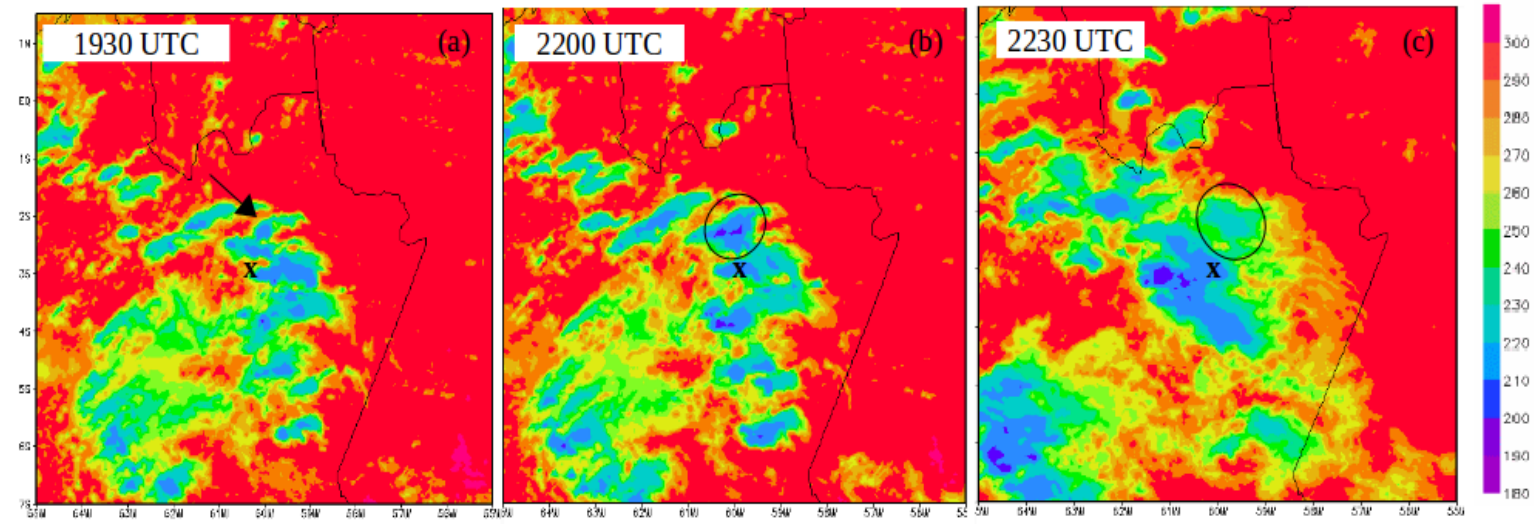

Figura 67 - Imagens de satélite do canal infravermelho em 29/07/2014 na fase de (a) gênese - 1930 UTC, (b) maturação - 2200 UTC e (c) dissipação - 2230 UTC.
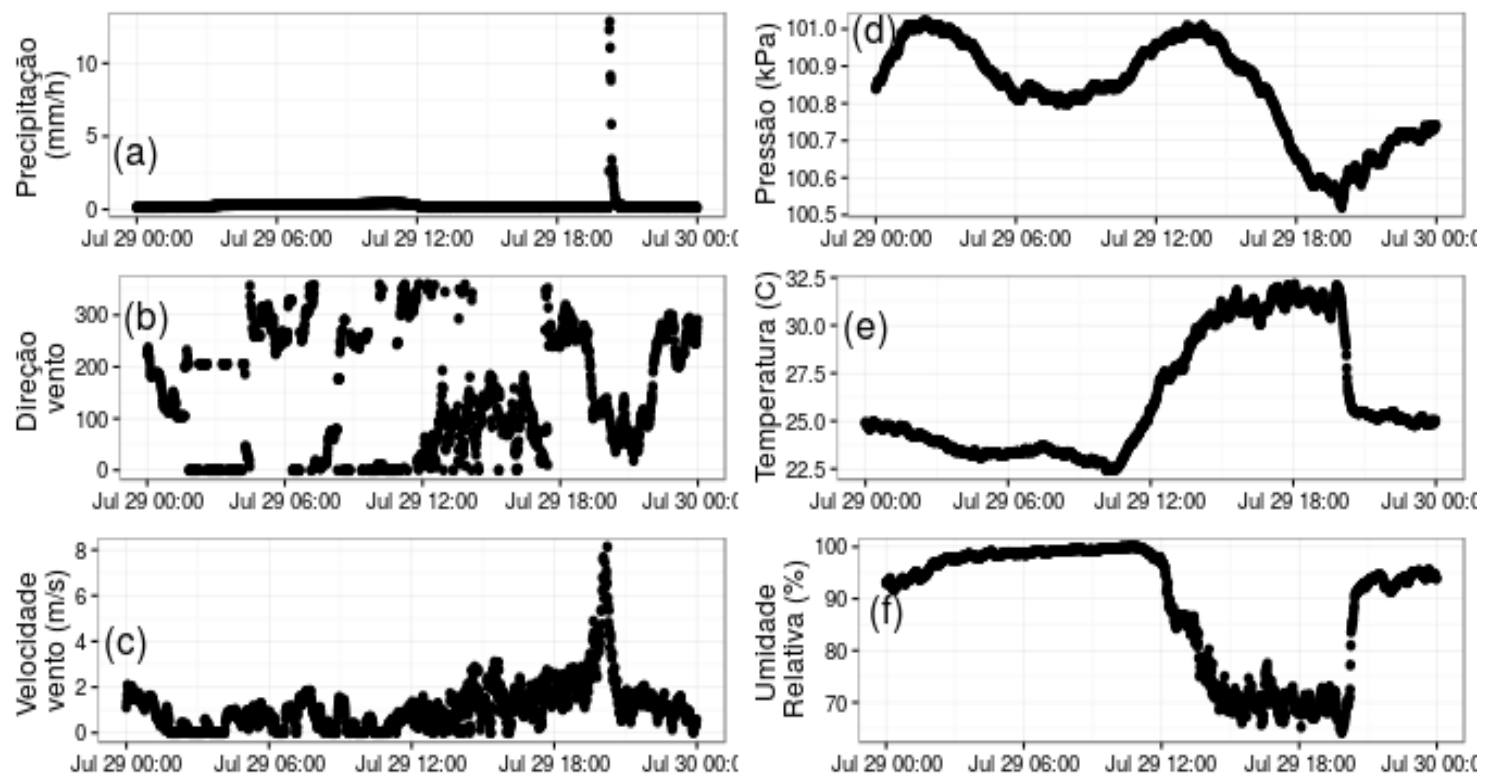

Figura 68 - Condições de tempo na estação de coleta de dados meteorológicos T3, localizada em Manacapuru, Amazonas no dia 29/07/2014. Em (a) precipitação (mm), (b) direção do vento $\left(^{\circ}\right)$, (c) velocidade do vento $(\mathrm{m} / \mathrm{s}),(\mathrm{d})$ pressão atmosférica $(\mathrm{kPa}),(\mathrm{e})$ temperatura do ar $\left({ }^{\circ} \mathrm{C}\right),(\mathrm{f})$ umidade relativa $(\%)$. 


\section{3/08/2014 - horário de gênese: 0430 UTC}

Um escoamento de noroeste predomina em altos níveis e de leste em baixos níveis sobre o Amazonas entre 00 e 06 UTC. As 12 UTC em baixos níveis os ventos alísios atuam bastante intensificados em direção à bacia Amazônica. No entanto, em altos níveis um sistema anticiclônico, que estava atuando no litoral do Maranhão, avançou para oeste desde as cartas anteriores e teve centro localizado sobre o norte do Pará. Em atuação conjunta com a circulação ciclônica de um VCAN, localizado na costa do Peru $\left(10^{\circ} \mathrm{S} / 82^{\circ} \mathrm{W}\right)$, este sistema gerou confluência de massa em altos níveis pelo oeste do Amazonas, o que inibe a formação de nuvens e favoreceu a dissipação do sistema ocorrido no dia 03/08.

As imagens de satélite na Figura 70 mostram o sistema, que se formou à nordeste de Manaus, mas não avançou muito de sua posição inicial (59,6 km) e teve curto ciclo de vida.

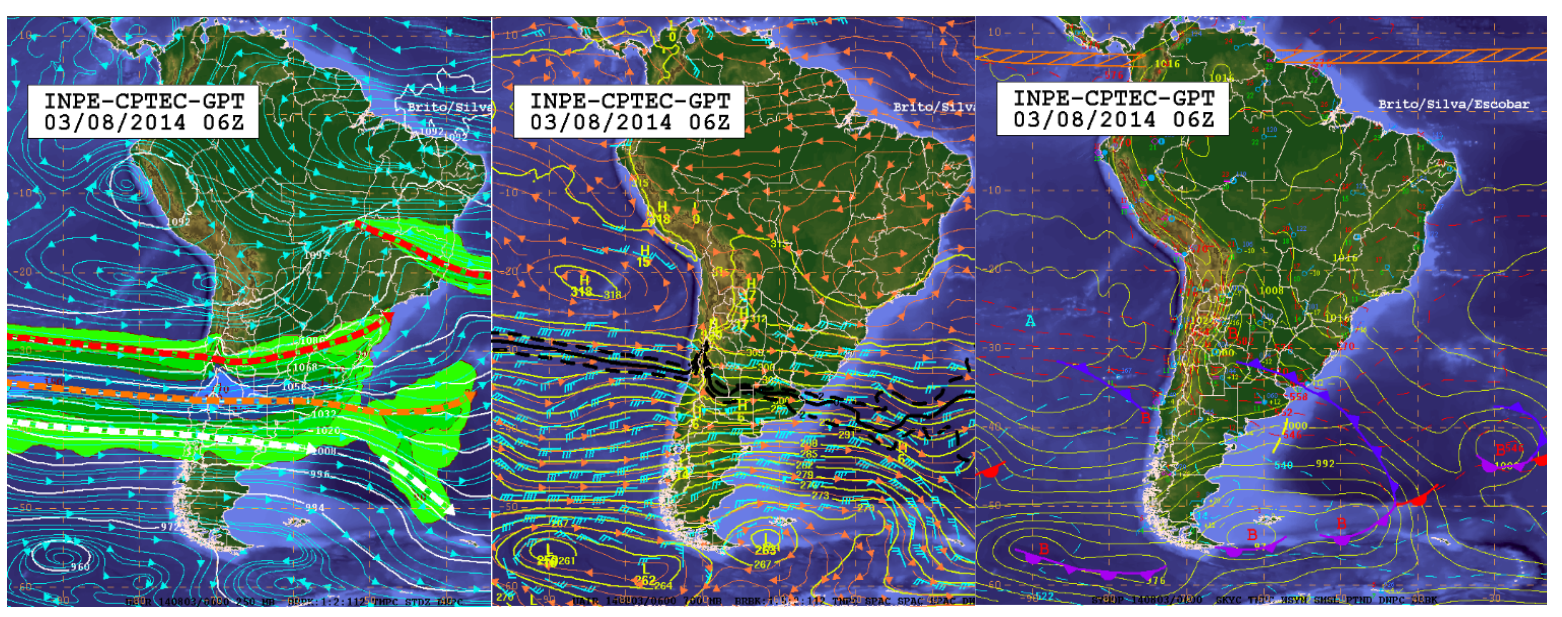
(a) $250 \mathrm{hPa}$
(b) $700 \mathrm{hPa}$
(c) Superfície

Figura 69 - Cartas sinóticas do dia 03/08/2014 - 06 UTC (a) 250 hPa, (b) 700 hPa e (c) superfície. Fonte: CPTEC/INPE.
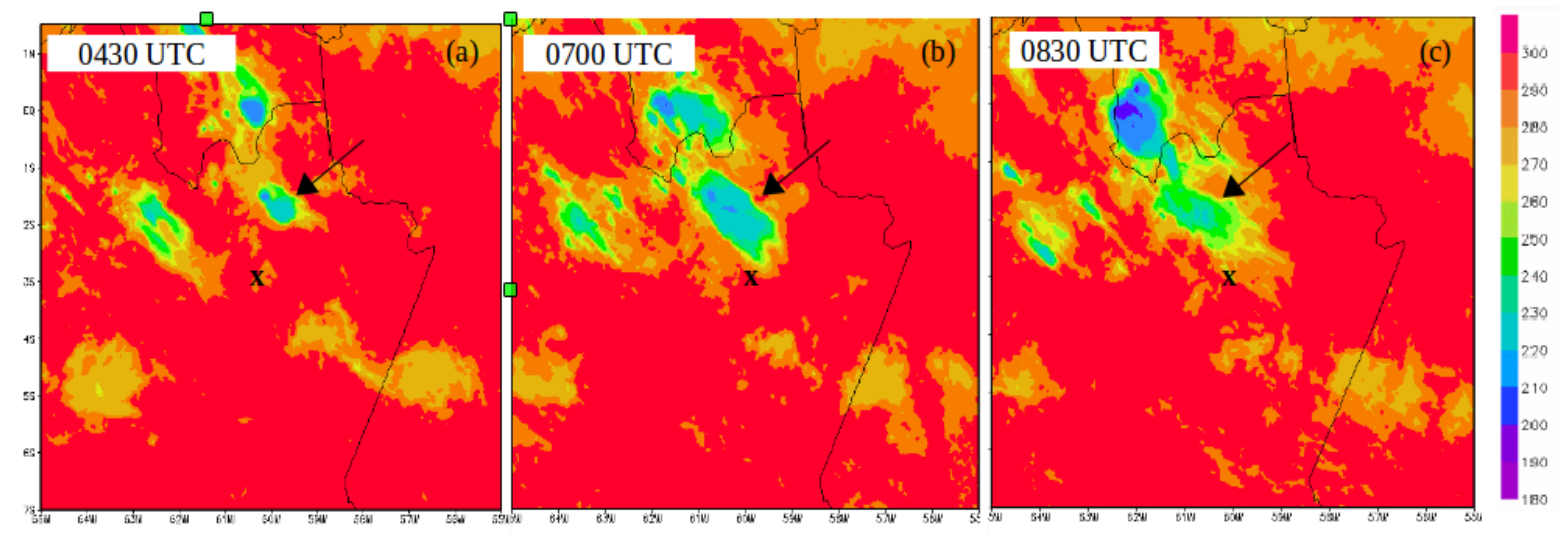

Figura 70 - Imagens de satélite do canal infravermelho em 03/08/2014 na fase de (a) gênese - 0430 UTC, (b) maturação - 0700 UTC e (c) dissipação - 0830 UTC. 

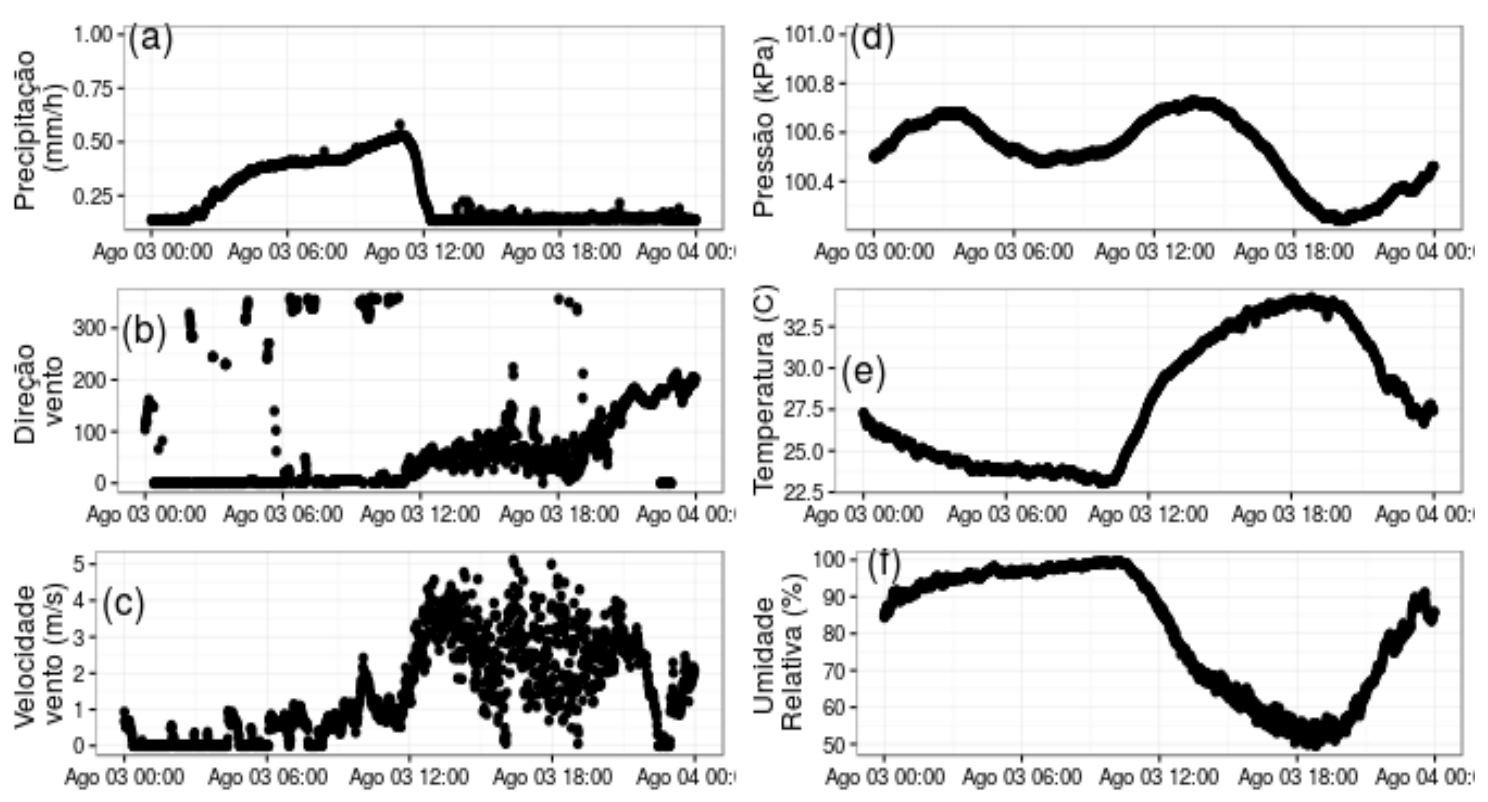

Figura 71 - Condições de tempo na estação de coleta de dados meteorológicos T3, localizada em Manacapuru, Amazonas no dia 03/08/2014. Em (a) precipitação $(\mathrm{mm})$, (b) direção do vento $\left({ }^{\circ}\right)$, (c) velocidade do vento $(\mathrm{m} / \mathrm{s}),(\mathrm{d})$ pressão atmosférica $(\mathrm{kPa}),(\mathrm{e})$ temperatura do $\operatorname{ar}\left({ }^{\circ} \mathrm{C}\right)$, (f) umidade relativa $(\%)$.

\section{4/08/2014 - horário de gênese: 1630 UTC}

O sistema ocorrido neste dia teve gênese sobre o regimento da difluência em altos níveis de massa observada entre o Amazonas e Pará, causada por um anticiclone posicionado sobre o noroeste do Amazonas. Em baixos níveis os ventos alísios adentratam o continente com forte intensidade $(46,3 \mathrm{~km} / \mathrm{h}$ e $55,6 \mathrm{~km} / \mathrm{h})$. A partir do sul da Bolívia, passando pelo Paraguai e Santa Catarina, observa-se o ramo estacionário de um sistema frontal. O SCM ocorrido neste dia teve deslocamento para noroeste e duração de 10 horas. A organização deste sistema e persistência parecem ser influenciadas pela atuação da frente, assim como o sistema ocorrido no dia 29/06/2014. Os índices de instabilidade não apresentaram muita variação em comparação aos demais dias, exceto o cisalhamento em Manacapuru as 18 UTC $\left(5 \cdot 10^{-4} s^{-1}\right)$.

As imagens de satélite apresentadas na Figura 73 mostram o desenvolvimento deste sistema durante seu ciclo de vida. Ele apresentou a maior área entre os 21 SCMs analisados. Na Figura 74 observa-se as mudanças de tempo associadas à sua passagem sobre a estação T3, causando taxas de precipitação de $200 \mathrm{~mm} / \mathrm{h}$, rajada de vento de 12 m/s e queda brusca na pressão de 1008 hPa para 1004 hPa. 


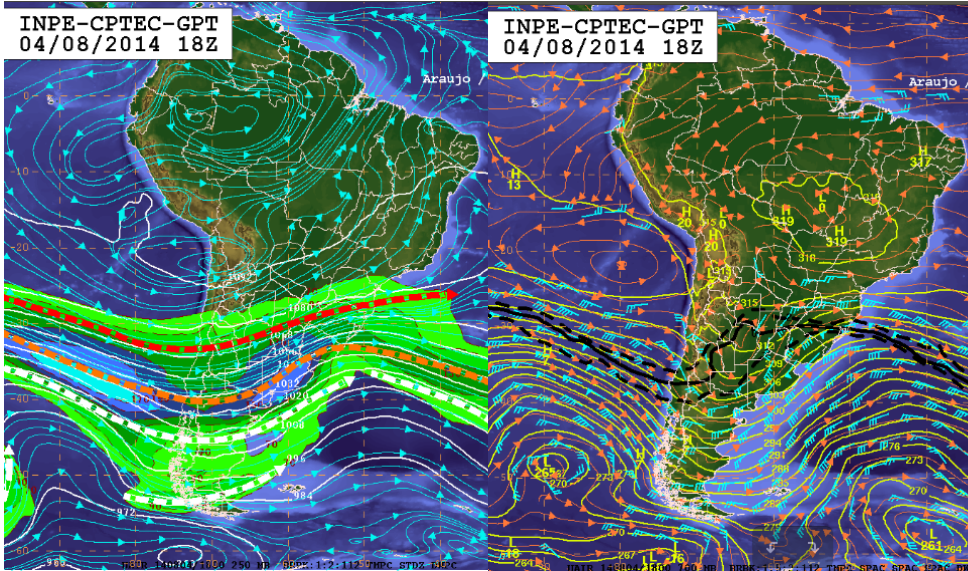

(a) $250 \mathrm{hPa}$

(b) $700 \mathrm{hPa}$

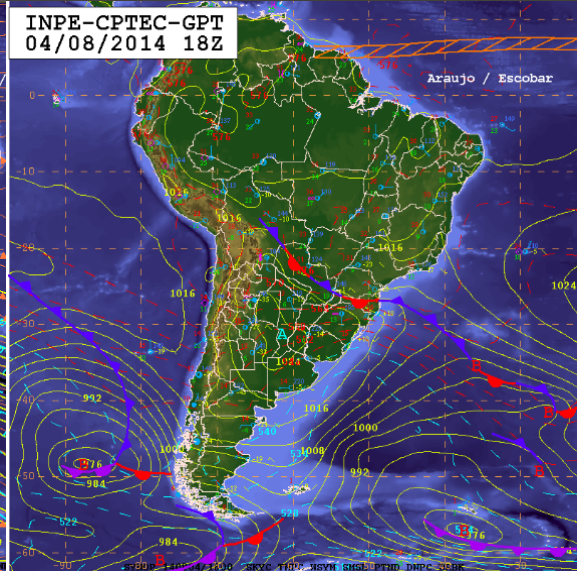

(c) Superfície

Figura 72 - Cartas sinóticas do dia 04/08/2014 - 18 UTC (a) 250 hPa, (b) 700 hPa e (c) superfície. Fonte: CPTEC/INPE.
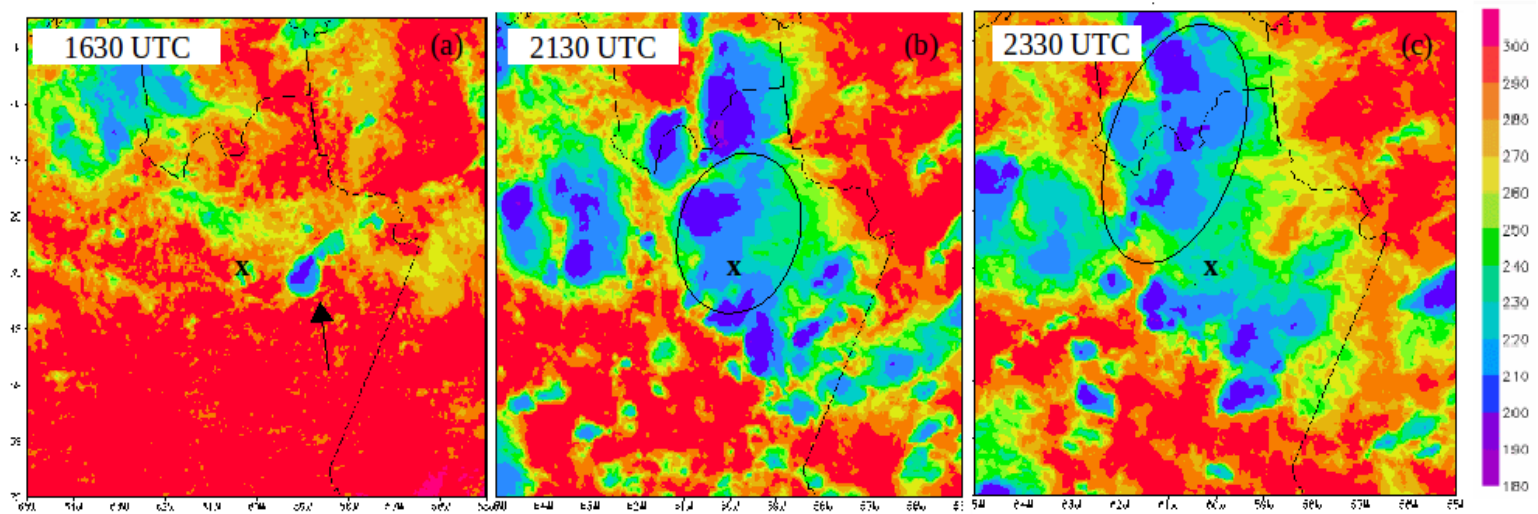

Figura 73 - Imagens de satélite do canal infravermelho em 04 e 05/08/2014 na fase de (a) gênese - 1630 UTC, (b) desenvolvimento - 2130 UTC e (c) maturação - 2330 UTC.
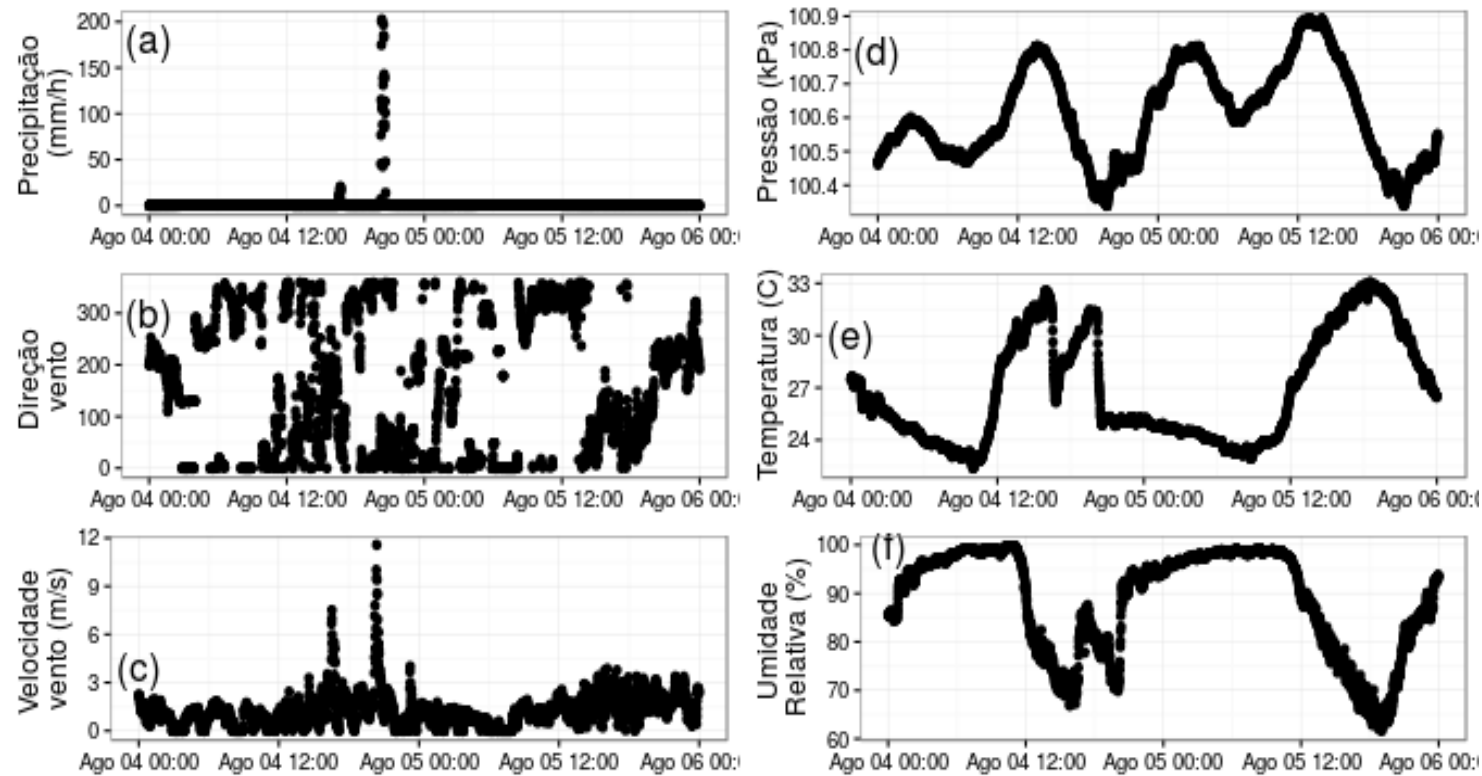

Figura 74 - Condições de tempo na estação de coleta de dados meteorológicos T3, localizada em Manacapuru, Amazonas nos dias 04 e 05/08/2014. Em (a) precipitação (mm), (b) direção do vento $\left(^{\circ}\right)$, (c) velocidade do vento $(\mathrm{m} / \mathrm{s}),(\mathrm{d})$ pressão atmosférica $(\mathrm{kPa}),(\mathrm{e})$ temperatura do $\operatorname{ar}\left({ }^{\circ} \mathrm{C}\right),(\mathrm{f})$ umidade relativa $(\%)$. 


\section{8/08/2014 - horário de gênese: 2230 UTC}

Em 250 hPa há uma circulação com giro anticiclônico sobre o norte da América do Sul, sua influência no oeste do Amazonas mostra difluência no escoamento neste nível sobre a metade sul do estado (Figura 75). Em médios níveis observa-se a atuação conjunta de ventos de sudeste sobre a região norte da América do Sul devido de uma circulação anticiclônica sobre o continente associada a uma região de alta pressão localizada no extremo sul do Mato Grosso do Sul e outra região de alta pressão no Atlântico em aproximadamente $20^{\circ} \mathrm{S} / 30^{\circ} \mathrm{W}$. Os ventos de sudeste sobre o Amazonas são intensos, variando entre $46,3 \mathrm{~km} / \mathrm{h}$ e $55,6 \mathrm{~km} / \mathrm{h}$ e transportam umidade para a região, auxiliando no desenvolvimento e manutenção do SCM ocorrido no dia 08/08/2014.

Apesar de ter gênese próxima em Manacapuru, o sistema não causou mudanças no tempo no local (Figura 77), pois ele deslocou-se para noroeste após a fase inicial (Figura 76).

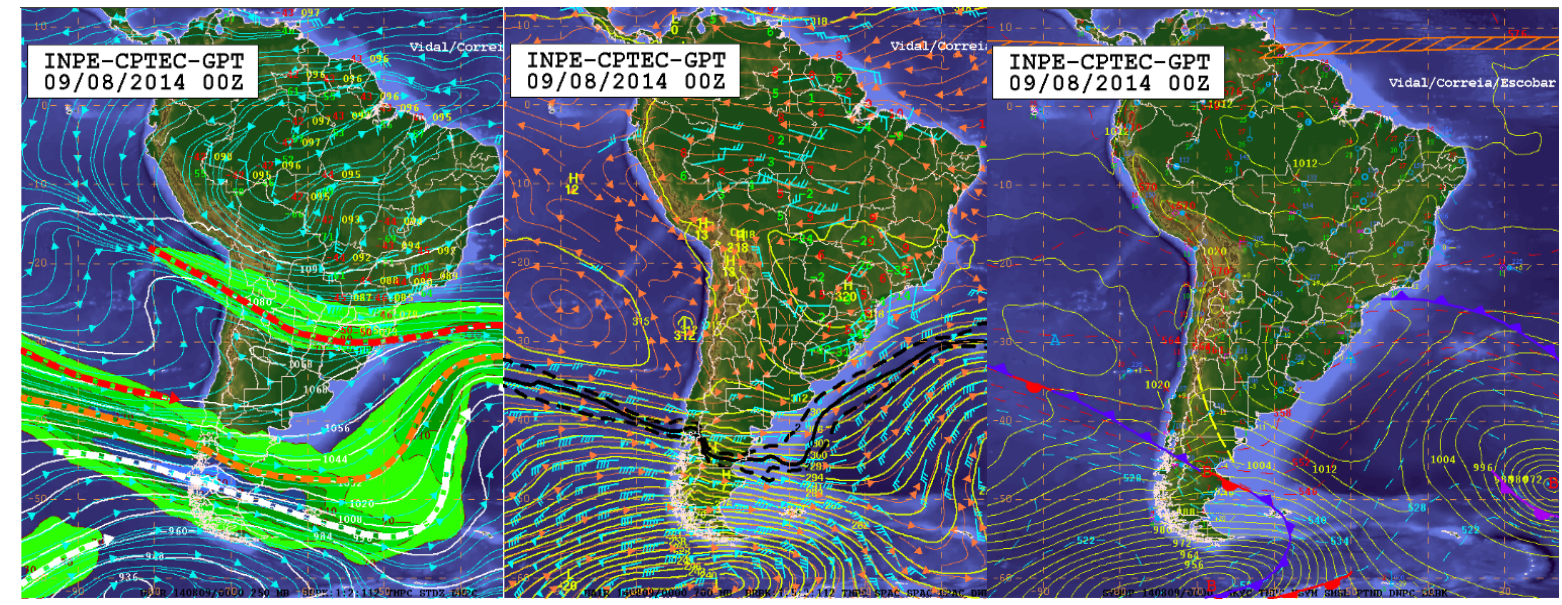

(a) $250 \mathrm{hPa}$

(b) $700 \mathrm{hPa}$

(c) Superfície

Figura 75 - Cartas sinóticas do dia 09/08/2014 - 00 UTC (a) 250 hPa, (b) 700 hPa e (c) superfície. Fonte: CPTEC/INPE.
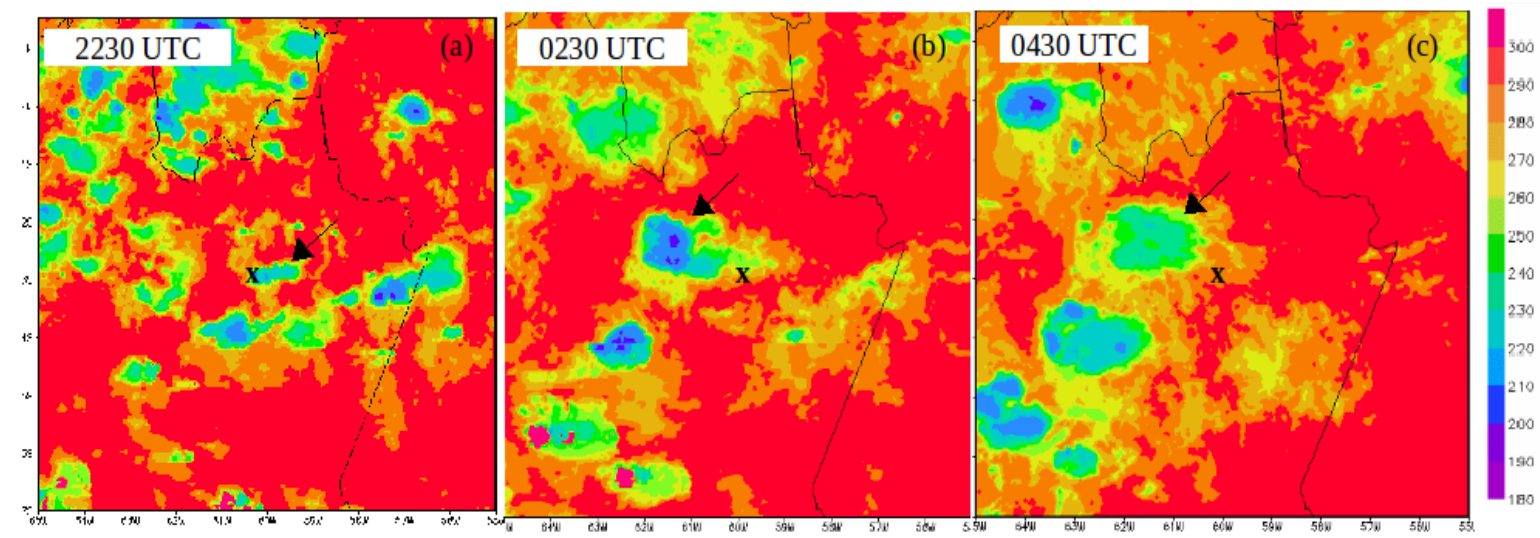

Figura 76 - Imagens de satélite do canal infravermelho em 08 e 09/08/2014 na fase de (a) gênese - 2230 UTC, (b) maturação - 0230 UTC e (c) dissipação - 0430 UTC. 

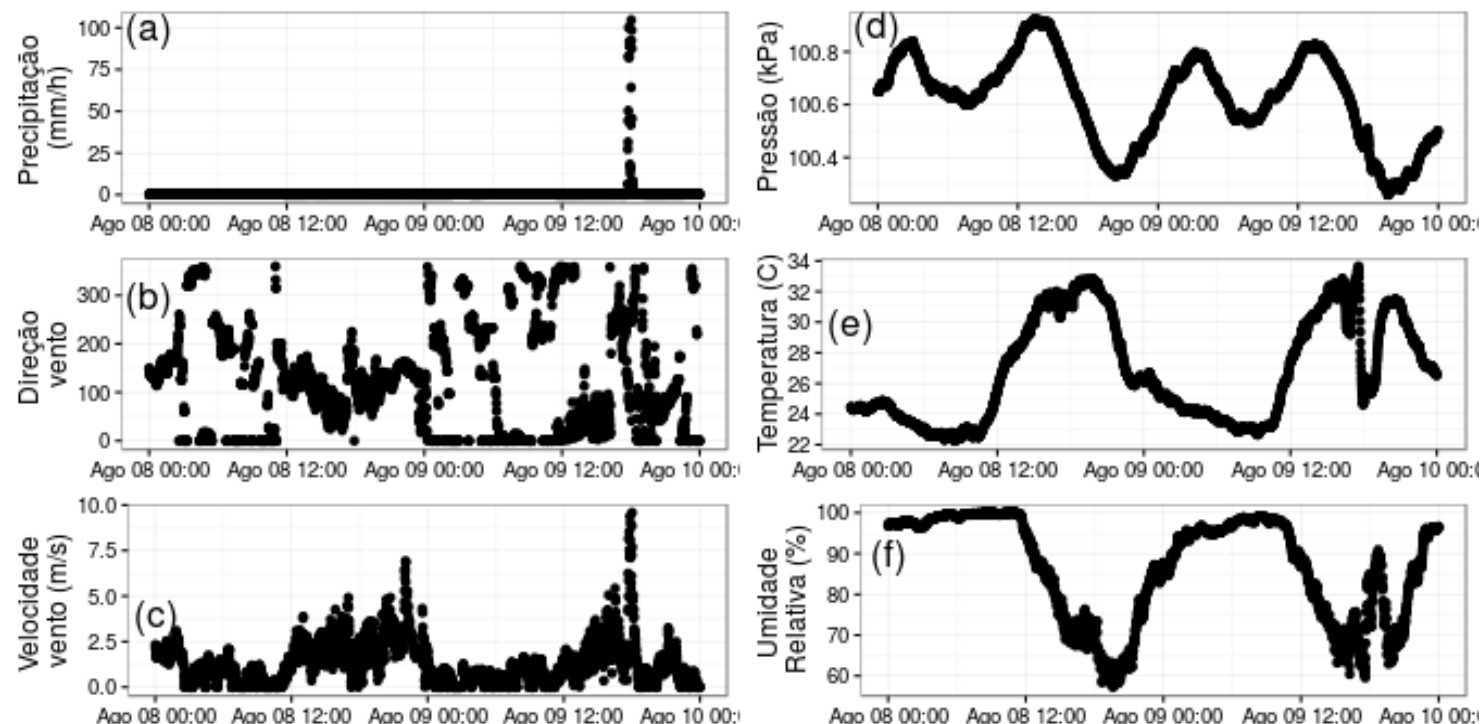

Figura 77 - Condições de tempo na estação de coleta de dados meteorológicos T3, localizada em Manacapuru, Amazonas no dia 08 e 09/08/2014. Em (a) precipitação $(\mathrm{mm})$, (b) direção do vento $\left(^{\circ}\right)$, (c) velocidade do vento $(\mathrm{m} / \mathrm{s}),(\mathrm{d})$ pressão atmosférica $(\mathrm{kPa}),(\mathrm{e})$ temperatura do $\operatorname{ar}\left({ }^{\circ} \mathrm{C}\right)$, (f) umidade relativa $(\%)$.

\section{5/08/2014 - horário de gênese: 18 UTC}

Entre o Amazonas e Roraima há difluência no escoamento em altos níveis, gerando divergência de massa neste nível e por consequência convergência na camada baixa da troposfera (Figura 78). Uma circulação anticiclônica em baixos níveis e centrada em aproximadamente $22^{\circ} \mathrm{S}$ e $40^{\circ} \mathrm{W}$ advecta ar úmido do oceano Atlântico para dentro do continente. A influência desta circulação chega até a região Amazônica atuando em conjunto com a Alta Subtropical do Atlântico Sul (ASAS), deslocada para oeste (fora do domínio da Figura mostrada aqui). Em superfície há a ocorrência de uma frente estacionária atuando sobre o Espírito Santo. Ao passar pela estação T3, o que ocorreu logo após sua gênese (Figura 79), o sistema causou rápidas mudanças no tempo, incluindo taxas de precipitação de até $80 \mathrm{~mm} / \mathrm{h}$ (Figura 80 ).

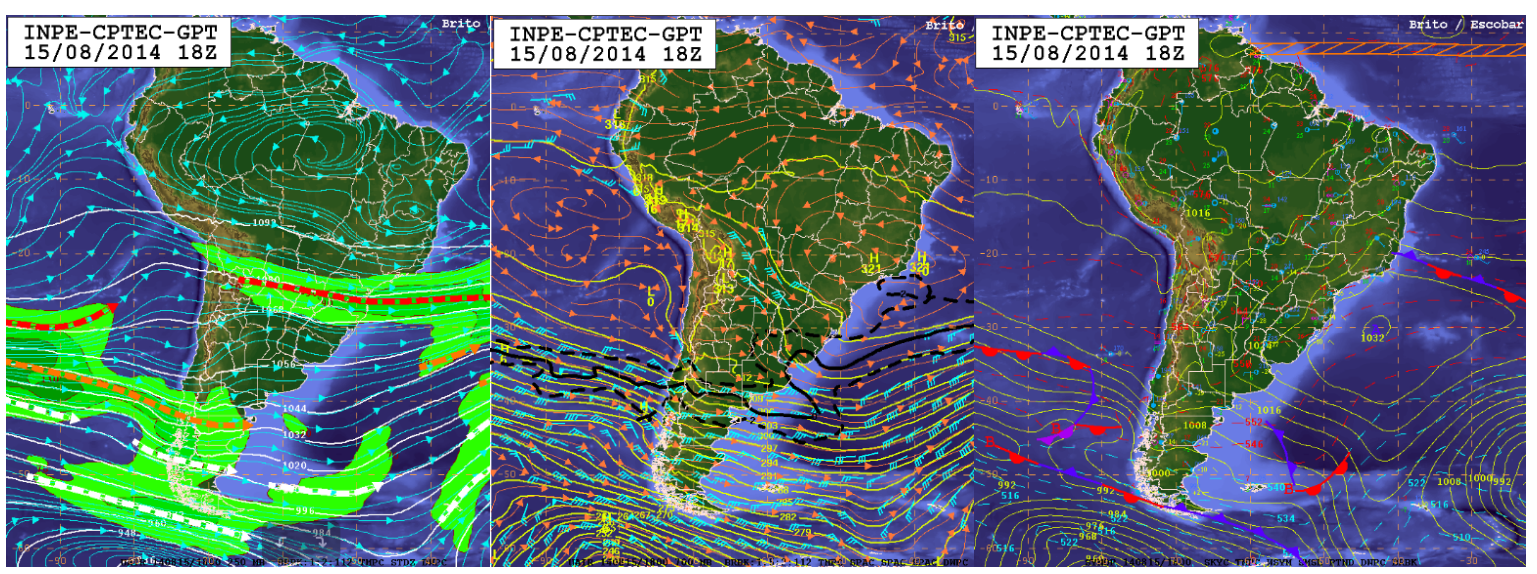

(a) $250 \mathrm{hPa}$

(b) $700 \mathrm{hPa}$

(c) Superfície

Figura 78 - Cartas sinóticas do dia 15/08/2014 - 18 UTC (a) 250 hPa, (b) 700 hPa e (c) superfície. Fonte: CPTEC/INPE. 

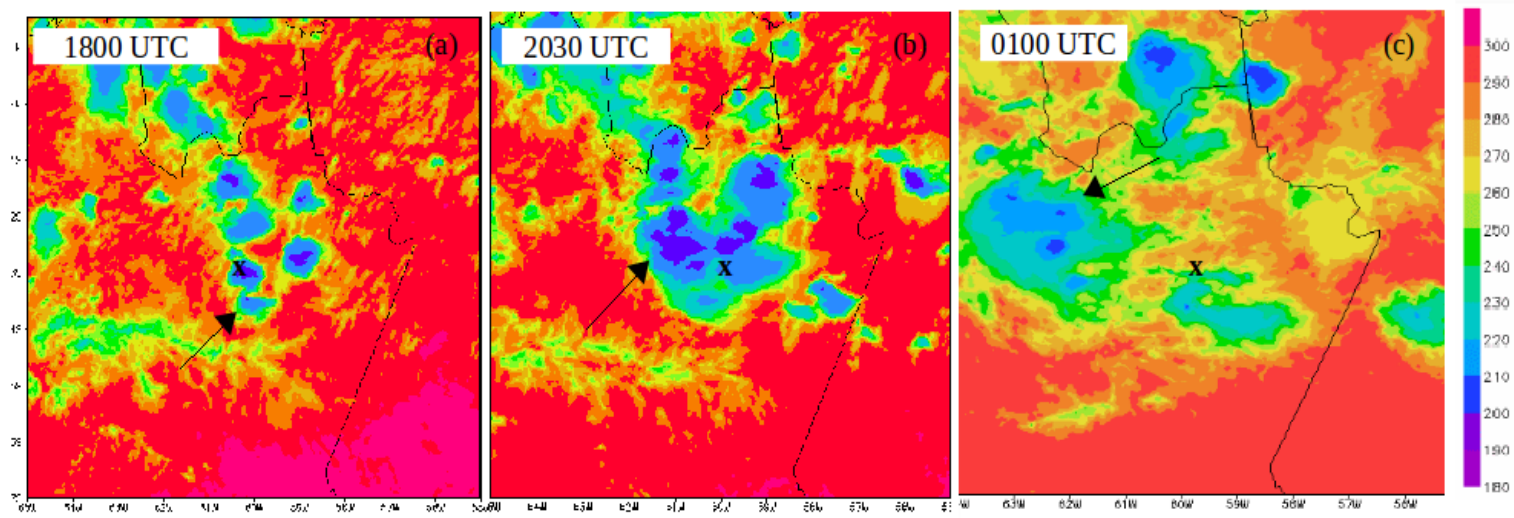

Figura 79 - Imagens de satélite do canal infravermelho em 15 e 16/08/2014 na fase de (a) gênese - 1800 UTC, (b) maturação - 2030 UTC e (c) dissipação - 0100 UTC.
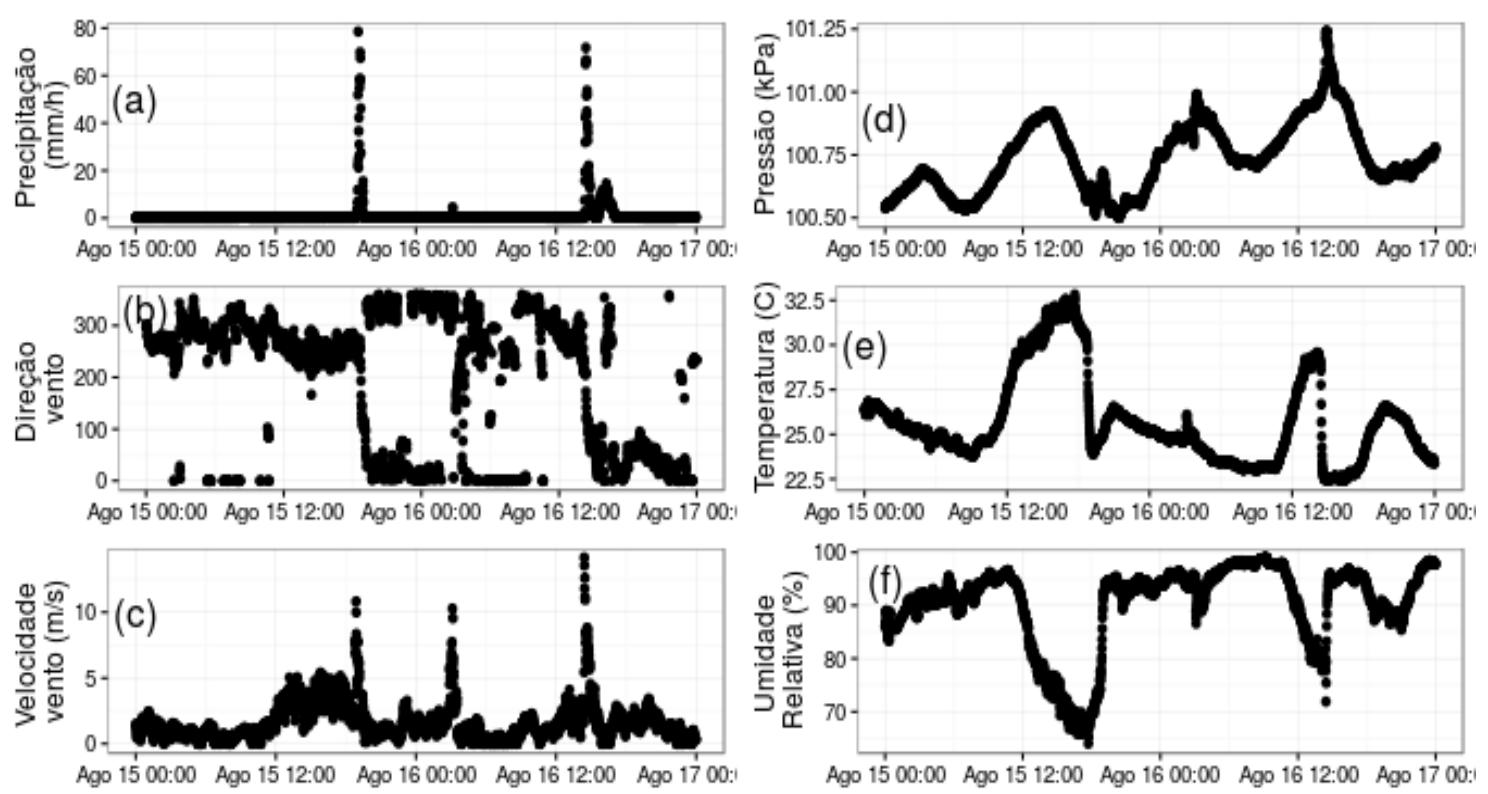

Figura 80 - Condições de tempo na estação de coleta de dados meteorológicos T3, localizada em Manacapuru, Amazonas no dia 15 e 16/08/2014. Em (a) precipitação (mm), (b) direção do vento $\left(^{\circ}\right)$, (c) velocidade do vento $(\mathrm{m} / \mathrm{s})$, (d) pressão atmosférica $(\mathrm{kPa}),(\mathrm{e})$ temperatura do $\operatorname{ar}\left({ }^{\circ} \mathrm{C}\right)$, (f) umidade relativa $(\%)$.

\section{2/09/2014 - horário de gênese: 15 UTC}

$O$ centro da ASAS ficou em torno de $27^{\circ} \mathrm{S} / 27^{\circ} \mathrm{W}$, influenciando o escoamento em baixos níveis sobre a América do Sul, gerando ventos de leste/sudeste entre o norte e nordeste do país e transportando umidade do oceano para o continente. Em superfície, as 12 UTC, observa-se uma frente estacionária sobre o Paraguai passando pelo norte do Rio Grande do Sul e Santa Catarina, seguindo com uma frente fria em direção ao Atlântico (Figura 81). As 18 UTC sobre o nordeste da Argentina e região central do Rio Grande do Sul há atuação de uma frente quente, que se une a uma estacionária sobre o oceano Atlantico adjacente. O dia apresentou bastante instabilidade e as 18 UTC o cisalhamento foi de $5 \cdot 10^{-4} \mathrm{~s}^{-1}$, relativamente maior que nos outros horários (Figura 41). Este sistema teve deslocamento para nordeste (Figura 82) e causou variação no 
tempo na estação localizada em Manacapuru, com precipitação associada próximo às 18 UTC (Figura 83).

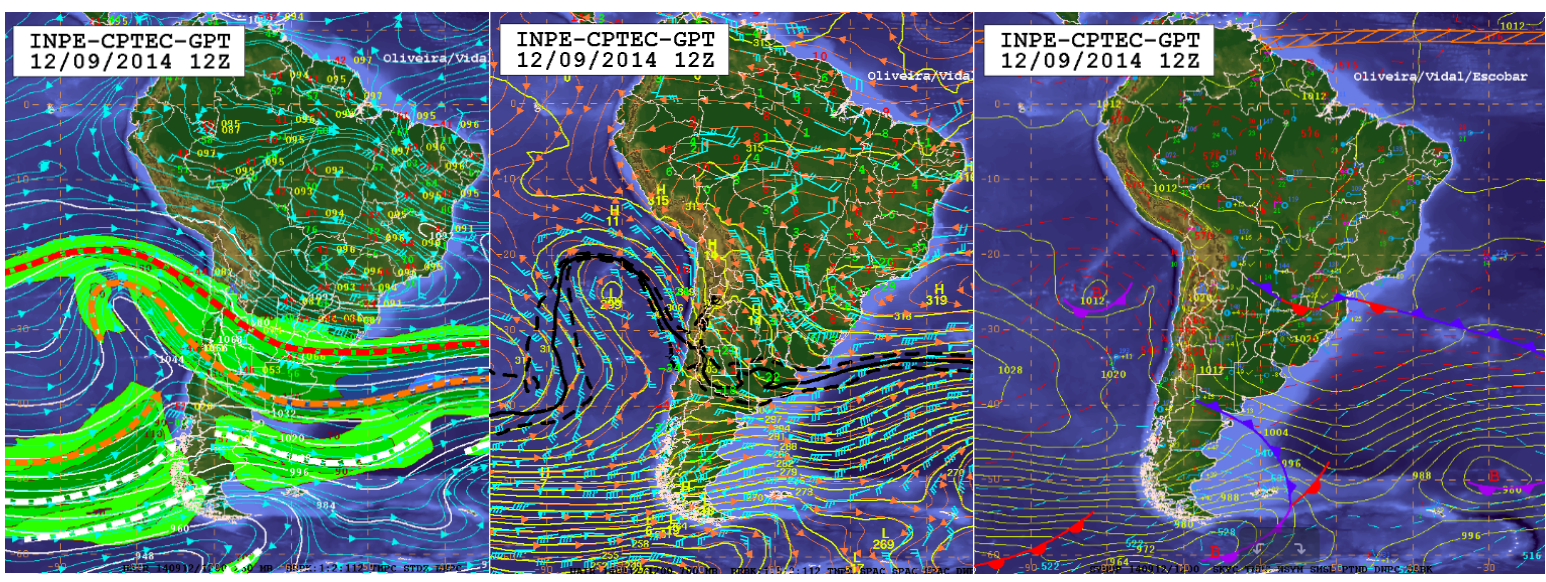

(a) $250 \mathrm{hPa}$

(b) $700 \mathrm{hPa}$

(c) Superfície

Figura 81 - Cartas sinóticas do dia 12/09/2014 - 12 UTC (a) 250 hPa, (b) 700 hPa e (c) superfície. Fonte: CPTEC/INPE.
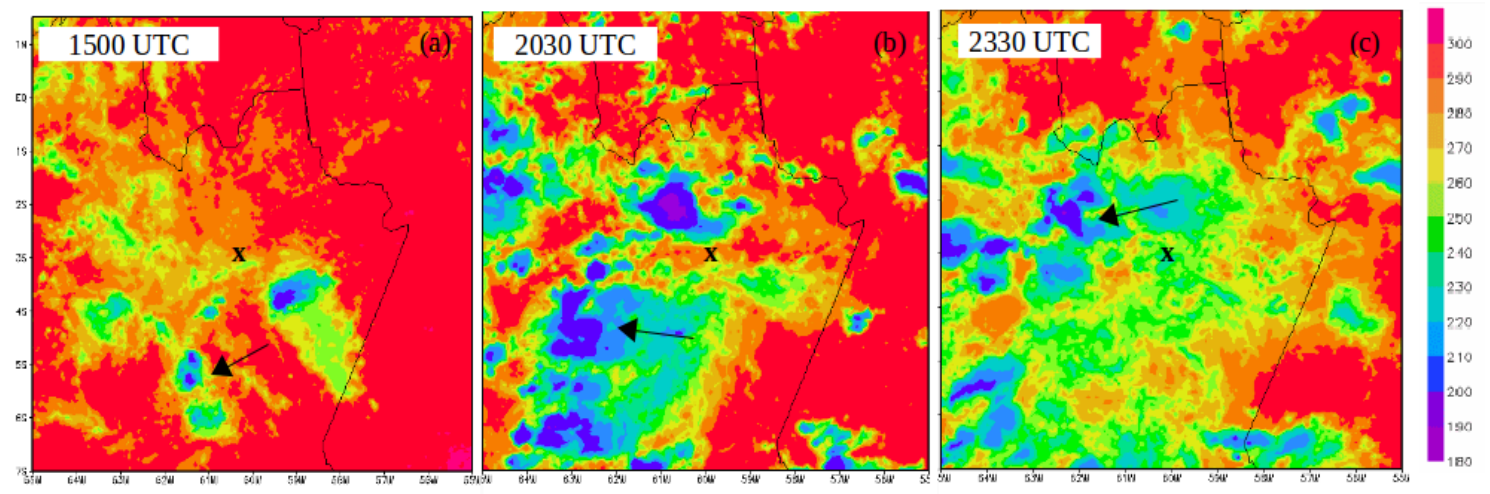

Figura 82 - Imagens de satélite do canal infravermelho em 12/09/2014 na fase de (a) gênese - 1500 UTC, (b) maturação - 2030 UTC e (c) dissipação - 2330 UTC.
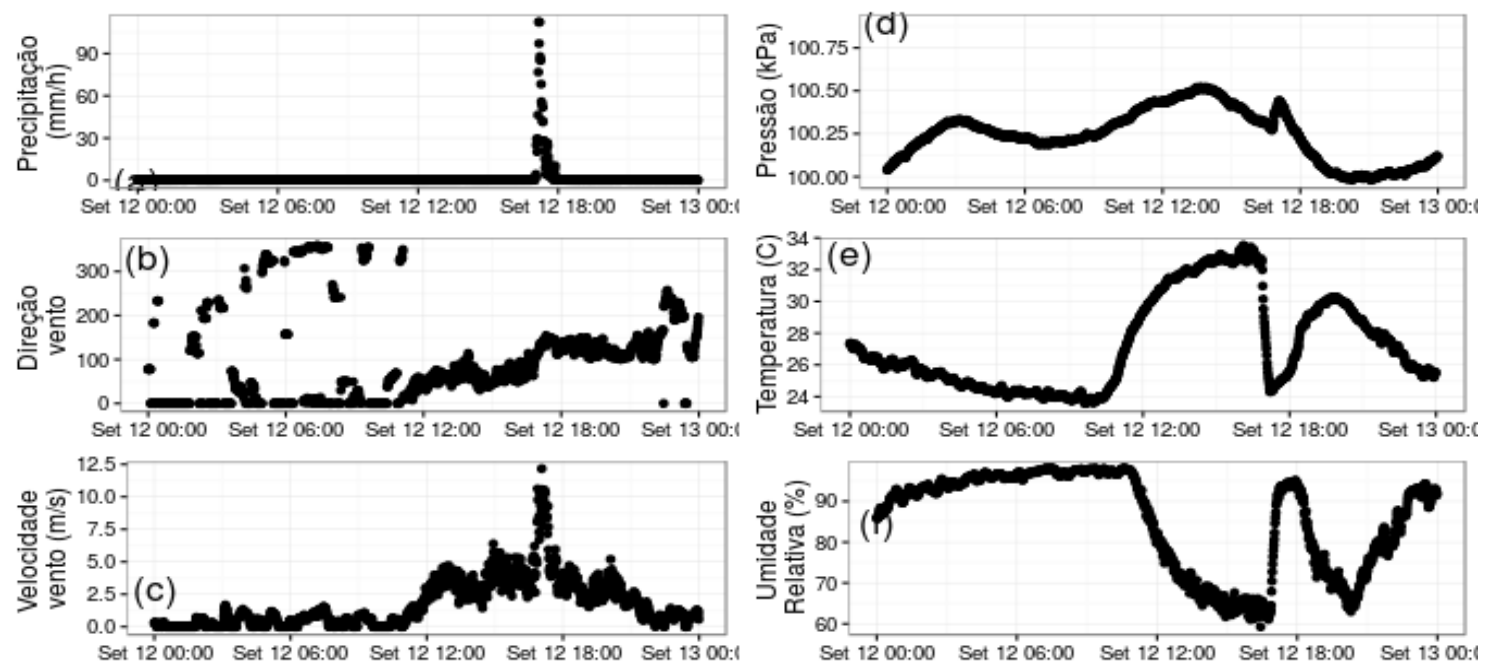

Figura 83 - Condições de tempo na estação de coleta de dados meteorológicos T3, localizada em Manacapuru, Amazonas no dia 12/09/2014. Em (a) precipitação $(\mathrm{mm})$, (b) direção do vento $\left(^{\circ}\right)$, (c) velocidade do vento $(\mathrm{m} / \mathrm{s}),(\mathrm{d})$ pressão atmosférica $(\mathrm{kPa}),(\mathrm{e})$ temperatura do $\operatorname{ar}\left({ }^{\circ} \mathrm{C}\right),(\mathrm{f})$ umidade relativa $(\%)$. 


\section{4/09/2014 - horário de gênese: 1230 UTC}

A carta sinótica em $250 \mathrm{hPa}$ as 12 UTC mostra que há difluência em altos níveis sobre o oeste do Amazonas que, juntamente com a convergência dos alísios (em baixos níveis) transportando umidade do oceano para região, favoreceram a formação do sistema observado. A carta sinótica em médios níveis no horário das 18 UTC mostra difluência dos escoamento de leste/nordeste sobre o Amazonas, o que pode ter atuado no sentido de diminuir o ciclo de vida do SCM neste dia.

Este sistema se desenvolveu e dissipou distante da estação T3 e, portanto, mudanças no tempo não foram observadas (Figuras 85 e 86).

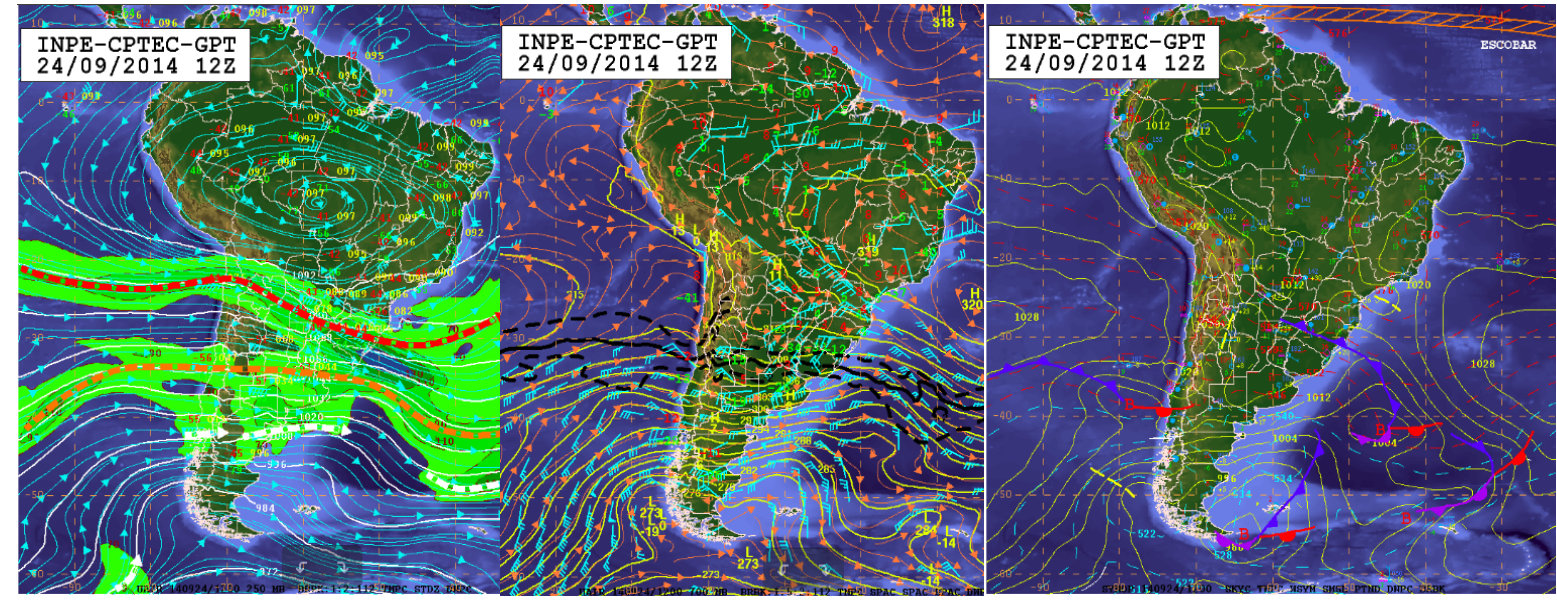

(a) $250 \mathrm{hPa}$

(b) $700 \mathrm{hPa}$

(c) Superfície

Figura 84 - Cartas sinóticas do dia 24/09/2014 - 12 UTC (a) 250 hPa, (b) 700 hPa e (c) superfície. Fonte: CPTEC/INPE.
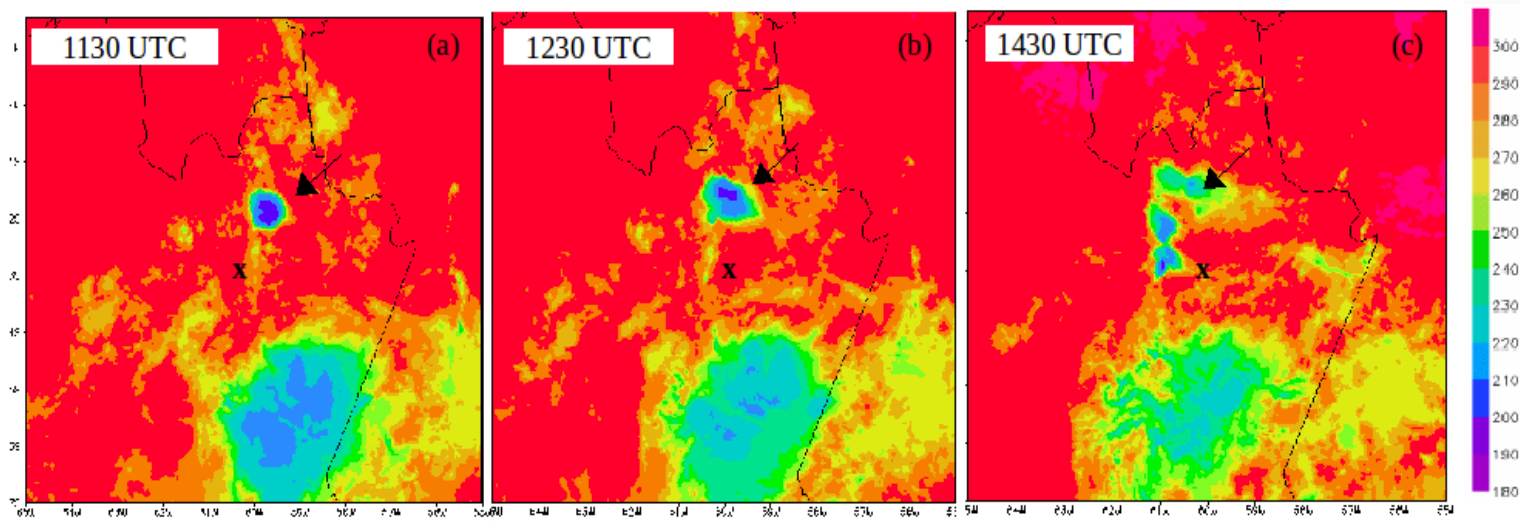

Figura 85 - Imagens de satélite do canal infravermelho em 24/09/2014 na fase de (a) gênese - 1130 UTC, (b) maturação - 1230 UTC e (c) dissipação - 1430 UTC. 

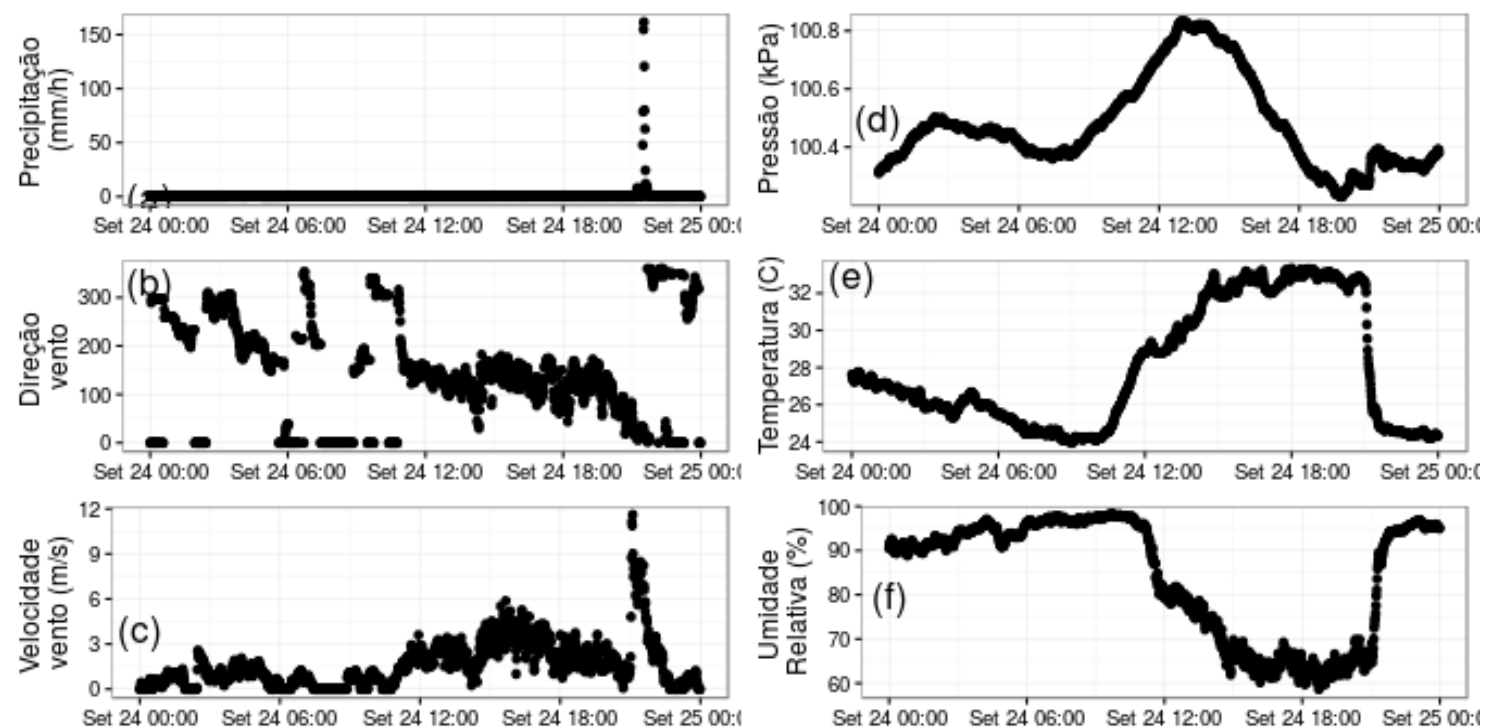

Figura 86 - Condições de tempo na estação de coleta de dados meteorológicos T3, localizada em Manacapuru, Amazonas no dia 24/09/2014. Em (a) precipitação $(\mathrm{mm})$, (b) direção do vento $\left(^{\circ}\right)$, (c) velocidade do vento $(\mathrm{m} / \mathrm{s}),(\mathrm{d})$ pressão atmosférica $(\mathrm{kPa}),(\mathrm{e})$ temperatura do $\operatorname{ar}\left({ }^{\circ} \mathrm{C}\right)$, (f) umidade relativa $(\%)$.

\section{6/11/2014 - horário de gênese: 19 UTC.}

As cartas sinóticas em superfície as 12 UTC do dia 16/11/2014 e 00 UTC do dia 17/11/2014 (os horários de 18 e 06 UTC, nas respectivas datas não encontram-se disponíveis) mostram a atuação da Zona de Convergência do Atlântico Sul (ZCAS). As 00 UTC do dia 17 ela esteve localizada desde o leste do Pará até o leste da Bahia e Atlântico adjacente, onde acopla-se a uma frente. Neste mesmo horário em altos níveis há difluência no escoamento no leste do Pará, provocado por um sistema anticiclônico posicionado próximo a $12^{\circ} \mathrm{S} / 62^{\circ} \mathrm{W}$, que em conjunto com a convergência de umidade em baixos níveis favoreceu a formação do SCM observado. Não houve mudança nas condições de tempo na estação T3 associado a ocorrência deste sistema (Figura 89), uma vez que ele ocorreu distante desta estação (Figura 88).

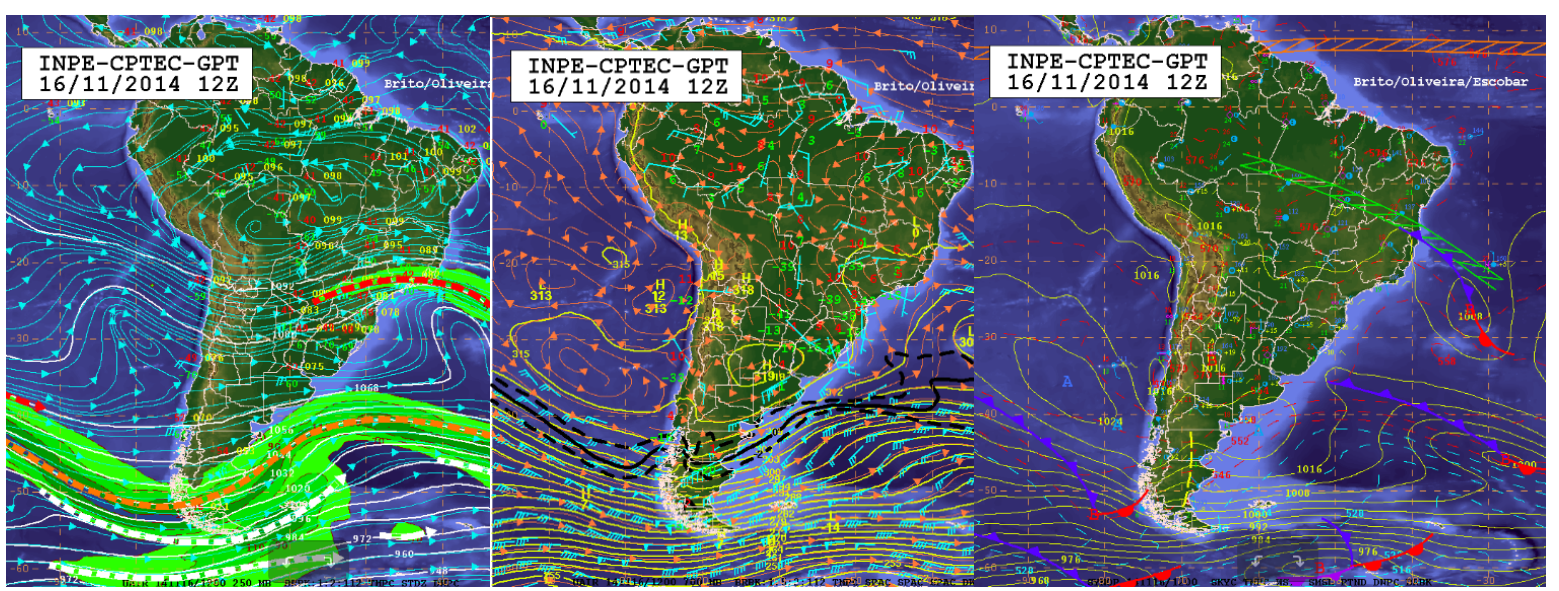

(a) $250 \mathrm{hPa}$

(b) $700 \mathrm{hPa}$

(c) Superfície

Figura 87 - Cartas sinóticas do dia 16/11/2014 - 12 UTC (a) 250 hPa, (b) 700 hPa e (c) superfície. Fonte: CPTEC/INPE. 


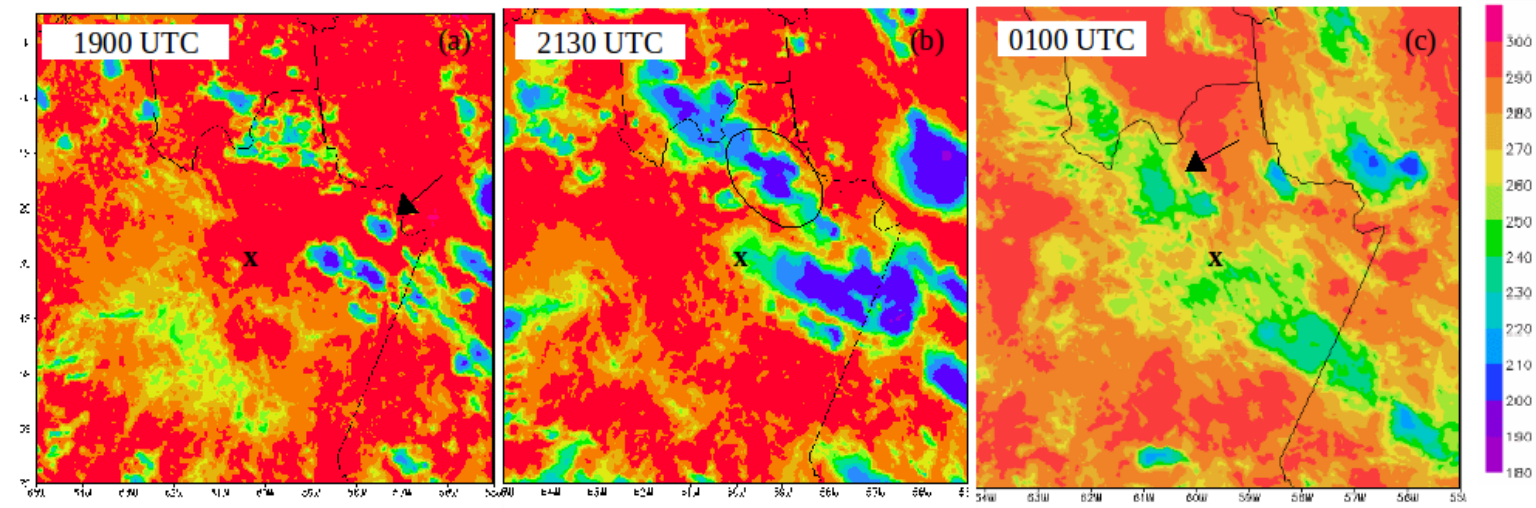

Figura 88 - Imagens de satélite do canal infravermelho em 16 e 17/11/2014 na fase de (a) gênese - 1900 UTC, (b) maturação - 2130 UTC e (c) dissipação - 0100 UTC.
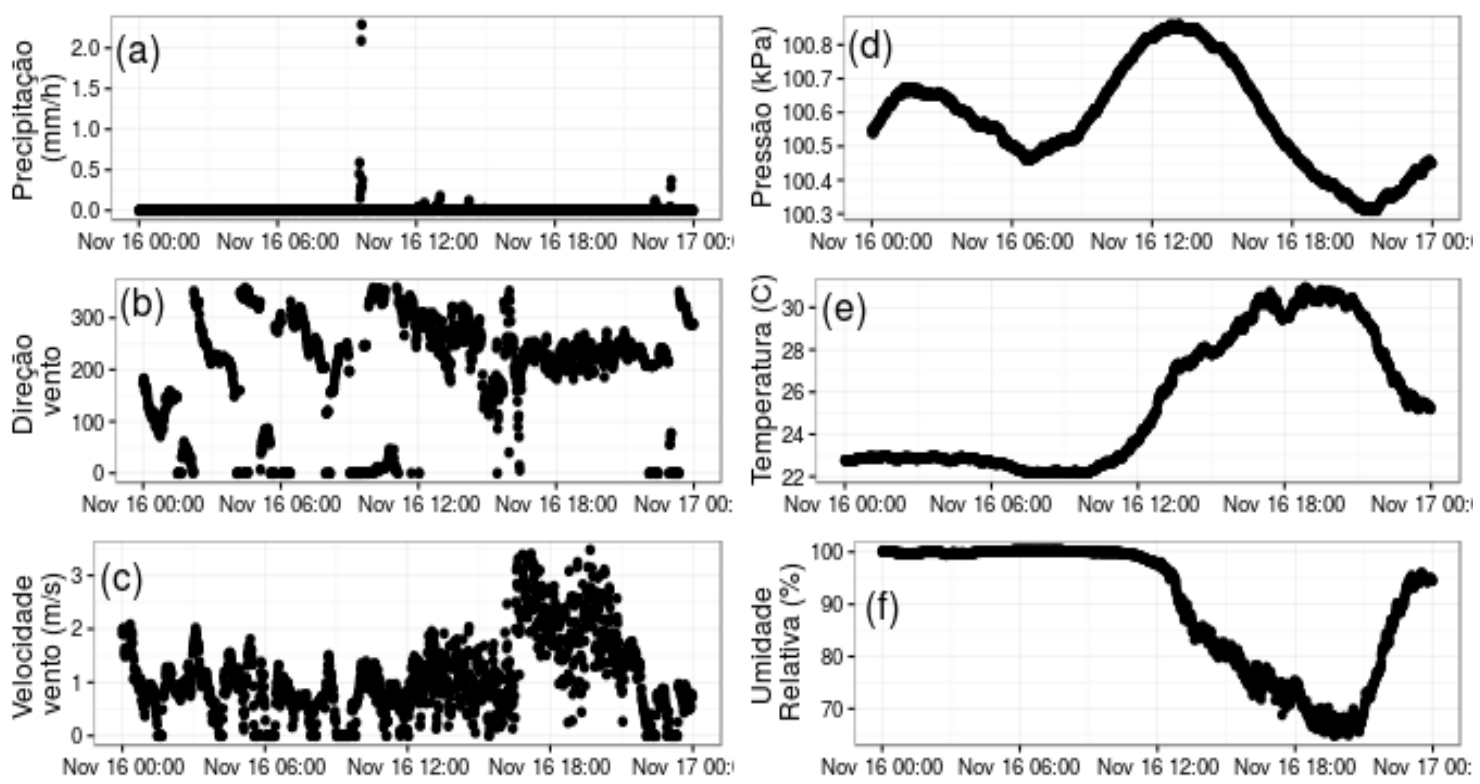

Figura 89 - Condições de tempo na estação de coleta de dados meteorológicos T3, localizada em Manacapuru, Amazonas no dia 16/11/2014. Em (a) precipitação $(\mathrm{mm})$, (b) direção do vento $\left(^{\circ}\right)$, (c) velocidade do vento $(\mathrm{m} / \mathrm{s}),(\mathrm{d})$ pressão atmosférica $(\mathrm{kPa}),(\mathrm{e})$ temperatura do $\operatorname{ar}\left({ }^{\circ} \mathrm{C}\right),(\mathrm{f})$ umidade relativa $(\%)$.

\section{3/12/2014 - horário de gênese: 05 UTC}

As cartas das 00 UTC (Figura 90) e 06 UTC em altos níveis mostram difluência no norte do Amazonas, devido a atuação de um anticiclone posicionado em aproximadamente de $18^{\circ} \mathrm{S} / 70^{\circ} \mathrm{W}$ e um VCAN no oceâno Atlântico em torno de $20^{\circ} \mathrm{S} / 30^{\circ} \mathrm{W}$. Em baixos níveis observa-se o escoamento de leste sobre o nordeste do Amazonas, na região de formação do SCM.

Este sistema completou seu ciclo de vida ao norte da estação T3 (Figura 91), de forma que não influenciou as condições de tempo naquela região (Figura 92). 


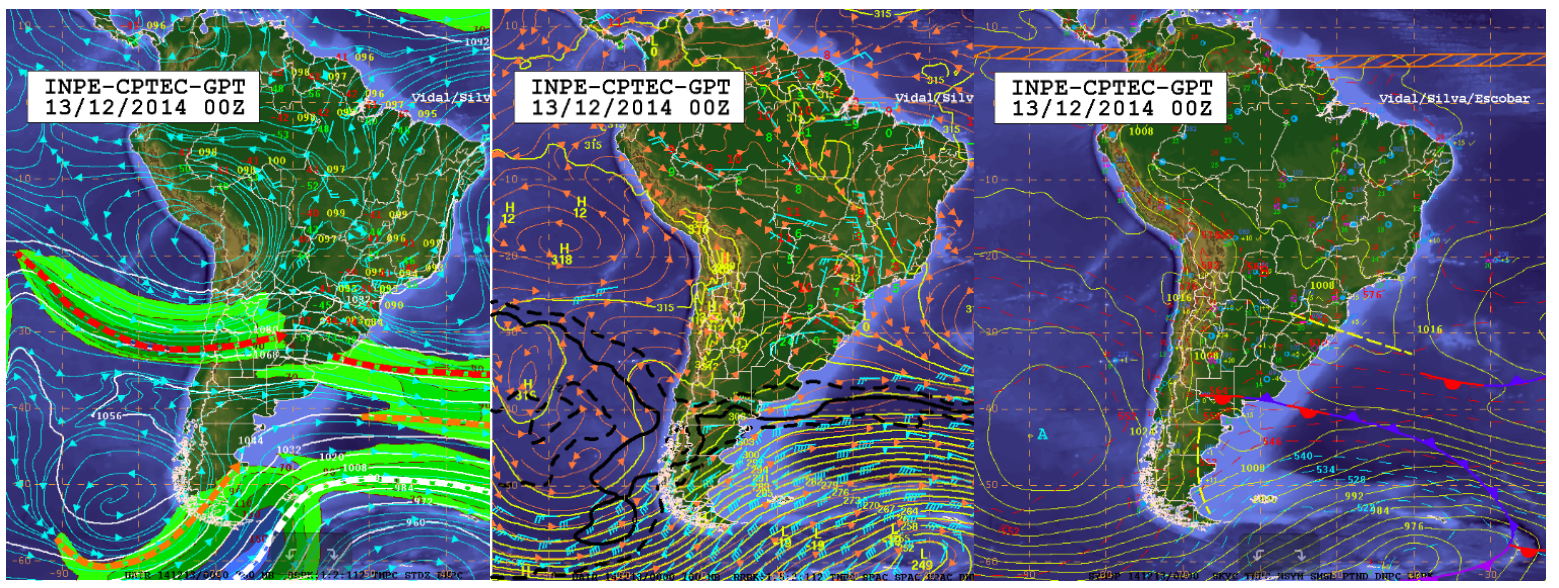

(a) $250 \mathrm{hPa}$

(b) $700 \mathrm{hPa}$

(c) Superfície

Figura 90 - Cartas sinóticas do dia 13/12/2014 - 00 UTC (a) 250 hPa, (b) 700 hPa e (c) superfície. Fonte: CPTEC/INPE.
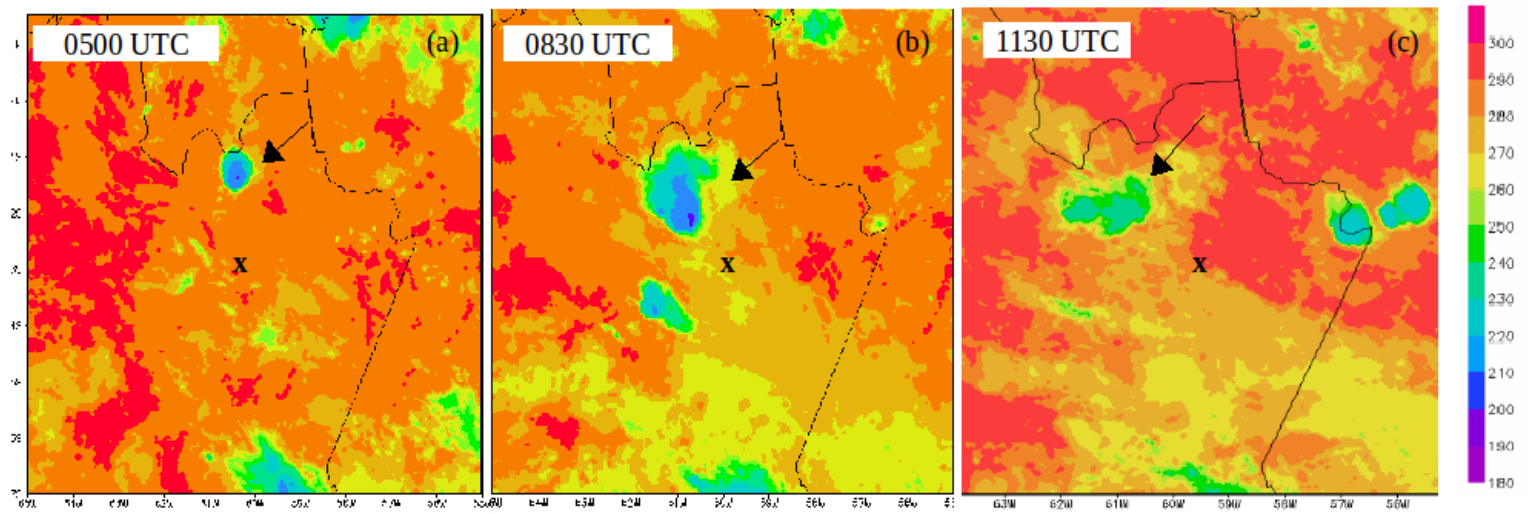

Figura 91 - Imagens de satélite do canal infravermelho em 13/12/2014 na fase de (a) gênese - 0500 UTC, (b) maturação - 0830 UTC e (c) dissipação - 1130 UTC.
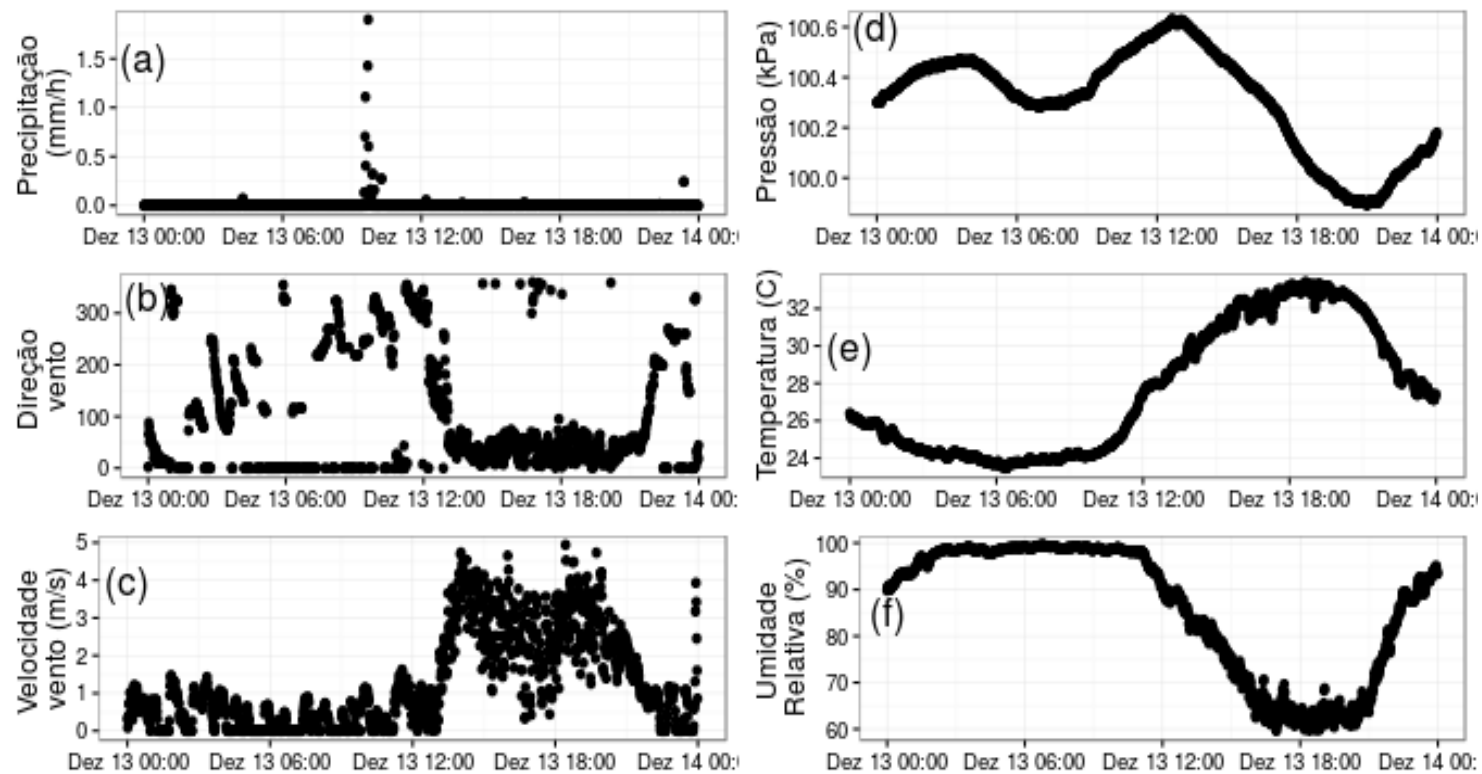

Figura 92 - Condições de tempo na estação de coleta de dados meteorológicos T3, localizada em Manacapuru, Amazonas no dia 13/12/2014. Em (a) precipitação $(\mathrm{mm})$, (b) direção do vento $\left(^{\circ}\right)$, (c) velocidade do vento $(\mathrm{m} / \mathrm{s}),(\mathrm{d})$ pressão atmosférica $(\mathrm{kPa}),(\mathrm{e})$ temperatura do ar $\left({ }^{\circ} \mathrm{C}\right),(\mathrm{f})$ umidade relativa $(\%)$. 


\section{9/01/2015 - horário de gênese: 13 UTC}

A carta em baixos níveis as 12 UTC mostra os alísios intensificados sobre grande parte do norte do país, com velocidades entre 46,3 km/h e 55,6 km/h (Figura 93; as cartas no horário de 18 UTC não estão disponíveis). O escoamento em altos níveis neste mesmo horário mostra um VCAN centrado entre o norte de Goiás e sul de Tocantins e ao sul deste vórtice há uma região anticiclônica centrada sobre o Paraguai. A combinação deste escoamento causou difluência sobre o Amazonas e juntamente com a termodinâmica favorável favoreceu a formação do SCM.

A sequência de imagens na Figura 94 mostra que o SCM se formou muito próximo à Manacapuru e teve seu ciclo de vida desenvolvido no seu entorno, causando precipitação na estação T3 durante sua ocorrência.

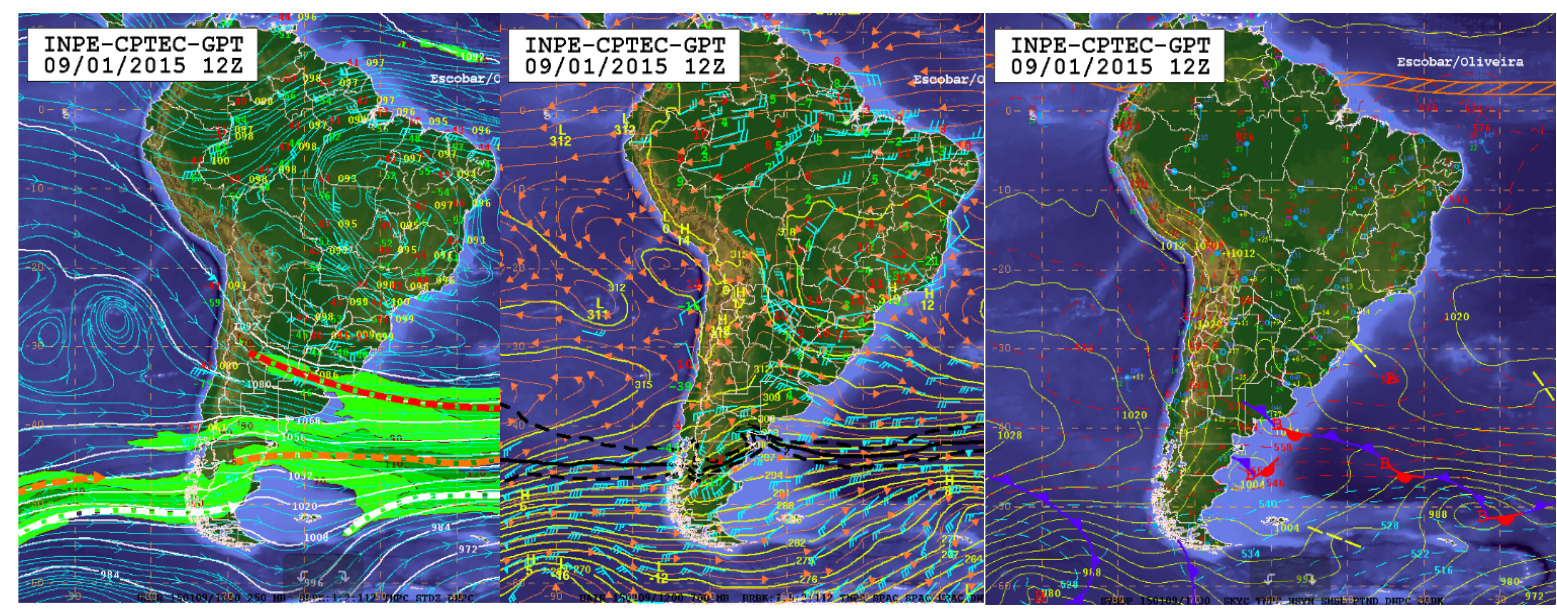
(a) $250 \mathrm{hPa}$
(b) $700 \mathrm{hPa}$
(c) Superfície

Figura 93 - Cartas sinóticas do dia 09/01/2015 - 12 UTC (a) 250 hPa, (b) 700 hPa e (c) superfície. Fonte: CPTEC/INPE.
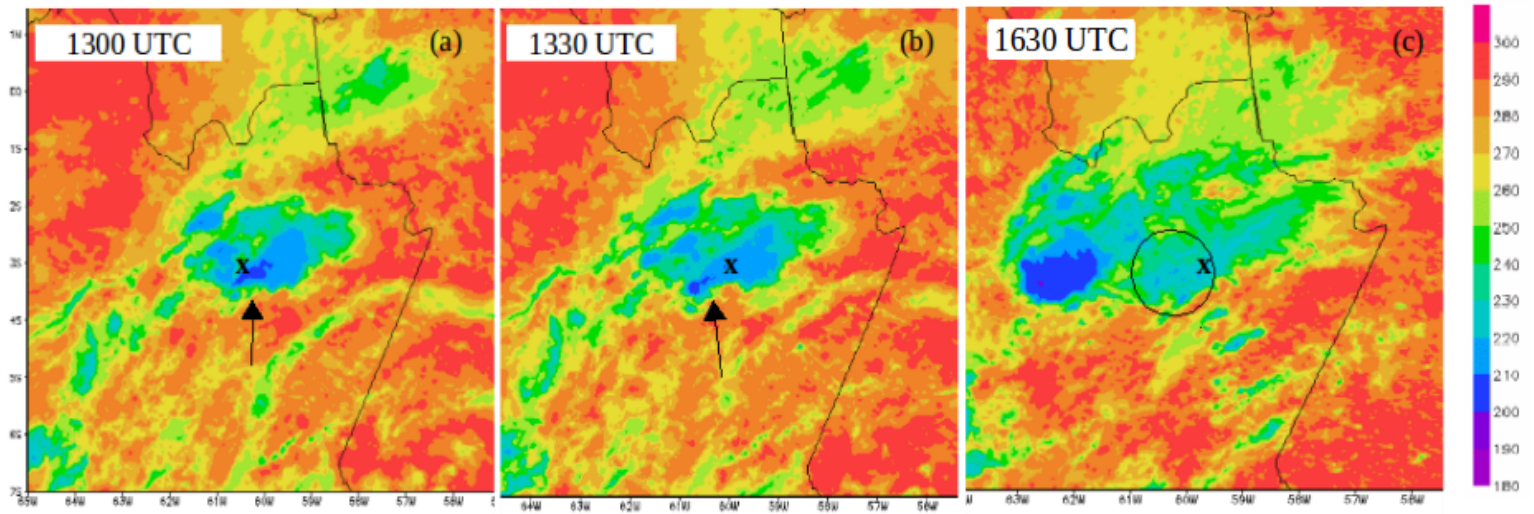

Figura 94 - Imagens de satélite do canal infravermelho em 09/01/2015 na fase de (a) gênese - 1300 UTC, (b) maturação - 1330 UTC e (c) dissipação - 1630 UTC. 

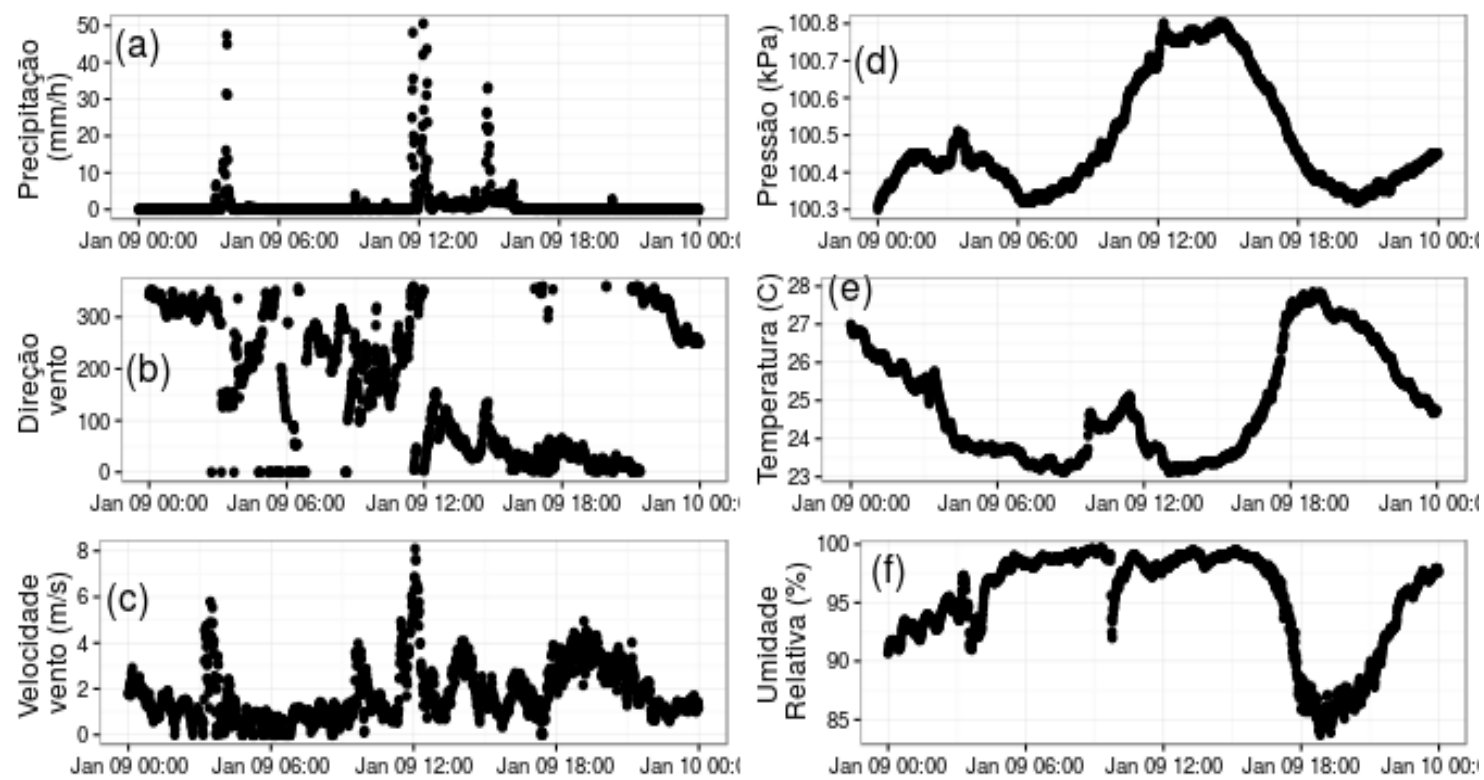

Figura 95 - Condições de tempo na estação de coleta de dados meteorológicos T3, localizada em Manacapuru, Amazonas no dia 09/01/2015. Em (a) precipitação $(\mathrm{mm})$, (b) direção do vento $\left(^{\circ}\right)$, (c) velocidade do vento $(\mathrm{m} / \mathrm{s}),(\mathrm{d})$ pressão atmosférica $(\mathrm{kPa}),(\mathrm{e})$ temperatura do $\operatorname{ar}\left({ }^{\circ} \mathrm{C}\right),(\mathrm{f})$ umidade relativa $(\%)$.

\section{2/01/2015 - horário de gênese: 2130 UTC}

Em altos níveis as 00 UTC há difluência partindo do sul do Amazonas e está associada à um VCAN centrado no norte da Bahia (Figura 96; a carta das 18 UTC não encontra-se disponível). Os alísios encontram-se bastante intensos, entre $27,8 \mathrm{~km} / \mathrm{h}$ e $55,6 \mathrm{~km} / \mathrm{h}$, principalmente na parte norte do Amazonas, onde o SCM teve formação.

Após a gênese do SCM houve precipitação na estação T3 e pequenas e rápidas mudanças no tempo (Figura 98) e possivelmente estão associadas à passagem do sistema pela região (Figura 97).

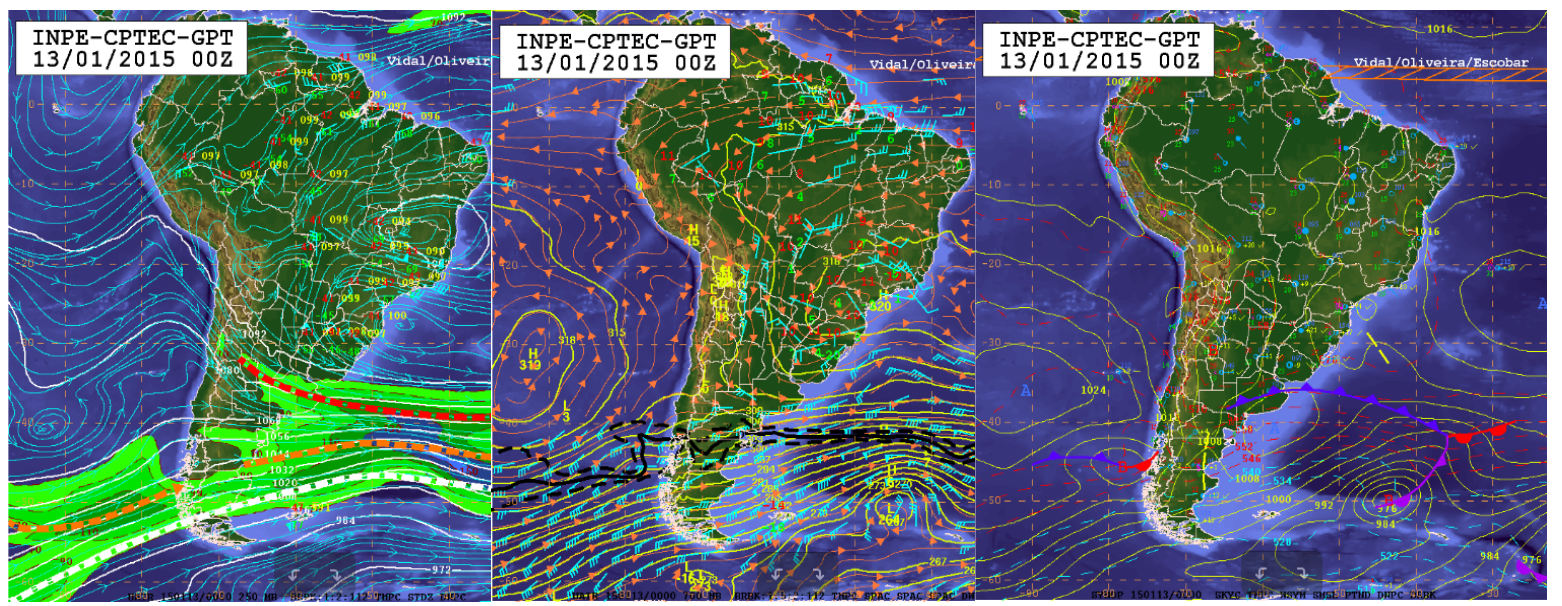

(a) $250 \mathrm{hPa}$

(b) $700 \mathrm{hPa}$

(c) Superfície

Figura 96 - Cartas sinóticas dos dias 12 e 13/01/2015 - 00 UTC (a) 250 hPa, (b) 700 hPa e (c) superfície. Fonte: CPTEC/INPE. 


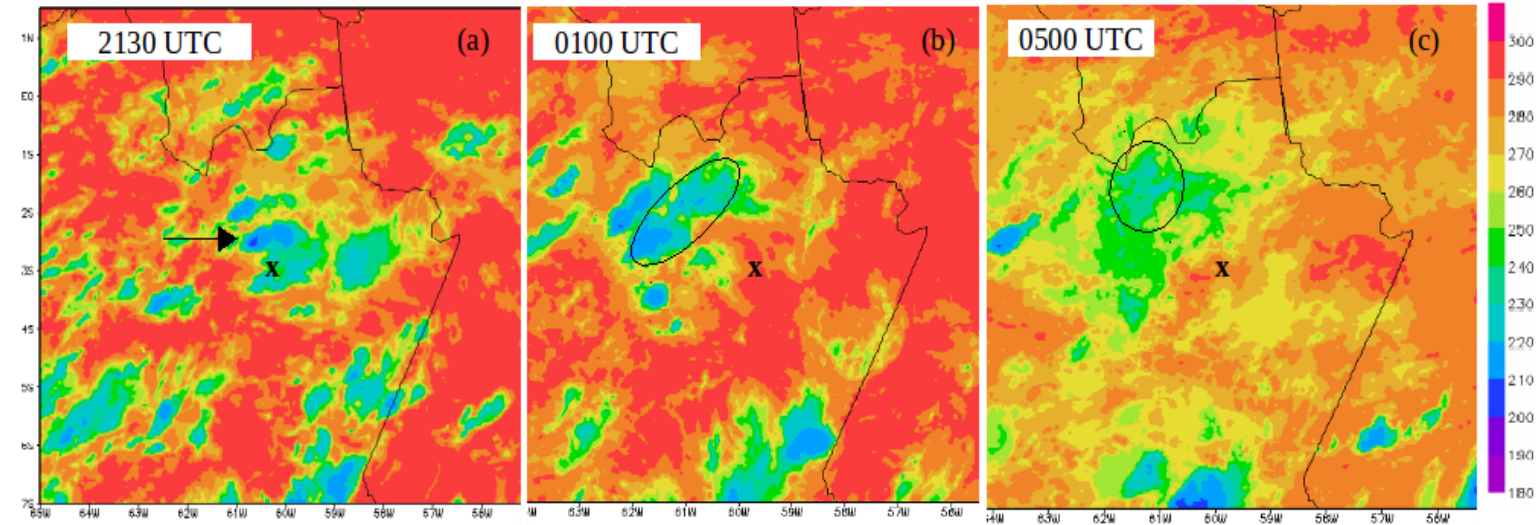

Figura 97 - Imagens de satélite do canal infravermelho em 12 e 13/01/2015 na fase de (a) gênese - 2130 UTC, (b) maturação - 0100 UTC e (c) dissipação - 0500 UTC.
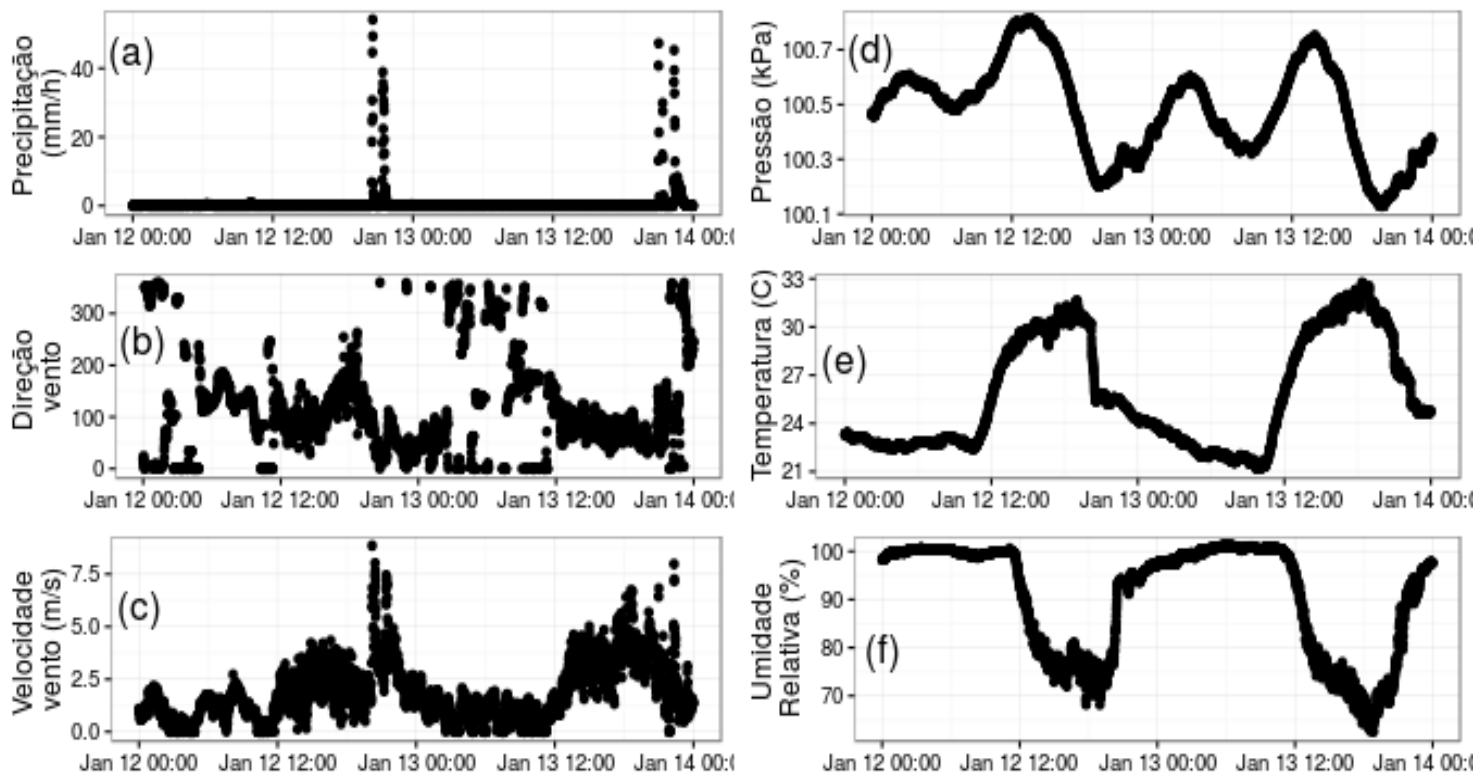

Figura 98 - Condições de tempo na estação de coleta de dados meteorológicos T3, localizada em Manacapuru, Amazonas no dia 12 e 13/01/2015. Em (a) precipitação $(\mathrm{mm})$, (b) direção do vento $\left({ }^{\circ}\right)$, (c) velocidade do vento $(\mathrm{m} / \mathrm{s})$, (d) pressão atmosférica $(\mathrm{kPa}),(\mathrm{e})$ temperatura do $\operatorname{ar}\left({ }^{\circ} \mathrm{C}\right)$, (f) umidade relativa $(\%)$.

\section{8/03/2015 - horário de gênese: 07 UTC}

A carta sinótica em médios níveis as 06 UTC mostra ventos de leste sobre o Amazonas e em superfície há uma frente estacionária sobre o nordeste da Argentina e sul do Brasil se estendendo para o oceano Atlântico adjacente, unindo-se com uma frente fria (Figura 99). A ZCIT apresenta-se com dois ramos, o ramo mais ao sul está em aproximadamente $5^{\circ} \mathrm{S}$ e o ramo norte sobre o oceano está sobre a linha do equador, mas próximo ao continente ligeiramente deslocado para norte. A termodinâmica favorável auxilou na formação deste sistema, contudo ele teve curto ciclo de vida.

A ocorrência deste sistema foi ao norte de Manacapuru (Figura 100) e não teve influência nas condições de tempo na estação T3 (Figura 100). 


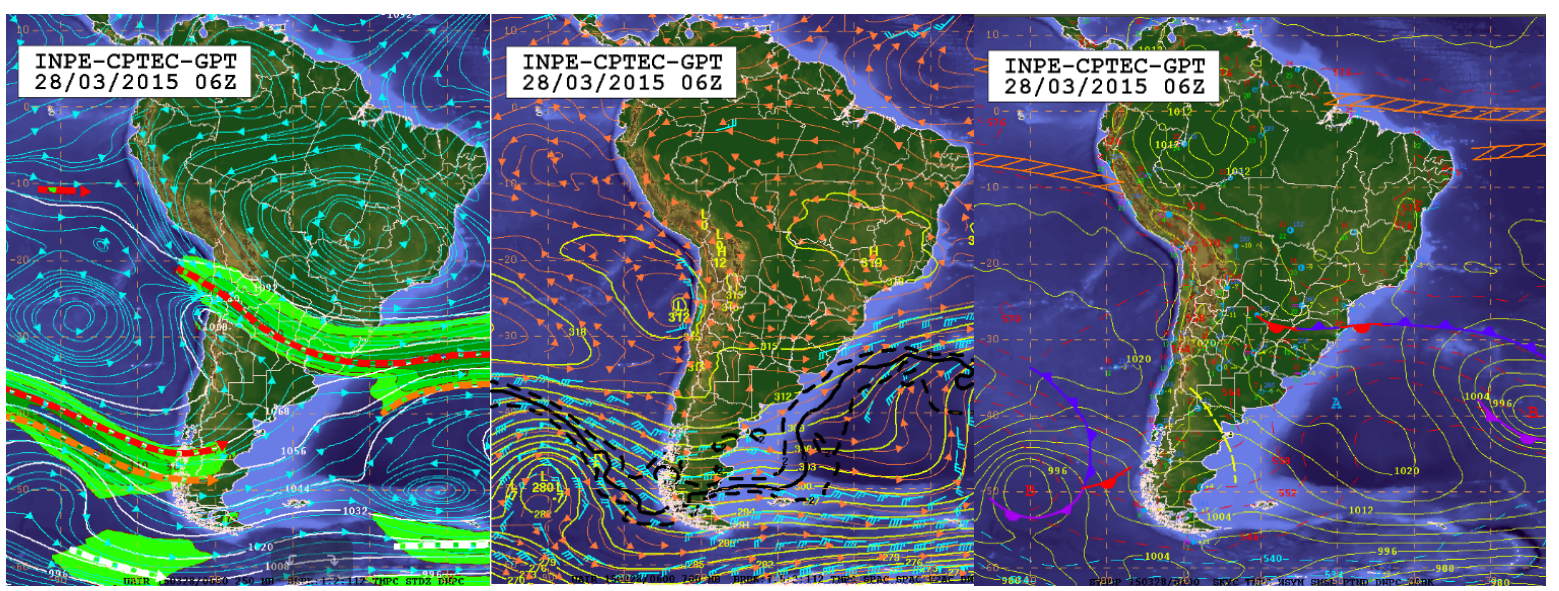

(a) $250 \mathrm{hPa}$

(b) $700 \mathrm{hPa}$

(c) Superfície

Figura 99 - Cartas sinóticas do dia 28/03/2014 - 06 UTC (a) 250 hPa, (b) 700 hPa e (c) superfície. Fonte: CPTEC/INPE.
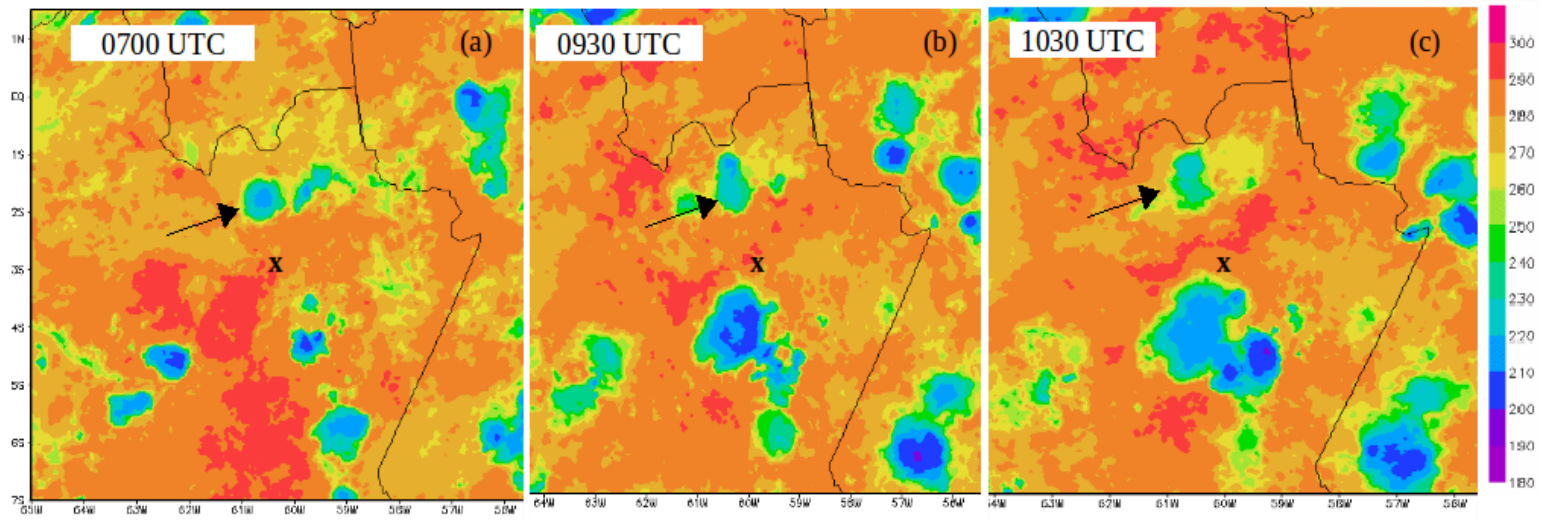

Figura 100 - Imagens de satélite do canal infravermelho em 28/03/2015 na fase de (a) gênese - 0700 UTC, (b) maturação - 0930 UTC e (c) dissipação - 1030 UTC.
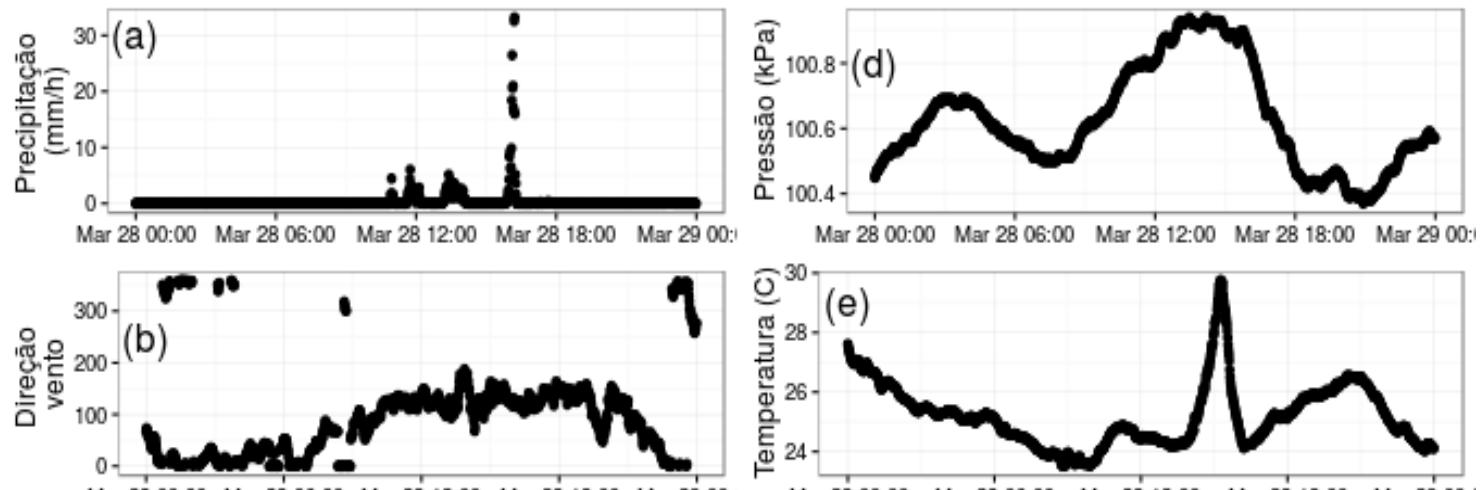

Mar 28 00:00 Mar 28 06:00 Mar 28 12:00 Mar 28 18:00 Mar 29 00:1
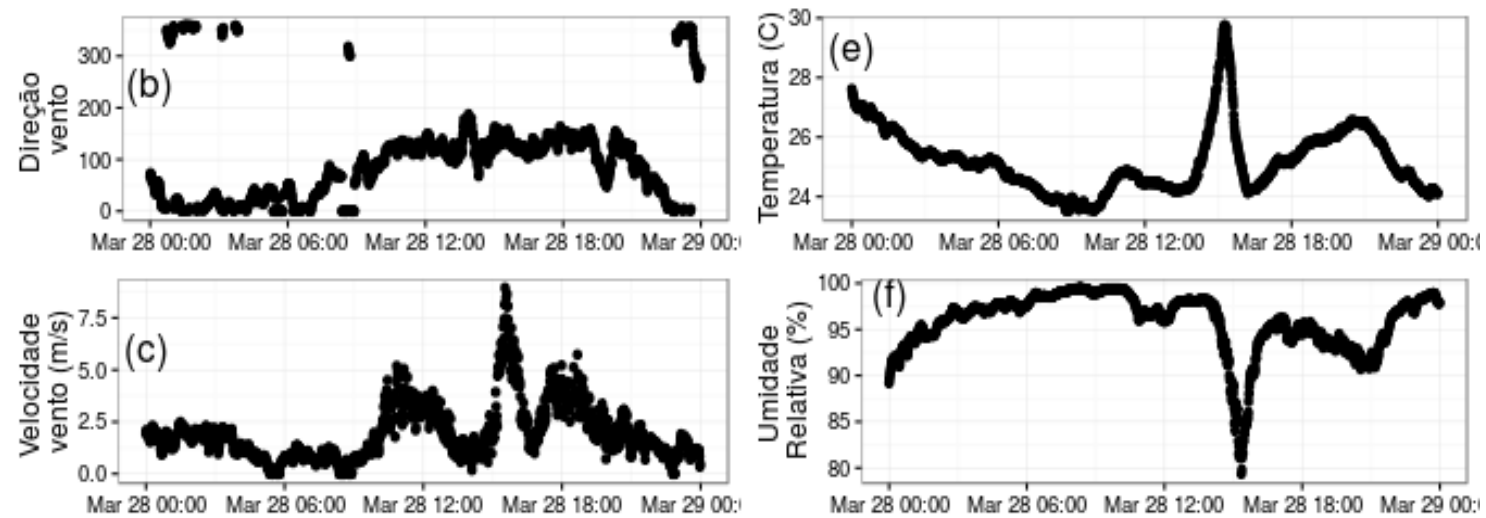

Figura 101 - Condições de tempo na estação de coleta de dados meteorológicos T3, localizada em Manacapuru, Amazonas no dia 28/03/2015. Em (a) precipitação (mm), (b) direção do vento $\left({ }^{\circ}\right)$, (c) velocidade do vento $(\mathrm{m} / \mathrm{s}),(\mathrm{d})$ pressão atmosférica $(\mathrm{kPa}),(\mathrm{e})$ temperatura do ar $\left({ }^{\circ} \mathrm{C}\right),(\mathrm{f})$ umidade relativa $(\%)$. 


\section{3/04/2015 - horário de gênese: 10 UTC}

O horário das 12 UTC mostra que em altos níveis há difluência do escoamento sobre o Amazonas o que causa divergência de massa neste nível e convergência em baixos níveis (Figura 103). Aliando este padrão com o transporte de umidade do Atlântico Tropical pelos alísios e a termodinâmica favorável houve a ocorrência do SCM.

Apesar do ambiente favorável à ocorrência do SCM, sua manutenção não foi garantida por muito tempo e o sistema teve apenas 3 horas de duração. Em compensação outros sistemas maiores e com maior longevidade ocorreram ao longo da bacia Amazônica, como mostra a Figura 103. O SCM aqui investigado teve ciclo de vida distante de Manacapuru e não causou influência na estação T3 Figura 104.

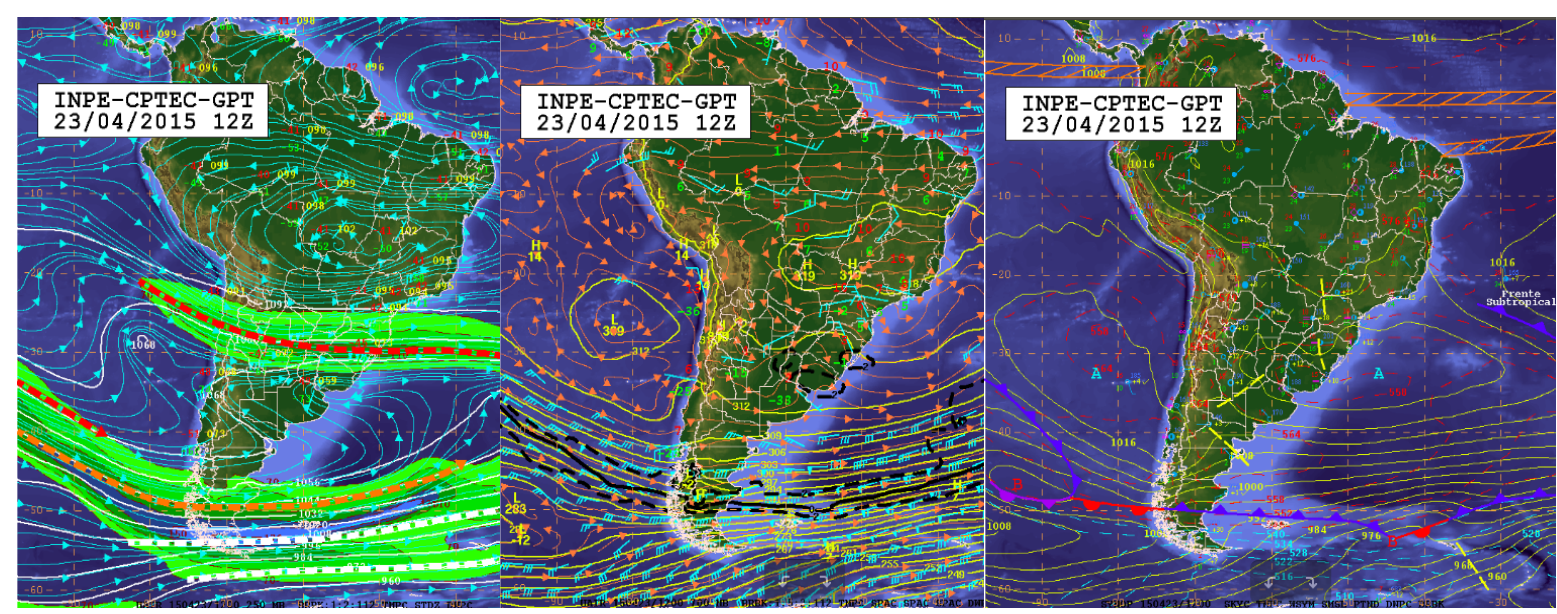
(a) $250 \mathrm{hPa}$
(b) $700 \mathrm{hPa}$
(c) Superfície

Figura 102 - Cartas sinóticas do dia 23/04/2015 - 12 UTC (a) 250 hPa, (b) 700 hPa e (c) superfície. Fonte: CPTEC/INPE.
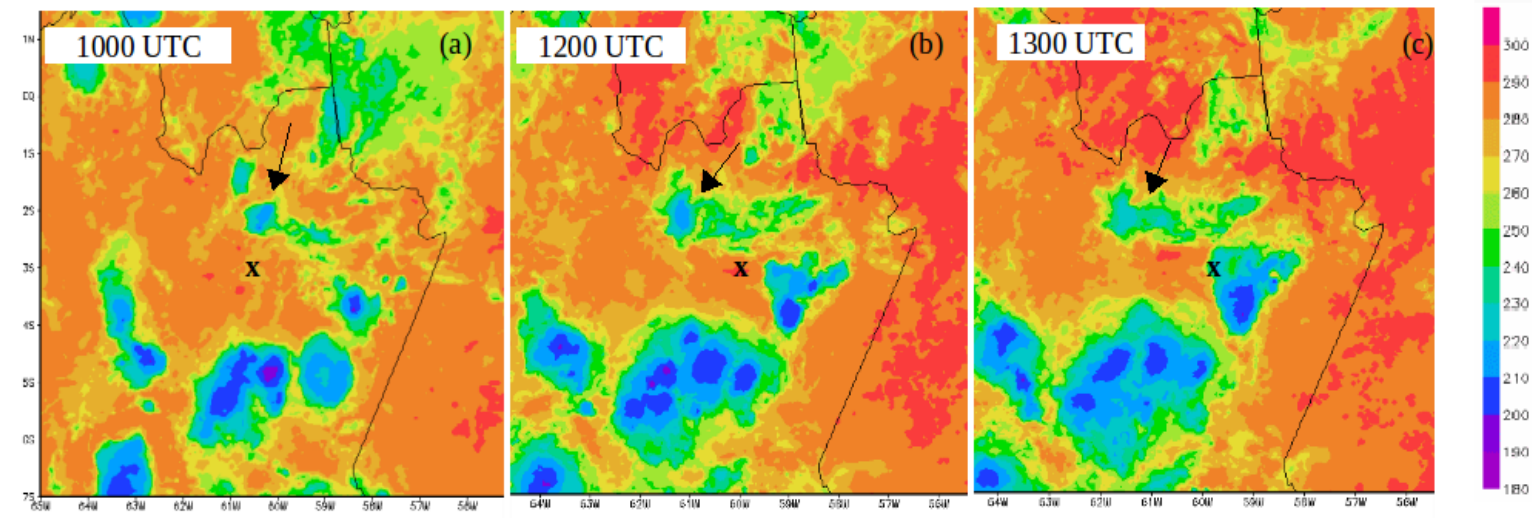

Figura 103 - Imagens de satélite do canal infravermelho em 23/04/2015 na fase de (a) gênese - 1000 UTC, (b) maturação - 1200 UTC e (c) dissipação - 1300 UTC. 

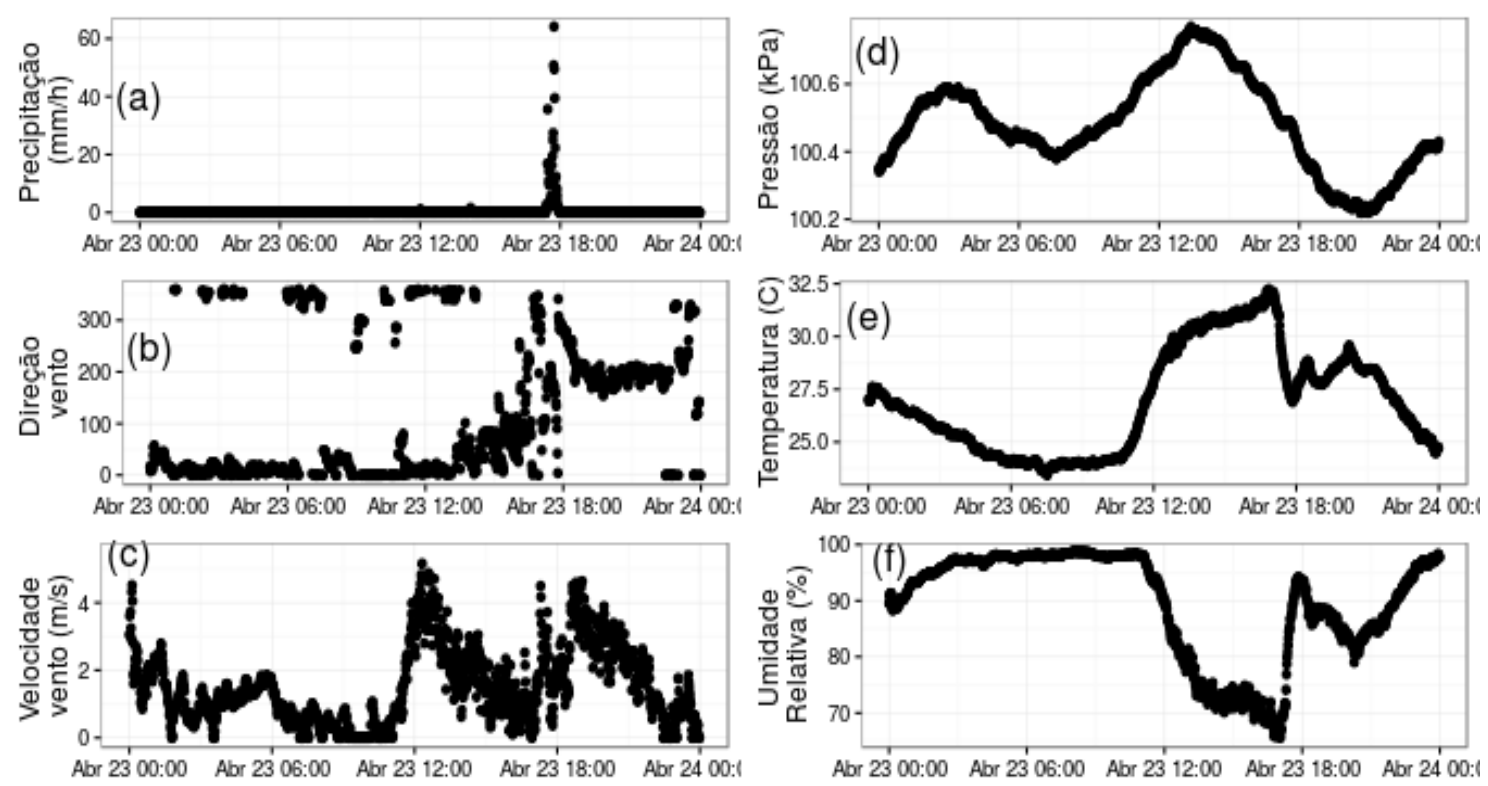

Figura 104 - Condições de tempo na estação de coleta de dados meteorológicos T3, localizada em Manacapuru, Amazonas no dia 23/04/2015. Em (a) precipitação $(\mathrm{mm})$, (b) direção do vento $\left(^{\circ}\right)$, (c) velocidade do vento $(\mathrm{m} / \mathrm{s}),(\mathrm{d})$ pressão atmosférica $(\mathrm{kPa}),(\mathrm{e})$ temperatura do $\operatorname{ar}\left({ }^{\circ} \mathrm{C}\right),(\mathrm{f})$ umidade relativa $(\%)$.

A difluência no escoamento em altos níveis sobre o norte do país, gerada pela combinação de padrões de escoamento atmosférico tais como anticiclones, VCANs, cavados e cristas, esteve presente na maioria dos casos observados. Esta difluência gera divergência de massa nas camadas mais altas da atmosfera e convergêrcia em níveis mais baixos. Os ventos alísios transportando mais umidade do oceano Atlântico Tropical para a região Amazônica, juntamente com a termodinâmica favorável, contribuem para que a convergência ocorrida nos baixos níveis eleve parcelas de ar úmido disparando a convecção. Quando estes padrões, principalmente o fluxo de umidade transportado pelos alísios, atuaram em conjunto com sistemas frontais que se aproximaram da região Tropical os SCMs formados sobre a região das estações do GOAmazon apresentaram tempos de vidas mais longo. Foi observado que entre uma carta sinótica e outra os padrões em altos níveis se modificavam e/ou se não houvesse uma frente, por exemplo, atuando como mecanismo de sustentação, os SCMs possuiam curto ciclo de vida. Os deslocamentos para oeste parecem estar associados aos ventos alísios.

Laurent et al. (2002) observaram que durante os regime de ventos de leste a propagação de SMCs no sudeste da Amazônia estava associada com o escoamento em médios níveis, com melhor ajuste em $700 \mathrm{hPa}$, mesmo se o vento em altos níveis fosse de direção oposta. Sobre a região das estações do GOAmazon este padrão se repetiu durante a atuação dos alísios. Por outro lado, com o posicionamento das ZCITs mais ao norte a tendência de deslocamento dos SCMs foi para leste.

Em geral, os índices de instabilidade não apresentaram um padrão bem definido de maior instabilidade comparado à média realizada. No entanto, os SCMs com longa 
duração, os quais geralmente possuem a maior área (MACHADO et al., 1998), foram acompanhados de valores de cisalhamento do vento maiores. Sakamoto (2009) observou valores de cisalhamento maiores nas fases iniciais e de maturação dos SCMs com duração acima de 24 horas, sendo que a ordem de grandeza encontrada por ela era de $10^{-3} \mathrm{~s}^{-1}$. Na presente investigação a ordem de grandeza encontrada para o cisalhamento é uma vez menor que a encontrada por Sakamoto, todavia nenhum SCM chegou a 24 horas de duração. O cisalhamento médio para todo o período de 2014 e 2015 apresentado na Figura 40 (f), mostra valores maiores durante o período de inverno. Os SCMs com maior área ocorreram nesta estação do ano e início da primavera (12/07/2014, 04/08/2014, 15/08/2014 e 12/09/2014), contudo, nos eventos de menor área e duração ocorridos durante o inverno e analisados aqui o cisalhamento era mais fraco. 


\section{Conclusões}

No presente trabalho foram analisadas as características e comportamentos dos sistemas convectivos de mesoescala (SCMs) continentais e oceânicos ocorridos sobre toda bacia Amazônica durante um ano e seis meses (02/01/2014 - 30/06/2015) de ocorrência do projeto GOAmazon. Uma climatologia foi criada utilizando 14 anos de dados, a partir do ano 2000, com alta resolução e poucas falhas para fins de comparação destas características e comportamentos. Os SCMs detectados próximo às estações de coleta de dados do projeto GOAmazon foram analisados com maior atenção, verificando as condições dinâmicas e termodinâmicas em que estes se desenvolveram.

A climatologia realizada mostrou que ao longo da bacia Amazônica ocorrem 7053 SCMs continentais por ano. Deste total, $64 \%$ possuem curto ciclo de vida e $36 \%$ possuem longo ciclo de vida. Apenas $0,7 \%$ do total de sistemas apresentam ciclo de vida acima de 24 horas. A duração média dos SCMs continentais é de 6 horas.

No período analisado durante o desenvolvimento do projeto GOAmazon ocorreram 6137 SCMs continentais, sendo que 3974 SCMs (54\% da média climatológica) ocorreram em 2014 e os 2163 SCMs restantes ocorreram entre janeiro e junho de $2015,58 \%$ do esperado para a mesma época do ano. A maioria dos SCMs ocorridos em 2014 (81,5\%) e em 2015 (83,5\%) tiveram curto ciclo de vida. Nenhum sistema teve duração acima de 24 horas e os maiores tempos de vida encontrados foram de 18 horas e 30 minutos em 2014 e 20 horas em 2015. A duração média foi de 4 horas e 30 minutos tanto em 2014, quanto em 2015.

A ocorrência de SCMs abaixo da média durante o projeto GOAmazon aconteceu distribuidamente ao longo do ano (Figura 21) e de toda a bacia Amazônica (Figuras 25, 26 e 27). Apesar de maiores investigações serem necessárias, algumas possíveis causas podem ser citadas como justificativa: fortalecimento do jato de baixos níveis (COELHO et al., 2015; SETH; FERNANDES; CAMARGO, 2015), transportando umidade da região Amazônica para América do Sul, o que implica em menor ocorrência de SCMs sobre a região Tropical (SALIO; NICOLINI; ZIPSER, 2007); anomalias de temperatura da superfície do mar acima de $+0,5^{\circ} \mathrm{C}$ no oceano Pacífico Equatorial Leste na maioria dos meses em 2014, acompanhadas de ventos alísios enfraquecidos na maioria dos meses sobre o oceano Atlântico e Pacífico (GREC/IAG-USP, 2014) e; configuração do El Niño em 2015, o qual pode causar supressão na convecção amazônica (ROPELEWSKI; HALPERT, 1987; MARENGO; HASTENRATH, 1993; GRIMM, 2003).

De um modo geral, a evolução do ciclo de vida dos SCMs com curta e longa duração apresentam um comportamento muito similar, com poucas horas de diferença 
entre a mesma fase. A gênese dos $\mathrm{SCMs}$ com curta duração possui três períodos preferenciais: 1) entre 17 a 20 UTC; 2) a 01 UTC e; 3) entre 06 e 07 UTC. Por outro lado, os SCMs com longa duração possuem somente dois períodos preferenciais de gênese: 1) entre 16 e 19 UTC e; 2) a 01 UTC. O período com menor frequência de gênese ocorre entre 12 e 14 UTC para os SCMs com curta duração e entre 11 e 13 UTC para os SCMs com longa duração. Durante o projeto GOAmazon os SCMs de curta duração em 2014 e 2015 tiveram dois períodos mais intensos de gênese: 1) entre 17 e 20 UTC e; 2) as 00 UTC. Os SCMs de longa duração em 2014 tiveram período preferencial de gênese entre 16 e 20 UTC e em 2015 entre 17 e 20 UTC. Durante o GOAmazon, os SCMs levaram em média 2 a 2 horas 30 minutos para atingir a maturação e os SCMs com longa duração levam em média 3 a 4 horas.

Os SCMs apresentam grande variabilidade espacial similar ao ciclo anual da convecção, onde durante o verão a gênese dos SCMs ocorre espalhada sobre todo o território amazônico e durante o inverno ela se desloca para o nordeste. Regiões com maior densidade de ocorrência de gênese destacam-se frente à outras e são localizadas próximas à topografias mais elevadas ou em confluências de grandes rios ou corpos d'água. Entre maio e setembro a maior atividade de gênese e desenvolvimento de SCMs encontra-se deslocada para nordeste e as regiões preferenciais de gênese ficam mais restritas nesta porção da Amazônia.

As regiões preferenciais de gênese dos SCMs de curta duração em ordem por frequência de ocorrência são: 1) na confluência do rio Tapajós com o rio Amazonas, em aproximadamente $2,5^{\circ} \mathrm{S} / 54^{\circ} \mathrm{W}$, ocorrendo entre janeiro e outubro; 2) na Serra do Imeri, no Planalto das Guianas, em aproximadamente $0^{\circ} / 65^{\circ} \mathrm{W}$, entre setembro e junho; 3) próximo aos Andes em $10^{\circ} \mathrm{S} / 75^{\circ} \mathrm{W}$, entre a primavera e o outono; 4) entre o norte de Mato Grosso e sul do Pará, em torno de $10^{\circ} \mathrm{S} / 55^{\circ} \mathrm{W}$, em outubro, janeiro, março, abril e maio; 5) nos Andes, em $14^{\circ} \mathrm{S} / 71^{\circ}$, nos meses mais quentes do ano; 6) na Serra da Pacaraíma, no Planalto das Guianas, em $5^{\circ} \mathrm{N} / 60^{\circ} \mathrm{W}$, em novembro, dezembro, fevereiro e março; 7) na foz do rio Amazonas em agosto e setembro e; 8) no norte da Cordilheira dos Andes, em $0^{\circ} / 75^{\circ} \mathrm{W}$, em novembro e dezembro. Algumas dessas regiões ocorrem tanto para SCMs com curta duração, quanto para aqueles de longa duração, mas elas variam de acordo com o mês. Desta forma, as regiões preferenciais de gênese dos SCMs com longo ciclo de vida em ordem por frequência de ocorrência são: 1) Serra da Pacaraíma, no Planalto das Guianas, em $5^{\circ} \mathrm{N} / 60^{\circ} \mathrm{W}$, nos meses de outono, inverno e início de verão; 2) Serra do Imeri, no Planalto das Guianas, em aproximadamente $0^{\circ} / 65^{\circ} \mathrm{W}$, ocorrendo preferencialmente nos meses de inverno; 3) confluência do rio Tapajós com o rio Amazonas, em aproximadamente $2,5^{\circ} \mathrm{S} / 54^{\circ} \mathrm{W}$, meses de primavera e outono; 4) próximo à Cordilheira dos Andes em $10^{\circ} / 75^{\circ}$, entre novembro a fevereiro; 5) próximo à Cordilheira dos Andes, em $14^{\circ} \mathrm{S} / 75^{\circ} \mathrm{W}$, nos meses mais quentes; 6 ) à Cordilheira dos Andes, em $16^{\circ} \mathrm{S} / 65^{\circ} \mathrm{W}$, nos meses mais quentes; 7) na foz do rio 
Amazonas e ; 8) entre o norte de Mato Grosso e sul do Pará, em torno de $10^{\circ} \mathrm{S} / 55^{\circ} \mathrm{W}$, em março e outubro.

As anomalias de densidade de gênese em 2014 e 2015 mostram que estas persistiram em todos os meses sem possuir região preferencial de ocorrência. Os SCMs com curto ciclo de vida exibem maior quantidade de regiões pontuais de anomalias positivas comparadas aos SCMs de longo ciclo de vida o que reforça as hipóteses de que a menor ocorrência de SCMs durante o projeto GOAmazon comparado à climatologia, ocorreu devido aos fenômentos de larga escala explicados anteriormente. Este reforço se deve ao fato de o impacto da circulação de maior escala, atuando no sentido de minimizar a convecção na Amazônia, abrange uma grande área e costumam ser persistentes.

A velocidade média anual dos SCMs com curta duração é de 22,4 km/h $( \pm 7,2$ $\mathrm{km} / \mathrm{h})$ e dos SCMs com longa duração é de $21,8 \mathrm{~km} / \mathrm{h}( \pm 6,5 \mathrm{~km} / \mathrm{h})$. As velocidades médias dos SCMs ocorridos durante o projeto GOAmazon foram menores que a climatologia: em 2014 a média dos SCMs com curta duração foi de 15,3 km/h ( $\pm 5,3$ $\mathrm{km} / \mathrm{h})$ e de longa duração foi de $15 \mathrm{~km} / \mathrm{h}( \pm 4,5 \mathrm{~km} / \mathrm{h})$; em 2015 a velocidade média dos SCMs com curta duração foi de $15 \mathrm{~km} / \mathrm{h}( \pm 5,3 \mathrm{~km} / \mathrm{h})$ e de longa duração $14,6 \mathrm{~km} / \mathrm{h}$ $( \pm 4,1 \mathrm{~km} / \mathrm{h})$.

O deslocamento médio dos SCMs varia bastante, devido a época do ano e localização ao longo da bacia Amazônica, sendo maiores durante o inverno. SCMs com curta duração possuem deslocamentos médios de 107 km ( $\pm 64,2$ km) e SCMs com longa duração 275,2 km ( $\pm 206,2$ km). Durante o projeto GOAmazon os deslocamentos dos SCMs foram menores que aqueles observados na climatologia. Os deslocamentos médios de SCMs com curta duração foram de 88,8 km ( $\pm 53,6$ km) em 2014 e 91,8 km $( \pm 59,6 \mathrm{~km})$ em 2015; sistemas com longo ciclo de vida tiveram deslocamentos médios de 194,1 km ( \pm 121 km) em 2014 e 190 km ( $\pm 124,2$ km) em 2015.

A direção de propagação também varia bastante ao longo da bacia Amazônica e de acordo com a época do ano. Nos meses de verão e início do outono a circulação na bacia Amazônica é bastante parecida, onde na região nordeste os SCMs tendem deslocar-se para noroeste e na região noroeste tendem a se deslocar para sudoeste. $\mathrm{Na}$ região central, em uma faixa zonalmente orientada entre $5^{\circ} \mathrm{S}-12^{\circ} \mathrm{S} / 50-70^{\circ} \mathrm{W}$ os $\mathrm{SCMs}$ deslocam-se preferencialmente para oeste, neste período. Na faixa oeste da bacia os sistemas são desviados para o sul. Os deslocamentos no sul da bacia Amazônica são intensos e para sudeste. Em novembro, na parte sul os SCMs ainda possuem tendência de deslocamento para leste, da mesma forma que no inverno, porém nos meses seguintes os deslocamentos são muito pequenos e não possuem direção preferencial. Os SCMs com longa duração, em geral, apresentam maiores deslocamentos ao longo de toda a bacia Amazônica e em todos os meses do ano comparados aos de curta duração. As maiores variabilidades ocorrem com relação à direção de propagação e 
as velocidades. Contudo, durante o verão, o sul da bacia Amazônica apresenta os menores deslocamentos e nos meses de inverno a metade sul da bacia apresenta maiores variabilidades na velocidade. Entre agosto e novembro, na região norte da bacia, a direção preferencial é para oeste com uma leve tendência para noroeste, porém nos outros meses é para sudoeste.

Os SCMs oceânicos que adentram a bacia Amazônica têm gênese muito próxima à costa do Brasil, no nordeste da bacia Amazônica, onde acontece a maior parte do seu desenvolvimento. Eles ocorrem preferencialmente no período de outono e inverno e possuem longas durações, em média 11,8 horas. A frequência de ocorrência, no entanto, é baixa (48 SCMs por ano), por outro lado, eles possuem grandes áreas durante sua fase de maturação (curta duração - 15381 km² e longa duração - 63354 $\mathrm{km}^{2}$ ) e grandes deslocamentos (curta duração - 168,1 km e longa duração - 502,2 km).

As características médias dos SCMs oceânicos ocorridos durante o projeto GOAmazon foram bem diferentes da média climatológica. Em 2014 ocorreram 15 SCMs (30\% da média climatológica) e a duração média deles foi de 6,4 horas e em 2015 apenas 2 (4,1\% da média climatológica) e a duração média foi de 3,7 horas. $O$ deslocamento médio dos SCMs de curta duração ocorridos em 2014 foi de $110 \mathrm{~km}$ $( \pm 36,8 \mathrm{~km})$ e de longa duração foi de $266,5 \mathrm{~km}( \pm 136,2 \mathrm{~km})$. Em 2015 o deslocamento médio foi de $89,4 \mathrm{~km}( \pm 16 \mathrm{~km})$.

As velocidades médias dos SCMs oceânicos em 2014 foram 15,9 km/h $( \pm 2,5$ $\mathrm{km} / \mathrm{h}$ ) para os SCMs de curta duração e $20,6 \mathrm{~km} / \mathrm{h}( \pm 5,4 \mathrm{~km} / \mathrm{h})$ para os SCMs de longa duração. Em 2015 a velocidade média foi 12,4 km/h ( $\pm 3,5 \mathrm{~km} / \mathrm{h})$.

Próximo às estações do projeto GOAmazon ocorreram 21 SCMs, nenhum deles teve origem oceânica. As análises sinóticas, dinâmicas e termodinâmicas para estes casos mostraram que a combinação entre os ventos alísios direcionados para a bacia Amazônica e sistemas frontais que se aproximaram da região Tropical, juntamente com a termodinâmica favorável, foram essenciais na manutenção dos SCMs com ciclo de vida maiores. As gêneses dos SCMs foram regidas por padrões de difluência no escoamento em altos níveis sobre o norte do país, geralmente causadas pela combinação entre anticiclones, VCANs, cavados e cristas. A difluência em altos níveis é responsável por divergência de massa nas camadas mais altas da atmosfera e convergêrcia em níveis mais baixos. Os ventos alísios transportando mais umidade do oceano Atlântico Tropical para a região Amazônica, juntamente com a termodinâmica local favorável, contribuem para que essa convergência ocorrida em baixos níveis sustente o levantamento de parcelas de ar úmido dando origem e manutenção aos SCMs.

Sobre a região das estações do GOAmazon e durante a atuação de ventos alísios a tendência de deslocamento dos SCMs foi para oeste. Por outro lado, com o 
posicionamento das ZCITs mais ao norte a tendência de deslocamento dos SCMs foi para leste.

Entre os índices utilizados para indicar o ambiente em que os SCMs tiveram gênese e se desenvolveram, o cisalhamento do vento quando acima de $5 \cdot 10^{-4} \mathrm{~s}^{-1}$ coincidiu com as maiores áreas e longos tempos de vida. Há necessidade do conhecimento dos índices de instabilidade ou outro método que indique e auxilie na identificação de ambientes com potencial para sustentar sistemas convectivos mais duradouros e com maior área na região Amazônica, uma vez que os índices de instabilidade termodinâmica mais difundidos estão voltados para identificar ambientes em que tempestade de médias latitudes podem se tornar severas (NASCIMENTO, 2005).

A partir do ano 2012 houve uma acentuada dimunuição de ocorrência de SCMs comparado aos anos anteriores e juntamente com o menor número de sistemas houve a diminuição dos deslocamentos médios destes sistemas a partir daquele ano (Figura 106, no Apêndice C). Os anos de 2012 e 2013 foram marcados pela fase neutra do El Niño-Oscilação Sul (ENOS). Segundo Blunden e Arndt (2013) em 2012 a temperatura global do oceano esteve entre os 10 anos mais quentes e em 2013 Blunden e Arndt (2014) verificaram alguns impactos em escala de tempo regionais ao redor do globo, porém modestos. Apesar de ter sido um ano marcado pela fase neutra do ENOS, o ano de 2013, o qual apresentou acentuada queda no número de ocorrências de SCMs, teve anomalias de temperatura na superfície do mar sobre o Pacífico Equatorial, no início do ano anomalias negativas e no restante anomalias positivas na região do Niño 1+2. Nos primeiros meses do ano e sobre o litoral norte do país ocorreram anomalias positivas intercalados com temperaturas dentro da faixa normal ao longo do ano. Sobre o oceano Pacífico Equatorial Oeste as anomalias variaram entre positivas, negativas e períodos de neutralidade. No entanto, os fatores responsáveis pela diminuição da ocorrência e modificação no comportamento destes SCMs a partir de 2012 não são claramente aparentes. Portanto, uma investigação das causas das anomalias de ocorrências e características anômalas de SCMs a partir do ano 2012 precisa ser realizada.

De acordo com a literatura revisada, este é o primeiro trabalho que realiza uma análise climatológica anual da ocorrência de SCMs através de dados de alta resolução temporal e espacial com pouquíssimas falhas usando uma delimitação geográfica da bacia Amazônica, isto é, considerando somente os SCMs que em pelo menos um momento do seu ciclo de vida interagiram com a bacia Amazônica. 



\section{Sugestões para trabalhos futuros}

As sugestões para trabalhos futuros são no sentido explorar e tentar encontrar respostas para as seguintes perguntas:

- Quanta precipitação sobre a bacia Amazônica é causada pelos SCMs?

- Quais são as causas das anomalias negativas de ocorrências e modificações das características dos SCMs observadas a partir do ano de 2013?

- Como será o comportamento e a frequência média de ocorrência de SCMs sobre a bacia Amazônica em cenário de mudanças climáticas?

- Como seria e em que situação ocorreria um cenário contrário ao observado a partir de 2013? Quais implicações este padrão de maior ocorrência e modificação das características médias de SCMs traria para a bacia Amazônica?

Além disso, há a necessidade do conhecimento de índices ou outro método que indique e auxilie na identificação de ambientes com potencial para sustentar sistemas convectivos mais duradouros e com maior área na região Amazônica. Estes índices, contudo, precisarão ser baseados não somente na termodinâmica, que é favorável na Amazônia durante a maior parte do tempo, mas principalmente na dinâmica da escala sinótica que se mostra fundamental na sustentação de SCMs e nem sempre favorece a sustentação de sistemas convectivos por longos períodos. Isto ajudaria, não somente o diagnóstico, mas principalmente em previsões de tempo para regiões Tropicais. 



\section{Referências}

ADAMS, D. K. et al. GNSS observations of deep convective time scales in the Amazon. Geophysical Research Letters, Wiley Online Library, v. 40, n. 11, p. 2818-2823, 2013. Citado na página 33.

BETTS, A. K. et al. Transport of ozone to the surface by convective downdrafts at night. Journal of Geophysical Research: Atmospheres, Wiley Online Library, v. 107, n. D20, 2002. Citado na página 31.

BLUNDEN, J.; ARNDT, D. S. State of the Climate in 2012. Bulletin of the American Meteorological Society, v. 94, n. 8, p. 1-258, 2013. Citado na página 155.

BLUNDEN, J.; ARNDT, D. S. State of the Climate in 2013. Bulletin of the American Meteorological Society, v. 95, n. 7, p. 1-279, 2014. Citado na página 155.

CARVALHO, L. M.; JONES, C. A satellite method to identify structural properties of mesoscale convective systems based on the MAximum Spatial COrrelation Tracking TEchnique (MASCOTTE). Journal of Applied Meteorology, v. 40, n. 10, p. 1683-1701, 2001. Citado na página 37.

COELHO, C. A. et al. The 2014 Southeast Brazil austral summer drought: regional scale mechanisms and teleconnections. Climate Dynamics, Springer, p. 1-16, 2015. Citado 2 vezes nas páginas 77 e 151 .

COHEN, J. C.; DIAS, M. A. S.; NOBRE, C. A. Environmental conditions associated with Amazonian squall lines: A case study. Monthly Weather Review, v. 123, n. 11, p. 3163-3174, 1995. Citado na página 32.

COHEN, J. C. P.; DIAS, M. A. a. F. d. S.; NOBRE, C. A. Aspectos climatologicos das linhas de instabilidade na Amazonia. 34-40. [S.I.]: INPE, 1989. Citado 2 vezes nas páginas 32 e 70.

DRUMOND, A. et al. The role of the Amazon Basin moisture in the atmospheric branch of the hydrological cycle: a Lagrangian analysis. Hydrol. Earth Syst. Sci, v. 18, p. 2577-2598, 2014. Citado na página 31.

ESPINOZA, J. C. et al. The extreme 2014 flood in south-western Amazon Basin: the role of tropical-subtropical South Atlantic SST gradient. Environmental Research Letters, IOP Publishing, v. 9, n. 12, p. 124007, 2014. Citado na página 78.

FISCH, G.; MARENGO, J. A.; NOBRE, C. A. Uma revisão geral sobre o clima da Amazônia. Acta Amazonica, v. 28, n. 2, p. 101-126, 1998. Citado 2 vezes nas páginas 29 e 31.

FOGACCIA, C. V. C. Análise de eventos de turbulência e cisalhamento do vento na área do Aeroporto Internacional de São Paulo em Guarulhos. Tese (Doutorado) - São Paulo: Inst. Astron., Geof. e C. Atmosf., IAG-USP, 2001. Citado na página 42.

GALWAY, J. G. The lifted index as a predictor of latent instability. Bull. Amer. Meteor. Soc, v. 37, n. 528529, p. 1993, 1956. Citado na página 41. 
GARSTANG, M. et al. Amazon coastal squall lines. Part I: Structure and kinematics. Monthly Weather Review, v. 122, n. 4, p. 608-622, 1994. Citado na página 32.

GEORGE, J. Weather Forecasting for Aeronautics-Academic Press. New York, 1960. Citado na página 41.

GREC/IAG-USP. Relatório Climático Mensal. In: Grupo de Estudos Climáticos, GrECS/IAG-USP. Universidade de São Paulo, USP, 2014. Disponível em: $<$ http://www.grec.iag.usp.br/data/monitoramentoclimatico_BRA.php>. Citado 2 vezes nas páginas 78 e 151.

GRIMM, A. M. The El Niño impact on the summer monsoon in Brazil: regional processes versus remote influences. Journal of Climate, v. 16, n. 2, p. 263-280, 2003. Citado 2 vezes nas páginas 78 e 151.

HASTENRATH, S.; LAMB, P. J. Climatic atlas of the tropical Atlantic and eastern Pacific Oceans. 1977. Citado na página 44.

HENRY, W. The Skew-T, Log P Diagram. National Weather Service Training Center, EUA, p. 68, 1987. Citado na página 41.

HOREL, J. D.; HAHMANN, A. N.; GEISLER, J. E. An investigation of the annual cycle of convective activity over the tropical Americas. Journal of Climate, v. 2, n. 11, p. 1388-1403, 1989. Citado 2 vezes nas páginas 31 e 44.

HOUZE, R. A. Cloud Dynamics, 573 pp. Academic, San Diego, Calif, 1993. Citado 2 vezes nas páginas 41 e 117.

HOUZE, R. A. Mesoscale convective systems. Reviews of Geophysics, Wiley Online Library, v. 42, n. 4, 2004. Citado 2 vezes nas páginas 29 e 31.

JANOWIAK, J. E.; JOYCE, R. J.; YAROSH, Y. A real-time global half-hourly pixel-resolution infrared dataset and its applications. Bulletin of the American Meteorological Society, v. 82, n. 2, p. 205-217, 2001. Citado na página 36.

LAURENT, $H$. et al. Characteristics of the Amazonian mesoscale convective systems observed from satellite and radar during the WETAMC/LBA experiment. Journal of Geophysical Research: Atmospheres (1984-2012), Wiley Online Library, v. 107, n. D20, p. LBA-21, 2002. Citado 3 vezes nas páginas 32, 37 e 149.

LAURENT, $\mathrm{H}$. et al. Características dos sistemas convectivos observados por satélite durante o experimento WETAMC/LBA. In: XI Congresso Brasileiro de Meteorologia, Rio de Janeiro. [S.I.: s.n.], 2000. p. 16-20. Citado 3 vezes nas páginas 29, 31 e 37.

MACEDO, S. R.; VILA, D.; MACHADO, L. A. FORTRACC-Previsão a curto prazo e evolução dos sistemas convectivos. FORTRACC V1. 1-Guia de Usuário, INPE/CPTEC São Paulo, 2004. Citado 3 vezes nas páginas 33, 37 e 38.

MACHADO, L.; ROSSOW, W. Structural characteristics and radiative properties of tropical cloud clusters. Monthly Weather Review, v. 121, n. 12, p. 3234-3260, 1993. Citado 5 vezes nas páginas 29, 31, 32, 44 e 69. 
MACHADO, L. et al. Life cycle variations of mesoscale convective systems over the Americas. Monthly Weather Review, v. 126, n. 6, p. 1630-1654, 1998. Citado 6 vezes nas páginas 32, 38, 39, 44, 60 e 150.

MACHADO, L. A. T.; LAURENT, H. The convective system area expansion over Amazonia and its relationships with convective system life duration and high-level wind divergence. Monthly Weather Review, v. 132, n. 3, p. 714-725, 2004. Citado 4 vezes nas páginas 33, 37, 38 e 72.

MACHADO, L. T.; DUVEL, J.-P.; DESBOIS, M. Diurnal variations and modulation by easterly waves of the size distribution of convective cloud clusters over West Africa and the Atlantic Ocean. Monthly Weather Review, v. 121, n. 1, p. 37-49, 1993. Citado na página 38.

MADDOX, R. A. Meoscale convective complexes. Bulletin of the American Meteorological Society, v. 61, n. 11, p. 1374-1387, 1980. Citado 2 vezes nas páginas 31 e 38.

MADDOX, R. A. Large-scale meteorological conditions associated with midlatitude, mesoscale convective complexes. Monthly Weather Review, v. 111, n. 7, p. 1475-1493, 1983. Citado na página 31.

MAPES, B.; HOUZE, R. A. An integrated view of the 1987 Australian monsoon and its mesoscale convective systems. I: Horizontal structure. Quarterly Journal of the Royal Meteorological Society, Wiley Online Library, v. 118, n. 507, p. 927-963, 1992. Citado na página 38.

MARENGO, J.; NOBRE, C. Clima da região Amazônica. Tempo e Clima no Brasil, edited by: Fonseca de Albuquerque Cavalcanti, I., Ferreira, N., Justi da Silva, M., Faus da Silva Dias, M., Oficina de Textos, p. 179-212, 2009. Citado 2 vezes nas páginas 31 e 44.

MARENGO, J. A. et al. Tropical South America East of the Andes. Bulletin of the American Meteorological Society, v. 96, n. 7, p. 179-182, 2015. Citado na página 78.

MARENGO, J. A.; HASTENRATH, S. Case studies of extreme climatic events in the Amazon basin. Journal of Climate, v. 6, n. 4, p. 617-627, 1993. Citado 2 vezes nas páginas 78 e 151.

MILLER, R. C. Notes on analysis and severe-storm forecasting procedures of the Air Force Global Weather Central. [S.I.], 1972. Citado na página 41.

MOLION, L. C. B. Climatologia dinâmica da região Amazônica: mecanismos de precipitação. Revista Brasileira de Meteorologia, v. 2, n. 1, p. 107-117, 1987. Citado na página 31.

NASCIMENTO, E. d. L. Previsão de tempestades severas utilizando-se parâmetros convectivos e modelos de mesoescala: uma estratégia operacional adotável no brasil. Revista Brasileira de Meteorologia, v. 20, n. 1, p. 121-140, 2005. Citado 5 vezes nas páginas 40, 41, 114, 116 e 155.

NOBRE, C. A. et al. Characteristics of amazonian climate: Main features. GEOPHYSICAL MONOGRAPH SERIES, p. 149-162, 2009. Citado na página 31. 
ORLANSKI, I. A rational subdivision of scales for atmospheric processes. Bulletin of the American Meteorological Society, v. 56, p. 527-530, 1975. Citado na página 31.

Pereira Filho, A. J. et al. Convective rainfall in Amazonia and adjacent tropics. Atmospheric and Climate Sciences, Scientific Research Publishing, v. 5, n. 02, p. 137, 2015. Citado 4 vezes nas páginas 33, 43, 44 e 60.

ROPELEWSKI, C. F.; HALPERT, M. S. Global and regional scale precipitation patterns associated with the El Niño/Southern Oscillation. Monthly weather review, v. 115, n. 8, p. 1606-1626, 1987. Citado 2 vezes nas páginas 78 e 151.

SAKAMOTO, M. Sistemas Convectivos de Mesoescala observados na Região Subtropical da América do Sul durante o SALLJEX. 2009. Citado 11 vezes nas páginas 29, 35, 36, 37, 38, 39, 42, 50, 60, 69 e 150.

SALIO, P.; NICOLINI, M.; ZIPSER, E. J. Mesoscale convective systems over southeastern South America and their relationship with the South American low-level jet. Monthly Weather Review, v. 135, n. 4, p. 1290-1309, 2007. Citado 6 vezes nas páginas 33, 43, 44, 69, 78 e 151.

SATYAMURTY, P.; COSTA, C. P. d.; MANZI, A. Moisture source for the Amazon Basin: a study of contrasting years. Theoretical Applied Climatology, ??, n. ??, p. ??, 2012. Citado 2 vezes nas páginas 31 e 78 .

SETH, A.; FERNANDES, K.; CAMARGO, S. J. Two summers of São Paulo drought: Origins in the Western Tropical Pacific. Geophysical Research Letters, Wiley Online Library, 2015. Citado 3 vezes nas páginas 77, 78 e 151.

SILVA DIAS, M. A. F. Índices de instabilidade para previsão de chuva e tempestades severas. 2000. Citado 2 vezes nas páginas 40 e 41.

SILVA DIAS, M. A. F. d. et al. Cloud and rain processes in a biosphere-atmosphere interaction context in the Amazon region. Journal of Geophysical Research: Atmospheres, Wiley Online Library, v. 107, n. D20, 2002. Citado na página 31.

UVO, C. B. et al. The relationships between Tropical Pacific and Atlantic sst and Northeast Brazil monthly precipitation. Journal of Climate, v. 11, n. 4, p. 551-562, 1998. Citado na página 44.

VELASCO, I.; FRITSCH, J. M. Mesoscale convective complexes in the Americas. Journal of Geophysical Research: Atmospheres (1984-2012), Wiley Online Library, v. 92, n. D8, p. 9591-9613, 1987. Citado 6 vezes nas páginas 32, 33, 38, 39, 44 e 69.

VILA, D. A. et al. Forecast and Tracking the evolution of Cloud Clusters (ForTraCC) using satellite infrared imagery: Methodology and validation. Weather and Forecasting, v. 23, n. 2, p. 233-245, 2008. Citado 3 vezes nas páginas 33, 37 e 38.

WEISMAN, M. L.; KLEMP, J. B. The structure and classification of numerically simulated convective stormsin directionally varying wind shears. Monthly Weather Review, v. 112, n. 12, p. 2479-2498, 1984. Citado na página 42. 
Apêndices 



\section{APÊNDICE A - Dados faltantes}

Tabela 5 - Datas e horários com falhas nas imagens.

\begin{tabular}{ll}
\hline Data & Ocorrido \\
\hline 01 a 31/01/2000 & Problema com os dados \\
$06 / 06 / 2000$ & Não processou \\
$21 / 01 / 2001$ & Parou o processo as 11 UTC \\
$01 / 03 / 2001$ & Não processou \\
$01 / 08 / 2001$ & Não processou \\
$27 / 08 / 2001$ & Não processou \\
$03 / 12 / 2001$ & Não processou \\
$31 / 01 / 2002$ & Parou o processo as 14 UTC \\
01 a 03/02/2002 & Não processou \\
$06 / 02 / 2002$ & Não processou \\
01 a 31/03/2002 & Não Processou \\
$19 / 07 / 2002$ & Parou o processo as 06 UTC \\
$16 / 08 / 2002$ & Parou o processo as 2030 UTC \\
$28 / 08 / 2002$ & Parou o processo as 1900 UTC \\
$01 / 03 / 2003$ & Parou o processo as 1900 UTC \\
$03 / 03 / 2003$ & Parou o processo as 1530 UTC \\
$14 / 03 / 2003$ & Não processou \\
$14 / 04 / 2003$ & Parou o processo as 1930 UTC \\
$16 / 07 / 2003$ & Parou o processo as 0100 UTC \\
01 a 31/08/2003 & Não processou \\
$06 / 05 / 2004$ & Não processou \\
$22 / 05 / 2004$ & Parou o processo as 1230 UTC \\
$10 / 06 / 2004$ & Não processou \\
$01 / 04 / 2005$ & Não processou \\
$02 / 05 / 2005$ & Não processou \\
$07 / 10 / 2005$ & Não processou \\
$01 / 11 / 2005$ & Não processou \\
26 a 30/11/2005 & Não processou \\
$01 / 01 / 2014$ & Não processou \\
$01 / 01 / 2015$ & Parou o processo as 1500 UTC \\
& Problema com os dados \\
\hline &
\end{tabular}





\section{APÊNDICE B - Sistemas filtrados}

A Tabela 6 mostra a quantidade de sistemas que foram rastreados pelo ForTraCC levando em conta somente os limiares de temperatura e tamanho apresentados anteriormente e quantos SCMs sobraram a cada filtragem realizada. Foram usados 4 filtros para a obtenção dos sistemas aqui estudados. Eles filtraram sistemas que completaram seu ciclo de vida em menos de 3 horas, sistemas cujas trajetórias não estiveram em pelo menos um momento de seu ciclo de vida sobre a bacia Amazônica, sistemas com curvas de crescimento (área $\times$ tempo) que não obedeceram padrão de crescimento, máxima expansão, seguida de decaimento da área e por último, sistemas cujos deslocamentos entre um passo de tempo e outro foram maiores que $300 \mathrm{~km}$. Tabela 6 - SCMs filtrados segundo o tempo de vida (F1), trajetória sobre a bacia Amazônica (F2), curva de cresci-
mento (F3) e deslocamento (F4).

\begin{tabular}{ccccccc}
\hline \multirow{2}{*}{ Ano } & \multirow{2}{*}{ F1 } & \multirow{2}{*}{ F2 } & F3 & \multicolumn{3}{c}{ F4 } \\
\cline { 5 - 7 } & & & & Total & Continentais & Oceânicos \\
\hline 2000 & 19864 & 9679 & 7645 & 7341 & 7282 & 59 \\
2001 & 19613 & 9604 & 7626 & 7364 & 7323 & 41 \\
2002 & 17954 & 8825 & 7032 & 6753 & 6700 & 53 \\
2003 & 18758 & 9407 & 7353 & 7079 & 7045 & 34 \\
2004 & 20569 & 10204 & 8090 & 7755 & 7710 & 45 \\
2005 & 17537 & 8273 & 6601 & 6317 & 6248 & 69 \\
2006 & 20276 & 9467 & 7375 & 7035 & 6977 & 58 \\
2007 & 20784 & 10104 & 8016 & 7643 & 7589 & 54 \\
2008 & 20592 & 9923 & 7873 & 7500 & 7446 & 54 \\
2009 & 20939 & 10307 & 8314 & 7983 & 7942 & 42 \\
2010 & 20812 & 9867 & 8079 & 7729 & 7656 & 73 \\
2011 & 21269 & 9866 & 8255 & 7863 & 7815 & 48 \\
2012 & 17785 & 8740 & 7074 & 6829 & 6785 & 44 \\
2013 & 11971 & 5745 & 4294 & 4233 & 4225 & 8 \\
\hline 2014 & 11156 & 5390 & 4057 & 3989 & 3974 & 15 \\
2015 & 5998 & 2984 & 2200 & 2165 & 2163 & 2 \\
\hline Total & 285877 & 138385 & 109884 & 105578 & 104880 & 699 \\
\hline
\end{tabular}





\section{APÊNDICE C - Distribuição e deslocamento médios anuais}

A Figura 105 mostra a distribuição anual dos SCMs utilizados para realizar a climatologia.

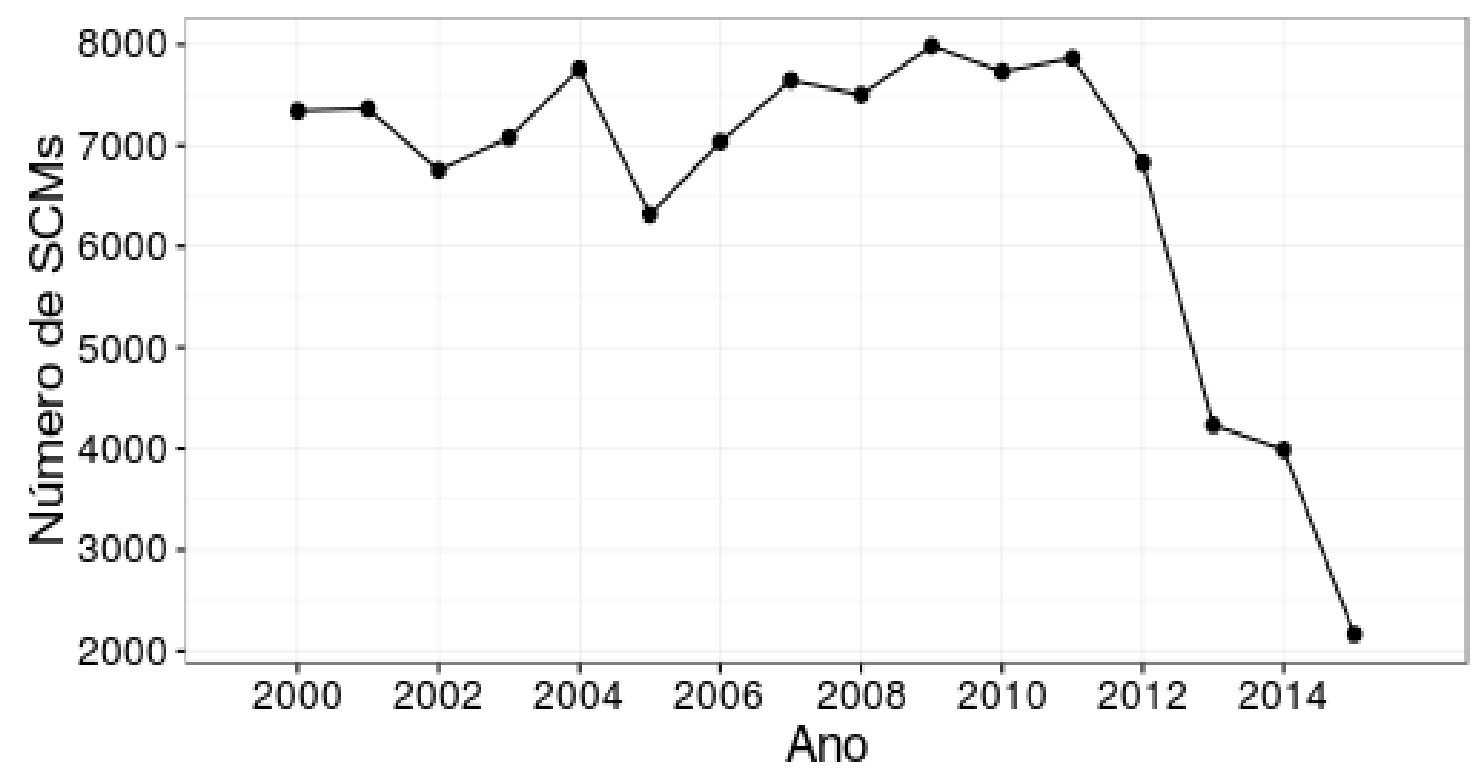

Figura 105 - Distribuição anual dos SCMs na bacia Amazônica. 

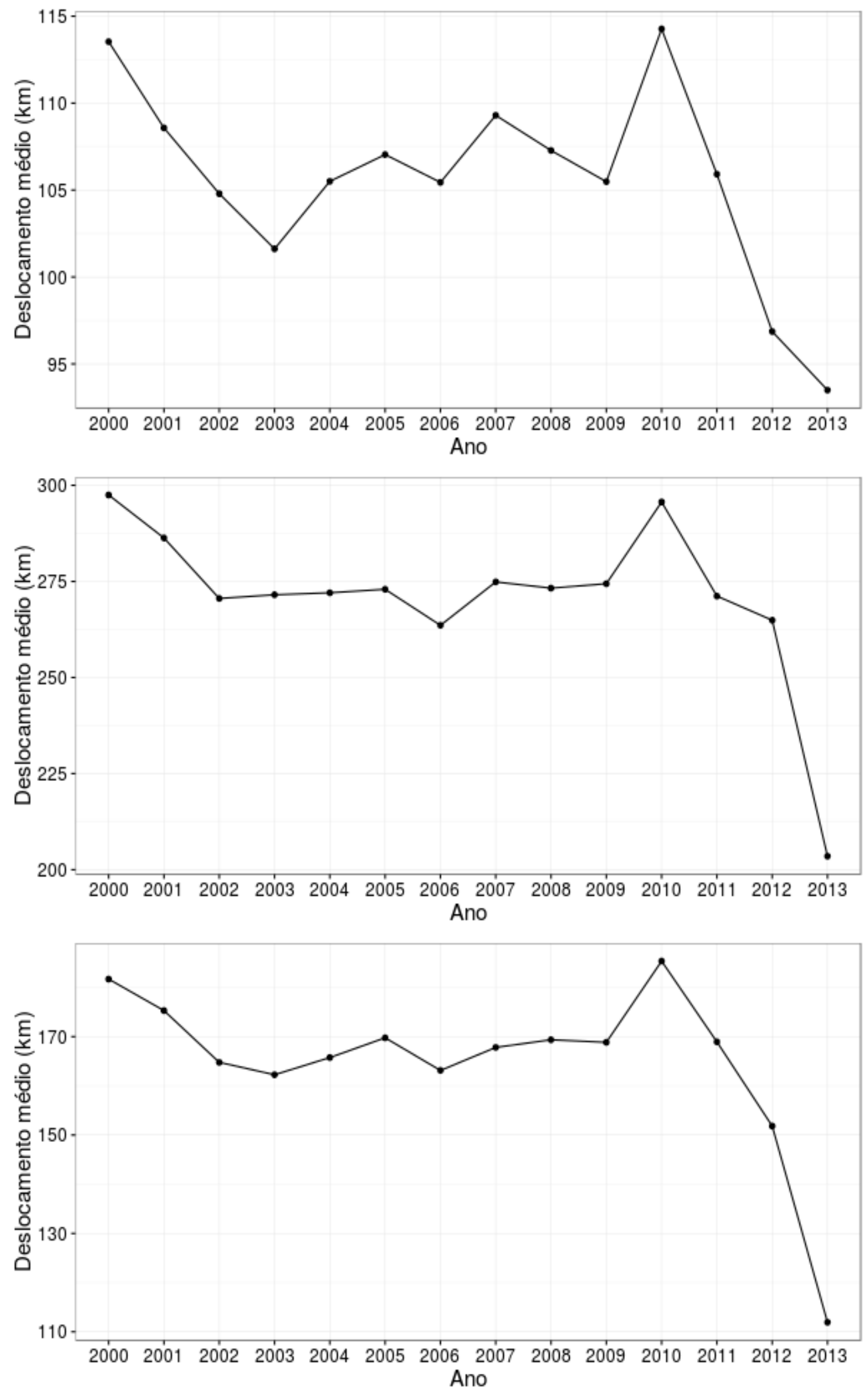

Figura 106 - Deslocamentos médios anuais dos SCMs ocorridos na bacia Amazônica de acordo com o tempo de duração. Em (a) SCMs com curta duração; (b) SCMs com longa duração e; (c) Todos os SCMs. 